Illinois State University

ISU ReD: Research and eData

Theses and Dissertations

$5-21-2019$

\title{
Broadening Our Understanding of Noble-Wieting: A Langford Tradition Village in Central Illinois
}

Kristin R. Travis

Illinois State University, kris.carsontravis@gmail.com

Follow this and additional works at: https://ir.library.illinoisstate.edu/etd

Part of the History of Art, Architecture, and Archaeology Commons

\section{Recommended Citation}

Travis, Kristin R., "Broadening Our Understanding of Noble-Wieting: A Langford Tradition Village in Central Illinois" (2019). Theses and Dissertations. 1132.

https://ir.library.illinoisstate.edu/etd/1132

This Thesis is brought to you for free and open access by ISU ReD: Research and eData. It has been accepted for inclusion in Theses and Dissertations by an authorized administrator of ISU ReD: Research and eData. For more information, please contact ISUReD@ilstu.edu. 


\section{BROADENING OUR UNDERSTANDING OF NOBLE-WIETING: A LANGFORD TRADITION VILLAGE IN CENTRAL ILLINOIS}

\section{KRISTIN R. TRAVIS}

\section{Pages}

The Noble-Wieting site is an Upper Mississippian Langford Tradition village and burial mound, located in east-central Illinois on the outskirts of the Langford Tradition region and distant from other known Mississippian villages. Archaeological excavations at Noble-Wieting during the 1960s and 1970s unearthed features within limited sections of the site, leaving a large portion unexplored. Excavations revealed a higher than average percentage of shell-tempered Middle Mississippian pottery as compared to other Langford villages, giving rise to questions regarding internal changes of cultural identity and suggestions of isolation from contemporary communities. However, the 1976 excavations in the southern portion of the site had yet to be processed, leaving a gap within the archaeological record that could prove initial conclusions inconsistent with material culture.

This project examines concepts of changing cultural identity while broadening the understanding of the external social interactions between Langford and Mississippian groups in the borderland region. In this thesis, the unprocessed excavation data from 1976 was analyzed and compiled with previous data to present an expanded view of the internal composition of the site and distribution of material culture. Material analysis resulted in a smaller proportion of shell-tempered ceramics at the site than previously concluded and no other Middle Mississippian artifacts, which suggests interaction with or influence from those groups was more limited than 
hypothesized for this thesis. However, the percentage of $18.75 \%$ of shell-tempered ceramics remains higher than most Langford villages. Examination of the surrounding area led to identification of other Langford sites, such as the nine Hinshaw A sites, thus revealing less isolation from other Langford people than has been suggested. GIS mapping was created to highlight other possible habitation locations within the east-central Illinois area.

Advancing the interpretations of this site's spatial and material culture relation within its own borders, as well as its connections to contemporary Langford and Middle Mississippian peoples in the surrounding area, contributes to the field of archaeology's foundational knowledge for the Langford Tradition and for understanding changes in cultural identity along border regions between cultures.

KEYWORDS: Langford Tradition, Mississippian, Noble-Wieting 
BROADENING OUR UNDERSTANDING OF NOBLE-WIETING: A LANGFORD

TRADITION VILLAGE IN CENTRAL ILLINOIS

KRISTIN R. TRAVIS

\author{
A Thesis Submitted in Partial \\ Fulfillment of the Requirements \\ for the Degree of \\ MASTER OF SCIENCE \\ Department of Sociology and Anthropology \\ ILLINOIS STATE UNIVERSITY
}

2019 
(C) 2019 Kristin R. Travis 
BROADENING OUR UNDERSTANDING OF NOBLE-WIETING: A LANGFORD

TRADITION VILLAGE IN CENTRAL ILLINOIS

KRISTIN R. TRAVIS

COMMITTEE MEMBERS:

G. Logan Miller, Chair

Abigail Chipps-Stone 


\section{ACKNOWLEDGMENTS}

This endeavor could not have been accomplished without the support of many people. Sincere appreciation goes to my thesis committee Dr. G. Logan Miller and Professor Abigail Chipps-Stone. My gratitude goes to Dr. Miller for patiently answering my never-ending questions and generously providing technical support. My mentor, Dr. Michael D. Wiant, deserves my unending thanks for sharing his expertise, experiences, and scholarly advice and for providing support during tough times. The foundation of this thesis lies on the hard work of Dr. Edward B. Jelks, who conducted the 1976 excavation, and Arlene Rose Schilt, who first reported the 1966-1972 excavations. They were inspiration for every step I took. The 1976 excavation crew deserves thanks for their hard work and also to those who painstakingly washed and numbered each artifact in the early years, making my job easier. Noble-Wieting property owners Chris and Mark Wittig are much appreciated for allowing ISU students to continue excavations at this interesting site and enabling my first experience with archaeological field work.

Illinois State Museum's Research and Collection Center's (RCC) graciously loaned materials with the assistance of the Anthropology Registrar DeeAnn H. Watt. Thanks also to Becky Dyer at RCC for copying manuscripts and maps. Matt Rahman was invaluable for creating the GIS area maps and I appreciate Ian Fricker for sorting and refitting ceramics.

My much beloved brother Scot Sterling lovingly shared his professional graphic design talents and expertise. His work graces the pages and can be found as site maps, feature maps, and all other graphic figures. I cannot express how much his help means and how pleased I am with the results. And... without my best friend and most loving supporter, my mama Jinx Stubbs, I would never have made it through any of this - this accomplishment is for her.

K.R.T. 


\section{CONTENTS}

Page

ACKNOWLEDGMENTS

TABLES vii

$\begin{array}{lll}\text { FIGURES } & \text { ix }\end{array}$

$\begin{array}{ll}\text { CHAPTER I: INTRODUCTION } & 1\end{array}$

Scope of Work 4

Organization of Presentation 4

CHAPTER II: CULTURAL SETTING

$\begin{array}{ll}\text { Mississippian Culture } & 6\end{array}$

$\begin{array}{lr}\text { Langford Tradition } & 9\end{array}$

Noble-Wieting: An Isolated Village in the Border Region? 11

$\begin{array}{ll}\text { Middle Mississippian Influence } & 17\end{array}$

$\begin{array}{ll}\text { CHAPTER III: EXISTING SCHOLARSHIP } & 19\end{array}$

CHAPTER IV: NOBLE-WIETING - THE SITE 24

$\begin{array}{ll}\text { Site Location and History } & 24\end{array}$

$\begin{array}{ll}\text { Physiography } & 26\end{array}$

$\begin{array}{ll}\text { Geological Context } & 27\end{array}$

$\begin{array}{ll}\text { Soils } & 27\end{array}$

$\begin{array}{ll}\text { Vegetation } & 29\end{array}$

$\begin{array}{ll}\text { Climate } & 31\end{array}$

CHAPTER V: HISTORY OF EXCAVATIONS AND METHODS 34

History of Excavations $\quad 34$ 
CHAPTER VI: 1976 FEATURES AND COMPILATION OF ALL FEATURES 44

1976 Feature Descriptions 446

Class I Features - Deep Trash or Storage Pits 46

$\begin{array}{ll}\text { Feature } 17 & 46\end{array}$

$\begin{array}{ll}\text { Class II Features - Shallow Trash Pits } & 47\end{array}$

$\begin{array}{ll}\text { Feature } 12 & 48\end{array}$

$\begin{array}{ll}\text { Feature } 13 & 51\end{array}$

$\begin{array}{ll}\text { Feature } 16 & 52\end{array}$

$\begin{array}{ll}\text { Feature } 19 & 54\end{array}$

$\begin{array}{ll}\text { Feature } 20 & 55\end{array}$

Class III Features - Shallow Pits with Fired Area $\quad 57$

$\begin{array}{ll}\text { Feature } 14 & 57\end{array}$

$\begin{array}{ll}\text { Feature } 23 & 60\end{array}$

$\begin{array}{ll}\text { Class IV Features }- \text { House Features } & 60\end{array}$

$\begin{array}{ll}\text { Feature } 15 & 62\end{array}$

$\begin{array}{ll}\text { Feature } 18 & 65\end{array}$

$\begin{array}{ll}\text { Feature } 21 & 70\end{array}$

$\begin{array}{ll}\text { Class VI Features - Irregular Pits } & 71\end{array}$

$\begin{array}{ll}\text { Feature } 22 & 72\end{array}$

Compilation of All Excavated Features $\quad 72$

$\begin{array}{ll}\text { Features Conclusion } & 75\end{array}$ 
Analysis Objectives

Lithic and Other Stone Tools

Ceramics

Flora, Fauna and Soil Samples

Processing for Curation

CHAPTER VIII: LITHICS ANALYSIS

Chipped Stone Artifacts

Projectile Points

Side-Notched

Madison

Perforators and Scrapers

Biface and Humpback Knives

Polished Artifacts and Ground Stones

Abraders, Celts, and Drilled Stone Fragments

Ground Stones

Stone By-product Artifacts

Fire-Cracked Rock 
1976 Ceramic Analysis

Body Sherds

Rim Sherds

Surface Treatments

Langford

Mississippian

Late Woodland

Burned Clay and Daub

Mini-Vessels Sherds

Ceramics Other Than Potsherds

Ceramics Discussion

Ceramics Conclusion

Modified Antler and Bone

Antler Beams, Flakers, and Tines

Modified Deer Phalanges and Gaming Pieces

Hooks, Awls and Needles

Teeth and Other Modified Bone

Other Bone

Modified Shell 
Faunal Remains Conclusion

$\begin{array}{ll}\text { CHAPTER XI: ARTIFACT DISTRIBUTION } & 147\end{array}$

$\begin{array}{ll}\text { Distribution of Materials } & 148\end{array}$

$\begin{array}{ll}\text { Lithics Distribution } & 148\end{array}$

$\begin{array}{ll}\text { Ceramics Distribution } & 155\end{array}$

$\begin{array}{ll}\text { Faunal Distribution } & 161\end{array}$

$\begin{array}{ll}\text { Discussion of Features } & 165\end{array}$

$\begin{array}{ll}\text { Lifestyle Inferences } & 165\end{array}$

$\begin{array}{ll}\text { Artifact Distribution Conclusion } & 166\end{array}$

$\begin{array}{ll}\text { CHAPTER XII: SUMMARY AND CONCLUSION } & 168\end{array}$

$\begin{array}{ll}\text { Summary } & 168\end{array}$

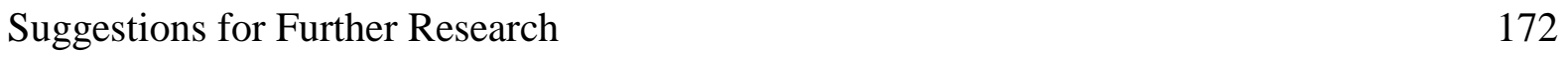

$\begin{array}{ll}\text { Conclusion } & 173\end{array}$

$\begin{array}{ll}\text { REFERENCES } & 175\end{array}$ 


\section{TABLES}

Table

Page

1. Summary of Features 1966-1972

2. Summary of Features 1976

3. Madison Projectile Points Summary 1966-1976

92

4. Madison Points Complete or Nearly Complete 1976

5. Madison Points Distal Fragments 1976

6. Madison Points Proximal Fragments 1976

7. Projectile Points Summary 1966-1976

8. Distribution and Quantity of Chipped Stone Debitage 1976

9. Distribution and Quantity of Fire-Cracked Rock 1976

10. Lithic Artifacts Summary 1966-1976

11. Rim Attributes 1976

12. Decorative Elements Summary 1966-1976

13. Burnt Clay, Daub and Sherdlets by Features and Classes Summary

14. Modified Fauna Summary 1966-1976

15. Lithics Distribution 1976

16. Lithics Distribution Summary 1966-1976

17. Ceramic Distribution 1976

18. Decorative Elements Distribution by Feature Class 1976

19. Decorative Elements by Feature 1976

20. Ceramic Decorative Elements Summary 1966-1976 
22. Distribution of Modified Fauna by Class Summary 1966-1976 


\section{FIGURES}

Figure

1. Cultural Setting Regions in the State of Illinois $\quad 8$

2. GIS Generated Map of Possible Habitation Sites in Study Area Central Illinois 16

3. Location of Noble-Wieting (11ML 24) 26

4. Noble-Wieting (11ML 24) within End Moraines of the Wisconsin Glacial Episode 28

5. Named Soils of Noble-Wieting (11ML 24) 30

6. Prairie Peninsula Region in the State of Illinois 32

7. Noble-Wieting Archaeological Excavations 1966-2018 36

8. Noble-Wieting $2017 \quad 38$

9. Walking Noble-Wieting 1976

10. Noble-Wieting Archaeological Excavations 1976

11. Feature $17 \quad 48$

12. Feature $12 \quad 50$

13. Features 13 and $16 \quad 53$

14. Features 19 and $20 \quad 56$

15. Feature $14+59$

16. Features 22 and $23 \quad 61$

17. Feature 15, Plan View with Features 22 and 23

18. Feature 15, Profile1 64

19. Feature 18, Plan View 68

20. Feature 18, Profile $\quad 69$

$\begin{array}{ll}\text { 21. Feature } 21 & 71\end{array}$ 
24. Chipped Stone Artifacts 98

25. Abraders, Celts, Drilled Stone Fragments, and Copper 102

$\begin{array}{ll}\text { 26. Ground Stones } & 104\end{array}$

27. Langford Vertical Cordmarked Vessel from Feature $18 \quad 120$

28. Design Elements on Body Sherds 122

$\begin{array}{ll}\text { 29. Mini-vessels } & 127\end{array}$

$\begin{array}{ll}\text { 30. Ceramics Other than Potsherds } & 128\end{array}$

31. Modified Antler and Bone 135

32. Bone Hooks, Needles and Awls 137

33. Teeth and Other Modified Bone 139

34. Shell Artifacts 142

35. Distribution of Madison Points and Humpback Knives 152

36. Distribution of Knives (non-Humpback) and Scrapers 153

37. Distribution of Ground Stones and Perforators 154

38. Distribution of Langford Series Ceramics 159

39. Distribution of Mississippian Series and Langford Series Ceramics 160

40. Distribution of Modified Faunal Bone, Antler and Shell 164 


\section{CHAPTER I: INTRODUCTION}

Noble-Wieting is an Upper Mississippian Langford Tradition village with a burial mound (ca. A.D. 1300) located in central Illinois. Located along small rivers at the southernmost border of the Langford Tradition region, the impression is of an "isolated" village (Coleman 1984: iii), an "outlier" from other Langford sites (Jeske 2000: 265), and situated in a "backwoods location" (Schilt 1977: 195). Its distance from the hub of Langford villages to the north and from Middle Mississippian villages to the west and south supports concepts of its isolation in a borderland between Langford and Middle Mississippian groups.

However, early excavations at Noble-Wieting revealed a higher than average percentage of shell-tempered Middle Mississippian pottery as compared to other Langford villages, which suggested social interaction was not affected or aided by the site's location (Craig and Galloy 1996, Jeske 2000, Schilt 1977). While the inhabitants may have been physically distant from other Langford people and economically self-sufficient (Schilt 1977: 196), the cultural material at the site also gives rise to questions regarding ethnogenesis or internal changes to cultural identity, also known as "Mississippianization" (Bird 1997: 23, Schilt 1977: 26). It has not been determined how socially isolated the inhabitants really were. This study aims to further our understanding of interaction or contact between Langford Tradition and Middle Mississippian peoples in the east-central Illinois area.

The extent of occupation and social interaction at Noble-Wieting is not completely known, however. A large portion of the site has yet to be explored through excavation and not all of the early excavations have been analyzed. Archaeological excavations at Noble-Wieting during the 1960s and 1970s unearthed features within limited sections of the site. Forty years later the 1976 excavation materials had yet to be analyzed, leaving a gap within the 
archaeological record that could prove initial conclusions inconsistent with material culture. In the larger picture, this gap in information may impede current and future investigations at this site, as well as hinder advances in our comprehension of the extent of the Langford region and interactions with other groups in the southern borderlands. Early reports interpreted NobleWieting as a small village of approximately 2.75 acres and possibly inhabited year-round (Schilt 1977: 1, 177). Geophysical mapping completed in 2017 reveals the site to be almost twice the size and more complex than recorded in 1977. Therefore, reanalysis of internal site structure and cultural materials may result in different conclusions of the extent of Mississippian influence and changes to cultural identity of the inhabitants.

This thesis builds on previous research conducted by Schilt (1977) and may be considered as a continuation of Schilt's work. The 1976 materials were still being processing at the time of Schilt's report and therefore were not included. However, the same personnel and same techniques were employed for the 1976 excavations. The field work focused on the southern portion of the site, not previously examined, and thus may yield important information regarding variation within the village. While this thesis uses much of Schilt's terminology and methods for consistency, I present new information not available in 1976, such as reports of other potential Langford sites in the local vicinity and Geographic Information Systems (GIS) mapping to highlight areas in eastern central Illinois with similar geographic settings to NobleWieting. Furthermore, my work combines the results of all excavations from 1966 through 1976, allowing for a more comprehensive view of the site as we know it today.

An examination of Schilt's conclusions brings forth the following questions guiding my research. Will an analysis of the 1976 excavation and synthesis of all data result in different conclusions regarding site structure and influence of Middle Mississippian lifeways? Will 
composite mapping and summary of features and artifact distribution change interpretations as to how features relate internally? Do current ideas of Langford lifeways give new perspectives of Noble-Wieting regarding ethnogenesis, interaction, or why settlement occurred at this location that were not considered in the initial site report? Should Noble-Wieting be considered an isolated outpost along the southern border of the Langford Tradition region or just one of many sites within the area?

My hypotheses are as follows: 1) analysis of the 1976 excavations will continue to show a higher percentage of Middle Mississippian materials as compared to other Langford sites and 2) the analysis of cultural material combined with research into the surrounding area will identify less isolation of this site than presumed. By following these guiding hypotheses, my thesis broadens our understanding of the internal nature of the site while also evaluating conclusions of social connections with Middle Mississippian groups. Ideas regarding possible changes to the cultural identity of the inhabitants may then be brought forth based on data. As Noble-Wieting is the closest Langford site to Middle Mississippian villages of the Illinois River Valley and to Cahokia, which creates more opportunities for interaction, I suggest a high percentage of cultural material indicating Mississippian interaction will be displayed within the southern portion of the site. My first hypothesis is built on the results of Schilt's analysis, but the second hypothesis is based on my preliminary research of the site. Surveys of the surrounding area prior to $1977 \mathrm{did}$ not reveal other nearby prehistoric communities (Schilt 1977: 180). However, more recent Cultural Resource Management surveys prove otherwise and I followed this lead in an attempt to identify other habitable areas and find references to other Langford sites in the vicinity.

Advancing the interpretations of this site's spatial and social relation within its own borders, as well as its connections to contemporary Langford and Middle Mississippian cultures 
in the surrounding area, contributes to the field of archaeology's foundational knowledge for the Langford Tradition and for understanding changes in cultural identity along border regions between cultures.

\section{Scope of Work}

This project examines concepts of intra-site physical structure and changing or emerging cultural identity through analysis of the 1976 unprocessed excavation data and synthesis of the information with data from previous excavations. Composite mapping of all excavations and artifact distribution provides a broader understanding of the internal composition and material culture of the site. In order to determine if Noble-Wieting is an isolated Langford outpost an investigation of Cultural Resource Management surveys of the surrounding area was conducted and locational attributes considered for other possible site locations.

My objectives for the analysis of the 1976 excavation materials analysis were: 1) to analyze the 1976 excavations and materials; 2) to synthesize results with Schilt's previous conclusions for the site and; 3) to identify the extent of Middle Mississippian social interaction and influence at this site. My fourth goal was to conduct a regional search for other sites in the borderlands between Upper and Middle Mississippian groups.

\section{Organization of Presentation}

Following this introduction, Chapter 2 will lay the foundation for an understanding of cultural setting for the Langford Tradition people within the Upper Mississippian complex and discuss other possible Langford habitation in the vicinity. A review of what has been theorized regarding the Langford Tradition and cultural evolution due to interaction with Middle Mississippian groups are presented in Chapter 3. The physiographic setting in which the NobleWieting is located is provided in Chapter 4, which will lead into Noble-Wieting's excavation 
history and the excavation methods used in 1976 covered in Chapter 5. Chapters 6 through 10 contain analysis results of the 1976 features and materials and Chapter 11 discusses distribution of the materials for all excavations up to and including 1976. Within each of the analysis chapters, I combine information from 1976 with data from previous excavation information and provide summaries that include 1976, then compare results with other Langford sites where possible, which gives a more comprehensive view of how this site compares or contrasts with the northern Langford Tradition sites. The final chapter will conclude this thesis with a summary and include suggestions for further research opportunities. This thesis compliments previous research for Noble-Wieting by increasing our understanding of the material culture of the site and more firmly placing it within social setting of the Mississippian cultures of its time. 


\section{CHAPTER II: CULTURAL SETTING}

\section{Mississippian Culture}

The Langford Tradition is classified by archaeologists as a northern expression of Mississippian culture. The Mississippian period (A.D. 900-1500) is considered a time of increased social complexity and technological advancement. The two Mississippian complexes, classified as Upper and Middle, share some similar characteristics, such as maize production and mound building, but they are also distinctly different in sociopolitical organization and key material traits.

Cahokia, the largest Middle Mississippian metropolis in North America, with a population estimated at over 25,000 people (Emerson 2012, Fowler 1975, Pauketat 2004), was situated in the American Bottom region of southwestern Illinois near St. Louis. It was considered the social and political apex of the period (Emerson et al 2005: 68). Cultures influenced by Cahokia's power are classified as Middle Mississippian and northern expressions of Mississippian culture, called Upper Mississippian, extended from Ohio west into Minnesota and south as far as central Illinois. These northern cultures are comprised of two large and spatially distinct groups, the Fort Ancient Tradition in Ohio and eastern Indiana (Griffin 1943), and the Oneota Tradition in Illinois, Wisconsin, Iowa, Minnesota, and Missouri (Emerson and Brown 1992: 80-84). Upper Mississippian groups in Illinois, especially the Oneota, overlapped in region with Middle Mississippian and during the decline of Cahokia moved further south (Jackson, Fortier, and Williams 1992) (Figure 1). The Upper Mississippian group classified as Langford Tradition has been identified in northern Illinois in an area overlapping the Oneota region.

Cahokia and its surrounding villages displayed social and economic hierarchy with elite housing, ceremonial temple mounds, community plazas, and had a heavy maize agricultural 
foundation (Emerson et al 2005: 69). Archaeologists have found social status represented in household size, burial configurations, and large villages surrounded by smaller hamlets (Fowler 1975). Upper Mississippian sites, on the other hand, were characterized by small villages that may not have been permanently occupied (Craig and Galloy 1996: 3-2; Jeske 1990: 224), smaller burial mounds with less distinction between social status, and an absence of communal architecture in the form of temple mounds (Craig and Galloy 1996: 3-2). Maize agriculture also was important to Upper Mississippian peoples. However, as in the previous Late Woodland phase (A.D. 400-1200), the Upper Mississippian people relied on a diversified subsistence which included wild plants and animal resources (Jeske 1990: 224).

Archaeological materials, such as ceramic and chipped stone tools, are also similar between the two Mississippian groups. Pottery vessels of both Upper and Middle Mississippian sites exhibit short necks and trailed designs, and some projectile points are found to be of similar size and triangular shape. However, differences in some forms of cultural materials provide the means to distinguish between Upper and Middle Mississippian peoples. Small, triangular projectile points of similar size and shape are found in both regions, but southern Cahokia points differ in that base and side notches are present, whereas in northern productions these aspects are virtually absent. Ceramic technology has long been considered a cultural marker to differentiate between different groups. Both traditions created vessels with shell temper, the construction medium mixed with clay to obtain better adhesive and firing qualities of vessels. Upper Mississippian pottery, however, is more globular in shape than Middle Mississippian ware, with less variation in form and design and with less effigy attachments or handles added. Another notable difference in Upper Mississippian ceramics is the occurrence of grit temper. Grit temper, 
also used by Late Woodland people, is the distinctive pottery trait of the Upper Mississippian Langford Tradition.

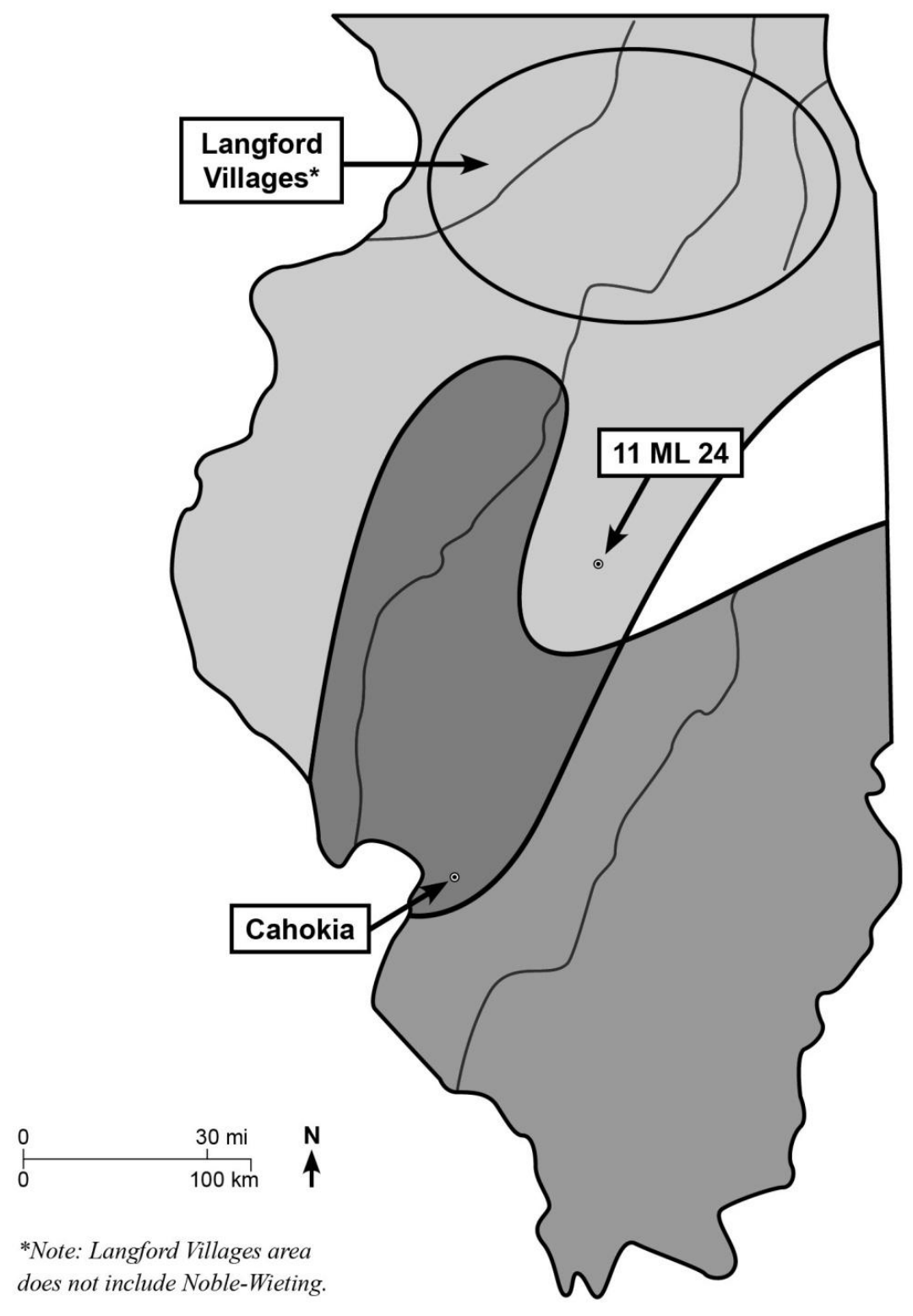

\section{LEGEND}

Upper Mississippian Region

Area of Overlap between Upper Mississippi and Middle Mississippi

Middle Mississippian Region

Area not determined as Upper Mississippian or Middle Mississippian

Figure 1. Cultural Setting Regions in the State of Illinois. 


\section{Langford Tradition}

The Upper Mississippian region in Illinois, overlapping with the Oneota region, is divided into two contemporary local groups of the Fisher Tradition and the Langford Tradition. Some experts also identify Huber and Danner as two Upper Mississippian phases, but both occur later than the Langford Tradition from A.D. 1450 to protohistoric times (Berres 2001: 18; Craig and Galloy 1996: 3-3; Jeske 1990: 223). The Huber phase may be known as Fisher-Huber by some, as Fisher appears to be a precursor of Huber (Craig and Galloy 1996: 3-5; Emerson et al 2005, 68). The three cultural groups of Oneota, Fisher, and Langford in Illinois are identified primarily through differences in ceramic technology, as many other characteristics such as village structure and subsistence are similar.

George W. Langford first identified the Langford culture while excavating the Fisher site 1912-1927 (Griffin 1946: 13). His separation and designation of grit tempered "Langford" ceramics from shell tempered "Fisher" pieces laid the foundation for further identification of this unique group of people. The Langford Tradition is dated to approximately A.D. 1000 - 1450, with the majority of sites ranging from A.D. 1200 - 1350 (Jeske 2000: 266). The Langford groups are thought to stem from the Terminal Late Woodland phase as there are close similarities between the two ceramics (Craig and Galloy 1996: 3-6). In fact, pottery is so similar with its grit temper, cord markings, and globular shape, that in some instances Langford ceramics may have been classified as Late Woodland by mistake (Jeske 1990: 224).

Geographically Langford Tradition sites are clustered primarily in northern Illinois along the Illinois River and its northern tributaries. The Upper Mississippian sites show a mix of older cultural influences from Late Woodland and also from contemporary Middle Mississippian culture, which was noted by Caldwell in 1971 (37-38). Bordered on the south by the strong 
Mississippian chiefdoms, Emerson (1999b) has argued that the influence of the Middle Mississippian culture from the south may have provided an impetus for development of the Langford Tradition from the Terminal Late Woodland. Many sites share similar village patterns with burial mounds and habitation areas in the same vicinity, as well as the similar small artifact components. Sites of significant Langford occupation in Illinois excavated after Fisher include Robinson Reserve (Fowler 1952; Lurie 1992), Zimmerman (Brown 1961; Jeske and Hart 1988), Gentleman Farm (Brown et al 1967), Noble-Wieting (Schilt 1977), Washington Irving (Jeske 1990), Cooke (Markman 1991), Reeves, (Craig and Galloy 1996), and Russel Koster (Pearce 2006).

Study of the Langford Tradition has gone through four phases according to Bird (1997) and the following information is condensed from her interpretation. The first phase, Antiquarian Stage (1673-1918), began with haphazard data collection from Euro-American contact, General Land Office notes and plat creation, and amateur artifact collecting. During the Early Professional Phase (1918-1945) field work and documentation went from rudimentary to more refined works and George Langford conducted his investigations of Fisher site, resulting in identification of the Langford ceramics and Griffin's Master's thesis (1946) that further interpreted the Langford Tradition. Between 1945 and 1971, the Mature Professional/Salvage Archaeology Stage occurred, unearthing more sites and materials in an effort to extract information before public works projects could decimate them. Surveys were conducted and local collectors and archaeologists worked together to record sites and materials. Many preliminary reports, graduate theses, and dissertations were produced. It is suggested, however, that compilations of excavations and research through published reports did not occur for twenty-five years of field work (Bird 1997; Brown 1961, 1967), resulting in the knowledge of 
the Langford Tradition containing numerous gaps. The final phase lasting until present is the Cultural Resource Management (CRM) Stage, beginning circa 1971. Many laws, beginning with the Antiquities Act (1906), led up to the present platform on which CRM is conducted. CRM strictures require surveys and site identification before any federally funded construction is implemented. During this last phase, previously unrecorded sites have been located and advances in technology provided new perspectives on the Langford settlement region. Theories regarding the Langford Tradition have also advanced during this last phase of forty-plus years. Analysis of Noble-Wieting's 1976 material culture and consideration of new information and theories will broaden our understanding of the Langford Tradition in central Illinois. The next segment contains an overview of the Noble-Wieting site and a more in depth physical description of this site is presented in later chapters.

\section{Noble-Wieting: An Isolated Village in the Border Region?}

As suggested previously, the Langford Tradition emergence from the Late Woodland cultures may have been due to cultural influences from Middle Mississippian groups. One question is why a Langford village was settled so far south of the rest of the villages that lie along the Illinois and DuPage Rivers. Schilt's (1977) research resulted in radiocarbon dates for the site as ca. A.D. 1250. Recent radiocarbon dates of A.D. $1295+/-15$ and $1355+/-15$, however, were obtained in the northernmost feature excavated during 2017-2018 (Miller, personal communication), which corresponds with dates found in 2002 (Hart et al. 2002). It is possible that the draw of being closer to Cahokia and potential trade or ideological influences brought Langford people from northern communities southward to the Noble-Wieting site in McLean County. The later dates could also suggest the movement of Langford people into eastcentral Illinois was due to the decline of Cahokia, which occurs during the $14^{\text {th }}$ century. The 
decline of Cahokia may have created habitable space without conflict in this borderland area. The smaller river valley at the convergence of the two Kickapoo creeks and the Burlington Creek provided abundant natural resources to supplement the cultivated crops of maize, beans, and squash. However, the abundant natural resources and possible lack of conflicting neighbors does not appear to have brought many Langford people to the area. Or, perhaps, other sites have just not been located yet. It is possible Noble-Wieting was not as isolated as is now presumed.

In 1900, The Daily Pantagraph newspaper in Bloomington, Illinois, reported the following regarding Native American mounds: "There are two small hills in Randolph Township, another south of Ellsworth and several along the Mackinaw River which are now supposed to be Indian mounds" (1900: 7). The "hills" in Randolph Township are what are now known as the Noble-Wieting site. However, the other mounds located near Ellsworth and along the Mackinaw River were not identified after this article and during archaeological surveys. During the 1970s and then again in the 1990s, archaeological surveys of the Mackinaw River watershed, north of Noble-Wieting, were conducted in an effort to identify sites for future cultural resource management. The conclusion was that no Upper Mississippian sites were identified (Mackinaw River 1997: 3-5). Yet, it was also suggested that sites may be hidden underneath the thick soils of the flood plains and surveys were limited to bluff crests that overlook streams, leaving many areas not considered (Mackinaw River 1997: 3-7).

One 1992 CRM project prior to construction of Interstate 39/US Route 51 identified other possible Langford Tradition sites in the vicinity of Noble-Wieting. However, they were not listed as "Langford” or even as "Upper Mississippian” (Warren 1992, Appendix A). These Mississippian sites were identified as of the Langford Tradition by Bird (1997:116) and it is suggested the nine sites may have actually been one large site (1997:120). Located on what is 
today a small tributary of the Mackinaw, the nine sites of Hinshaw A are approximately 24 miles north of Noble-Wieting (Warren et al 1992: 210) and only identified later by Bird as Langford due to ceramic artifacts (Figure 2). Bird's research concluded that 224 Illinois sites were identified as containing Langford ceramics and concludes with the suggestion that more Langford sites may be within the Mackinaw and Sangamon River basins (1997:121-122).

Ceramics are traditionally used as the diagnostic material for cultural identification of sites. However, ceramics decompose at a faster rate than lithics and surface finds of ceramics at Noble-Wieting have been seen to disappear in only one season (G. Miller, personal communication 2019). It has been noted that Late Woodland and Langford ceramics appear so similar in some instances that classification is difficult (Bird 1997, Brown et al 1967, Jeske 2000). Koldehoff and Kearns (1993:4) suggest that surface surveys based on ceramics alone are not always reliable in locating the presence of Mississippian homesteads and suggest lithics should also be considered. This may be possible with the more identifiable lithic artifacts, such as the multiple-notched Cahokia points, but Madison projectile points, which are often associated with Langford sites, have also been recovered from Late Woodland and Mississippian sites (1993:4). Identification of Langford sites appears more problematic than identification of Middle Mississippian sites due to confusion with Late Woodland components in both categories of lithics and ceramics. It has also been noted that not all Mississippian homesteads were alike and relationships between artifact density and size of the sites may vary (Pauketat, Alt, and Pauketat 2006: 154). With this in mind, it may be possible that there were Langford people living in the east-central Illinois vicinity of Noble-Wieting who were not living in larger villages. Smaller homesteads and villages may have been abundant, but after many years of agriculture and 
destruction of bluffs along waterways due to erosion, the sites have been decimated. Without mounds to more easily identify these sites, they may have been overlooked.

Coleman suggests little effort has been placed on identifying "ephemeral" sites (1984: 51) in the upland areas of east-central Illinois, as archaeological focus is primarily along major rivers valleys and larger habitation sites. Focusing on areas of specific vegetation for optimal hunting, a small "hunting camp" (Coleman 1984: 95) was identified 14 miles to the east of Noble-Wieting through spatial analysis of Madison projectile points. Thirteen Cahokia projectile points were also within the vicinity of Noble-Wieting, according to this study (Coleman 1984: 97). Therefore, the movement of Middle Mississippian artifacts in the area, if not the habitation of those peoples, indicates those groups were within the vicinity of Noble-Wieting. This does not indicate contact or cultural exchange, however, only possible use of the same hunting areas. Research such as Coleman's thesis and Bird's dissertation have been able to reach beyond the results of CRM projects, finding potential Langford sites that were not identified as such previously.

Because CRM projects are only conducted due to public construction projects and many areas do not require surveys, especially if on private lands, without further research we cannot deny other Langford Tradition sites could have been located somewhere between the northern Langford villages and Noble-Wieting. Geographic Information Systems (GIS) are a form of technology that can assist with further research in this area. GIS, a computerized system used to capture and analyze spatial and geographic data, was first created in the 1960s. This technology was not released for public desktop computer use until the 1980s (Foresman 1977: 416) and therefore GIS mapping of the 1966-1972 excavations by Schilt in 1977 was not readily accessible. While other forms of predictive modeling were used, GIS affords the ability to show 
possible Langford habitation locations using a variety of variables on a spatial maps and can define specific parameters from the known Langford sites, including landscape aspects such as slope and distance to water. GIS has improved means of modeling and identifying areas that should be researched further that fit those parameters.

In order to support the idea of possible Langford sites in central Illinois between NobleWieting and the northern Langford sites, new research by Matthew Dring used GIS mapping to view the landscape (Figure 2). Parameters used to define possible habitation locations included slope, vegetation, and distance to water. These measures were based on information of a selection of currently known Langford sites, especially those along the northern segment of the Illinois River and therefore represent possible Upper Mississippian habitation sites. As seen from GIS map of central Illinois to the north and east of Noble-Wieting, the landscape presents a large area devoid of possible habitation sites that include habitat along rivers.

The previously mentioned studies and the GIS map assist in identifying potential Langford habitation sites between Noble-Wieting and the northern Langford sites and suggest more sites may have been in this region. This is to imply that Noble-Wieting is not necessarily isolated from contact with other Langford groups. It does not, however, identify interaction and influence of Middle Mississippian groups in the border region, but only a sharing of potential landscape. The archaeological components of Noble-Wieting, on the other hand, can show Middle Mississippian influence or interaction, but do not show connections with other Langford groups. However, due to limited excavations, surveys, and reports for the east-central Illinois region, it must be concluded that Noble-Wieting can still be considered an outlier or outpost. It is suggested that further research should be conducted in the area to give a definitive answer to the question of whether there were other Langford villages or homesteads between the northern 
Illinois River Langford sites and Noble-Wieting. Only through cultural material may interaction or influence be somewhat determined.

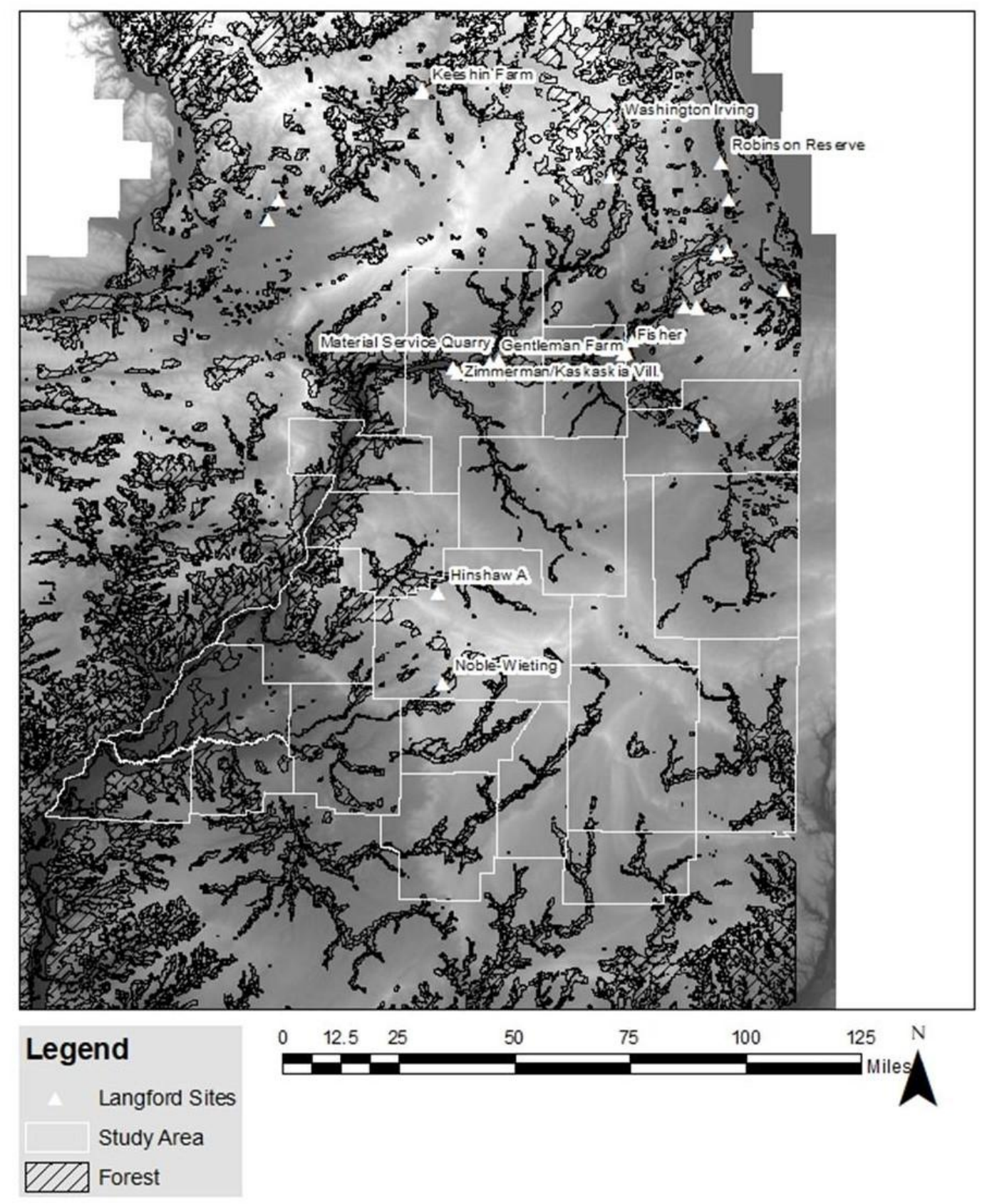

Figure 2. GIS Generated Map of Possible Habitation Sites in Study Area Central Illinois. (Courtesy of Matthew Dring, preparer. Sources: USGS Digital Elevation Model and Site location data obtained from the Inventory of Archaeological Sites maintained by the Illinois State Museum, Illinois Department of Natural Resources.) 


\section{Middle Mississippian Influence}

Research regarding movement of lifeways through trade of artifacts or influence of Middle Mississippian traditions can contribute to new perspectives on Noble-Wieting. Evidence of one Langford pottery sherd found as far south as the Sweat Bee site, a Middle Mississippian satellite of the Newman site near Lake Shelbyville Reservoir in Illinois, provides the southernmost example of connections between Langford and Middle Mississippian peoples (Bird 1997; Gardner 1973; Schilt 1977). The Collins Complex, a Late Woodland habitation site and mound in Vermillion County, Illinois (A.D. 1000-1100) and approximately 80 miles east of NobleWieting, contains locally made Mississippian style pottery as well, also establishing movement of social ideologies well before Noble-Wieting was established ca 1300 (Jackson 2018; Riley and Apfelstadt 1978).

Interaction with Mississippian culture has been identified at Noble-Wieting, where a high percentage (23.5\%) of shell-tempered pottery, as compared with other Langford sites, has been identified (Schilt 1977:191). Perhaps this higher percentage shows more intrusion or interaction from the southern neighbors, either representing a higher percentage of trade or perhaps more emulation of the Middle Mississippian culture by the Noble-Wieting residents. However, violent interaction does not appear to be the cause of intrusion of Middle Mississippian wares.

Magnetometry indicated a potential palisade on the perimeters of the site, but excavation and technological data does not support any form of defense structure, such as a palisade (Miller, Skousen, McCullough 2017), and burials have not been proven to contain evidence of violent deaths (Schilt 1977, 191). These two facts indicate that a more peaceful economic or social interaction may have been occurring between the groups. 
Questions arise due to the information presented above. Can the previously unanalyzed and unreported 1976 cultural material present any new evidence to further link Noble-Wieting to Middle Mississippian groups, such as Cahokian projectile points or more abundance of shell tempered pottery? Will effigies and symbols of religious or spiritual associations with Middle Mississippian groups be found, such as was recovered from the Late Woodland Collins Complex? Material components may show more influence from Middle Mississippian groups than previously determined and, therefore, completion of the 1976 material analysis is a necessary step toward better understanding of social interaction and possible changes to cultural identity at this site. 


\section{CHAPTER III: EXISTING SCHOLARSHIP}

Neo-Evolutionism and Neo-Historicism in Mississippian research are considered as two traditional theoretical approaches to archaeology that connect the material artifacts with how past people engage with their world. The Neo-Evolutionary view places emphasis on the concept that uniformity is the basis for cultural systems and the surrounding world impacts humans and is the mechanism causing change (Bird 1997: 13). Following this line of theory, humans are biological and therefore they react to environment and external change according to biology. The settlement of a group of people and the technology (e.g. pottery, stone tools) created by a culture, under this theory, is done so in relation to environmental factors, such as climate and raw material sources. The process of cultural variation of technology and settlement patterns could be interpreted from the materials and this idea was followed by processual archaeologists, based on theories of Lewis Binford (1965), with emphasis placed on the material world. Interpretations of sites and artifacts define social change as a construct of environment and biological factors. For example, seminomadic cultures and the seasonality of their sites were thought to be due to the available seasonal resources. Social interactions between groups, such as trade or violence, were thought to be due to the depletion or requirement of resources. With a primary focus on environmental and biological forces causing variation of technology that present in material form, it could be assumed the Neo-Evolutionism's emphasis forgets that social groups did not occur in isolation, when they were, in fact, in contact with each other in broad social networks. However, according to Bird (1997: 18), Neo-Evolutionism is the traditional theory behind social interactions between Middle Mississippians of Cahokia and the Upper Mississippian peoples, which includes the Langford Tradition people. 
Neo-Historicism, on the other hand, holds the perspective that human agency is also a factor in the construction of social boundaries and interactions, not environmental causes alone. Archaeologists such as Ian Hodder (1984) suggested the intentional social actions of humans also needed consideration. Cultural variability, and thus the changes in technology, symbolism, and settlement patterns, could also be constructed from negotiating roles of power, including economic and ideological (Bird 1997: 9). Ideas could be borrowed, changed, or rejected from other nearby societies. Groups could be influenced by social interaction to change in ways they might not have done from environmental pressure alone.

Emerson has suggested a "tribalization" or "ethnogenesis" process between Middle Mississippian and Upper Mississippian cultures (1999b: 3). Ethnogenesis, according to Emerson's definition, refers to the continuous process of changes within the social, political, and economic structures of groups through interaction and is caused by a reaction to unequal, or asymmetrical, power relations and can be seen within the material culture of the peoples (1999b: 9). It is still not understood why some Late Woodland and Langford settlements appear to have been influenced more by their Middle Mississippian neighbors while others appear to reject these influences. It is also undetermined whether conflict and violence or cooperation and trade, or a combination of both, caused internal and external changes of the Langford Tradition. As previously mentioned, Noble-Wieting shows no evidence of violence and until all material culture is analyzed, it is unknown how extensive Cahokian ideological influence infiltrated into the inhabitants' lives.

Bridging the two traditional theoretical approaches, Bird (1997: 17) suggests an Alternative Model that takes into consideration the many influences of both the environmental world as well as the socially constructed world that surrounds a group. Mechanisms for change 
can be attributed to climate and lack of resources as well as the pressures of a more economically advantaged neighboring group. Emergence of the Langford Tradition cultural group from the Terminal Late Woodland, an idea agreed upon by most Langford experts (Brown et al. 1967: Emerson 1999, Fowler 1952, Jeske 1992a), may be attributed to change in environment and climate as well as pressures from the Oneota influence from the north and Cahokia's influence from the south.

Material culture of the two groups, Late Woodland and Langford, are similar and include ceramics design, wall trench house construction, subsistence patterns, and mound construction and use. Whether Langford culture was a result of the Late Woodland groups attempting to emulate Middle Mississippian culture in an environment not suited for that lifestyle or if intrusion of Cahokian traits into Late Woodland culture through trade or migration was due to the deepening influence Cahokia's dominating political power, however, has been difficult to ascertain. This view of social influence and change caused by human agency aligns with the Neo-Historical theory. Cahokia was a large, socially and politically complex society and its influences can be identified on material remains of other groups, including Late Woodland and Langford. The northern groups, seen as non-hierarchically organized and economically inferior, were thought to have been intruded on by their southern neighbors through trade, migration, or spatial pressure (Emerson 1999b: 4). However, these views tend to be centered on Cahokia and do not take into account the internal mechanisms within the groups that could have influenced design aspects of their material.

To combat this Cahokia-centered viewpoint, some experts have emphasized the internal changes between local groups that may have transformed the northern cultures (Jeske 1990). Jeske's theory based on environment and subsistence suggests northern groups retained their 
diverse subsistence patterns due to availability of resources and because they opposed becoming heavily dependent on maize, as their Cahokian neighbors were. This resistance to maize agriculture is seen as a form of reinforcing their individualized ethnic identities (Jeske 1992a). However, studies supported by archaeology, paleopathology, and isotopic analysis suggest some Langford villages consumed more maize than previously determined (Emerson 2005). Emerson has argued that broader models of interaction between distinct social groups based on “asymmetrical relationships" (1999: 4) cause internal transformation and must also be considered. This view recognizes varying degrees of influence between a strong political and economic culture, such as Cahokia, and its peripheral neighbors, such as the Oneota. Spatial boundaries play a role in interactions as well between Middle Mississippian culture and the northern cultures. Stresses along those boundaries in the form of conflict may also be impetus for changes within a group, which then can be seen by archaeologists as a reflection on material remains.

While social theories abound regarding the influence of Cahokia on Langford peoples, and thus relate to the Noble-Wieting inhabitants, theories regarding environment should not be disregarded. As suggested previously, the two traditional theories can be combined and with this in mind the suggestions of Warren et al (1992) regarding settlement patterns in McLean County apply. The surveys conducted by the Illinois State Museum and Illinois State University in 1988 resulting in Warren's technical report (1992) were mandated due to construction of Interstate 39 (I-39) in Illinois. Evidence of 56 archaeological sites, some historic and some prehistoric, and the combined data from the surveys led Warren to surmise the settlement patterns in McLean County had changed due to climatic changes. Early Holocene (10,000-8,000 ya) sites were found on the upper landscapes on the prairies of the end moraines. At this time there was more water in those 
locations and the hunter-gathering people traveled extensively. Middle Holocene (8,000-5,000 ya) sites were found to be along the middle range of landscape. Later sites, which include Langford and Mississippian sites, were lower on the landscape and found along the forest-prairie boundaries and closer to the rivers and waterways. It is suggested the water table had dropped significantly causing people to follow the water table, moving from the uplands to the lower river valley areas. Increase in sedentism, resulting from maize production, perhaps influenced by the rise of the socially complex maize reliant Cahokia, may have been caused settlement closer to waterways as well. With this example, it can be seen how both environment and social influence may have changed the settlement patterns of the Late Woodland people, creating the rise of the Langford people as a more maize dependent and sedentary culture.

Border villages between Langford and Middle Mississippian cultures, such as NobleWieting, provide opportunities combine Neo-Evolutionism and Neo-Historicism when analyzing a site and broaden our perspective of interaction within the border region. The following chapter will discuss the physical environment of this region in which Noble-Wieting is situated. 


\section{CHAPTER IV: NOBLE-WIETING - THE SITE}

\section{Site Location and History}

The Noble-Wieting site is located in the NW1/4 of the SW1/4, Section 27, Township $22 \mathrm{~N}$, Range $2 \mathrm{E}, 3^{\text {rd }}$ meridian, on the Leroy quadrangle, which is approximately 1 mile $(1.6 \mathrm{~km})$ north of the town of Heyworth, in Randolph Township, McLean Country, Illinois (Figure 3). The site overlooks a small floodplain of the Little Kickapoo and the Kickapoo creeks approximately .19 miles $(.30 \mathrm{~km})$ to the west of their junction, the latter which is joined by the Burlison creek approximately .24 miles $(.38 \mathrm{~km})$ south of the site. The creeks flow south and west into the Salt Creek, Sangamon River, and Illinois River systems. Earlier accounts of the site indicate it to be approximately 2.75 acres $\left(11,129 \mathrm{~m}^{2}\right)$ (Schilt 1977: 1). Magnetometry technology reveals the actual site size to be closer to 5.93 acres $\left(24,000 \mathrm{~m}^{2}, 26,246.72 \mathrm{yds}^{2}\right)$. Noble-Wieting has had two site numbers of $11 \mathrm{ML} 24$ and $\mathrm{ML}^{\mathrm{v}} 28$, a point discussed later in Chapter V.

During the 1834 land sales of U.S. government lands, claimed from the Native Americans, William Baldwin purchased eighty acres of land, which included the village and mound site. In The Sunday Bulletin of December 9, 1900, Burnham claims the Noble-Wieting site was cultivated in the early 1840s by the Bishop family (Burnham 1900), and while the Bishop family may have farmed the land, a land sale document has not been located to support Bishop owning the land at that time. Plat maps from 1874 indicate the Bishop family owned land to the north of the site and J. Noble to the west, but the maps are vague on the actual ownership of the land at that time. Bishop and Noble were two of the earliest white settlers in Randolph Township and the Noble family cultivated the site's land from the late 1800s to 1968 when it was obtained by Wallace Wieting, son-in-law of Mrs. Harry B. Noble (Schilt 1977: 5). 
According to historical accounts, the Kickapoo Indians resided in Illinois since the 1670s (Jesuit Relations 1904, as cited in Vermaat 2011), but local Kickapoo people had no knowledge of the origins of the burial mound at Noble-Wieting, which was originally known to early white settlers as the Randolph Mound (Burnham 1900; Schilt, 1977: 4) as it was named after the founder of Randolph Township. Burnham indicated the mound, having been cultivated for at least sixty years, was estimated to be $2.5 \mathrm{ft}(.76 \mathrm{~m})$ high and $75 \mathrm{ft}(22.86 \mathrm{~m})$ in diameter (Burnham 1900; Schilt 1977: 6). The site is today is recorded at $216 \mathrm{~m}$ (708.67 ft) A.S.L. The mound rises only a foot above the surrounding surface and is barely visible. Noble-Wieting's burial mound is the only one confirmed in McLean County, although Burnham discussed other mounds located near Ellsworth and along the Mackinaw River (Burnham 1900). Human remains from the Noble-Wieting mound were excavated by Burnham in 1900 and he cited at least "onehalf dozen skeletons" in context with burnt earth and charcoal, over which the mound was constructed (Burnham 1900). In 1969 excavations of the mound also brought forth human remains within the area determined to be the original burial mound. A brief summary of the excavation and these remains are discussed by Schilt (1977). The remains are now curated at the Illinois State Museum's Research and Collection Center and are listed according to the NAGPRA law requirements.

The site passed into the hands of Mary Noble and then was sold to Chris and Mark Witte, who as of this report continue to conventionally farm the land with rotating crops of corn and soybeans with a no-till method that preserves the topsoil integrity. No-till methods of cultivation also prevent archaeological materials to be brought up to the surface, which somewhat retains the site's integrity. Evidence of historic deep plowing of the site has been observed in the excavations of a house feature during the 2017-18 seasons. 


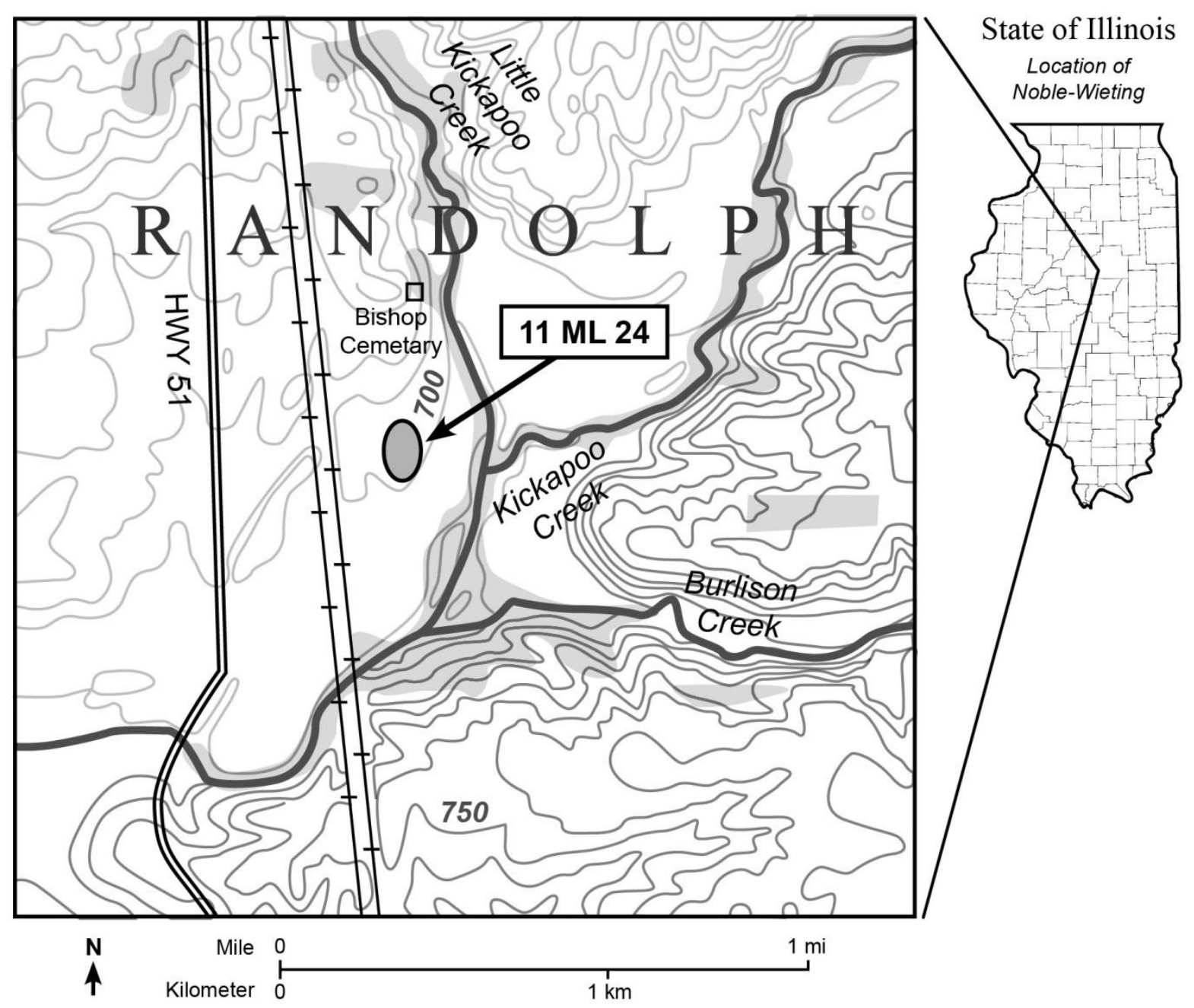

Figure 3. Location of Noble-Wieting (11ML 24).

(Adapted from USGS Quadrangle Map, 1951.)

\section{Physiography}

Reconstruction of the physical nature of Noble-Wieting when it was occupied in the $13^{\text {th }}$ century has limitations, as it is difficult to determine certain aspects of the physical environment at that time, such as flooding or climate. Historical accounts reach back only to white settlement times in the early 1800s. The possible physiography of Noble-Wieting is described in this section. 


\section{Geological Context}

The Woodfordian Substage of the Wisconsinan Ice Age of Illinois was the last glacial advance during the Pleistocene epoch (10,000-25,000 B.P.) Ridges of till were left in deposits as end moraines, created when the glacial ice front was melting at the same rate of advancement. McLean County has numerous end moraines, the largest of which is the Bloomington Moraine. Valleys created by the receding glaciers provided avenues for melt waters to run, carrying deposits of outwash sediments that were left stratified on flood plains. Deposits of sediments were sorted by size as the movement of the water carried the lighter sands, silts and clays further downstream (ISGS 2018). Glacial deposits provided a variety of cherts for production of lithic tools and these chert sources are still found in abundance along the Little Kickapoo Creek and Kickapoo Creek to the east and south of the site.

Noble-Wieting is located in a valley between the Sibley, LeRoy, and Heyworth Moraines, just south of the Bloomington Moraine (Figure 4). The Kickapoo Creek valley was formed as channel for glacial water runoff, depositing various rock and sediment as it flowed. The site is on a slight slope of approximately 13 feet $(3.96 \mathrm{~m})$ above the flood plain and is located to the north and west of an exposed line of gravel deposit along the $700 \mathrm{ft}$ topographic contour line (Figure 3). The gravel "strath", as Schilt called it (1977: 16), is apparent on the surface of the site today and is clearly visible as a lighter colored line sweeping around the site on the east and south sides on 1940 aerial photos as well as on modern Google satellite images (Figure 7).

Soils

As the glacier receded, finer grained deposits became loess, windblown silt deposits, which cover almost all of Illinois (ISGS 2018). In 1903 the loess in southern McLean county was 


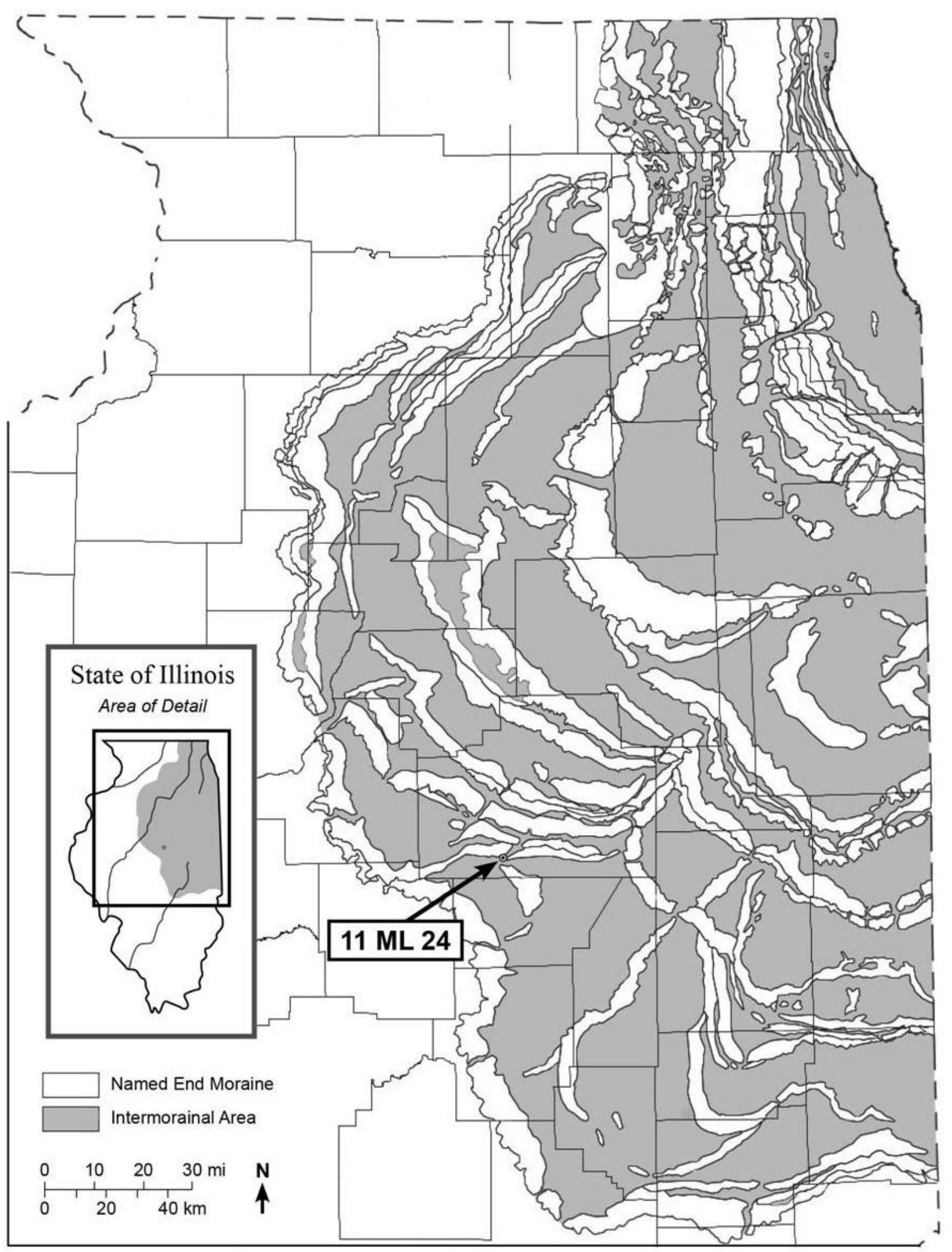

Figure 4. Noble-Wieting (11ML 24) within End Moraines of the Wisconsin Glacial Episode. (Adapted from Killey, M. M., 2000.) 
measured at approximately 6 to 7 feet (1.83 to $2.13 \mathrm{~m}$ ) thick (Coffey et al 1903: 782). McLean County's 1903 soil survey recognized five types of silt loam soil in McLean county with underlying yellow "clayey silt" (Coffey et al 1903: 784). The darker silt loams of the survey are Mollisols, a dark soil rich in nutrients, developing from the breakdown of prairie grasses. The dense organic composition of this prairie soil, while providing an abundance of nutrients for cropland, proved difficult for the first white settlers to turn with metal plows and thus can be assumed difficult to cultivate also for prehistoric inhabitants. Alfisols, a light colored soil, occur under forested areas and while providing less nutrients for crops are easier to cultivate. Current soil surveys show the Noble-Wieting site contains strips of three silt loams: Keomah, Russell, and Miami (Figure 5). Excavations show the yellow clay at approximately 12 inches $(30.5 \mathrm{~cm})$ below surface. The site is located next to a strip of forest and along the edge of prairie providing inhabitants with a looser soil for cultivation than the heavy prairie Mollisols. Soil at the site appears to be the lighter color timber Alfisols and not the darker prairie Mollisols.

\section{Vegetation}

During the Holocene epoch soils formed and vegetation increased. The Prairie Peninsula, in which the site is located, is part of a biome of tallgrass prairie that extends from the Great Plains into the Midwest states of Iowa, Illinois, and western Indiana in a peninsula shaped projection (Figure 6). While the climate of the region supported forests, forest vegetation encroaching into the prairie is thought to have been impeded by naturally occurring fires (ISM 2000). Early settlement accounts of the area reported the local timber to be an oak-hickory ecosystem which contains a variety of deciduous trees, many of which are nut-bearing.

Peter Folsom, the county surveyor in 1856, suggested the tree line was east of the site and just along the creeks (Prince and Burnham 1908). However, there is a span of approximately 550 


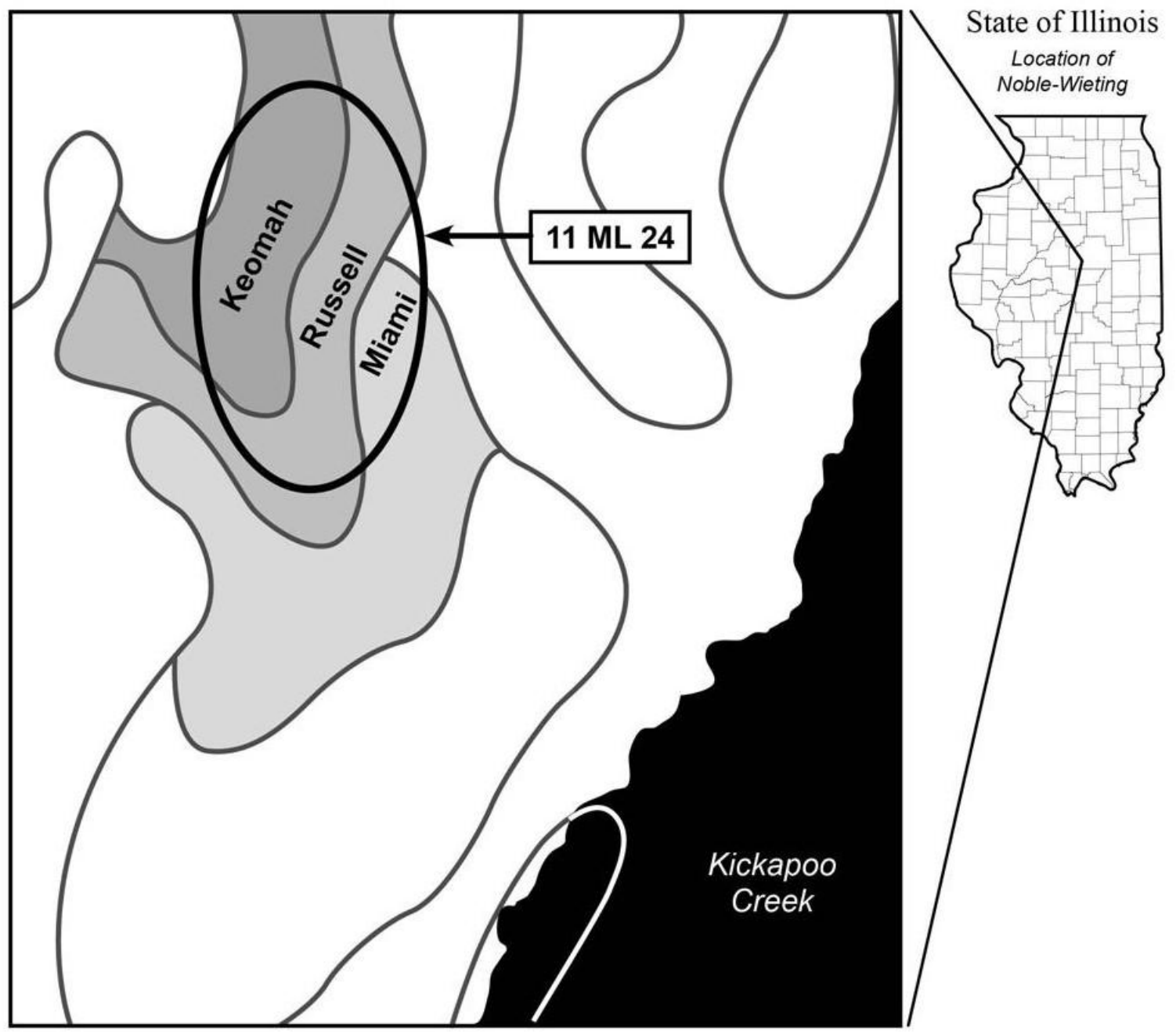

Figure 5. Named Soils of Noble-Wieting (11ML 24). (Adapted from USDA, NRCS, 1998: 171.)

years or more in which the forest edge could have been changed by the Noble-Wieting inhabitants and others who resided in the area. The "History of McLean County" of 1908 listed 39 tree species (1908: 627), but also mentions the groves and tree lines were drastically changed by the settlers and non-native trees, such as the Black Locust, were introduced into the area (Prince and Burnham 1908: 626). Therefore, it is difficult to ascertain the exact location of the forested areas during the $14^{\text {th }}$ century. To date, an analysis of wood charcoal remains from the 
site has not been conducted for this site and thus identification of woody species is unavailable beyond what was found from seed remains.

Flotation samples from the 1972 excavations revealed flora species of several wild edible plants including Black Walnut (Juglans nigra), Bullrush (Scirpus), wild grape (Vitaceae fam.), Pawpaw (Asimina triloba), and sunflower (Helianthus) as reported by Schilt (1977: 113 ). It is

possible that many other edible plants were consumed as part of the resident's diet and traces did not remain. Cultivated species found in the 1972 flotation samples included corn (Zea maize), beans (Phaseolus vulgaris), and squash (Cucurbita pepo), also as reported by Schilt (1977: 113).

The abundance of varied vegetation supports a diverse faunal component for the site. Faunal remains from the site indicate 53 vertebrate species and 12 species of mollusks, with mammals the primary faunal food source (Parmalee and Bogan 1980: 1-2). Elk and white tailed deer, the largest of the mammals listed in the archaeological record of Noble-Wieting, are associated grasslands during the Holocene epoch (Hoffmeister 1989: 41).

\section{Climate}

The vast diversity of floral and faunal species found during early investigations at NobleWieting suggest a wide variety of food sources for the people living at the site. This diversity is also indicative of the possible climate of the area during that time. Included in the Prairie Peninsula region, the Noble-Wieting site experiences a continental climate with extreme temperatures of heat and cold. The summer season can have temperatures over one-hundred degrees Fahrenheit and is typically wetter than the winter season. Dangerous thunderstorms, lightening, and tornadoes can be common during the summer months. Winters are known for temperatures below zero degrees Fahrenheit and for frosts during the spring and fall. The extreme variations in temperatures and moisture throughout the year allows for growth of 


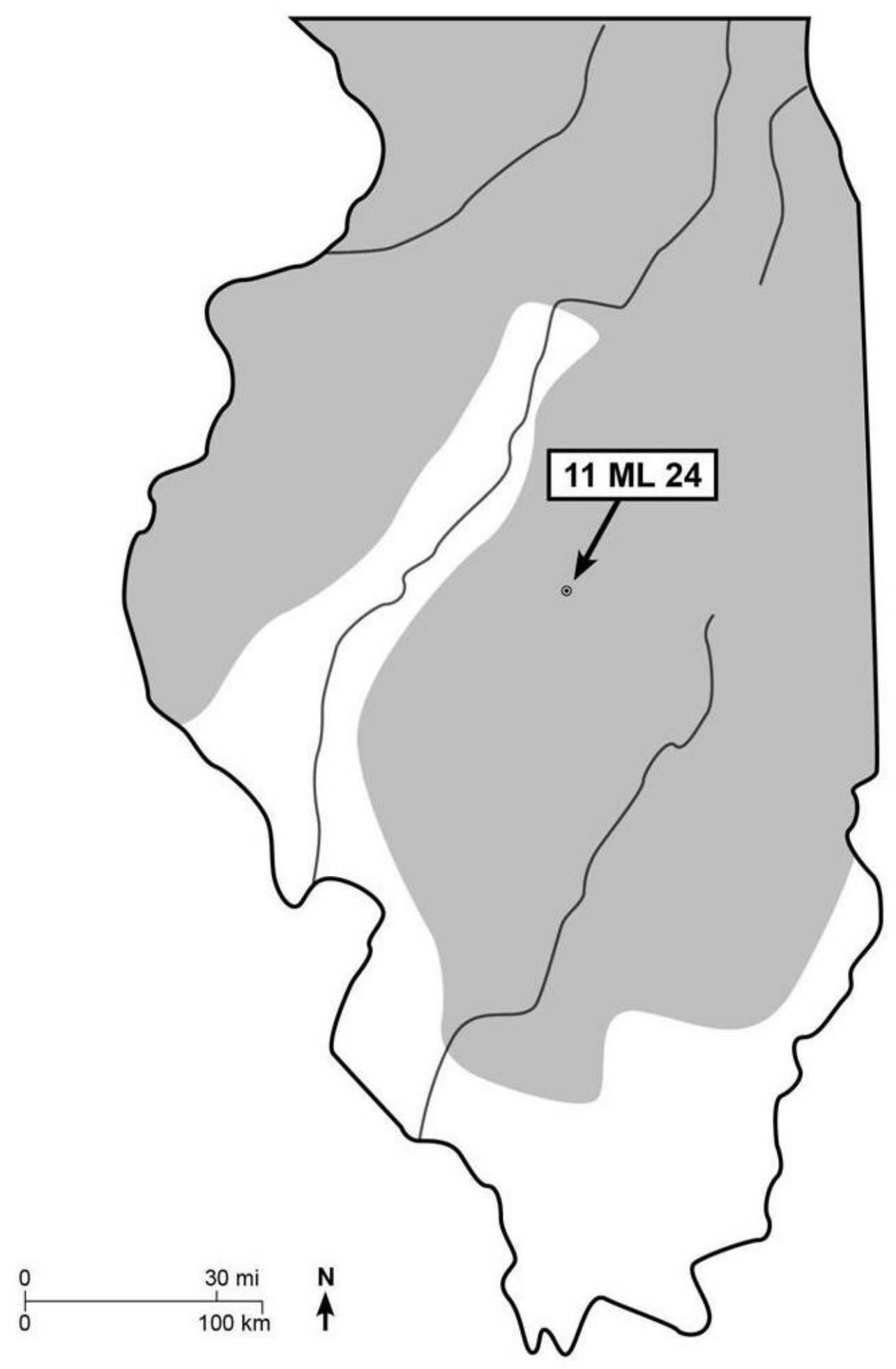

Figure 6. Prairie Peninsula Region in the State of Illinois. (Adapted from Transeau, 1935.) 
different annual and perennial species without competition with each other. Approximately 123 species of native prairie plants were available for food and medicinal uses for Native Americans during historic times and available seasonally (Kindsher 1987: 4).

Just prior to the time period of habitation at the site in the $14^{\text {th }}$ century, a global warming trend occurred and is known as the "Medieval Climate Anomaly" (D'Arrigo et al. 2014: 31). This climatic event, occurring approximately A.D. 950 - 1250, marks the further retreat of glaciers and has been verified with dendrochronological methods. The warm trend, perhaps lasting into habitation times, may have assisted with the growth of squash, corn and beans at the site, which all grow more abundantly in warmer climates. While this warmer period brought milder winters and summers, a drought is also thought to have occurred between A.D. 1120 and 1350 (Bryson 1978: 322). Evidence of this period of drought has been determined by tree rings and through analysis of faunal remains found in archaeological sites (Wendland 1978: 273). A period of large floods, between A.D. 750 and 1150, prior to the settlement of the site, may have increased the size of the Kickapoo Creek system, provided suitable silt for cultivation of crops, and perhaps allowed for cultivation of crops during the later drought period. Climate changes in the form of milder temperatures and more abundant water supply just prior to the habitation of Noble-Wieting may have influenced the people locating to this area.

The suitable site location and abundant resources at Noble-Wieting are not unique to this area of central Illinois. The inferences that Noble-Wieting was an isolated outpost in this region are proven groundless if other sites can be identified within this border region. As discussed in this chapter, the vegetation, soils, and climate in this vicinity was able to provide ample sustenance to support small villages, such as this site. Further research in the east-central Illinois area is necessary to support the theory of more habitation sites. 


\section{CHAPTER V: HISTORY OF EXCAVATIONS AND METHODS \\ History of Excavations}

This summary of Noble-Wieting's excavation history is based on information contained in Schilt's 1977 thesis report for 1966-1972 excavations, field notes by Dr. E. B. Jelks and students for 1976, the 1993 excavation notes, and from notes and maps of the 2017-2018 excavations.

The Noble-Wieting site first attracted archaeologists in 1900 when J. H. Burnham, along with volunteers and several members of the McLean County Historical Society, conducted an excavation of the burial mound. The owner of the property at the time, John Noble, and the Burnham party had discovered human bones in the mound located near the center of the village site, which they reported were reinterred. Burnham's crew, as reported by Schilt (1977), restored some bones to the center of the mound and restored the mound area as near as possible to the original condition after excavating a trench into the mound. Burnham's accounts of the excavation were not carefully recorded and thus his interpretations may be questioned. However, this activity has been recorded as the first official excavation of this mound, which is the only confirmed burial mound in McLean County.

Surface collecting of artifacts at the site by local collectors continued for another sixtyfive years until 1965, when local collector Nuel Downs of Heyworth, Illinois, brought archaeologists William Haney (IIllinois State University) and Fred Brian (Illinois Wesleyan University) to the site. Haney and Brian were interested in recording prehistoric sites for the Illinois Archaeological Survey, as well as creating an archaeology field school program for the two universities. During a preliminary investigation, Haney and Brain found cultural material on the surface of the site abundant enough to determine the site culturally significant. They obtained 
permission from the Noble and Wieting families to conduct excavations at the site indefinitely as long as the work did not impede the families' income from crop production. While the site has changed hands since that first agreement, the landowners throughout the years have generously allowed continued excavations by Illinois State University's (ISU) field schools. A composite map of all excavations up to and including 2018 is provided for reference (Figure 7).

In 1966, Haney and Brian created a grid system over their proposed excavation area, using magnetic north and aligning test trenches along north-south and east-west lines. They designated their lines of trenches as E-1 and W-1 for the east-west line and N-1 and S-1 for the north-south line. An iron pipe embedded in the ground and located approximately 1.25 feet (38 $\mathrm{cm}$ ) from a large hackberry tree that grew along the fence-line on the north edge of the Wieting's field became the datum point. The presence of the fence-line trees, including a large tree near where the datum would have been located, is confirmed in an aerial photograph from 1940.

This datum and grid system was used in subsequent years by Brian and Nuel Downs in 1968, 1969, and 1970 for excavations in other locations at the site. In 1972, Dr. E. B. Jelks used this same datum point and grid system, matching up with Brian's previous excavations. Jelks simplified the grid system by designating the north-south E-1 trench line of Brian's excavation as W300 and the east-west line running through the datum as N700. Brian used a Bruntun compass and Jelks used a transit, resulting in slight deviations between the two grids, however the degree or error was minimal. Jelks began using numbers for located features, as Brian had almost exhausted the alphabet during the previous season.

Excavations conducted between 1966 and 1972 were reported by Schilt (1977). However, the excavations conducted by Jelks from June 20 thru July 17, 1976, were not included in Schilt's report as the materials had not been processed at the time of her writing. The 1966-1972 

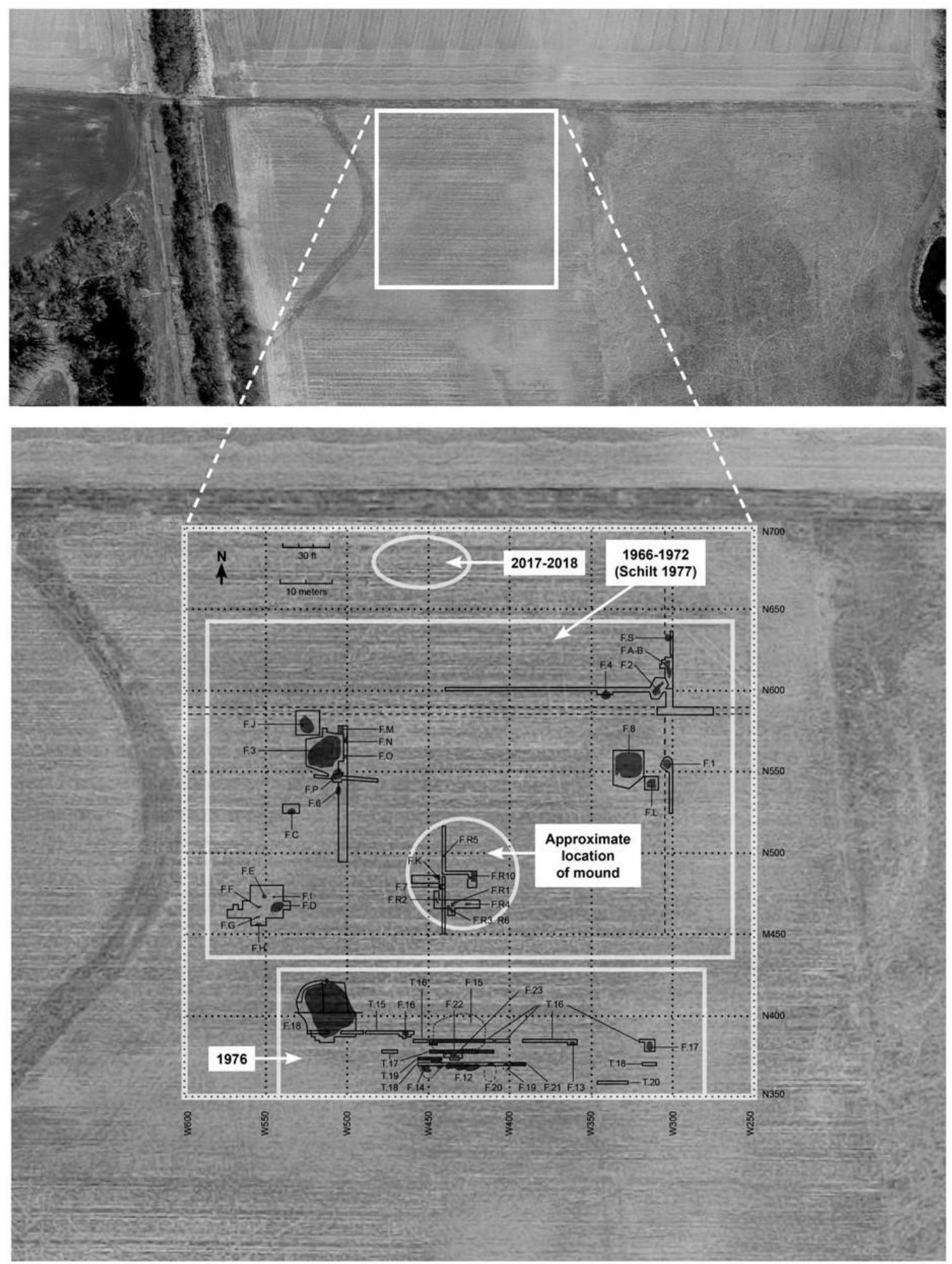

Figure 7. Noble-Wieting Archaeological Excavations 1966-2018. (1966-1972 areas adapted from Schilt, 1977.) 
and 1976 site number for Noble-Wieting, which is used in the field notes archived at Illinois State Museum (ISM) and in Schilt's thesis (1977), is ML ${ }^{\mathrm{v}} 28$ and was assigned to the site, representing the $28^{\text {th }}$ registered archaeological site in McLean County, Illinois, with the superscript ' $v$ ' designating it as a village site. The site numbering system changed sometime after the 1976 excavations and Noble-Wieting's site number became 11ML 24, referencing 11 for Illinois and 24 for the number of the site in McLean County, Illinois. This is the number used for all excavation references after 1976. To alleviate confusion, future researchers should note that one or both numbers (11ML 24 and $\left.\mathrm{ML}^{\mathrm{v}} 28\right)$ are used together on the materials bags, inventories, and in past reports. This thesis primarily uses the current Illinois site file number of 11ML 24 .

In 1993, Dr. James Skibo, an archaeologist at ISU, conducted excavations with an ISU field crew of archaeology students. While boxes curated at the ISM and inventoried are listed as from 1998, documentation regarding an excavation during 1998 have yet to be found and it has been suggested some of the 1993 material was sent to the museum for curation during 1998 , hence the later date found on the boxes and on the inventories at ISM. The excavations conducted by Skibo have not been summarized and are still in curation at the ISM.

During the summers of 2017-2018, Dr. G. Logan Miller of ISU led a field school for archaeology students with the assistance and support of the Illinois State Archaeological Survey (ISAS) of the University of Illinois (Figure 8). New technology in the form of Geographic Information System (GIS) and magnetic survey has assisted with more accurate locations of potential features at the site and allows researchers to gain a better understanding of how previous excavations encompass the whole Noble-Wieting village. The iron post datum used from 1966-1976 was extrapolated during these later excavations using modern technology and is shown on a map of the site along with previous and current excavation locations. 


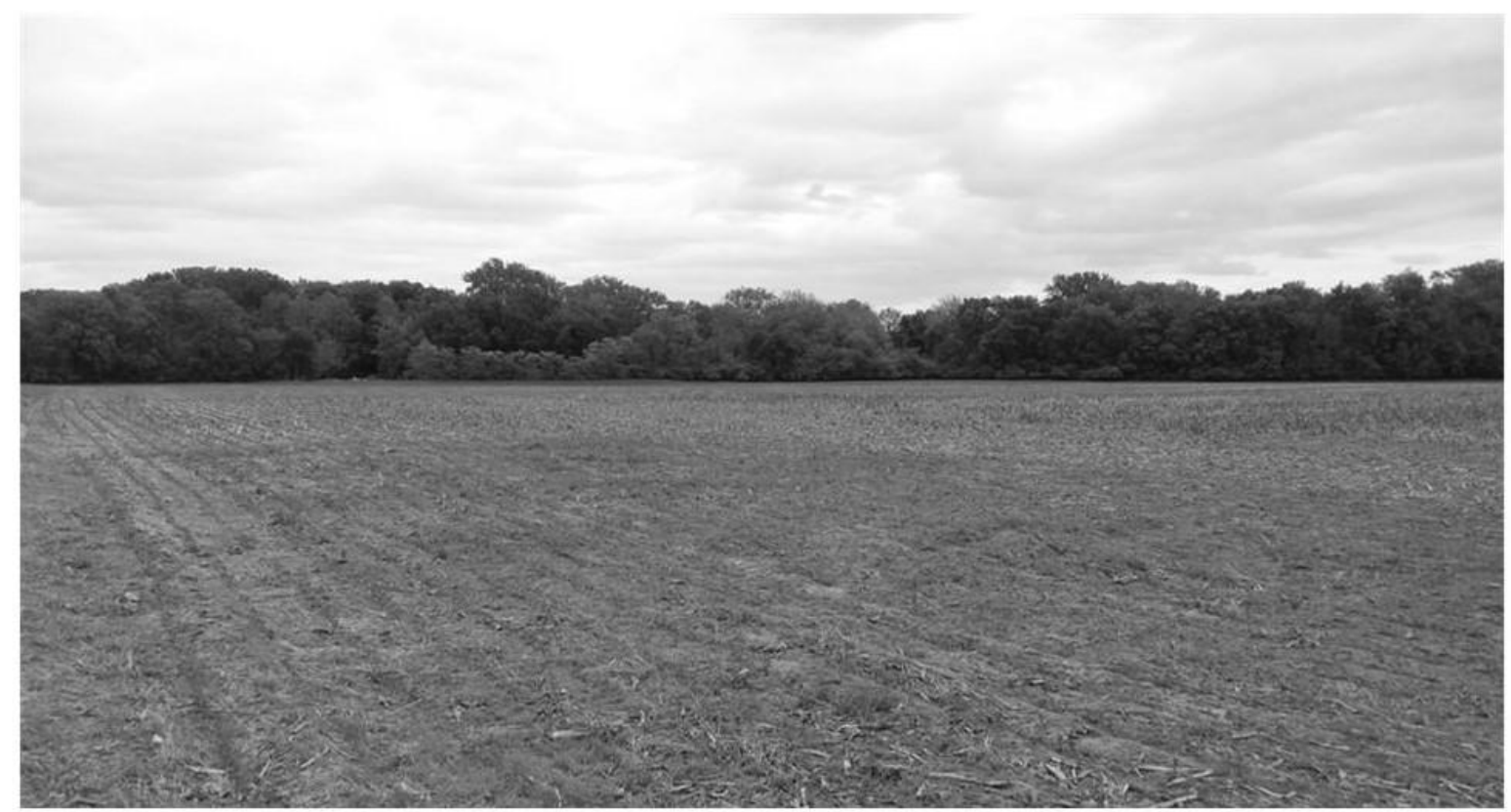

Figure 8. Noble-Wieting 2017.

\section{Excavation and Processing Methods}

Between June 20 and July 17, 1976, Jelks returned to Noble-Wieting with eighteen archaeology students from Illinois State University, as well as with Brian and Downs, for further excavation. However, much of the excavation memory for the 1976 archaeological endeavor has been lost during the last forty years. According to student journals, one of the main goals of this excavation was the question of what seasons the site was occupied, but any other research questions governing the excavation are unknown at the time of this report as they were not recorded within the journals and field notes. All that is reported here is taken from the student journals and a few notes by Dr. Jelks.

Jelks used the same datum used in 1972, with his previous east-west and north-south line designations mentioned above, and he again used numbers for the features. A transit was used to relocate the iron post datum, which was determined to be 711.4 feet $(216.8 \mathrm{~m})$ above sea level by 
using a U.S.G.S. benchmark from the east side of the railroad track, which lies west of the site. This datum was used to lay the grid system, running a line from the iron post south, and attempting to align with the 1972 grid. However, Jelks noted that the compass needle did not move completely free and therefore the coordinate lines may have been as much as a degree off from the 1972 orientation. Notes refer to this line requiring correction at a later date, but no further reference was found in the notes that it had been reworked.

In the summer of $1976, \mathrm{Mr}$. Wieting had the field at the site planted partly in wheat and partly in corn and anticipated harvesting the wheat during excavation time (Figure 9). The 1976 excavation was set up south of the wheat area and between the corn rows. The excavation plan was to dig a series of exploratory trenches between the corn rows running east-west, 18 " wide $(45.7 \mathrm{~cm})$ and $200 \mathrm{ft}$ long $(61 \mathrm{~m})$. The trenches were begun approximately $50 \mathrm{ft}$ to $100 \mathrm{ft}$ (15.24 to $30.5 \mathrm{~m}$ ) from the southernmost edge of the previous excavations' features. Six crews dug the test trenches in $10 \mathrm{ft}(30 \mathrm{~m} 5 \mathrm{~cm})$ sections, which were numbered in sequence as they were excavated, beginning with Trench 15 as 14 was the last number used in 1972 and ending with Trench 20. Each test trench was aligned on a separate east-west line, parallel to each other. The 10' sections of each test trench were labeled with a letter (e.g. Test 15A, 15B, etc.) A couple of trenches contained sections that were not excavated and thus not labeled, but the alphabetic label was picked up again when a portion was dug. Examples of Trenches 16 and 17 represent this method (Figure 10). Stratitests were dug at intervals within each trench and recorded with profile maps when anomalies were encountered. A base map of trenches was created by students. Cores, using an $8 \mathrm{ft}$ (2.44 m) long core device, were taken at various locations outside of trenches to discover the depth of the sterile yellow clay zone and the core sample data was to be used to construct an isometric soil map. This soil map has not been located within the 


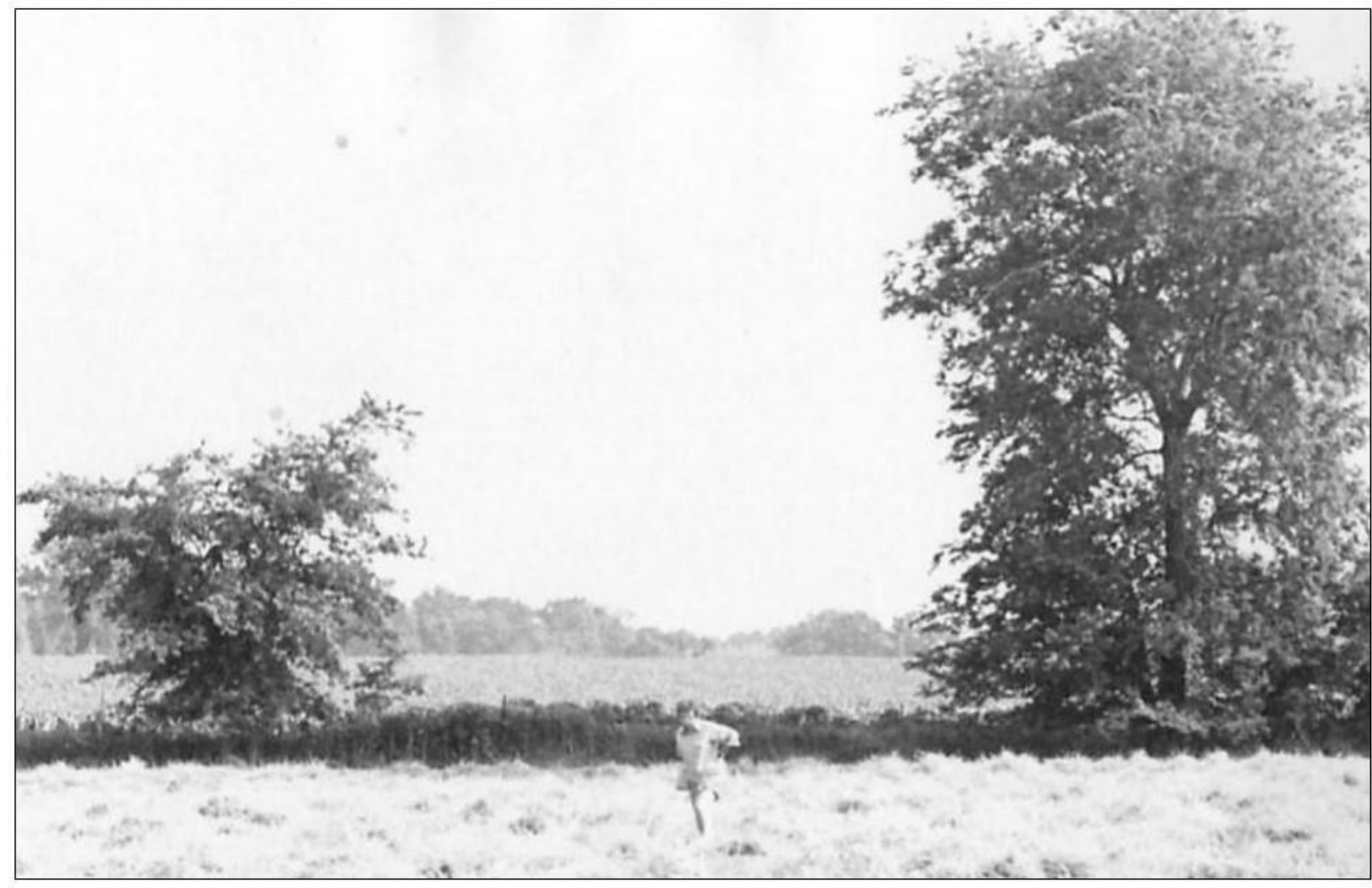

Figure 9. Walking Noble-Wieting 1976.

(Courtesy of the Illinois State Museum.)

documentation for this excavation. Under the plow zone, which was sometimes less than 12 inches $(30.5 \mathrm{~cm})$ deep, a layer of gray soil containing cultural material could be found in some locations, which indicated a feature to further explore, and then a layer of sterile yellow clay substrate beneath that cultural zone proved the depth of the feature. Features were located using this method of observation of a darker soil and more abundant cultural material within it.

Features were numbered in sequence as found, beginning with Feature 12, as previous 1972 excavation feature numbers ended with Feature 11. The 1976 excavations ended with Feature 23. Features were recorded on the Feature Record sheet, mapped on individual feature maps in plat and profile, and photographed. The base map, including trenches, and the feature plan views for the 1976 excavation were created as separate maps. The 1976 composite map of 


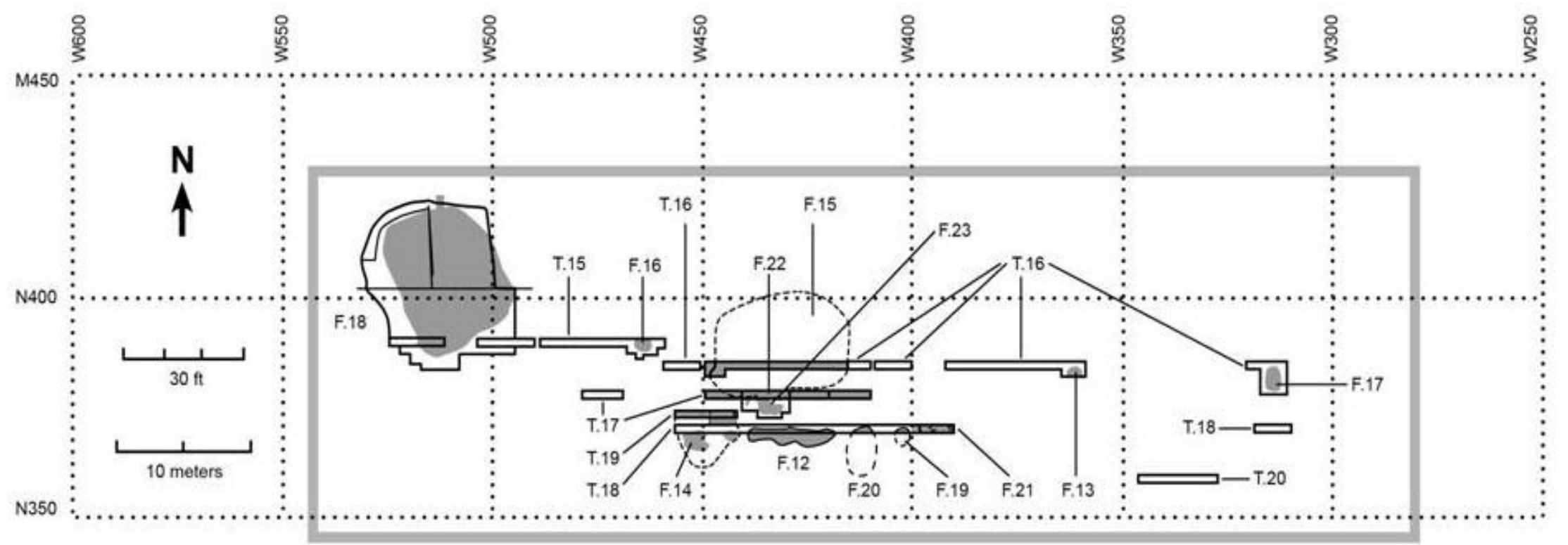

Figure 10. Noble-Wieting Archaeological Excavations 1976. 
features and trenches (Figure 10) was created by me from individual plan views and the base map of trenches, as no composite had been created in 1976. Further discussion of features and discussion regarding distribution of cultural materials is presented in Chapters VI through XI of this report.

Many forms, notes, and journals created in 1976 for the excavation were duplicated with carbon copies by the students. Some were handwritten and then typed later. Records and notes were in the form of daily journals, feature and test trench notes, site report, photo record, test and feature record, plans and profiles records, notes on excavation methods, materials inventory, and general notes by students and Dr. Jelks. Site visitors and other assistants occasionally helped with the field work and record keeping. Mrs. Jelks assisted with keeping records in order. Color and black and white photographs were taken of features, artifacts, the site, excavation work, and the crew. Photographs were recorded in the Field Photo Record. Most photos contain an arrow pointing north and a menu board indicating the site number, project, and date.

Screening for cultural material was done at site and some areas were piece plotted and not screened. These are noted within the Feature Description chapter of this report. Samples of charcoal, botanical material, and bone were kept separate from other materials and sometimes placed in bottles or foil, and sometimes in bags. All other materials were washed in the lab under the supervision of archaeology student Preston Hawks, labeled with lot numbers 8 through 159, which was logged onto a lot inventory sheet, and then artifacts were bagged. It is unknown if lots 1 through 7 were used during this year as they were not included on the inventory or located. Lot "S" was also not included on the lot inventory, but has been recorded and is assumed to be surface finds. It is unknown if artifacts were bagged in Ziplocs at that time or if that was done at a later date by ISM/RCC. Diagnostic artifacts were sometimes enclosed in bottles or bags 
separately, but not always. Bags retrieved from storage to use in this analysis were not labeled with collector's names or the date of collection or processing, but usually with the site number, year of the excavation, and lot number. 


\section{CHAPTER VI: 1976 FEATURES AND COMPILATION OF ALL FEATURES}

In this chapter each feature will be described individually followed by a compilation of all features excavated between and including 1966 to 1976. A discussion of artifact distribution and relation to features is located in Chapter XI. The goal of the features analysis is to determine if influence of Middle Mississippian culture can be identified in the formation of the southern features or from their material. Compiled data regarding all excavated features will assist with broadening our understanding of the site and determining if social isolation or internal changes to cultural identity can be identified.

As previously mentioned, the base map including trenches and the feature plan views for the 1976 excavation were not compiled into one map until this thesis. The 1976 features and trenches map was created from individual plan views and the base map of trenches (Figure 10). Then the 1976 excavation composite map was combined with Schilt's 1977 excavation map to create an overview of all of the site's excavations up to and including 1976 (Figures 7 and 22). Excavations during 1976 were located south of the previous excavations by approximately 50 to 100 feet $(15.24 \mathrm{~m}$ to $30.48 \mathrm{~m})$ and on a slight slope leading downward to the south and east (Figure 22). The elevation of the highest point at the site is $708.67 \mathrm{ft}(216 \mathrm{~m})$ A.S.L. as determined in 2017. It should be noted that this elevation does not align with some of the readings taken during 1976 and contradictions are noted within those feature descriptions in this chapter.

As previously mentioned in Chapter V, exploratory test trenches were placed where high concentrations of surface artifacts were observed. Trenches were dug between corn rows on an East/West setting, dug in 10 foot $(3.05 \mathrm{~m})$ sections. These test trenches exposed twelve features, labeled Features 12 through 23, consecutively labeled as found. The plow zone was variable in depth from .6 to $.8 \mathrm{ft}(.18$ to $.24 \mathrm{~m})$ and all features originated in this zone. Stratitests were dug at 
intervals within each trench and artifacts recovered from layers were later labeled with corresponding lot numbers. When time permitted and it was determined essential, soil was screened with one quarter inch hardware cloth. It is noted within the comments of each feature when screening occurred.

Feature data for this report was obtained from the 1976 Feature Record, student journal notes, and Jelks' field notes, and then compiled into computer spreadsheets to cross-compare location, size, type, and materials found with those of earlier excavations. It must be noted that the journal entries and the feature maps do not always agree for measurements and elevations with each other, or with current technological information. Differences are noted in the comments and on the feature maps in this chapter when discrepancies were found. Within the descriptions for each feature, depths are reported for actual feature as starting below plow zone as well as the base depth, which includes the plow zone. Summary of all features at the conclusion of this chapter includes previous excavated features as reported by Schilt (1977). This summary includes depth of features, not including plowzone. Length and width is sometimes estimated from core sampling and is noted within the description for the features where this occurs as well as on the maps when available from the originals. Some features were not completely excavated and this is also noted. In order to compare the 1976 features with features represented in Schilts' summary of earlier excavations (1977), I have used the same classification system, which divides features by size, shape and evidence of function as determined by the excavation participants. There are five descriptive classes: Class I - deep trash pits with circular or oval orifices, possibly for food storage then secondarily as trash pits; Class II - shallow trash pits with circular, ovoid or irregular horizontal plans, fill similar to Class I but unknown whether these are trash pits or had another function; Class III - shallow midden with central fired area and large and irregular horizontal 
plans, fired areas with charcoal or charred debris may indicate cooking or burning of trash; Class IV - house or other structural pits with the floors below the ground surface level for that time; and Class V - burials. Instead of a category of "miscellaneous" as Schilt recorded, features that were found to have inadequate data or were anomalous were grouped under heading Class VI for this report. Summary tables comparing the data from Schilt with the 1976 excavation data reported in this chapter is presented in Tables 1 and 2.

\section{Feature Descriptions}

\section{Class I Features - Deep Trash or Storage Pits}

Class I features are thought to have been used as storage pits initially then possibly as a trash receptacle later when they no longer could retain freshness for storing food or other items. Storage pits are found to have a base floor deeper than Class II features, such as $4.65 \mathrm{ft}(1.42 \mathrm{~m})$ as compared to $1.9 \mathrm{ft}(.58 \mathrm{~m})$. Storage pits at other Langford sites, such as Reeves (11WI 555) have many shapes, but most were of a circular shape with a roughly cylinder shape or truncated cone shape (Craig and Galloy 1996: 5-3). Only Feature 17 fit the description of a Class I feature for the 1976 excavation.

Feature 17

(Figure 11)

Location - N 376.75 - 382.5, W 310.5 - 315.5; T16 T; A.S. L. 709.19 ft (216.16 m) (no profile available)

Shape - Plan - circular; Profile - cone from descriptions but no profile available

Size - Depth - $4.65 \mathrm{ft}(1.42 \mathrm{~m})$, base depth $5.6 \mathrm{ft}$ (1.71 m) bs; Length - $5.75 \mathrm{ft}(1.75 \mathrm{~m})$; Width $5.0 \mathrm{ft}(1.52 \mathrm{~m})$ 
Soil - dark soil, then as pit deepened it became mottled with yellow clay becoming more prominent toward center, layer of sand occurring in level IV.

Material Remains - Lithic Artifacts: 2 distal projectile tips, 1 bifacial scraper, 1 proximal Madison fragment, 1 red ochre, large flakes and shatter.

Ceramics: 10 shell tempered, 37 grit tempered, 1 untempered, 1 mini-vessel, 20 sherdlets, 1 burned clay, 10 Mississippian series, 35 Langford series

Modified Fauna: One antler tine and 1 modified bone fragment

Discussion - This pit feature was excavated in four levels. Level I depth was recorded as .95 to 1.2 $\mathrm{ft}(.37 \mathrm{~m})$ below surface, level II from 1.2 to $2.0 \mathrm{ft}$ (.37 to $.61 \mathrm{~m})$, level III from 2.0 to $2.35 \mathrm{ft}$ (.61 to $.72 \mathrm{~m}$ ), and level IV from 2.35 to $5.6 \mathrm{ft}(.72$ to $1.71 \mathrm{~m})$. A soil sample was taken for flotation from level I, which was dark soil. Yellow clay became mottled with the dark soil in level two and sloped inward toward center as the pit deepened. Soil was screened. Cultural material changed between level I and level II to contain less material and smaller pieces in level II and then larger and more abundant again in level III. In level IV sand was encountered that sloped toward the center of the pit but was determined to be a natural occurrence, mixing with the fill and the fill a mottled clay mixture containing little cultural material. Sand and gravel was found at the bottom.

Crew - Sod Squad

\section{Class II Features - Shallow Trash Pits}

Three features fit the description for Class II pits (Features 12, 13, and 16). Two others (Features 19 and 20) are included with this class because of their shallow depth but their classification is tentative due to incomplete excavation. Class II features were of an average depth of $1.48 \mathrm{ft}(.45 \mathrm{~m})$ in previous excavations and the average depth in 1976 was $1.18 \mathrm{ft}(.36 \mathrm{~m})$. These features were perhaps middens used for waste or other unknown purposes. Features 12, 13 and 16 
LOCATION - Trench $16 \mathrm{~T}$

PLAN VIEW $\underline{\text { A.S.L.: } 709.19}$
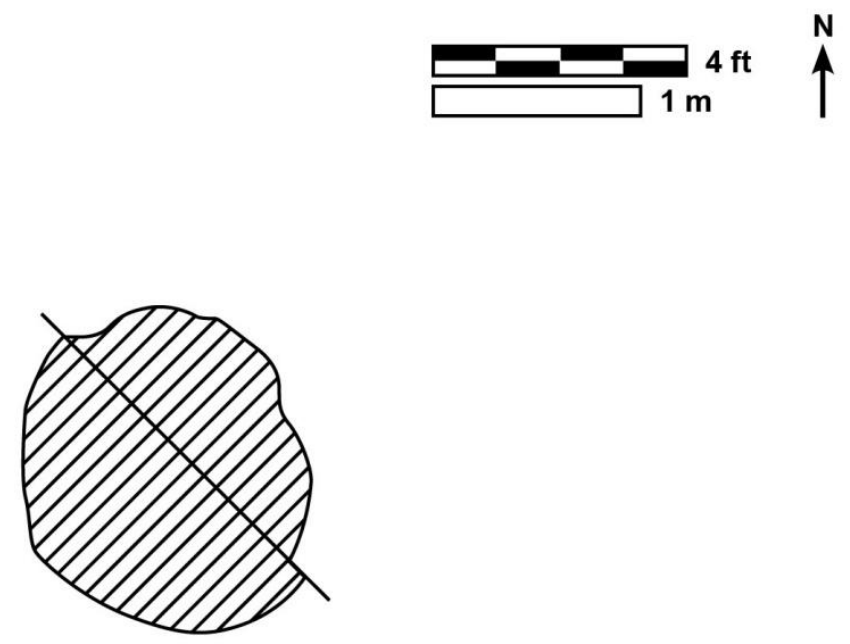

Note: no Profile available.

Figure 11. Feature 17.

contained charred earth, charcoal, or burnt clay, suggesting use burning of trash or cooking and faunal remains were found in all five.

\section{Feature 12}

(Figure 12)

Location - N 372.0 - 367.5, W 439.5 - 416.0; T18 G-I; A.S.L. unknown

Shape - Plan - irregular; Profile - irregular

Size - Depth $-.5 \mathrm{ft}(.15 \mathrm{~m})$, base depth $2.2 \mathrm{ft}(.67 \mathrm{~m})$ below surface $(\mathrm{bs})$; Length $-23.5 \mathrm{ft}(7.16$ $\mathrm{m}) ;$ Width $-4.75 \mathrm{ft}(1.45 \mathrm{~m})$

Sections: $\quad$ 12A: $6 \mathrm{ft}$ long $\times 4.0 \mathrm{ft}$ wide $\times 1.9 \mathrm{ft}(1.83 \times 1.22 \times .58 \mathrm{~m}) \mathrm{bs}$ 12B: $4 \mathrm{ft}$ long $\times 3.25 \mathrm{ft}$ wide $\times 2.2 \mathrm{ft}(1.22 \times .99 \times .67 \mathrm{~m}) \mathrm{bs}$ 12C: $3.6 \mathrm{ft}$ long $\times 4.0 \mathrm{ft}$ wide $\times 1.3 \mathrm{ft}(3.6 \times 1.22 \times .40 \mathrm{~m}) \mathrm{bs}$ 
It should be noted the plan map shows four designated anomalies instead of three, but a fourth was not mentioned within the field notes. Section lengths recorded above reflect journal references as the profile map does not divide the three sections by the same measurements as the journals reference. The whole feature was divided into 9 units when excavated (Figure 12, profile). Soil - Dark gray with darker soil area in the middle of the feature, clay mottled throughout. Units 3 and 7 present with reddish-brown tint and mottled with clay. Unit 4 contained light grey-brown soil with ash.

Material Remains - This feature had the greatest number of artifacts and also the most variety. Lithic Artifacts: 1 side-notched proximal fragment, 18 complete Madison points, 9 proximal Madison fragments, 5 distal or mid and 1 unknown proximal projectile fragments, 1 perforator, 1 knife, 21 biface humpbacks, 2 biface scrapers, 3 cores, 1 ground stone, 1 drilled stone fragment, 3 pieces red ochre, 1 fire cracked rock, 6 copper pieces.

Ceramics: 77 shell tempered, 813 grit tempered, 13 untempered, 7 mini-vessels, 5 red ochre, 192 sherdlets, 6 burnt clay and daub, 1 shaped clay, 75 Mississippian series, 800 Langford series. Modified Fauna: One shell hoe, 2 shell scrapers, 2 notched shell pieces, 2 shell beads, 2 gaming pieces, 1 modified deer phalange, 4 detached antler tines, 2 modified antler beam, 2 bone hooks, 2 bone awl, 2 modified bone fragments

Discussion - Feature 12 was found at $.8 \mathrm{ft}(.24 \mathrm{~m})$ below surface and thought to be a series of trash pits. The scatter of debris covered approximately $23.5 \mathrm{ft}(7.16 \mathrm{~m})$ in an east/west direction. Material culture tended to occur in clusters with soil noticeably darker where the clusters occurred. The middle section was very dark and contained burnt clay and earth. The soils were described in 9 zones and the feature was found to be comprised of 3 or 4 distinct pit areas, all containing cultural debris. The feature was divided into 3 pits areas and labeled 'A' through ' $C$ '. Pit 'A' 

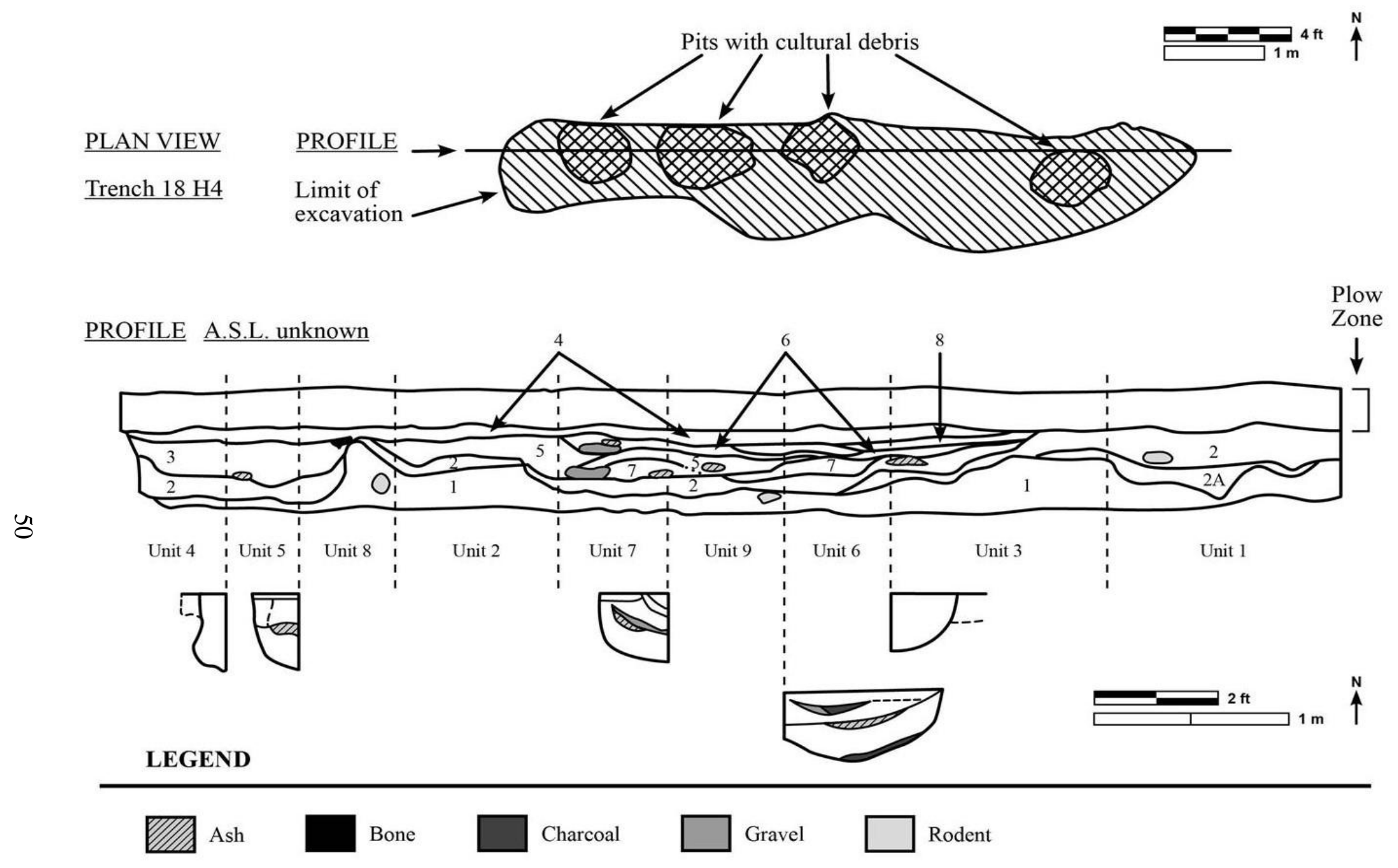

Figure 12. Feature 12. 
contained the largest and most diverse concentration of debris, with the most distinct stratigraphy of the three with layers of gravel, ash, debris, charcoal, and soil defined. Pit 'A' was found to have a claycap over the main area with more debris deposited later. In pit ' $\mathrm{B}$ ', in zone 5, a single bean and copper fragments were found. Pit ' $\mathrm{C}$ ' contained little material and mostly bone. The material from Feature 12 was not screened. Crew - Turkeys and Brian

\section{Feature 13}

(Figure 13)

Location - N 380.25 - 383.0, W 359.5 - 365.5; T16 O; A.S.L. 709.19 ft (216.16 m) (this does A.S.L. not align with 2017 A.S.L. for site)

Shape - Plan - circular but not completely excavated, estimated; Profile - no profile was available Size - Depth $-1.5 \mathrm{ft}(.46 \mathrm{~m})$, base depth $2.7 \mathrm{ft}(.73 \mathrm{~m}) \mathrm{bs}$; Length $-6 \mathrm{ft}(1.83 \mathrm{~m})$; Width $-2.75 \mathrm{ft}$ (.84) m excavated

Soil - dark gray mixed with cultural material Material Remains - Lithic Artifacts: 5 humpback bifaces, 1 core, 6 proximal Madison fragments, 1 abrader, 1 yellow ochre, 6 FCR

Ceramics: 60 shell tempered, 169 grit tempered, 4 mini-vessels, 33 sherdlets, 4 burned clay and daub, 1 perforated disc, 1 shaped clay, 57 Mississippian series, 162 Langford series.

Modified Fauna: One triangular shell pendant with perforation in one angle, 1 complete shell bead and 2 halves, 1 triangular serrated shell piece, 1 cut square shell piece, 2 "U” shape bone hooks, 1 gaming piece, 3 modified antler beams, 1 detached antler tine, 7 modified bone fragments Human Remains: a molar tooth was identified within the faunal remains for this feature. 
Discussion - This feature was excavated in three levels: level I from .9 to $1.4 \mathrm{ft}(.27$ to $.43 \mathrm{~m})$ below surface, level II from 1.4 to $1.9 \mathrm{ft}(.43$ to $.58 \mathrm{~m}$ ), and level III from 1.9 to $2.4 \mathrm{ft}$ (.58 to .73 m). Soil samples were taken from both levels. Cultural materials were found within all levels. Level I contained the most cultural material and burned remnants but the whole pit did not appear to be used for burning of trash. Level II contained less material and snails, and level III contained the least cultural material, but also contained shell-tempered sherds. A shell pendant was discovered in the dark soil above a thin layer of gravel, which was just above the sterile layer of clay. Only the north half of the feature was excavated completely. The south half was explored and a possible edge determined.

Crew - Sod Squad

Feature 16

(Figure 13)

Location - N 387.5 - 390.0, W 462.0 - 466.5; T15 E; A.S.L. $710.0 \mathrm{ft}$ (216.40 m) (This does A.S.L. not align with 2017 A.S.L. for site.)

Shape - Plan - possibly circular, partially excavated; Profile - concave

Size - Depth $-.95 \mathrm{ft}(.29 \mathrm{~m})$, base depth $1.3 \mathrm{ft}(.40 \mathrm{~m}) \mathrm{bs}$; Length $-4.5 \mathrm{ft}(1.37 \mathrm{~m})$; Width -2.5 $\mathrm{ft}(.76 \mathrm{~m})$

Soil - dark gray soil

Material Remains - Lithic Artifacts: 1 distal projectile fragment, 2 cores, 1 copper piece Ceramics: 25 shell tempered, 46 grit tempered, 2 untempered, 1 mini-vessel, 13 sherdlets, 1 perforated disc, 1 handle/lug, 23 Mississippian series, 46 Langford series. Modified Fauna: no modified bone or shell 
$\underline{\text { FEATURE } 13}$ LOCATION: Trench $16 \mathrm{O}$

$\underline{\text { PLAN VIEW }} \quad \underline{\text { A.S.L.: } 709.19}$

Note: no Profile available.

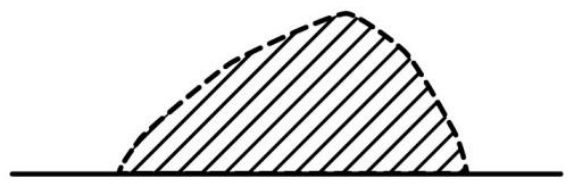

FEATURE 16 LOCATION: Trench $15 \mathrm{E}$

PLAN VIEW

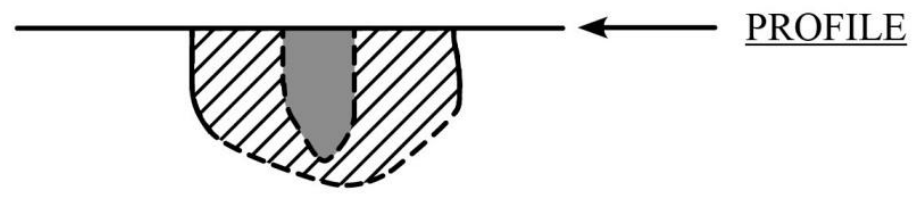

$\underline{\text { PROFILE }}$

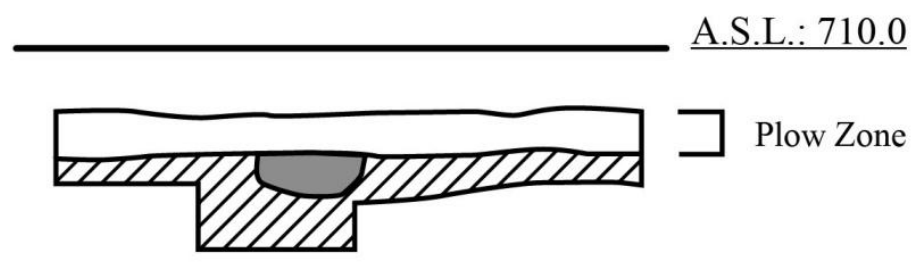

\section{LEGEND}

$\square$ Feature limit $\square$ Dark soil with bones, $4 \mathrm{ft}$ 个

Figure 13. Features 13 and 16. 
Discussion - This feature's floor sloped upward to the south from $1.3 \mathrm{ft}(.40 \mathrm{~m})$ below surface on the north to $1.0 \mathrm{ft}(.30 \mathrm{~m})$ on the south. The plow zone was found to a depth of $.75 \mathrm{ft}(.23 \mathrm{~m})$, and at $.9 \mathrm{ft}(.27 \mathrm{~m})$ below surface a concentration of bone was located in one ovoid area in the west half of the feature with another concentration at $1.3 \mathrm{ft}(.40 \mathrm{~m})$ below surface. The feature contained a large concentration of deer or elk bone, flakes, pottery, charred earth, and charcoal. No soil was screened. At approximately $1.3 \mathrm{ft}(.40 \mathrm{~m})$ below surface, journals recorded bones found that were thought to be human remains of a child in association with a piece of pottery which had a hole in the middle and was thought to be a bead. This material was not identified later within this feature's materials. It is thought by this author that the remains were possibly faunal instead, but no written references were found to verify this. A soil sample was taken at this level.

Crew - Trench Mouths

Feature 19

(Figure 14)

Location - N 367.0 - 370.5; W 399.0 - 402.0; T18 K - L; A.S.L. 706.0 ft (215.19 m)

Shape - Plan - possibly circular, not completely excavated; Profile - squared, concave

Size - Depth $-2.7 \mathrm{ft}(.82 \mathrm{~m})$ bs; Length $-3.5 \mathrm{ft}(1.07 \mathrm{~m})$; Width $-3.0 \mathrm{ft}(.91 \mathrm{~m})$

Soil - mixed black and yellow clay

Material Remains - Lithic Artifacts: this feature had the second least amount of lithic artifacts with only flakes and shatter.

Ceramics: 13 grit tempered, 2 burned clay, 13 Langford series.

Modified Fauna: One modified bone fragment 
Discussion - The plow zone contained a few potsherds, bones, and flint chips and ended at $.8 \mathrm{ft}$ $(.24 \mathrm{~m})$. At $.9 \mathrm{ft}(.27 \mathrm{~m}) \mathrm{bs}$, a portion of elk cranium was recovered at the east end. Between $.8 \mathrm{ft}$ $(.24 \mathrm{~m})$ and $1.4 \mathrm{ft}(.43 \mathrm{~m})$ mussel shells, sherds, bones, and flint chips were also found. A core sample showed the depth at $2.7 \mathrm{ft}(.79 \mathrm{~m})$ and the southern limit was estimated using the coring device, but the feature was not excavated further than $2.0 \mathrm{ft}(.61 \mathrm{~m})$ bs due to time constraints. While this pit is deeper than the other trash pits in this class, it was not thought to be a storage pit as Feature 17 was and is therefore classified as a shallow trash pit.

Crew - Nuel Downs and Schilt

Feature 20

(Figure 14)

Location - N 359.5 - 371.0, W 407.25 - 414.5; T18 J - K; A.S.L. 706.0 ft (215.19 m)

Shape - Plan - possibly ovoid, not completely excavated; Profile - basin, concave

Size - Depth - $1.05 \mathrm{ft}(.32 \mathrm{~m})$ bs; Length - Est. $11.5 \mathrm{ft}(3.51 \mathrm{~m})$, Exc. $1.5 \mathrm{ft}(.46 \mathrm{~m})$; Width -

Est. $7.25 \mathrm{ft}(2.21 \mathrm{~m})$, Exc. $7.0 \mathrm{ft}(2.13 \mathrm{~m})$ in trench (note discrepancy in trench profile mapping and profile line on plan map of approximately $2.0 \mathrm{ft}(.61 \mathrm{~m})$

Soil - black soil

Material Remains - Lithic Artifacts: 3 cores, 5 copper pieces (4 found with 1 bone)

Ceramics: 4 shell tempered, 51 grit tempered, 1 untempered, 5 sherdlets, 1 burned clay, 1 shaped clay, 4 Mississippian series, 50 Langford series.

Modified Fauna: One modified bone fragment

Discussion - There was very little written information recorded for this feature. Feature 20 was found while Feature 19 was being excavated, but was not completed due to time constraints. 
The extent of the feature was estimated with the coring device and mapped on the plan map. It was thought to be ovoid in shape. Crew - Nuel Downs and Schilt

\section{$\underline{\text { FEATURE } 19}$ LOCATION: Trench $18 \mathrm{~K} / \mathrm{L}$}

PLAN VIEW

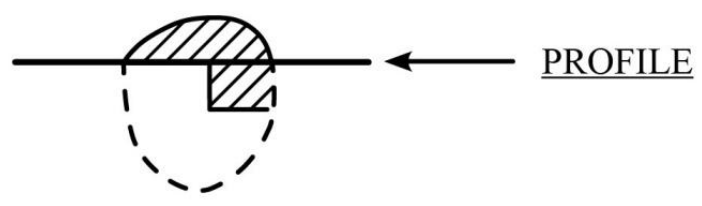

\section{PROFILE}

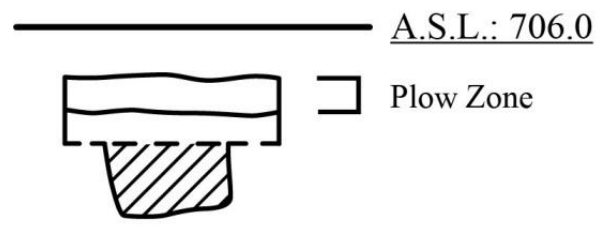

\section{FEATURE 20 LOCATION: Trench $18 \mathrm{~J} / \mathrm{K}$}

PLAN VIEW

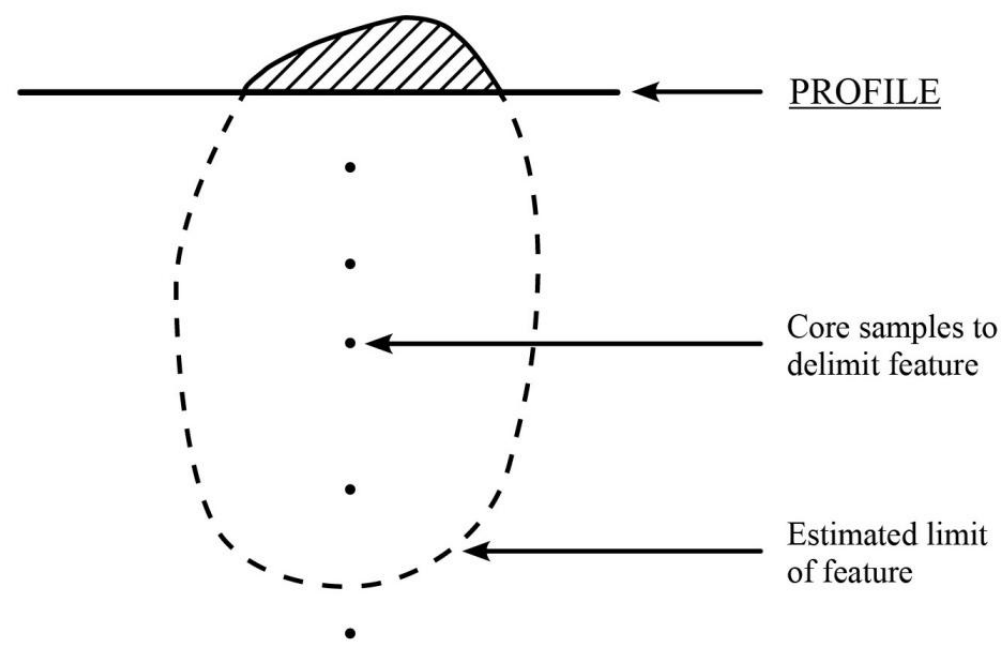

\section{PROFILE}

Note: profile

measurement did

not match plan

view on original.

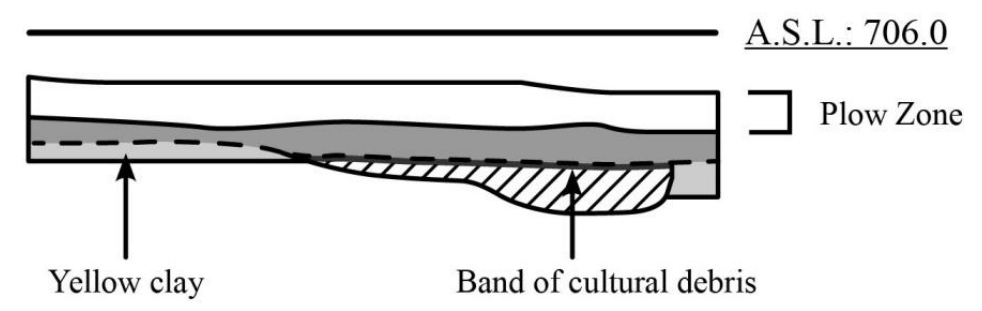

\section{LEGEND}

Feature limit

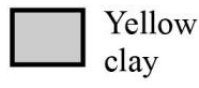

Yellow
clay

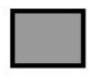

Gray soil with cultural debris
Band of

cultural debris

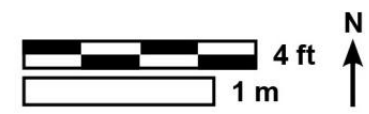

Figure 14. Features 19 and 20. 


\section{Class III Features - Shallow Pits with Fired Area}

Features 14 and 23 contain burned earth or heavy charcoal concentrations are interpreted as fire pits, placing them in the Class III category. Additional contents include ash, burnt clay, charcoal, and charred bone, but also contain various cultural materials, such as a gaming piece and projectile points.

\section{Feature 14}

(Figure 15)

Location - N 373.5 - 362.0, W 442.0 - 457.0; T18 F - G, T19 F - G; A.S.L. 706.0 (215.19 m) Shape - Plan - series of four ovoid shaped areas, contained within a larger area of cultural soil roughly ovoid shape; Profile - Bowl or bell shape Size - Depth $-1.0 \mathrm{ft}(.30 \mathrm{~m})$, base depth $1.8 \mathrm{ft}(.55 \mathrm{~m})$ bs; Length $-11.5 \mathrm{ft}(3.51 \mathrm{~m})$; Width $15.0 \mathrm{ft}(4.57 \mathrm{~m})$

Sections: $\quad$ 14A: 6.0 long x 4.25 wide $\times 1.4 \mathrm{ft}(1.83 \times 1.3 \times .43 \mathrm{~m})$ bs 14B: 3.5 long x Exc. 1.5 wide x $1.1 \mathrm{ft}(1.07$ x .46 x $34 \mathrm{~m})$ bs 14C: Exc. 8.0 long x 6.25 wide x $1.4 \mathrm{ft}(2.44 \times 1.91 \times .43 \mathrm{~m}) \mathrm{bs}$ 14D: 3.75 long x 2.5 wide $\times 1.8 \mathrm{ft}(1.14 \times .76 \times .55 \mathrm{~m}) \mathrm{bs}$ Soil - dark soil containing cultural material. Ash and charcoal present. Material Remains - Lithic Artifacts: 2 side-notch points, 5 complete Madison, 1 proximal Madison fragment, 1biface, perform, 2 distal and mid projectile fragments, 1 perforator, $1 \mathrm{knife}$, 2 biface humpback, 1 biface scraper, 1 retouched flake, 1 core, 1 ground stone, 3 FCR Ceramics: 45 shell tempered, 265 grit tempered, 6 untempered, 1 mini-vessel, 67 sherdlets, 17 burned clay and daub, 45 Mississippian series, 262 Langford series. 
Modified Fauna: One gaming piece, 1 modified deer phalange, 1 bone awl, 1 modified antler beam, 2 smoothed canid teeth, 5 modified bone fragments

Human Remains: a calcaneous bone was identified within the faunal remains for this feature. Discussion - Feature 14 was first discovered by observation of burned earth in Test 18 and then extended past baulk into Test 19. It was believed to be a fire pit. Several anomalies were discovered and labeled 14A, B, C, and D on the plan map. Coring was attempted to delimit the feature. Limits of the feature were not clear as the darker feature soil blended with the outlying yellow clay along the edges. It was suggested at time of excavation that this feature was outside of a house structure as no house structural elements were found in relation to it. Charcoal samples were taken throughout the feature.

14A: A circular bowl shaped area containing white ash was discovered from $1.25 \mathrm{ft}(.38 \mathrm{~m})$ below surface. Area contained two mussel shells, charcoal, sherds, and bone. Charcoal samples were taken. Two side-notched projectile points were found south of 14A, were "mapped" and photographed. Artifact maps and photos mentioned in the journals were not located.

14B: Pottery sherds, shell and bone were found in this smaller circular area.

14C: Ash was located at $1.2 \mathrm{ft}(.37 \mathrm{~m})$ below surface and bone and sherds at $1.5 \mathrm{ft}(.46 \mathrm{~m})$ below surface.

14D: Burned clay, charcoal and few bones were obtained from this area. A soil sample was taken for flotation at $1.3 \mathrm{ft}(.40 \mathrm{~m})$ below surface. This area sloped gradually up on north side. The baulk, approximately $1 \mathrm{ft}(.30 \mathrm{~m})$ wide and to $1.4 \mathrm{ft}(.43 \mathrm{~m})$ below surface, between Test 18 and Test 19, was removed last and contained projectile points, clay, sherds, ash, charcoal, and bone. In the words of one student “To conclude, the feature was victorious, and we still don't know what the thing was. Oh well." Crew - Primos 
LOCATION - Trench $18 \mathrm{~K} / \mathrm{L}$

PLAN VIEW
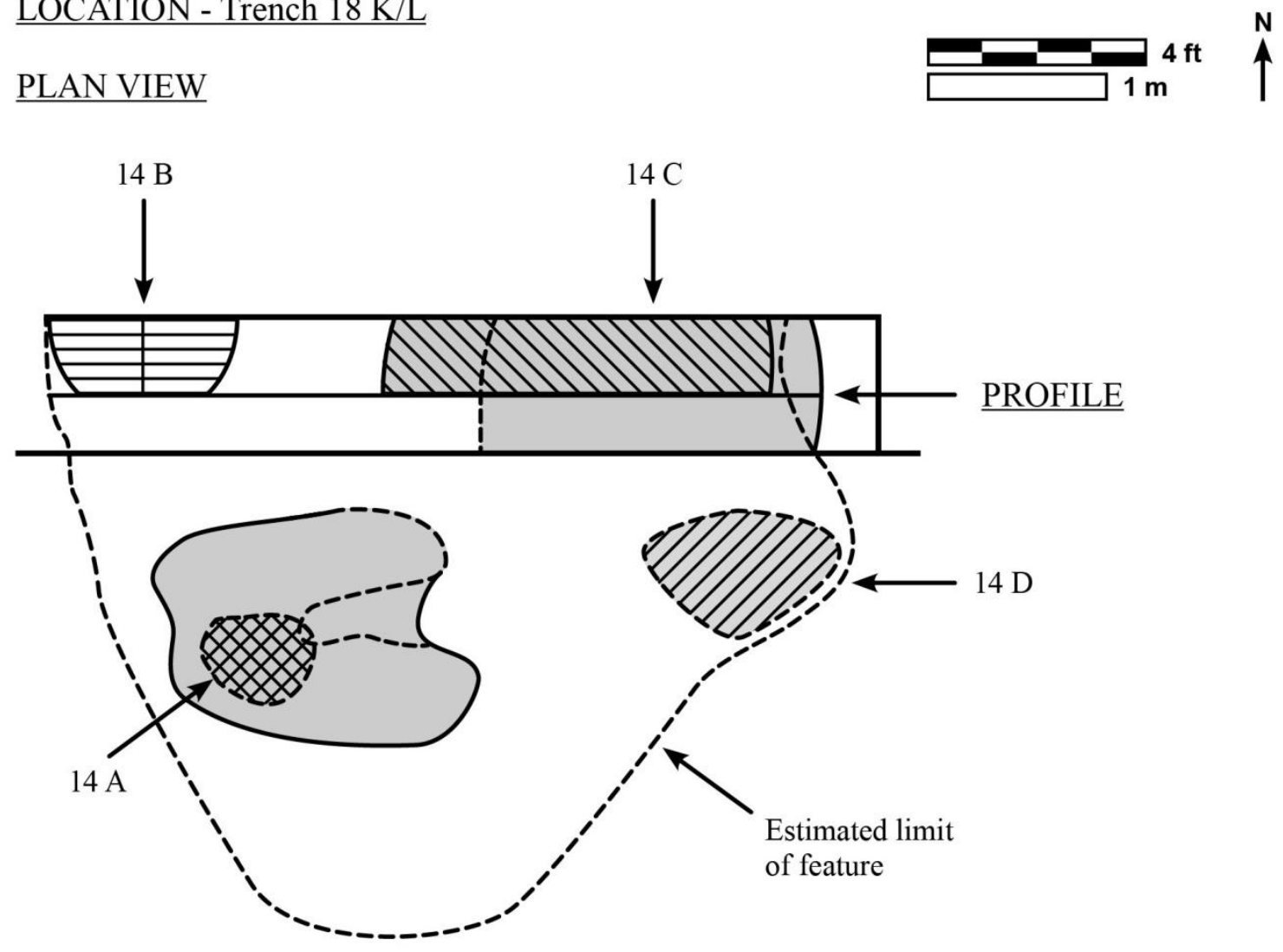

PROFILE Note: profile measurement did not match plan view on original.

A.S.L.: 706.0

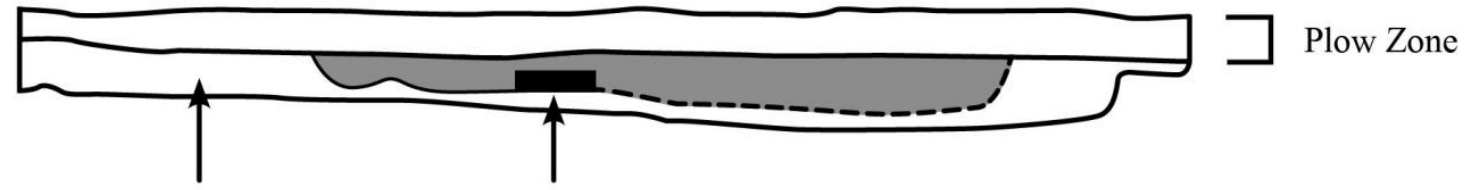

Sterile yellow clay

Ash layer

\section{LEGEND}

14 A: Large sherds and charred bone

14 B: Feature limit
$\mathbb{Q}$

$14 \mathrm{C}$ : Feature limit

14 D: Feature limit
Feature limit areas

$14 \mathrm{~A}, \mathrm{~B}, \mathrm{C} \& \mathrm{D}$

Dark soil with bones, sherds and ash

Figure 15. Feature 14. 


\section{Feature 23}

(Figure 16)

Location - N 373.75 - 372.0, W 433.0 - 435.0; T17 H; A.S.L. 706.0 (215.19 m)

Shape - Plan - circular; Profile - concave

Size - Depth $-1.0 \mathrm{ft}(.30 \mathrm{~m}) ;$ Length $-2.0 \mathrm{ft}(.61 \mathrm{~m}) ;$ Width $-2.0 \mathrm{ft}(.61 \mathrm{~m})$

Soil - dark soil containing cultural material. Ash and charcoal present.

Material Remains - Lithic Artifacts: chipped stone flakes

Ceramics: 2 shell tempered, 5 grit tempered, 1 burned clay, 2 Mississippian series, 5 Langford series.

Modified Fauna: no modified bone or shell

Discussion - Feature 23 was discovered when extensions were made for delimiting Feature 22. A circular shape, this feature was found under a layer of gravel, which reached from $.8 \mathrm{ft}(.24 \mathrm{~m})$ to $1.3 \mathrm{ft}(.40 \mathrm{~m})$ below surface. The dark soil contained elk bones, pottery sherds, and a few chipped stone flakes was believed to have been in place when Feature 22 was formed as it did not extend into the gravel layer of the latter feature. The layer of cultural material at the bottom of this pit was $.7 \mathrm{ft}(.21 \mathrm{~m})$ thick and a thin layer of charcoal and ash lined the bottom of the pit. Crew - Beardsley

Class IV Features - House Features

Two features of large, rectangular or ovoid shape were determined to be house structures. Both Features 15 and 18 were semi-subterranean with the floor less than $3.0 \mathrm{ft}(.91 \mathrm{~m})$ below surface and post molds and/or wall trenches. A third feature in this class, Feature 21, was only 
FEATURES 22 and 23

$\underline{\text { PLAN VIEW }}$ LOCATION - Trench 17 G/H

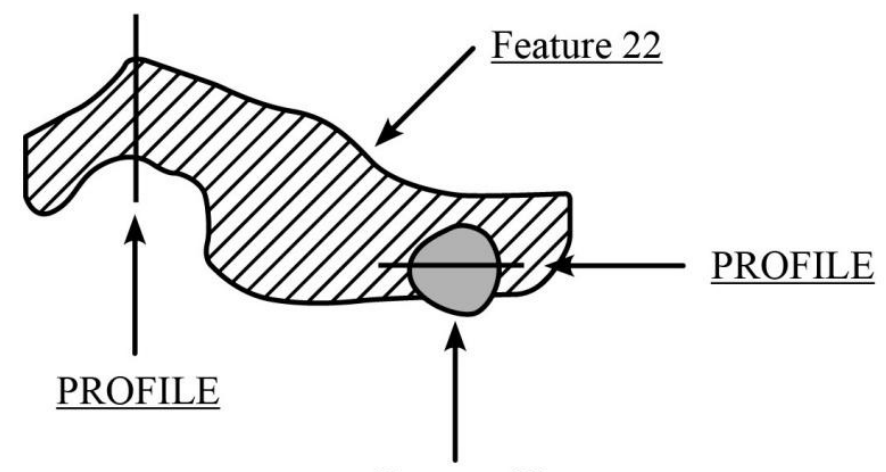

Feature 23

\section{Class VI FEATURE 22}

PROFILE

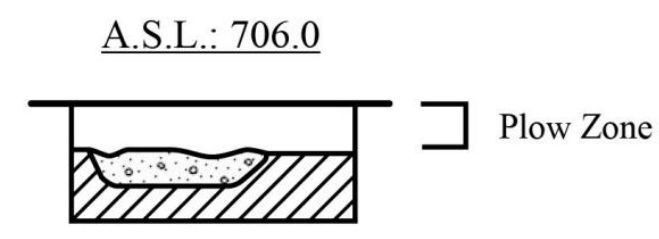

\section{Class III FEATURE 23}

PROFILE

A.S.L.: 706.0

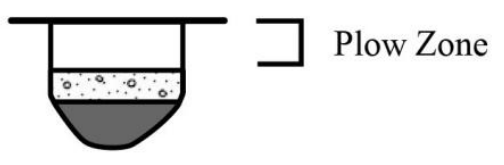

\section{LEGEND}

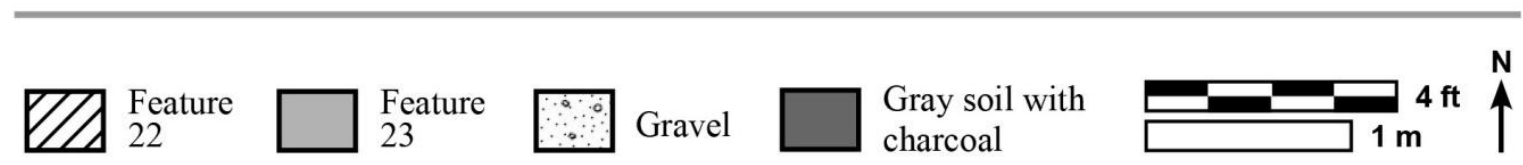

Figure 16. Features 22 and 23.

(Note: Feature 22 overlays Features 23 and 15. See Figure 17 for relation to Feature 15.) 
excavated within the trench, but was thought to contain a wall trench and therefore be the edge of a house feature. As in previous excavations, time and circumstances prevented complete excavation of all of these features. Feature 18 was the most completely excavated. The plowzone was removed and the house basin mapped in plan view before the northwest quadrant was fully excavated and piece plotted. House features reported at other Langford Tradition sites, such as Fisher (Griffiin 1946), Zimmerman (Brown 1961), and Reeves (Craig and Galloy 1996) are found to have rectangular or ovoid shapes with post molds. All except the Reeves site are reported as semi-subterranean with wall trenches. Prior and later excavations at the NobleWieting site have also located similar house features.

\section{Feature 15}

(Figures 17 and 18)

Location -N 374.0 - 399.5, W 415.5 - 449.0; T16 G - J, T17 G - I; A.S.L. 706.0 ft (215.19 m) Shape - Plan - estimate, undetermined, possibly rectangular or ovoid; Profile - concave basin. Size - Depth - $1.8 \mathrm{ft}(.55 \mathrm{~m})$, base depth $2.6 \mathrm{ft}(.79 \mathrm{~m})$ bs; Length - est. $25.5 \mathrm{ft}(7.77 \mathrm{~m})$; Width est. $33.5 \mathrm{ft}(10.21 \mathrm{~m})$; Vertical - ranges from .8 to $2.6 \mathrm{ft}(.24$ to $.79 \mathrm{~m})$ bs determined by core samples.

Soil - mottled gray containing cultural debris throughout, dark gray-black soil Material Remains - Lithic Artifacts: 1 celt, 3 FCR

Ceramics: 1 shell tempered, 4 grit tempered, 1 sherdlet, 1 Mississippian series, 4 Langford series. Modified Fauna: no modified bone or shell

Discussion - A portion of Feature 15 occurs under Feature 22, suggesting a different feature episode altogether as opposed to a separate fill layer in this feature (Figure 17). Five post molds were located along the south edge of Feature 15. Coring was used to find the boundaries to the 


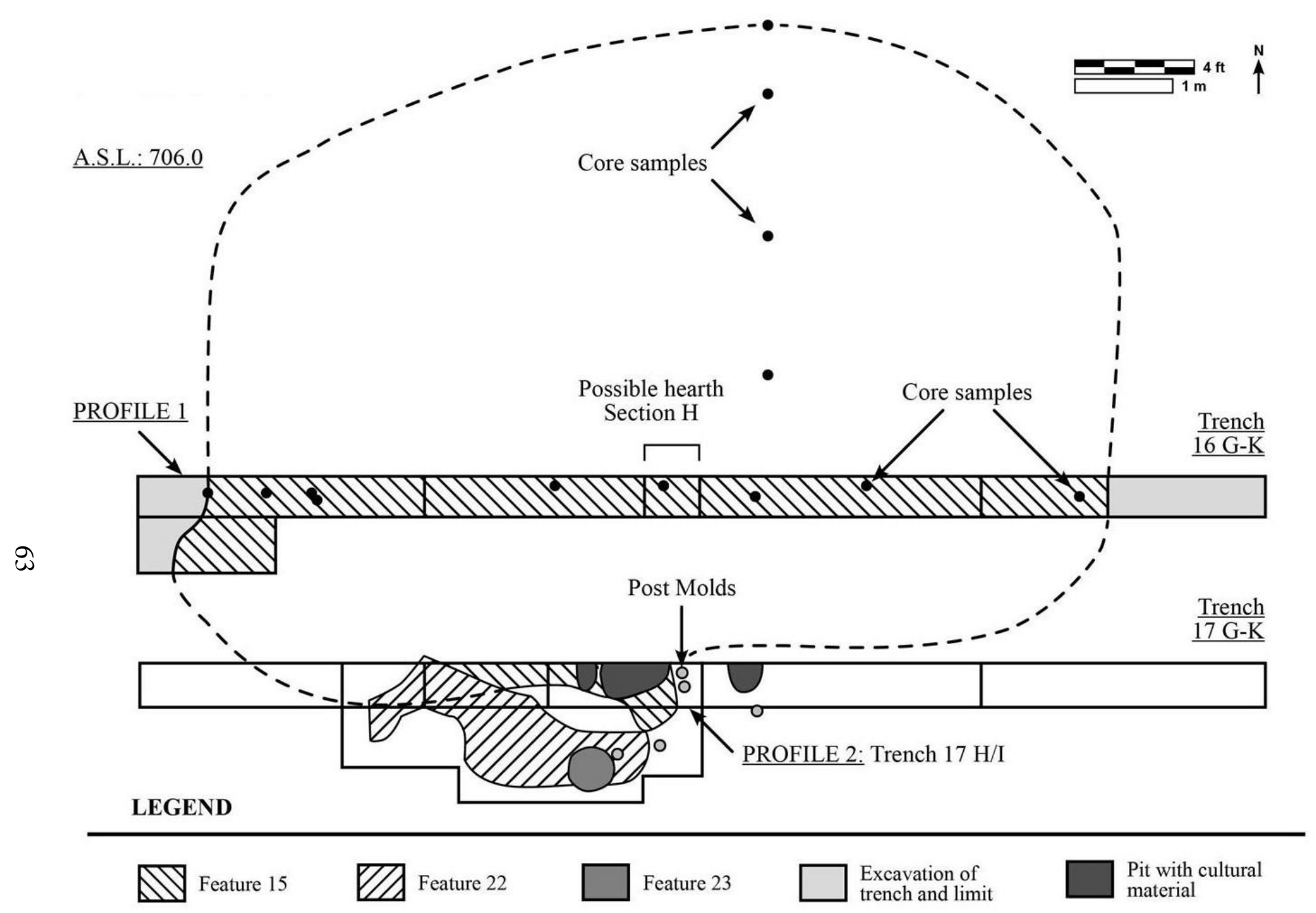

Figure 17. Feature 15, Plan View with Features 22 and 23. 
PROFILE 1 Trench 16 G-J A.S.L. 706.0

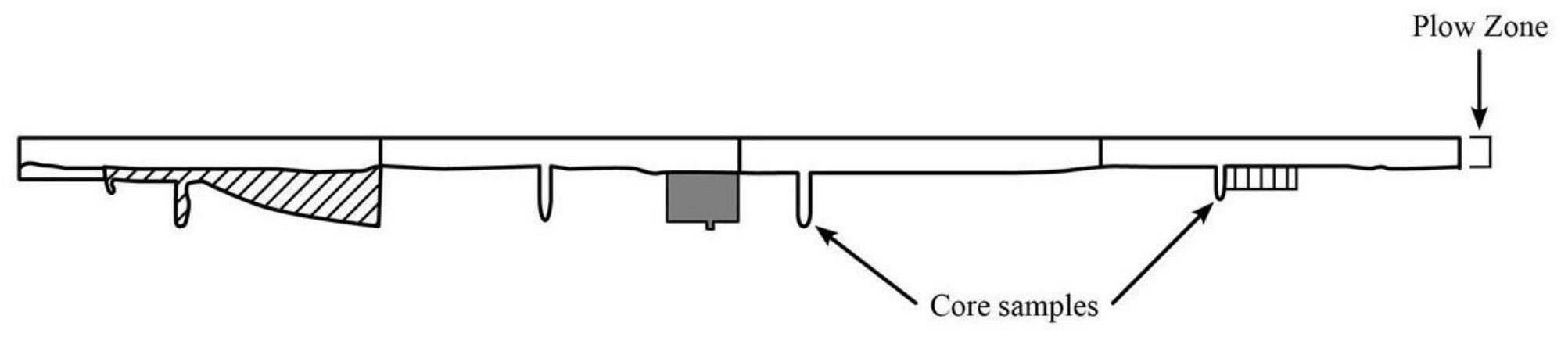

PROFILE 2 Trench $17 \mathrm{H} \&$ I A.S.L. 706.0

a

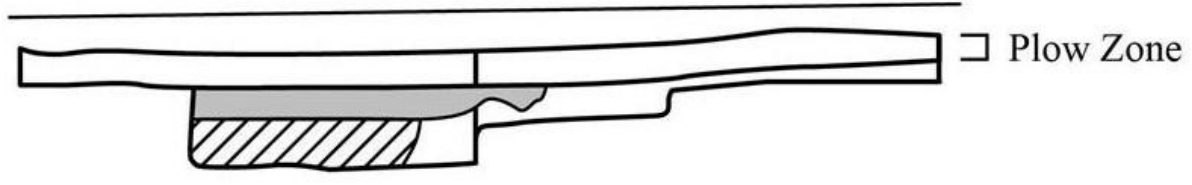

\section{LEGEND}

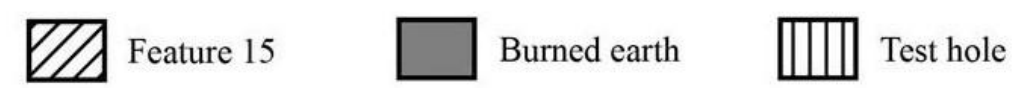

Feature 22

with charcoa

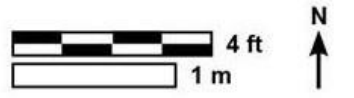

Figure 18. Feature 15, Profile. 
north and south. Sterile soil found from the cores ranged from 2.6 feet $(.79 \mathrm{~m})$ below surface along the middle of the determined feature area to 1.4 feet $(.43 \mathrm{~m})$ to the northern edge. A burned layer occurred above the sterile soil layer and assisted with determination of the approximate area of the feature to the north.

It was suggested a hearth feature might be located at $\mathrm{T} 16 \mathrm{H}$, as that was thought to be the center of the structure due to the core sample results. Much of the gray-black layer excavated from the trench sections from .8 to $2.6 \mathrm{ft}(.24$ to $.79 \mathrm{~m})$ below surface was found to not contain much cultural material.

Five post molds were located at the south edge of the feature and a well defined edge separation between the dark soil and yellow clay. Field notes report that a shell hoe was found near the post molds, however, the shell hoe in the assemblage was labeled as from Feature 12 instead. In section $\mathrm{T} 16 \mathrm{G}$, a large piece of charcoal was found in a horizontal position approximately $.8 \mathrm{ft}(.24 \mathrm{~m})$ long and thought to be a piece of post that had burned. Just outside of the south edge of the feature the dark soil slopes down to the east where a heavy layer of burned material was located. The whole feature was not excavated and size and shape were abstracted. Crew - Beardsley

Feature 18

(Figures 19 and 20)

Location - N 387.0 - 418.5, W 499.5 - 529.0; T15AA - C; A.S.L. $710.0 \mathrm{ft}$ (216.40 m) (This does A.S.L. not align with 2017 A.S.L. for site.)

Shape - Plan - Ovoid; Profile - basin

Size -Depth-1.4 ft (.43 m), depth $2.2 \mathrm{ft}$ (.67) bs; Length-31.5 ft (9.6 m); Width-29.5 ft (8.99 m) 
Soil - very dark gray throughout most of the feature almost immediately under the plow zone and ending a "few feet" from the limits of the feature.

Material Remains - Lithic Artifacts: 10 complete Madison, 2 proximal Madison fragments, 1 distal projectile fragment, 1 perforator tip, 2 biface humpback, 1 biface scraper, 1 retouched flake, 2 cores, 1 FCR

Ceramics: 29 shell tempered, 86 grit tempered, 1 untempered, 12 sherdlets, 36 burned clay, 29 Mississippian series, 84 Langford series.

Modified Fauna: no modified bone or shell

Discussion - A line defining the edge of this feature in Trench 15A was determined and then extensions of the test trench revealed more of the feature to the south and to the north. A core taken in one area of the southeast quadrant showed depth to $2.2 \mathrm{ft}(.67 \mathrm{~m})$ below surface was disturbed and charcoal was found in that same area of the core sampling. This core is mentioned within the journals but not shown on the map. Large charcoal pieces were also found outside of the feature in that vicinity. Test pits dug to the north revealed the limit of the feature as much larger than a shallow trash pit and suggestive of a house.

The limits of the feature were defined and it was determined to be approximately $30 \mathrm{ft}$ by $28 \mathrm{ft}(9.14 \times 8.53 \mathrm{~m})$ and ovoid in shape. It was divided into four quadrants. Due to time constraints the northeast and southwest quarters were only excavated to remove the plow zone. The southeast limits were difficult to define, but the northwest edge was clearly located.

Charcoal timbers were located at depths between $1.6 \mathrm{ft}$ and $1.9 \mathrm{ft}(.49$ and $.58 \mathrm{~m})$ and were located just inside the edges of the feature and a plan map was drawn of the burnt timbers 
in the northwest quadrant. Some charcoal remains were found in a vertical position in the northwest quadrant, suggesting posts. Under burnt timbers in the northwest quadrant, a $1.2 \mathrm{ft}$ wide $(.37 \mathrm{~m})$ wall trench was located. Test pits were then dug in all quadrants and wall trenches were located in each quadrant with corners located in the southeast and southwest quadrants. The corners had an open space between the wall trenches and a separate plan map was created for the trenches. A charcoal log base was found vertical in situ in a post mold in the northwest quadrant. Charcoal was also found throughout the northwest quadrant at the level of cultural material between 2.1 and $2.3 \mathrm{ft}(.64$ and $.70 \mathrm{~m})$ and mapped. A composite of the three separate maps, which include the whole feature, wall trenches, and charcoal locations, was created for this report (Figure 19). It was noted that samples were taken for C-14 and botanical analysis. These sample and analysis reports have not been located from that year or subsequent years and it has not been determined if the curated material is the same as was taken for these reports.

The northwest quadrant was the only area taken completely down to the sterile soil level at $2.1 \mathrm{ft}(.64 \mathrm{~m})$ below surface at the outer edge and sloping downward to $2.3 \mathrm{ft}(.70 \mathrm{~m})$ in the center of the feature. The floor was also found to slope from $1.5 \mathrm{ft}(.46 \mathrm{~m})$ at the north edge to $2.1 \mathrm{ft}(.64 \mathrm{~m})$ at the south edge in this quadrant. The locations of cultural material were plotted on the plan map for the northwest and southeast quadrants and it was noted that material was not screened from any of the quadrants. In the southeast quadrant, a Langford pot, identified within the material as Vessel \#220 by Fricker, was located under a burnt timber, in situ, and plotted on the plan map. This feature contained the most burnt clay and the largest pot.

Crew - everyone, overseen by Jelks 


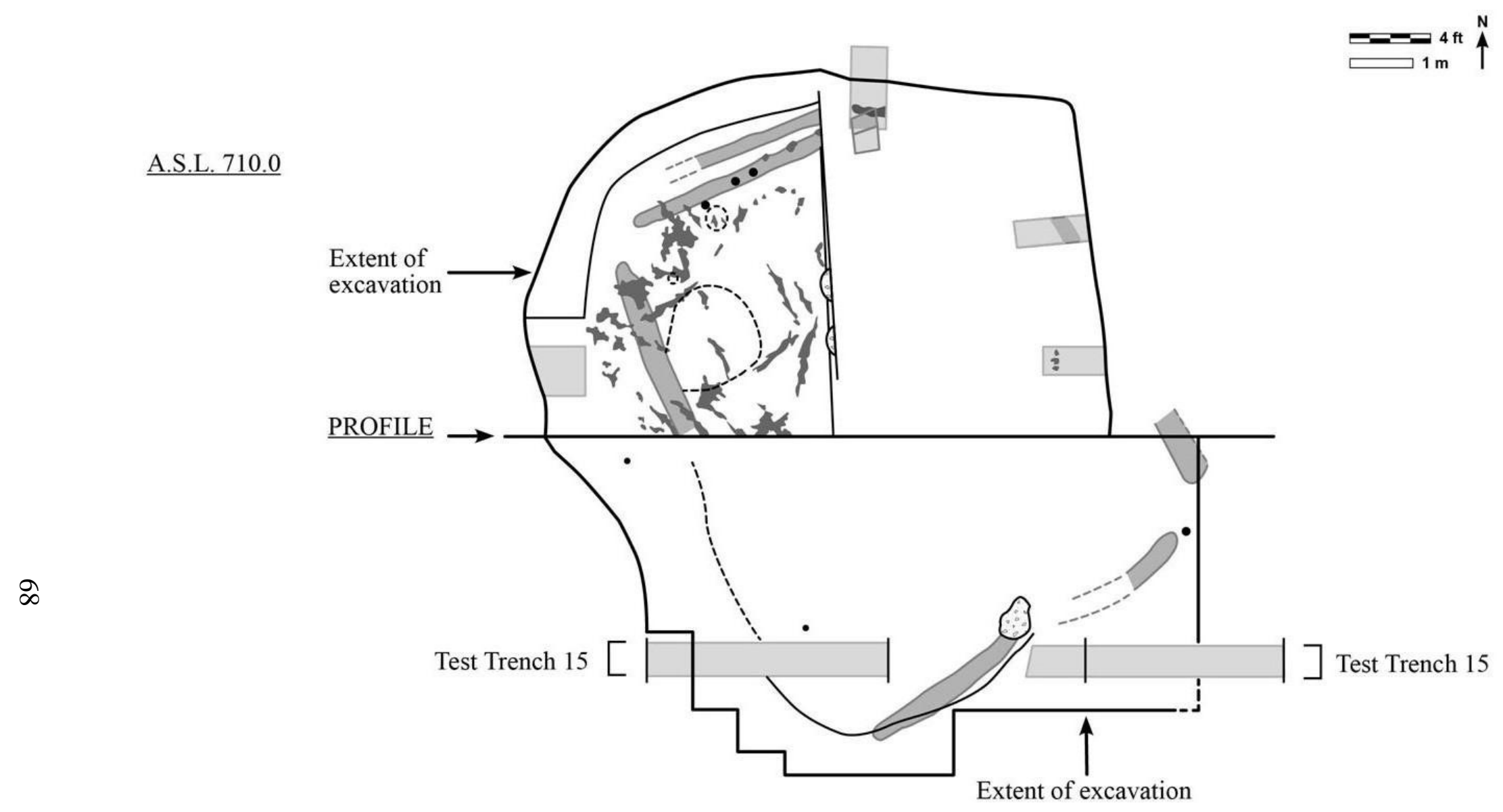

\section{LEGEND}

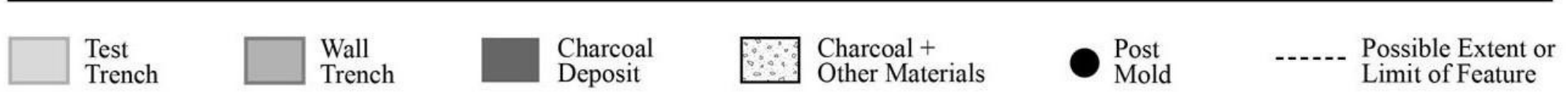

Figure 19. Feature 18, Plan View. 
A.S.L. 710.0

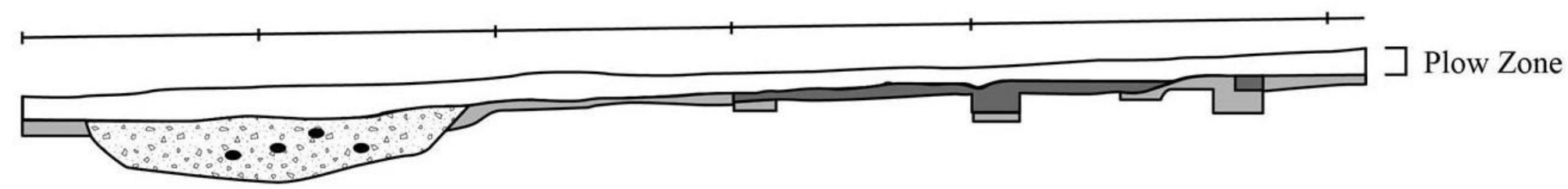

LEGEND

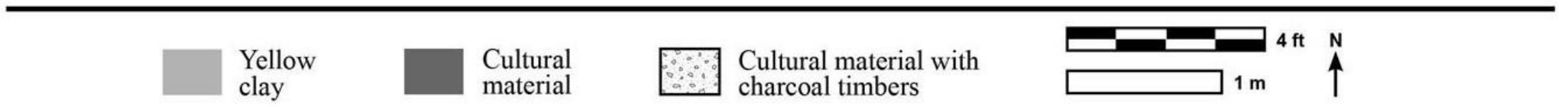

Figure 20. Feature 18, Profile. 


\section{Feature 21}

(Figure 21)

Location - N 372.0 - 373.5, W 390.0 - 398.25; T18L; A.S.L. 706.0 ft (215.19 m)

Shape - Plan - unknown, not completely excavated, possibly edge of house feature; Profile basin

Size - Depth $-3.6 \mathrm{ft}(1.10 \mathrm{~m})$, base depth $3.0 \mathrm{ft}(.91 \mathrm{~m})$ with wall trench base depth $4.4 \mathrm{ft}(1.34$

m) bs; Length - excavated $8.25 \mathrm{ft}(2.51 \mathrm{~m}) ;$ Width - trench width $1.5 \mathrm{ft}(.46 \mathrm{~m})$

Soil - gray and black soil

Material Remains - Lithic Artifacts: 1 distal Madison fragment, 1 ground stone, 1 FCR

Ceramics: 11 shell tempered, 21 grit tempered, 3 untempered, 4 sherdlets, 2 daub, 11

Mississippian series, 20 Langford series.

Modified Fauna: One modified deer phalange, 1 used deer femur ball, 2 beaver teeth (possibly used)

Discussion - This feature was recorded as beginning at a depth of approximately $.8 \mathrm{ft}(.24 \mathrm{~m})$ bs and extending to $2.6 \mathrm{ft}(.79 \mathrm{~m})$ with gray soil and cultural material throughout. It was thought this feature was the edge of a house structure, but excavation and coring to delimit it was not possible due to time constraints. Soil was not screened. A gradual slope from $2.3 \mathrm{ft}$ to $3.0 \mathrm{ft}$ (.70 to $.91 \mathrm{~m}$ ) below surface, with a deeper portion extending to $4.4 \mathrm{ft}(1.34 \mathrm{~m}) \mathrm{bs}$ that was thought to be a wall trench. At the floor level of $3.0 \mathrm{ft}(.91 \mathrm{~m}) \mathrm{bs}$, four pieces of charcoal log fragments were uncovered.

Crew - Nuel Downs \& Schilt 
FEATURE 21 LOCATION - Trench $18 \mathrm{~L}$

PLAN VIEW
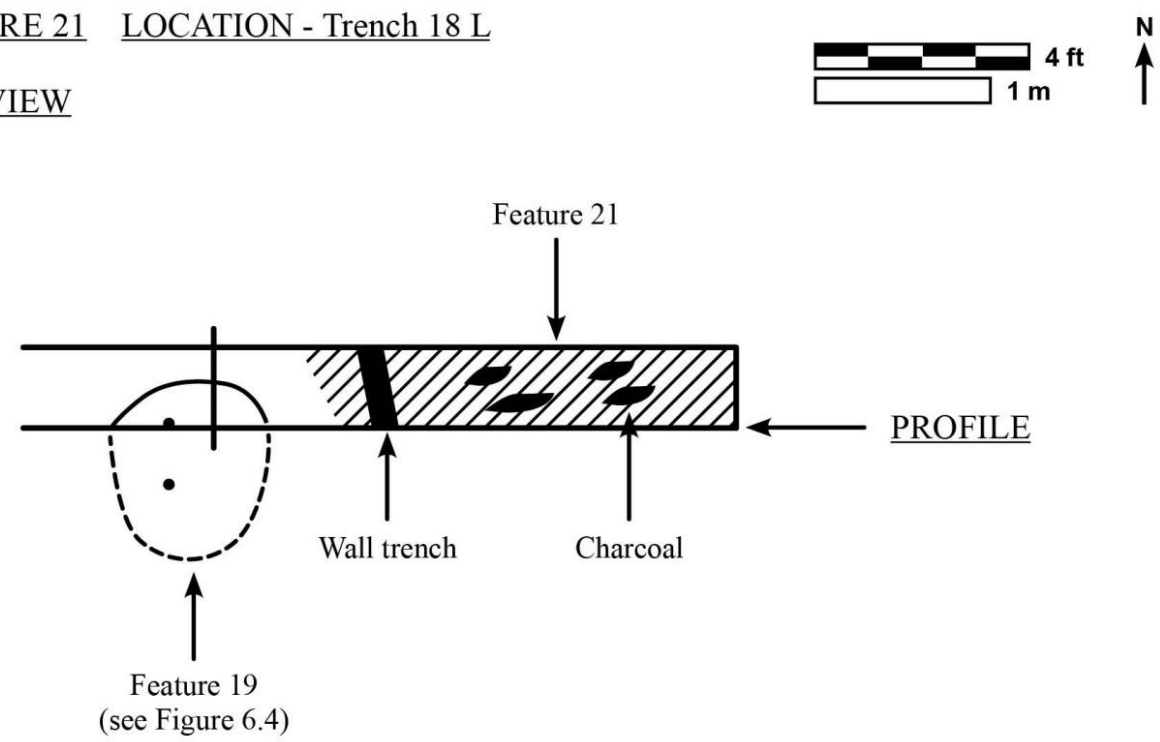

PROFILE $\quad \underline{\text { South Wall }}$

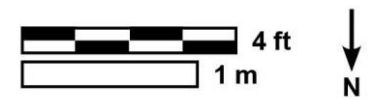

A.S.L.: 706.0

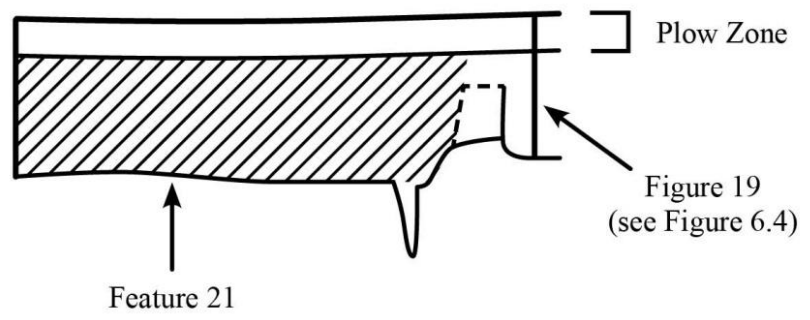

Figure 21. Feature 21.

\section{Class VI Features - Irregular Pits}

Feature 22 represents an irregular shaped pit, placed over another feature (Feature 23) of shallow depth, and contained very little cultural material but much gravel. It did not contain 
charcoal or evidence of burning, so is not considered a shallow heating or cooking facility. The use of this feature is undetermined.

\section{Feature 22}

(Figures 16, 17, and 18)

Location - N 373.5 - 378.0, W 431.75 - 442.0; T17 G - H; A.S.L. 706.0 ft (215.19 m)

Shape - Plan - irregular; Profile - irregular

Size - Depth - .5 ft (.15 m), base depth $1.3 \mathrm{ft}(4.0 \mathrm{~m})$ bs; $\quad$ Length $-10.25 \mathrm{ft}(3.12 \mathrm{~m})$; Width $4.5 \mathrm{ft}(1.37 \mathrm{~m})$

Soil - gravel and rock mixed with dark gray soil

Material Remains - Lithic Artifacts: 1 complete Madison, 1 FCR

Ceramics: 32 grit tempered, 114 sherdlets, 32 Langford series.

Modified Fauna: no modified bone or shell

Discussion - This feature occurs over Features 15 and 23, which suggests its placement at a later date. Very distinct edges were found. The pit appears to curve and get narrow and shallow on the west end. The gravel area occurs at $.8 \mathrm{ft}(.24 \mathrm{~m})$ below surface and extends to the depth of $1.3 \mathrm{ft}$ $(.40 \mathrm{~m})$ below surface. Soil was screened, but very little cultural material was found within this gravel-filled area. Yellow clay underlies this feature.

Crew - Beardsley

\section{Compilation of All Excavated Features}

The following tables present a summary of measurements and shapes of all the features excavated between and including 1966 and 1976 (Table 1 and 2). A composite map of all excavations represented in these tables follows (Figure 22.). 
Table 1

Summary of Features 1966-1972.

(Adapted from Schilt, 1977.)

\begin{tabular}{|c|c|c|c|c|c|}
\hline $\begin{array}{l}\text { Feature } \\
\text { and Class }\end{array}$ & Plan Shape & $\begin{array}{l}\text { Profile } \\
\text { Shape }\end{array}$ & Depth (ft/m) & Length $(\mathrm{ft} / \mathrm{m})$ & Width (ft/m) \\
\hline $\mathrm{C}-\mathrm{I}$ & Circular & Concave & $2.9 \mathrm{ft}(.88 \mathrm{~m})$ & $4.35 \mathrm{ft}(1.33 \mathrm{~m})$ & $3.55 \mathrm{ft}(1.08 \mathrm{~m})$ \\
\hline $\mathrm{L}-\mathrm{I}$ & Ovoid & Concave & $4.35 \mathrm{ft}(1.33 \mathrm{~m})$ & $6.2 \mathrm{ft}(1.89 \mathrm{~m})$ & $4.5 \mathrm{ft}(1.37 \mathrm{~m})$ \\
\hline $\mathrm{P}-\mathrm{I}$ & Circular & Bell & $4.35 \mathrm{ft}(1.33 \mathrm{~m})$ & $4.0 \mathrm{ft}(1.22 \mathrm{~m})$ & $5.0 \mathrm{ft}(1.52 \mathrm{~m})$ \\
\hline $4-I$ & Circular & Concave & $5.0 \mathrm{ft}(1.5 \mathrm{~m})$ & $5.0 \mathrm{ft}(1.52 \mathrm{~m})$ & $5.0 \mathrm{ft}(1.52 \mathrm{~m})$ \\
\hline $1-\mathrm{II}$ & Ovoid & Concave & $1.45 \mathrm{ft}(.44 \mathrm{~m})$ & $5.5 \mathrm{ft}(1.67 \mathrm{~m})$ & $4.7 \mathrm{ft}(1.43 \mathrm{~m})$ \\
\hline $6-$ II & Ovoid & Concave & $1.7 \mathrm{ft}(.52 \mathrm{~m})$ & $5.0 \mathrm{ft}(1.52 \mathrm{~m})$ & $3.0 \mathrm{ft}(.91 \mathrm{~m})$ \\
\hline $9-$ II & Circular & Bell & $1.3 \mathrm{ft}(.40 \mathrm{~m})$ & $2.1 \mathrm{ft}(.64 \mathrm{~m})$ & $2.5 \mathrm{ft}(.76 \mathrm{~m})$ \\
\hline $\mathrm{A} / \mathrm{B}-\mathrm{III}$ & Irregular & Irregular & $.7 \mathrm{ft}(.21 \mathrm{~m})$ & $12.0 \mathrm{ft}(3.66 \mathrm{~m})$ & $3.0 \mathrm{ft}(.91 \mathrm{~m})$ \\
\hline J - III & Ovoid & Irregular & $.95 \mathrm{ft}(.29 \mathrm{~m})$ & $12.5 \mathrm{ft}(3.81 \mathrm{~m})$ & $9.5 \mathrm{ft}(2.9 \mathrm{~m})$ \\
\hline $\mathrm{D}-\mathrm{IV}$ & Ovoid & Basin & $.75 \mathrm{ft}(.23 \mathrm{~m})$ & $9.0 \mathrm{ft}(2.74 \mathrm{~m})$ & $5.5 \mathrm{ft}(1.68 \mathrm{~m})$ \\
\hline $3-I V$ & Rectangular & Basin & $1.5 \mathrm{ft}(.46 \mathrm{~m})$ & $20.8 \mathrm{ft}(6.34 \mathrm{~m})$ & $18.8 \mathrm{ft}(5.73 \mathrm{~m})$ \\
\hline $8-$ IV & Rectangular & Basin & $.9 \mathrm{ft}(.27 \mathrm{~m})$ & $17.5 \mathrm{ft}(5.33 \mathrm{~m})$ & $16.0 \mathrm{ft}(4.88 \mathrm{~m})$ \\
\hline $\mathrm{R} 1-\mathrm{V}$ & Ovoid & (unk) & $1.46 \mathrm{ft}(.45 \mathrm{~m})$ & $1.5 \mathrm{ft}(.46 \mathrm{~m})$ & $1.0 \mathrm{ft}(.30 \mathrm{~m})$ \\
\hline $\mathrm{R} 2-\mathrm{V}$ & Rectangular & (unk) & $.5 \mathrm{ft}(.15 \mathrm{~m})$ & $2.0 \mathrm{ft}(.61 \mathrm{~m})$ & $3.5 \mathrm{ft}(1.07 \mathrm{~m})$ \\
\hline R3/R6 - V & Ovoid & (unk) & (unk) & $4.0 \mathrm{ft}(1.22 \mathrm{~m})$ & $6.0 \mathrm{ft}(1.83 \mathrm{~m})$ \\
\hline $\mathrm{R} 4-\mathrm{V}$ & Square & (unk) & (unk) & $1.5 \mathrm{ft}(.46 \mathrm{~m})$ & $1.5 \mathrm{ft}(.46 \mathrm{~m})$ \\
\hline $\mathrm{R} 5-\mathrm{V}$ & Ovoid & (unk) & (unk) & $2.5 \mathrm{ft}(.76 \mathrm{~m})$ & $5.0 \mathrm{ft}(1.52 \mathrm{~m})$ \\
\hline $5-V$ & (unk) & (unk) & $.34 \mathrm{ft}(.10 \mathrm{~m})$ & (unk) & (unk) \\
\hline $7-V$ & (unk) & (unk) & $1.6 \mathrm{ft}(.49 \mathrm{~m})$ & $2.5 \mathrm{ft}(.76 \mathrm{~m})$ & $3.0 \mathrm{ft}(.91 \mathrm{~m})$ \\
\hline $10-\mathrm{V}$ & Rectangular & (unk) & $3.0 \mathrm{ft}(.91 \mathrm{~m})$ & $2.25 \mathrm{ft}(.69 \mathrm{~m})$ & $6.5 \mathrm{ft}(1.98 \mathrm{~m})$ \\
\hline$E-(V I)$ & Circular & Concave & $.35 \mathrm{ft}(.11 \mathrm{~m})$ & $2.0 \mathrm{ft}(.61 \mathrm{~m})$ & $2.0 \mathrm{ft}(.61 \mathrm{~m})$ \\
\hline $\mathrm{F}-(\mathrm{VI})$ & Ovoid & Irregular & $.35 \mathrm{ft}(.11 \mathrm{~m})$ & $2.2 \mathrm{ft}(.66 \mathrm{~m})$ & $1.2 \mathrm{ft}(.35 \mathrm{~m})$ \\
\hline $\mathrm{G}-(\mathrm{VI})$ & Irregular & Irregular & $.25 \mathrm{ft}(.08 \mathrm{~m})$ & $1.0 \mathrm{ft}(.30 \mathrm{~m})$ & $.5 \mathrm{ft}(.15 \mathrm{~m})$ \\
\hline $\mathrm{H}-(\mathrm{VI})$ & Irregular & Irregular & $.75 \mathrm{ft}(.23 \mathrm{~m})$ & $.5 \mathrm{ft}(.15 \mathrm{~m})$ & $.5 \mathrm{ft}(1.5 \mathrm{~m})$ \\
\hline $\mathrm{I}-(\mathrm{VI})$ & Circular & Concave & $.5 \mathrm{ft}(.15 \mathrm{~m})$ & $.5 \mathrm{ft}(.15 \mathrm{~m})$ & $.5 \mathrm{ft}(1.5 \mathrm{~m})$ \\
\hline $\mathrm{K}-(\mathrm{VI})$ & (unk) & (unk) & $3.0 \mathrm{ft}(.91 \mathrm{~m})$ & (unk) & (unk) \\
\hline $\mathrm{M}-(\mathrm{VI})$ & Ovoid & (unk) & $.35 \mathrm{ft}(.11 \mathrm{~m})$ & $3.5 \mathrm{ft}(1.07 \mathrm{~m})$ & $2.0 \mathrm{ft}(.61 \mathrm{~m})$ \\
\hline $\mathrm{N}-(\mathrm{VI})$ & Circular est & (unk) & $.35 \mathrm{ft}(.11 \mathrm{~m})$ & $5.0 \mathrm{ft}(1.5 \mathrm{~m})$ & $2.5 \mathrm{ft}(.76 \mathrm{~m})$ \\
\hline $\mathrm{O}-(\mathrm{VI})$ & Circular & (unk) & $.35 \mathrm{ft}(.11 \mathrm{~m})$ & $1.0 \mathrm{ft}(.30 \mathrm{~m})$ & $1.0 \mathrm{ft}(.30 \mathrm{~m})$ \\
\hline $\mathrm{S}-(\mathrm{VI})$ & Circular & (unk) & $.35 \mathrm{ft}(.11 \mathrm{~m})$ & $6.5 \mathrm{ft}(1.98 \mathrm{~m})$ & $6.5 \mathrm{ft}(1.98 \mathrm{~m})$ \\
\hline $2-(\mathrm{VI})$ & Irregular & Concave & $2.4 \mathrm{ft}(.73 \mathrm{~m})$ & $11.4 \mathrm{ft}(3.47 \mathrm{~m})$ & $5.9 \mathrm{ft}(1.52 \mathrm{~m})$ \\
\hline
\end{tabular}


Table 2

Summary of Features 1976.

\begin{tabular}{|c|c|c|c|c|c|}
\hline 1976: & Plan shape & $\begin{array}{l}\text { Profile } \\
\text { Shape }\end{array}$ & Depth $(\mathrm{ft} / \mathrm{m})$ & Length $(\mathrm{ft} / \mathrm{m})$ & Width $(\mathrm{ft} / \mathrm{m})$ \\
\hline $17-\mathrm{I}$ & Circular & Concave & $4.65 \mathrm{ft}(1.42 \mathrm{~m})$ & $5.75 \mathrm{ft}(1.75 \mathrm{~m})$ & $5.0 \mathrm{ft}(1.52 \mathrm{~m})$ \\
\hline $12-$ II & Irregular & Irregular & $.5 \mathrm{ft}(.15 \mathrm{~m})$ & $23.5 \mathrm{ft}(7.16 \mathrm{~m})$ & $4.75 \mathrm{ft}(1.45 \mathrm{~m})$ \\
\hline $13-$ II & Circular & (unk) & $1.5 \mathrm{ft}(.46 \mathrm{~m})$ & $6 \mathrm{ft}(1.83 \mathrm{~m})$ & Exc. $2.75 \mathrm{ft}(.84) \mathrm{m}$ \\
\hline $16-$ II & Ovoid & Concave & $.95 \mathrm{ft}(.29 \mathrm{~m})$ & $4.5 \mathrm{ft}(1.37 \mathrm{~m})$ & $2.25 \mathrm{ft}(.69 \mathrm{~m})$ \\
\hline $19-$ II & Circular & Concave & $2.7 \mathrm{ft}(.82 \mathrm{~m})$ & $3.5 \mathrm{ft}(1.07 \mathrm{~m})$ & $3.0 \mathrm{ft}(.91 \mathrm{~m})$ \\
\hline $20-$ II & Ovoid & Concave & $1.05 \mathrm{ft}(.32 \mathrm{~m})$ & $\begin{array}{l}\text { Est. } 11.5 \mathrm{ft}(3.51 \\
\mathrm{m}), \text { Exc. } 1.5 \mathrm{ft} \\
(.46 \mathrm{~m})\end{array}$ & $\begin{array}{l}\text { Est. } 7.25 \mathrm{ft}(2.21 \\
\mathrm{m}), \text { Exc. } 7.0 \mathrm{ft}(2.13 \\
\mathrm{m}) \text { in trench }\end{array}$ \\
\hline $14-$ III & Ovoid & Bell & $1.0 \mathrm{ft}(.30 \mathrm{~m})$ & $11.5 \mathrm{ft}(3.51 \mathrm{~m})$ & $15.0 \mathrm{ft}(4.57 \mathrm{~m})$ \\
\hline $23-$ III & Circular & Concave & $1.0 \mathrm{ft}(.30 \mathrm{~m})$ & $2.0 \mathrm{ft}(.61 \mathrm{~m})$ & $2.0 \mathrm{ft}(.61 \mathrm{~m})$ \\
\hline $15-\mathrm{IV}$ & Rectangular & Basin & $1.8 \mathrm{ft}(.55 \mathrm{~m})$ & $\begin{array}{l}\text { Est. } 25.5 \mathrm{ft} \\
(7.77 \mathrm{~m})\end{array}$ & $\begin{array}{l}\text { Est. } 34 \mathrm{ft} \\
(10.36 \mathrm{~m})\end{array}$ \\
\hline $18-$ IV & Ovoid & Basin & $1.4 \mathrm{ft}(.43 \mathrm{~m})$ & $30 \mathrm{ft}(9.14 \mathrm{~m})$ & $28 \mathrm{ft}(8.53 \mathrm{~m})$ \\
\hline $21-I V$ & (unk) & Basin & $3.6 \mathrm{ft}(1.10 \mathrm{~m})$ & $\begin{array}{l}\text { Exc. } 8 \mathrm{ft}(2.44 \\
\mathrm{m})\end{array}$ & Exc. $1.5 \mathrm{ft}(.46 \mathrm{~m})$ \\
\hline $22-\mathrm{VI}$ & Irregular & Irregular & $.5 \mathrm{ft}(.15 \mathrm{~m})$ & $10.25 \mathrm{ft}(3.12 \mathrm{~m})$ & $3.5 \mathrm{ft}(1.07 \mathrm{~m})$ \\
\hline
\end{tabular}

('Exc.' measurement refers to feature only understood in measurement of test trench and not

fully excavated. 'Est.' refers to measurements estimated by core sampling.)

1966-1976 results:

I - deep trash; circular or oval orifice; storage first then trash (5 examples)

II - shallow trash; circular, ovoid, or irregular plan (8 examples)

III - shallow with central fired area; large and irregular plan (4 examples)

IV - house or structural pit; basin (6 examples)

V - burial (9 examples)

VI - inadequate data, anomalous in nature (12 examples)

Total features excavated -44 


\section{Features Conclusion}

A more comprehensive discussion of the artifact distribution is contained in Chapter XI. However, as a brief summary it can be determined that the 1976 excavations revealed features similar in nature to those uncovered in previous excavations. Material remains were identified as a majority of Langford elements, with minor Middle Mississippian components, and no 1976 features were identified as associated with the burials or mound, although they were closer to the mound. Shallow trash pits and fire pits contained the majority of cultural remains, in the form of extracted artifacts, and then deep trash pits followed suit. The Feature 18 house uncovered in 1976, which was the one most fully examined of the three possible house features, was constructed with wall trenches and post molds and followed the rectangular pattern of the house features previously excavated to the north west of 1976 excavation. Wall trench houses have been excavated at other Langford sites and are typical for Mississippian sites. No additional human burials were identified in 1976, although two human bones were found within trash pits. This analysis concludes that the southern portion of the site is strongly Langford in nature, as Schilt had determined about earlier features excavated. This analysis does not support any additional interaction or cultural influence than previously determined from earlier excavations at this site. 


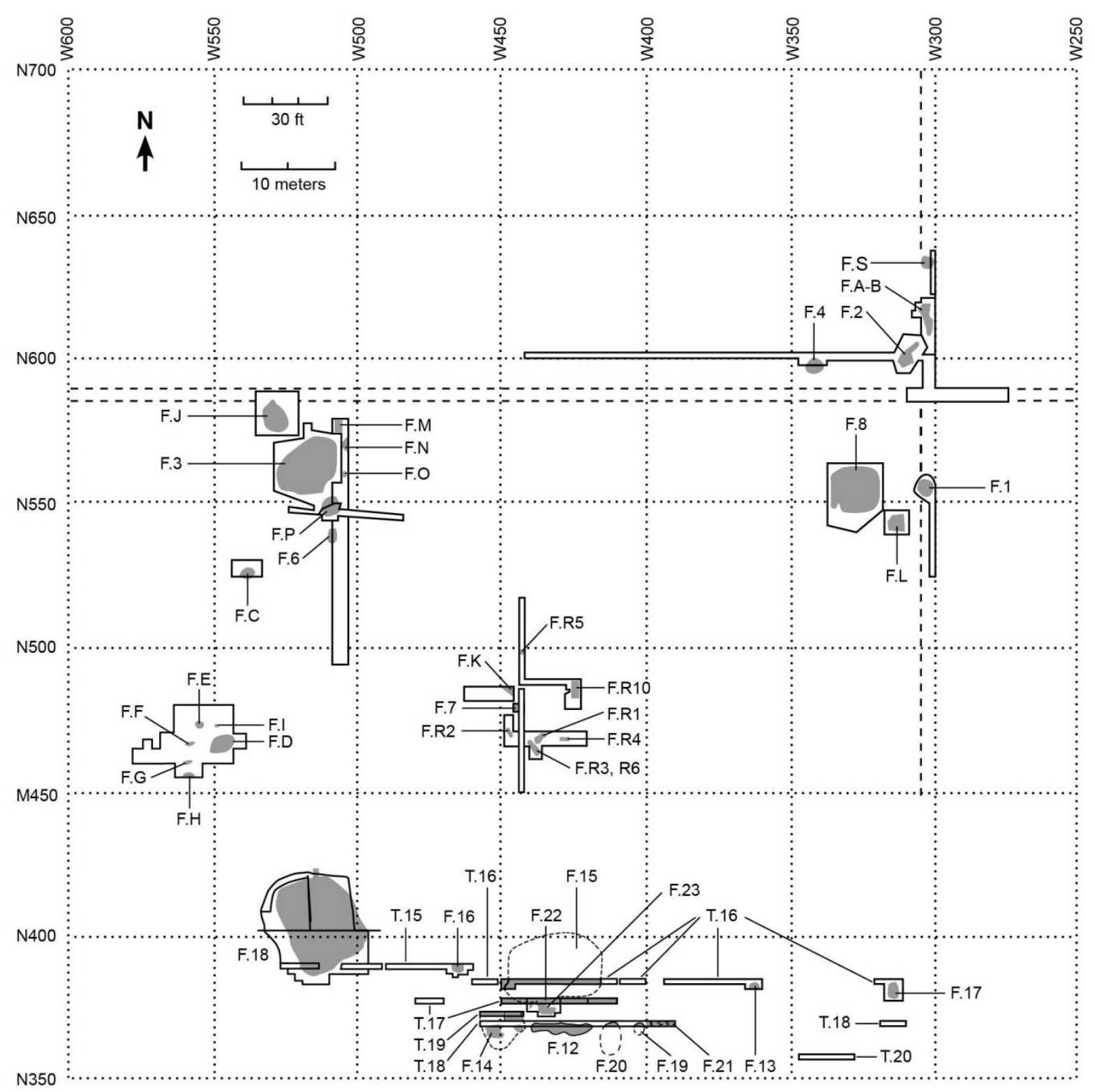

Figure 22. Noble-Wieting Archaeological Excavations 1966-1976. (1966-1972 adapted from Schilt, 1977: Figure 6.) 


\section{CHAPTER VII: ANALYSIS OBJECTIVES FOR ARTIFACTS}

Materials inventories created in 1976 by ISU students were transferred for this thesis into Microsoft Excel and Access programs for all features and Test trenches, which provided easier comparison with the actual physical materials available. Physical materials were loaned from ISM to ISU for this project and were transported to ISU between June 1 and August 1, 2018. Inventories of each RCC box were checked as the artifacts were analyzed and box inventories were updated as needed. Materials had been sorted by type of materials (e.g. lithics, ceramics, charcoal/botanicals, faunal, and miscellaneous) by RCC. Materials transferred for this study were lithics, ceramics, floral, soil, faunal, and a few miscellaneous artifacts of other nature. One large refit pottery pieces was not transported to ISU due to fragility. Refits for ceramics were conducted by graduate student Ian Fricker during his analysis and these were inventoried and assessed at RCC due to the fragility of the pieces.

During the years of storage at ISU and during the transfer to ISM/RCC from ISU, some materials were displaced and mixed with the collections from 1968-1972, as some were found within those boxes during the analysis for this report. A search for artifacts missing from the 1976 boxes was conducted and artifacts found in other boxes were reunited with their year and provenience. Some artifacts from other collections were also found within the Noble-Wieting boxes and returned to their proper locations at RCC. A box of ground stones containing numerous collections also contained some that were not labeled and not otherwise identified in any of the 1976 excavation paperwork. These were not included in this analysis as it was not known their true provenience. Because of the mix of materials from various collections and excavation years, and even with a thorough investigation of all the site's boxes, it is unknown if all the artifacts for 1976 were accounted for. Materials listed on the materials list, written about 
in student journals, and listed on the lots inventory sheets, did not completely align with what was actually counted for this study. It is unknown if this is due to reporting error or due to loss during storage at ISU or transfer to RCC.

Due to these discrepancies of possible loss and mixed materials, it is my determination that analysis conducted and reports generated as soon as possible after a site's excavation, or while there is still sufficient excavation memory available from the participants, increases the accuracy of the analysis and reporting. This site's materials have encountered numerous transitions of location and handling by different researchers and, therefore, have sustained some loss of material and documentation through the last forty years, a fact also noted by other researchers (Bird 1997; Schilt 1977). The issues of loss of cultural material and excavation information encountered for this study attest to the necessity of analysis and reporting of archaeological excavations as soon as possible after the field work is finished.

\section{Analysis Objectives}

Analysis was conducted of all materials following the methods reported later in this chapter. Artifacts have a wide range of variability of morphology and require classification, which assists researchers in reducing data into manageable units. Classification of archaeological materials serves as an aid for interpretation of a site and to identify possible behavior of the people who inhabited the space (Andrefsky 1998: 60).

This analysis attempts to answer if diagnostic artifacts will show further influence of Middle Mississippian culture and ideologies and if Noble-Wieting should be considered an isolated outpost with little social interaction. My objectives for the 1976 excavation materials analysis include: 1) to analyze the 1976 excavations and include them within the site's record; 2) 
to synthesize results with previous conclusions for the site by Schilt (1977); and 3) to identify the extent of Middle Mississippian social interaction and influence at this site.

\section{Lithic and Other Stone Tools}

This section discusses the analysis methods for lithic and modified stone artifacts of the Noble-Wieting 1976 excavations. Stone tools may be considered a cultural marker, identifying the prehistoric group of people who may have occupied a site, as well as providing data supporting inferences of activities at the location (Andrefsky 1998: 60; Reber et al 2017: 10). For example, analysis of artifact form may reveal artifact function which suggests site function and seasonal use. Schilt's conclusion states the Noble-Wieting site material remains suggest permanent to semi-permanent residence of the site, rather than use as a hunting or base camp which would be used as a temporary location without burial mounds and houses (1977: 177).

The goals of the stone tool analysis are to provide a description of the 1976 excavation's chipped stone tool, ground stone or rough stone artifacts, and chipped stone byproduct assemblage (flakes, debitage), and to combine data with previous excavation data from 19661972. Specifically, Middle Mississippian type lithics, such as tri-notch projectile points and chunky stones, were watched for that would indicate cultural exchange. Addition of the 1976 data to previous summaries allows for an understanding of the full complement of the lithics retrieved from the site up to 2016 for future comparison with other Langford sites.

To accomplish the above listed goals for research of the lithic assemblage, a sort was conducted to separate natural debris from those created by human agency. Categories included bifaces, projectile points, perforators, cores, flakes, shatter, fire-cracked rock (FCR), and other ground or rough stone artifacts. Included within the lithic summary is a brief description of ochre 
and copper recovered. Bone or antler artifacts that may have been used as tools are included with the faunal analysis portion of this thesis.

Natural materials and naturally chipped debris were re-bagged and labeled if found within bags containing diagnostic stone tools or waste from manufacture of tools and were not included in the analysis results. Pigments, such as red or yellow ochre, were weighed, recorded, and bagged. Modified stone tools and ground stone tools were first divided by location, for distributional comparisons, and then into morphological and functional categories based on macroanalysis by sight and with a hand magnifier. Microwear analysis was not conducted on this assemblage. Thermal alteration of chert, as determined by color change and a lustrous appearance also was not recorded. Both microwear analyses and thermal alteration assessments are opportunities for future research for this site's lithic materials. As an in-depth use analysis was not conducted, the function and use of tools is inferred from the general shape and apparent wear.

Bifaces are defined as two-sided pieces, flaked to form an edge on the entire artifact, with evidence of chipping on both sides (Andrefsky 1998: 76; Crabtree 1972: 38). Projectile points, usually biface, are chipped along edges converging into a point. While the name implies use as a hafted object to throw, or project, the name is used for typology and not to assume function (Andrefsky 1998: 73). Perforators, also called drills, show bifacial retouch, but taper to the tip and are more circular around the middle region (Wiant and McGimsey 1986: 547). As with other stone tool names, the name "drill" does not imply function, but is a designation for typology.

Attributes of bifacial artifacts, other than projectile points, and other stone artifacts are recorded and described separately in Chapter VIII, of this report. Attributes of projectile points were compiled and include provenience, length, width of proximal or distal ends, and thickness. 
Chipped stone debitage consisting of flakes and cores were recorded by provenience and quantity. Reduction stage analysis for bifacial and projectile artifacts and cortex analysis of debitage was not conducted as part of this study, due to time restrictions. Further research using methods of reduction and cortex analysis, as well as microanalysis of these artifacts, may provide evidence regarding manufacture, use, maintenance, and seasonal-specific activities, and may also assist in determining manufacturing strategies and recycling by the Noble-Wieting inhabitants.

Cores are defined as a primary source of raw material of which usable pieces were detached and having negative flake scars (Andrefsky 1998: 137). Cores may show various stages of preparation and removal of pieces, but this analysis did not include further classification of cores other than initial identification. Flakes, pieces removed from cores and identified by evidence of percussion or pressure, were separated from shatter, which did not show evidence of striking platform or pressure reduction (Andrefsky 1998: 81). Amounts of cortex present, curvature, and measurements of strike platforms of flakes were not included as part of this analysis.

FCR are of igneous, metamorphic or sedimentary rock and show evidence of use and exposure to extreme temperatures, but not necessarily evidence of manufacture (Craig and Galloy 1996: 7-24). Other ground or rough stone tools also show evidence of use, but do not fall into the other categories used in this study. These are included in the summaries for all excavations if able, however.

The final step of the lithic assemblage analysis included a brief assessment of rawmaterial type. Raw materials were identified using comparative samples from the Illinois State University archaeology laboratory. However, an in-depth analysis of raw materials was not conducted for this report and presents an opportunity for further research. 
All data was entered into Microsoft Excel spreadsheets or into a Microsoft Access database, photos were attached for diagnostic artifacts. Comparative tables were created for this thesis and are included within the lithic analysis chapter. Photos were placed into the Ziplocs with diagnostic artifacts as part of the rehabilitation of the collection.

\section{Ceramics}

Ceramics recovered at archaeological sites have long been considered a marker for defining one group of people from another. The decoration and shape, as well as the internal material from which the pottery is manufactured and how the piece was constructed, are found to be variables that differ between cultures, traditions, or regions. The Langford Tradition is typically known for vessels of a globular shape, with few decorative elements, and manufactured from clay combined with grit temper. Langford ceramics are similar in shape and size to the Oneota and Fisher ceramics. While the Langford Tradition is considered to be an Upper Mississippian group, along with Oneota, Fisher, and Huber, the ceramics differ enough due to temper and design elements that Langford can be defined as a separate culture or phase from the others. Shell-tempered ceramics, usually thinner and with more decoration and style variants than Langford grit-temper pieces, are signifiers of the Middle Mississippian culture. Differences in ceramics at Langford sites are used to identify possible interaction between Langford people and other Mississippian groups or individuals.

Specific goals for the 1976 ceramic analysis are to identify Middle Mississippian influence or artifacts and to determine if the interactions between Noble-Wieting inhabitants with other groups, as based on ceramic typology, will show similar results as Schilt's previous conclusions for other areas of this site. 
Analysis of ceramics from previous excavations of 1966-1972 was conducted by Schilt (1977) and again by graduate student Ian Fricker (2015-2018). Fricker also included 1976 ceramics in his analysis, but at the time of my thesis his conclusions were not available. Fricker sorted, identified, rebagged, and refit ceramics. Inventories, which divided sherds based on materials, surface finish, decorations, and form were created by Fricker and bags were found labeled with lot numbers and provenience. The ceramics were sorted by provenience, but internal labels were not included. Analysis of the ceramics for this report included a recount of ceramics to verify accuracy, compilation of all ceramic information contained on the bags with additional observations by myself and information from the 1976 excavation journals, and entering of all information into a Microsoft Excel sheet.

Physicochemical fingerprinting of clays to determine material procurement, evaluation of residue for understanding use of vessels, and any destructive analysis techniques were not administered for this report. Visual inspection was my method used for observations of pieces to compare them with Fricker's inventories. Sherds were divided by temper, (i.e. grit or shell), grit type of mafic or dark grit, surface treatment, and decoration, all which assist in determining local typology. These pieces were also separated and identified by structure, such as rim, body, or handle, and rim pieces further analyzed by attributes such as thickness, lip profile, and angle of rim to body. Typological categories presented by Schilt (1977) were used where appropriate in order to give comparison with previous findings and with findings from other Langford sites.

Typically, counting sherds and calculating percentages of sherds according to local typology is used to assist with interpretations of the cultural affiliation of the inhabitants of a site, but this method is thought to contain flaws. Two flaws suggested by Ellis (2006: 246) are that the 
individual fragments do not represent unique vessels and that different types of ceramics will have different degrees of fragility and therefore different numbers of broken pieces.

Matching sherds to each other gives a more accurate vessel count and a weight and thickness analysis may assist with determining breakage of different vessels (Ellis 2006: 247), but proves to be a time consuming method. Estimated vessel equivalents (EVE) calculations, based on one distinctive part of the vessel such as the rim for representing a whole vessel, is one method used to alleviate the task of matching individual sherds and reconstructing vessels. One potential problem with the EVE method is underestimating the number of vessels because rim sherds are usually not as numerous in the assemblage as body sherds. Even though methods such as quantifying sherd weight and EVE contain problems, these methods are considered more reliable than others for ceramic analysis (Ellis 2006: 248). Schilt employed methods of dividing sherds by typology and producing percentages to determine interaction, as well as identifying the metrics and attributes of rim sherds. Following suit, the methods for my report also quantify sherds by typology and present rim sherd attributes by typology. Counts of burned earth, also called burned clay, were also recorded by provenience and by any surface impressions were noted. The results of the ceramic portion of the 1976 analysis and summaries with previous excavation data are located in Chapter IX.

\section{Flora, Fauna and Soil Samples}

An analysis of the floral remains was not conducted for this thesis as it did not pertain to the direct research objectives. Floral remains for 1976 are minimal and may not greatly enhance the previous conclusions or overall interpretation of the site. A faunal analysis was conducted with three goals: 1) to determine if there were any faunal remains used as tools or ornaments; 2) to identify faunal artifacts that may represent Middle Mississippian influence with carved 
symbols and; 3) to identify possible human remains not already removed from the faunal material. Time constraints limited full analysis of all 1976 faunal material, including identification of species other than mentioned above, and the analysis was confined to a search for remains that showed modification for use as tool or ornamentation. Due to these time constraints, it is my suggestion that further analysis be conducted on these remains, including a thorough search for human remains. Future opportunities for full analysis to understand species, possible usable meat, and seasonality of site as found through analysis of the 1976 fauna remains are still available and may change previous conclusions. Modified fauna and shell are discussed within Chapter X.

Soil samples and cores were taken during excavation in 1976 and reports for them were mentioned in journals, however no results of their analysis were found within the literature. Soil samples included in the material remains from Illinois State Museum were small and of a nature that flotation of them was not thought the best procedure. A few small bags of botanical material were found within the boxes of fauna and it may be that flotation was already done, but no written information was located to corroborate this. For previous excavations, Schilt sent samples away for identification by an outside source, but this opportunity was not available for this thesis.

\section{Processing for Curation}

Curation is a vital step in the process of archaeology that sometimes is not considered to the extent it should be. It ensures the preservation of cultural heritage in perpetuity for future research and education, yet collections are often not processed completely and brought to curation standards that ensure their survival in storage and for further use. Without the proper lab preparation in 1976-1977 and curation of this collection by ISM's RCC facility, my research and 
analysis would not have been possible. The Noble-Wieting materials have been kept secure since their transfer to RCC from ISU in 1998. They were formally accessioned into the museum in 2004. After my analysis and before their return to RCC, I made improvements to their storage bags, boxes, and inventories. The following process taken to enhance these materials for future researchers and ensure their preservation is presented here as an example for a process all archaeologists should follow for curation of materials.

Upon initial inspection of the materials at RCC it was noted that the boxes of material remains from the ISM contained remains from all the excavations between 1966 and 1976, sorted by type of material (i.e. lithic, ceramic, fauna) and some contained various excavations mixed in the box. The artifacts and natural debris were sorted by excavation years as 1966-1972, 1976, and 1993. The material had been bagged by feature, but not all necessary information was written on the bags. As a result, the RCC inventories did not accurately reflect the contents of the boxes. However, as the persons who created the inventories were not the excavators or working on this collection at time of excavation, it is possible the years the materials represented was unknown and these discrepancies are understandable. Therefore, it is my suggestion that processing and preparation for curation be undertaken as soon as possible and with the excavators available to assist with questions. As part of my loan agreement, I upgraded this collection and created new inventories for each box of material, with the exception of ceramics which was done by Ian Fricker. The inventory updates provide accuracy of the material dates and proveniences. A few artifacts were identified that belong with other archaeological collections and those were relocated to those collections at RCC.

During analysis the following was performed for lithics: 1) photographs of diagnostic artifacts included in bags; 2) materials grouped by type and placed in plastic bags with acid-free 
paper label on the inside of bag with appropriate provenience information; 3) provenience for artifacts updated or recorded on outside of bags and other containers; 4) internal box inventory of contents of box created, if not already available, or updated as needed. Ceramics were already sorted and external bag labels were found accurate. No internal labels were provided for ceramics at this time and this is work that should still be completed. Faunal material was sorted by provenience and re-bagged with identification on the bags but no internal labels. The faunal material was re-boxed to keep materials from features together as it had been previously mixed. Flora, soil and charcoal samples were not processed or identified further. The boxes and internal bags are now accurately separated by material type, years, and features' "lots" as identified by excavation notes and are labeled accordingly.

Knowledge of the site and excavations was helpful for accurate provenience labeling of the artifacts for curation. During analysis of artifacts and processing of them into acceptable curation bags, prior labels for some artifacts were found to be inaccurate and this information was corrected. Artifacts were placed within a small plastic $2 \mathrm{ml}$. Ziploc bags and the bags were labeled with the following information: ISM accession number (2004-227), site number (11ML 24), previous site number ( $\left.\mathrm{ML}^{\mathrm{v}} 28\right)$, site name (Noble-Wieting), feature or proveniencee of artifact, lot as designated by Jelks' processing system in 1976, type of artifact (e.g. flake, shatter, copper, etc.), year (1976), source (IL State University), and the number of artifacts or pieces contained in the bag. Within the small bags, acid-free paper listed the same information as found on the bag and a photo of the artifact was included if it was diagnostic for lithics. Small bags were placed within a larger plastic $2 \mathrm{ml}$. Ziploc bags and labeled in similar fashion. All plastic bags were placed into cardboard boxes provided by RCC. A label had already been placed on the boxes by ISM and contained information for contents which included site, ISM accession 
number, year, provenience, type of material, and number of boxes within the accession. These external box labels were updated as necessary. This curation format is in compliance with RCC's requirements, as a state repository facility, and also meets federal requirements for federally owned archaeological collections.

As analysis was completed, an updated inventory of the contents of the boxes was included in each box with the artifacts. The results of the analyses are discussed in the following three chapters separated for lithics, ceramics, and faunal material. However, the data presented does not address what the artifacts can tell about the internal site structure, relationship between and use of features, and possible influence from other nearby cultures. Chapter XI, therefore, offers the reader a discussion of features and their contents with compilations from previous excavation results for a more comprehensive and broader understanding of the site. 


\section{CHAPTER VIII: LITHICS ANALYSIS}

The goals of the stone tool analysis are to provide a description of the 1976 excavation's assemblage and to combine data with previous excavation data from 1966-1972. Addition of the 1976 data to previous summaries allows for a broader understanding of the full complement of the lithics retrieved from the site up to 2016 for future researchers to compare with other Langford sites and to identify change to cultural identity at this border region site. Specifically, Middle Mississippian type lithics, such as tri-notched projectile points and chunky stones, were watched for that would indicate cultural exchange. In this chapter, analysis of each type of cultural material recovered is discussed and summaries with Schilt's 1966-1972 results (1977) provided (Table 9). Distribution of lithic artifacts is discussed in depth within Chapter VI.

Observations were made of 2,722 pieces of chipped stone artifacts and debris, firecracked rock, and ground-stone artifacts. As discussed previously in Chapter VII, stone artifacts were divided by morphology and inferred function, and physical attributes were recorded for each type. Raw material was abundant at the site for lithic tool manufacture and can still be found along the Little Kickapoo Creek and the Kickapoo Creek to the east and south of the site. Using the Illinois State University type collection as a source for visual identification, raw materials were found to include Burlington, Moline, Dongola, and possibly Attica cherts. Glacial till also may have been utilized for stone tool production. Other materials may be apparent as well, but were not identified at this time, and this collection presents an opportunity for further research in this area. The predominant colors are white, light grey, and dark grey. Other colors include tan, olive, brown, orange, pink, red, purple, and very dark grey to almost black. While heat treatment can be determined by change in color and surface appearance of the chert, an analysis of thermal alteration was not conducted. 


\section{Chipped Stone Artifacts}

\section{Projectile Points}

Side-Notched. Variations in styles of projectile points may be attributed to different flintknappers who manufactured these tools. But, it is argued that point-type variations may have also been a way for groups to identify themselves from other groups (Reber et al 2017: 10). Some experts believe point types can be attributed to certain groups and within a site, if a few points differ greatly from the larger assemblage, it may indicate contact with other neighboring groups or that points were deposited from earlier or later times (Reber et al 2017: 16).

Out of eighty-five complete and fragments of projectile points, only two complete sidenotched projectile points and one side notch proximal fragment were recovered, the first two in Feature $14 \mathrm{a}$, a shallow fire-pit at $.9-1.2 \mathrm{ft}(.27$ to $.37 \mathrm{~m})$ below surface and the proximal fragment in Feature 12, an irregular shaped midden, at 1.05-1.3 ft (.32 to $.30 \mathrm{~m})$ below surface. The measurements of the complete side-notched points ranged between 39.4 to $49.7 \mathrm{~mm}$ length, 25.5 to $28.1 \mathrm{~mm}$ width, 6.9 to $7.0 \mathrm{~mm}$ thick, and 7.0 to 9.5 grams (Figure 23.a).

As mentioned above, these side-notched points could be representatives of inhabitants or visitors of an earlier time period and of Archaic origin. Their morphology is similar to the Brewerton Side-Notched points, dating from 2980 to 1723 B.C. (Ritchie 1969 in Justice 1987: 115). However, the Brewerton point type is considered limited in occurrence in Illinois (Reber et

al 2017: 240). These points could also be categorized as Raccoon Side-Notched points, which are of a similar size and morphology as the Brewerton, and also made of local materials such as glacial till chert. Raccoon Side-Notched points are found in much of Illinois, but most commonly in the eastern half of the state, and they are attributed to the Late Woodland Period from approximately A.D. 650 to 1200 (Reber et al 2017: 212-214), which is just prior in time period to 
radiocarbon dates for the Noble-Wieting site. The smaller of the two side-notched points appears to be reworked, of Archaic origin and considered a dart point, possibly of the Brewerton type (G. Miller and M. Wiant, personal communications 2019), (Figure 23.a, right). The larger of the points fits the description for both Brewerton and Raccoon Side-Notched (Figure 23.a, left).

Madison. Sixty-nine triangular Madison complete or nearly complete projectile points and proximal fragments were measured and weighed. Madison points can be found across the eastern half of the United States (Justice 1987: 227; Reber et al 2017: 220; Schilt 1977: 81). These "true arrowpoints" (Reber et al 2017: 220) are typically $3 / 4$ to $1 \frac{1}{1 / 2}$ inches $(1.9$ to $3.8 \mathrm{~cm}$ ) long, although some have been found to be up to 2 inches $(5.1 \mathrm{~cm})$ and smaller than $3 / 4$ inch $(1.9$ cm) (Reber et al. 2017: 220) (Figure 23.b). Similar designed points are the Levanna, typically found in the northeastern United States, although rarely in northeastern and east-central Illinois, and the Fort Ancient style, usually found in the lower Ohio River Valley (Reber et al 2017: 220). Use of Madison arrowpoints is identified at about A.D. 800 to the beginning of the Historic Period (Justice 1987: 224; Reber et al 2017: 220), replacing the Levanna style in the northeast at about A.D. 1350 (Justice 1987: 227; Ritchie 1961: 31).

A range of nine shapes of Madison were determined by Griffin (1946: 38-39) and Schilt (1977: 81 - 83) and of those nine, six forms were detected in the 1976 assemblage. The maximum width on Madison points has proven to always be at the base (Justice 1987: 224). The Madison form most recovered at Noble-Wieting in 1976 is the straight-sided, strait based (68\%) and the form second in abundance is the straight-sided, incurvate base (12\%) (Table 3). The ranges of length observed for 1976 is 10.2 to $34.6 \mathrm{~mm}$, base width is 10.9 to $20.3 \mathrm{~mm}$, thickness is 2.6 to $5.5 \mathrm{~mm}$, and weights range from .41 to 1.78 grams. Measurements for the complete or nearly complete Madison points and their form styles (Table 4), proximal fragments (Table 5), 
and distal fragments (Table 6) were compiled for comparison with previous excavations.

Complete or nearly complete Madison projectiles and proximals were found in Features 12, 13, $14,16,17,18$, and 22. Seven were recovered from trenches and eight were collected on the surface. A summary for of all projectile points recovered for the site as of 1976 after this section are provided in Table 7 and a summary of all lithic tools and debitage can be found later in the chapter (Table 10).

Table 3

Madison Projectile Points Summary 1966-1976

(Adapted from Schilt, 1977.)

\begin{tabular}{|c|c|c|c|c|c|c|c|c|c|c|}
\hline Form & 1 & 2 & 3 & 4 & כ & 6 & 1 & 8 & 9 & Total \\
\hline \multicolumn{11}{|l|}{1976} \\
\hline Number & 46 & 8 & 6 & 3 & 1 & 4 & 0 & 0 & 0 & 68 \\
\hline Percent & $68 \%$ & $12 \%$ & $9 \%$ & $4 \%$ & $1 \%$ & $6 \%$ & $0 \%$ & $0 \%$ & $0 \%$ & $100 \%$ \\
\hline \multicolumn{11}{|l|}{ 1966-1972 } \\
\hline Number & 28 & 12 & 4 & 4 & 1 & 4 & 8 & 1 & 0 & 62 \\
\hline Percent & $45 \%$ & $20 \%$ & $6 \%$ & $6 \%$ & $2 \%$ & $6 \%$ & $13 \%$ & $2 \%$ & $0 \%$ & $100 \%$ \\
\hline Totals for site: & 74 & 20 & 10 & 7 & 2 & 8 & 8 & 1 & 0 & 130 \\
\hline $\begin{array}{l}\text { Percent of } \\
\text { total }\end{array}$ & $57 \%$ & $15 \%$ & $8 \%$ & $5 \%$ & $2 \%$ & $6 \%$ & $6 \%$ & $1 \%$ & $0 \%$ & \\
\hline
\end{tabular}




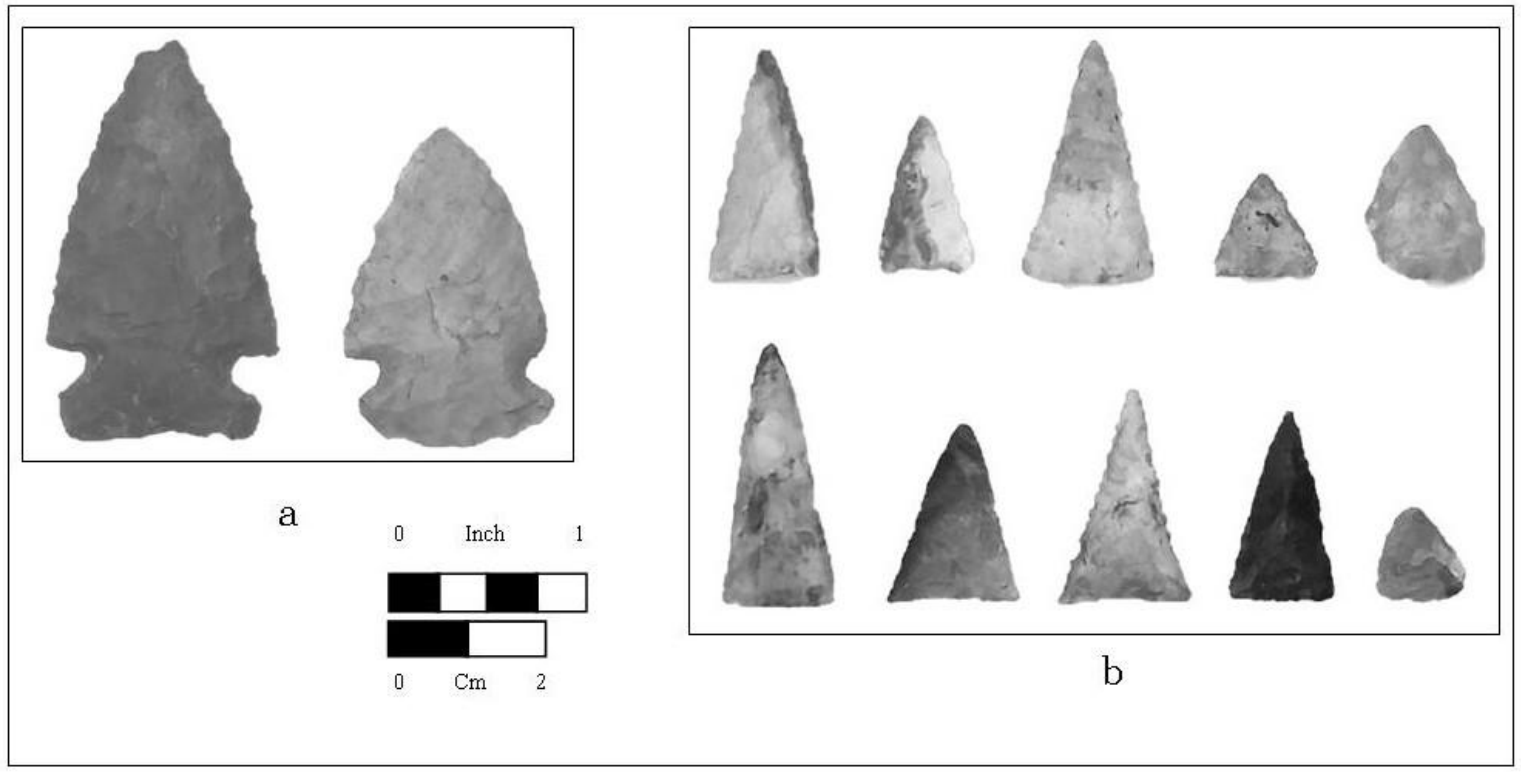

Figure 23. Projectile Points. a. Side-notched, b. Madison.

Table 4

Madison Points Complete or Nearly Complete 1976

\begin{tabular}{|c|c|c|c|c|c|c|c|}
\hline Provenience & Vertical & Length & Base & Thickness & Weight & Form & Remarks \\
\hline Surface & unk & 22.1 & 15 & 5.2 & 1.73 & 2 & tip broke \\
\hline Surface & unk & 16.8 & 17.6 & 4 & 1.05 & 1 & tip broke \\
\hline Surface & unk & 24.1 & 12.6 & 4.8 & 1.28 & 3 & $\begin{array}{l}\text { one base corner } \\
\text { broke }\end{array}$ \\
\hline Surface & unk & 19.4 & 14.6 & 4 & 0.71 & 2 & Complete \\
\hline Surface & unk & 20.7 & 18.4 & 4.1 & 1.27 & 2 & tip broke \\
\hline Surface & unk & 13.9 & 13.8 & 3 & 0.56 & 1 & $\begin{array}{l}\text { complete, one } \\
\text { corner chipped }\end{array}$ \\
\hline Surface & unk & 19.1 & 12.2 & 2.8 & 0.75 & 1 & tip broke \\
\hline F 12 & $1.05-1.3^{\prime}$ & 28.3 & 16.9 & 3.5 & 1.09 & 2 & Complete \\
\hline F 12 & $.8-1.3^{\prime}$ & 20 & 15.5 & 3.6 & 0.82 & 1 & Complete \\
\hline F 12 & $1.5-2.25^{\prime}$ & 23.9 & 17.5 & 5.3 & 1.57 & 1 & Complete \\
\hline F 12 & $.8-1.3^{\prime}$ & 25 & 17.5 & 4 & 1.4 & 6 & $\begin{array}{l}\text { one base corner } \\
\text { broke }\end{array}$ \\
\hline F 12 & $.8-1.05^{\prime}$ & 15 & 17.4 & 3.6 & 0.9 & 1 & $\begin{array}{l}\text { two sides broke, } \\
\text { nearly complete }\end{array}$ \\
\hline F 12 & $.8-1.05^{\prime}$ & 20.3 & 20.3 & 5.4 & 1.4 & 3 & tip broke \\
\hline F 12 & $0-.75^{\prime}$ & 19.2 & 15.2 & 3.8 & 0.89 & 1 & tip broke \\
\hline
\end{tabular}

(Table Continues) 
(Table 4, Continues)

\begin{tabular}{|c|c|c|c|c|c|c|c|}
\hline Provenience & Vertical & Length & Base & Thickness & Weight & Form & Remarks \\
\hline F 12A & $\begin{array}{l}.8-2.0^{\prime} \\
\end{array}$ & 18.9 & 14.5 & 3.5 & 0.77 & 1 & base broke \\
\hline F 12A & $.8-2.0^{\prime}$ & 24.8 & 12.3 & 3.5 & 0.94 & 2 & base broke \\
\hline F 12A & $.8-2.0^{\prime}$ & 21.5 & 14.1 & 5.3 & 1.39 & 1 & $\begin{array}{l}\text { one base corner } \\
\text { broke }\end{array}$ \\
\hline F 12A & $.8-2.0^{\prime}$ & 18.7 & 15.6 & 5.4 & 1.24 & 1 & tip broke \\
\hline F $12 \mathrm{~A}$ & $.8-2.0^{\prime}$ & 22.7 & 14.7 & 4.8 & 1.05 & 6 & Complete \\
\hline F 12A & $.8-2.0^{\prime}$ & 17.4 & 14.7 & 3.1 & 0.81 & 6 & Complete \\
\hline F 12A & $.8-1.4^{\prime}$ & 25.1 & 13.7 & 3.8 & 0.92 & 1 & Complete \\
\hline $\mathrm{F} 12 \mathrm{~A}$ & $1.2-2.0^{\prime}$ & 12.4 & 11.4 & 3.2 & 0.42 & 1 & complete, tiny \\
\hline F $12 \mathrm{~A}$ & $.8-2.0^{\prime}$ & 21.8 & 17.6 & 3.4 & 1.08 & 2 & $\begin{array}{l}\text { complete, } \\
\text { serrated }\end{array}$ \\
\hline F 12A & $2.0^{\prime}$ & 16.9 & 14.3 & 3.6 & 0.76 & 1 & Complete \\
\hline F 14 & $.8-1.3^{\prime}$ & 21.2 & 14.3 & 4 & 0.98 & 3 & Complete \\
\hline F 14a & $.9-1.2^{\prime}$ & 21.2 & 15.7 & 3.9 & 1.29 & 6 & $\begin{array}{l}\text { one base corner } \\
\text { broke }\end{array}$ \\
\hline F 14a & $.9-1.2^{\prime}$ & 19.8 & 14.2 & 4.3 & 0.73 & 1 & Complete \\
\hline F 14a & $.9-1.2^{\prime}$ & 17.1 & 14.8 & 3.2 & 0.67 & 1 & $\begin{array}{l}\text { complete, } \\
\text { serrated }\end{array}$ \\
\hline F 14c & $.7-1.0)^{\prime}$ & 23.1 & 10.9 & 4.1 & 0.94 & 4 & Complete \\
\hline F 18 & $1-1.7^{\prime}$ & 23.3 & 17 & 2.6 & 0.79 & 1 & Complete \\
\hline F 18 & $2.0-2.2^{\prime}$ & 34.6 & 14.1 & 4 & 1.46 & 1 & $\begin{array}{l}\text { complete, } \\
\text { serrated }\end{array}$ \\
\hline F 18 & $2.3^{\prime}$ & 31.3 & 15.3 & 3.5 & 1.27 & 1 & \\
\hline F 18 & $1.5-2.1^{\prime}$ & 32.1 & 17.2 & 4.1 & 1.78 & 3 & \\
\hline F 18 & $.8-2.0^{\prime}$ & 21.9 & 14.6 & 3.9 & 1.01 & 1 & $\begin{array}{l}\text { one corner } \\
\text { chipped }\end{array}$ \\
\hline F 18 & $.8-2.0^{\prime}$ & 20.4 & 12.3 & 3.6 & 0.78 & 1 & Complete \\
\hline F 18 & $2.0-2.2^{\prime}$ & 28.2 & 16.9 & 4.6 & 1.34 & 1 & $\begin{array}{l}\text { complete, } \\
\text { serrated }\end{array}$ \\
\hline F 18 & $1.2-1.5^{\prime}$ & 19.7 & 13.8 & 3.6 & 0.76 & 1 & Complete \\
\hline F 18 & $1.3-1.6^{\prime}$ & 19.9 & 16.4 & 3.5 & 1.24 & 1 & tip broke \\
\hline F 18 & $.8^{\prime}$ & 16.5 & 14.3 & 3.8 & 0.95 & 1 & $\begin{array}{l}\text { tip broke, one } \\
\text { corner broke }\end{array}$ \\
\hline F 22 & $1.1-1.4^{\prime}$ & 24.8 & 15.3 & 3.7 & 1.17 & 1 & $\begin{array}{l}\text { tip broke, } \\
\text { corner broke }\end{array}$ \\
\hline T $15 \mathrm{~A}$ & PZ -.75' & 15 & 13.9 & 3.4 & 0.68 & 1 & tip broke \\
\hline T 16G & $.9-1.9^{\prime}$ & 25.3 & 15.3 & 5.1 & 1.35 & 1 & complete \\
\hline $\mathrm{T} 18 \mathrm{I}$ & $.7-1.1^{\prime}$ & 21.2 & 15.5 & 5.2 & 1.31 & 1 & $\begin{array}{l}\text { one base corner } \\
\text { broke }\end{array}$ \\
\hline T 18T & $0-.7^{\prime}$ & 18.2 & 15.4 & 3.6 & 0.83 & 1 & complete \\
\hline $\mathrm{N}=44$ & & & & & & & \\
\hline
\end{tabular}


Table 5

Madison Points Distal Fragments 1976

\begin{tabular}{lcrccc}
\hline Provenience & Vertical & Length & Base Width & Thickness & Weight \\
\hline Surface & Unk & 13.1 & 12.8 & 2.4 & 0.31 \\
F 12 & $1.5-2.0^{\prime}$ & 14.2 & 12.1 & 3.5 & 0.61 \\
F 12 & $0-.75^{\prime}$ & 25.4 & 20.5 & 6.3 & 2.68 \\
F 12A & $2.0^{\prime}$ & 14.9 & 13 & 2.9 & 0.49 \\
F 16 & $.^{\prime}-1.1^{\prime}$ & 17.3 & 10.7 & 2.8 & 0.4 \\
F 17 & $1.2-2.0^{\prime}$ & 14.3 & 14.2 & 4.9 & 0.64 \\
F 18 & PZ 0-.7' & 15.6 & 11 & 2.8 & 0.49 \\
F 21 & $2.0-2.3^{\prime}$ & 27.6 & 14 & 4 & 1.43 \\
T 15A & PZ 0-.75' & 18.2 & 14.7 & 5.8 & 1.42 \\
T 16H & PZ & 13.1 & 9.4 & 3.2 & 0.37 \\
T 16T & $0-.7^{\prime}$ & 14.4 & 10.4 & 2.9 & 0.34 \\
T 18I & $.7-1.1^{\prime}$ & 25.7 & 13.9 & 4.2 & 1.29 \\
T 18K & $.8-1.5^{\prime}$ & 16.2 & 13.3 & 4.6 & 0.89 \\
& & & & & \\
N $=13$ & & & & & \\
\hline
\end{tabular}

Table 6

Madison Points Proximal Fragments 1976

\begin{tabular}{llcccccc}
\hline Provenience & Vertical & Length & Base & Thickness & Weight & Form & Remarks \\
\hline Surface & unk & 13.1 & 16.3 & 3.4 & 0.86 & 1 & \\
Surface & unk & 14.3 & 17.2 & 3.7 & 1 & 1 & \\
F 12 & $0-.75^{\prime}$ & 18.2 & 16.5 & 4.9 & 1.51 & 1 & one corner round \\
F 12 & $0-.75^{\prime}$ & 10.7 & 15.5 & 2.9 & 0.48 & 1 & \\
F 12 & $0-.75^{\prime}$ & 10.7 & 16.4 & 3.3 & 0.59 & 2 & \\
F 12 & $.8-1.05^{\prime}$ & 15.1 & 17 & 5.5 & 1.3 & 1 & \\
F 12 & $1.3-1.6^{\prime}$ & 17.7 & 18.7 & 3.3 & 0.96 & 1 & \\
F 12 & $1.5-2.0^{\prime}$ & 11.7 & 14.1 & 5 & 0.87 & 1 & \\
F 12 & $1.5-2.25^{\prime}$ & 12.2 & 14.5 & 2.7 & 0.41 & 1 & one side chipped \\
F 12A & $2.0^{\prime}$ & 19.1 & 17.7 & 3.4 & 1.09 & 1 & \\
F 12A & $.8-2.0^{\prime}$ & 13.4 & 18.1 & 3.7 & 1 & 3 & \\
F 13 & $.9-1.4^{\prime}$ & 13.8 & 18.8 & 3.5 & 0.9 & 2 & \\
F 13 & $.9-1.4^{\prime}$ & 12.7 & 12.8 & 2.5 & 0.47 & 4 & \\
F 13 & $.9-1.4^{\prime}$ & 18.1 & 14.1 & 2.6 & 0.64 & 3 & \\
F 13 & $1.4-1.9^{\prime}$ & 18.6 & 18.1 & 3.9 & 1.3 & 1 & \\
F 13 & $1.4-1.9^{\prime}$ & 13.2 & 15.1 & 5.5 & 0.92 & 1 & \\
(Table Continues) & & & & & &
\end{tabular}


(Table 6, Continues)

\begin{tabular}{llcccccl}
\hline Provenience & Vertical & Length & Base & Thickness & Weight & Form & Remarks \\
\hline F 13 & $.9-1.4^{\prime}$ & 18.9 & 19.2 & 4.8 & 1.63 & 5 & \\
F 14 & $.9^{\prime}$ trans & 21.5 & 17.4 & 5.8 & 2.08 & 1 & \\
F 17 & $.95-1.2^{\prime}$ & 8.3 & 15.5 & 3.4 & 0.42 & 1 & serrated \\
& & & & & & & one corner \\
F 18 & $1.3-1.6^{\prime}$ & 13.7 & 13.9 & 4.1 & 0.82 & 1 & broke \\
F 18 & $2.0-2.2^{\prime}$ & 13.2 & 16.7 & 3.9 & 0.91 & 1 & \\
T 16T & $0-7^{\prime}$ & 10.2 & 13.2 & 3.1 & 0.44 & 1 & \\
T 18I & $.7-1.1^{\prime}$ & 12.2 & 15.2 & 3.6 & 0.81 & 1 & \\
unk & & 16.1 & 19.2 & 4.5 & 1.42 & 4 & \\
& & & & & & & \\
N =25 & & & & & & & \\
\hline
\end{tabular}

Table 7

Projectile Points Summary 1966-1976

(1966-1972 adapted from Schilt, 1977: Table 9.)

\begin{tabular}{|c|c|c|c|c|c|}
\hline Type & Length & Base Width & Thickness & Weight & $\begin{array}{l}\text { Total } \\
\text { Numbers }\end{array}$ \\
\hline \multicolumn{6}{|c|}{ Madison Complete } \\
\hline 1966-1972 & $16-34$ & $13-20$ & $3-5$ & $\mathrm{n} / \mathrm{a}$ & 29 \\
\hline 1976 & $10-35$ & $11-20$ & $3-6$ & $.4-1.8$ & 44 \\
\hline \multicolumn{6}{|c|}{ Madison Proximals } \\
\hline 1966-1972 & $\mathrm{n} / \mathrm{a}$ & $14-21$ & $3-5$ & $\mathrm{n} / \mathrm{a}$ & 33 \\
\hline 1976 & $8-22$ & $13-19$ & $3-6$ & & 24 \\
\hline Total Madison & & & & & 130 \\
\hline \multicolumn{6}{|c|}{ Side-Notched Points } \\
\hline 1966-1972 & 27 & 22 & 6 & $\mathrm{n} / \mathrm{a}$ & 1 \\
\hline 1976 & $39-50$ & $26-28$ & 7 & 0.3 & 2 \\
\hline $\begin{array}{l}\text { Total Side-Not } \\
\text { (measurements }\end{array}$ & and grams) & & & & 3 \\
\hline
\end{tabular}




\section{Perforators and Scrapers}

Perforators, also known as drills, are defined as bifacially worked with the projection parallel sided and at least one-third the total length and rhomboid or circular in cross-section (Wiant and McGimsey 1985: 547). Three artifacts fit this definition of perforators, one with the projection one-third of total length of $25.8 \mathrm{~mm}$ and one with it two-thirds the total length of 24.0 $\mathrm{mm}$ (Figure 24.a). The third artifact is a fragment of $18.3 \mathrm{~mm}$ long, long and narrow, convex and bifacially worked. The larger pieces were obtained from Features 12 and 14, $2.2 \mathrm{ft}(.67 \mathrm{~m})$ and .9 $(.27 \mathrm{~m})$ below surface, respectively. The fragment piece was recovered from the house Feature 18, NW quarter, from 1.5 to $2.1 \mathrm{ft}$ (.46 to $.64 \mathrm{~m})$ below surface.

Two plano-convex, unifacially worked scrapers, one of quadrilateral asymmetrical shape and one an ovate shape, were recovered from test trenches 17 and 18 in the plow zone level. They measure 24.0 to $33.3 \mathrm{~mm}$ long, 18.2 to $20.4 \mathrm{~mm}$ in width, 7.1 to $7.2 \mathrm{~mm}$ thick, with weights between 2.58 and 5.15 grams. The first scraper, measurements and weight listed first, is concave on one face, convex on the other face, with one edge rounded. Both are without cortex.

Bifacially worked scrapers, numbered eight in total. They were found in various

locations, including two on surface, four in storage or trash pits, one in the Feature 18 house, and one in a test trench, at depths of .7 to $2.2 \mathrm{ft}(.21$ to $.67 \mathrm{~m})$. These scrapers were all quadrilateral in shape, all with at least one excurvate edge. Measurements ranged from 18.2 to $44.1 \mathrm{~mm}$ long, 18.5 to $40.6 \mathrm{~mm}$ wide, 4.9 to $16.4 \mathrm{~mm}$ thick, and weights of 1.77 to 28.97 grams.

The largest of these, size $44.1 \mathrm{~mm}$ long and $40.6 \mathrm{~mm}$ wide, also the heaviest and thickest, was found within the house Feature 18, and was also the only scraper of a brownish color, all others of a white or light grey and possibly manufactured from local glacial till. This scraper is flat on one side, rounded on the opposite side with bifacial working, and with a slightly convex 
one face and concave on the other face (Figure 24.d, left). A summary of all perforators, knives, and scrapers is provided (Table 10), along with counts for all other lithic tools and debitage for the site.

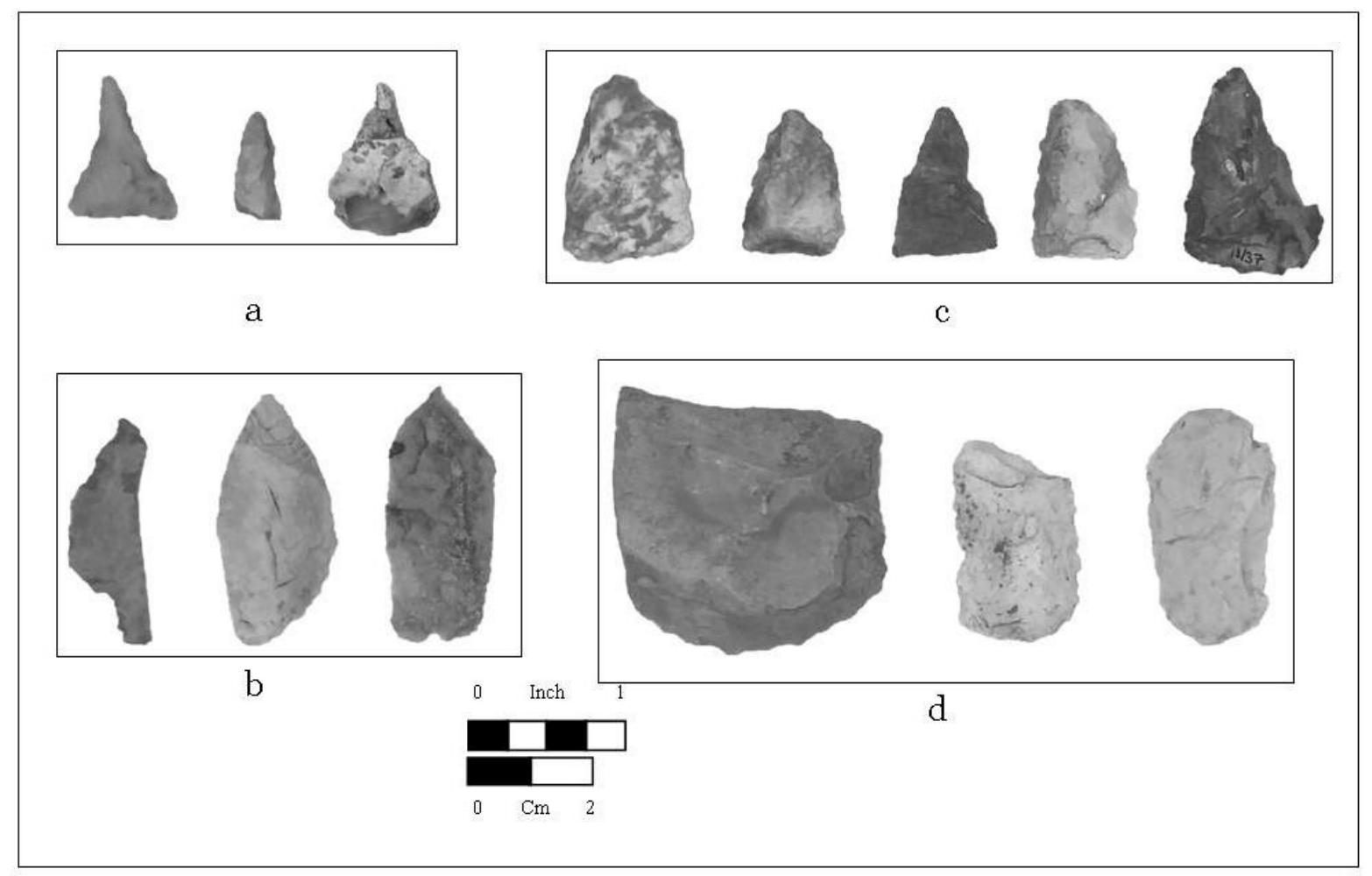

Figure 24. Chipped Stone Artifacts. a. Perforators, b. Knives, c. Humpback Knives, d. Scrapers.

\section{Biface and Humpback Knives}

Four knives were retrieved: one in Feature 12 at $2.0 \mathrm{ft}(.61 \mathrm{~m})$ bs which appears to be a flake knife; Feature 18 produced a lanceolate form in the plow zone up to $.8^{\prime}$ bs; the third knife was a surface find with location unknown; and the fourth is a stemmed knife from Feature 14. The first, a flake knife of five-sided polygonal shape, has minimal original bifacial work or later retouch repairs and comes to a point on one end. This piece is $45.2 \mathrm{~mm}$ long and $19.4 \mathrm{~mm}$ wide at the widest point. The lanceolate, or expanding-ovate form knife, is $44.8 \mathrm{~mm}$ long and $21.4 \mathrm{~mm}$ 
width midrange. It is bifacially worked and asymmetrical. The surface find at $38.8 \mathrm{~mm}$ long and $14.8 \mathrm{~mm}$ wide is similar in shape to the knife mentioned below in that both have one length broken to form a flat edge, are curved on the opposite edge, and come to a point on one end. The stemmed knife, $40.2 \mathrm{~mm}$ long and $12.6 \mathrm{~mm}$ in width midrange, was recovered from Feature 14 at $.9 \mathrm{ft}(.27 \mathrm{~m}) \mathrm{bs}$. It is medium gray in color, bifacially worked along the other edges, pointed on one end, and the other end has an indented bifacially worked section, possibly for attachment as a hafted tool (Figure 24.b). A similarly formed knife was retrieved at the Reeves site (11WI 555) (Craig and Galloy 1996).

Humpbacked knives, originally referred to as scrapers, are found in many Upper Mississippian sites, including Langford, Oneota, and Monongahela (Brown 1961: 54; Brown et al 1967: 30; Jeske 1990, 226; Munson and Munson 1972: 34). Humpbacks were originally thought to be a form of scraper by Brown (1961) and Brown et al (1967), but the implement later experienced a name change after a study by Munson and Munson (1972) determined manufacture and use of humpbacks to be more similar to that of knives than scrapers. Jeske and Sterner-Miller have concluded through microwear studies on bipolar tools that form does not always follow function and, therefore, the naming of an artifact as 'scraper' or 'knife' may be misleading as to its functions (2015: 374). However, Schilt's analysis places humpbacks in the knife category, separate from other knives, following the suggestions by Munson and Munson (1972) and Brown (1975) and this analysis follows suit in order to align my results with previous data for this specific site.

These small knives are triangular in shape and bifacially chipped with sinuous edges, and contain a humped projection in the central or lower portion of one face. Their asymmetry and thickness are two traits used for categorizing them. Humpbacks may have cortex present or not. 
While the view of crudeness is subjective, to some researchers these knives appear crudely made as compared to the more refined Madison points.

Jeske argues that bipolar reduction for manufacturing Madison points and humpbacked knives offered a way for toolmakers to economize their time and energy for tool creation. Lack of quality raw materials, increase in sedentism due to increase in horticulture, and an increase in social and political activities may have pressured people to spend less time on lithic production (Jeske 1992b: 468). Crafting less complex scrapers or knives, such as humpbacks, may have been one efficiency strategy used. Jeske suggests a "crudeness index" to measure the "crudeness" of biface artifacts, such as humpbacks, by dividing the width of the tool by its thickness (Jeske 1992b: 468). Jeske notes this method is itself somewhat crude, but that Madison points are noticeably much thinner relative to their width than humpback knives. Using Jeske's crudeness index, it was found with the 1976 collection of Madison points and humpback knives that the Madison index was 3.95 and the humpback index was 2.46 mean. These numbers are similar to those figured by Jeske for the Washington Irving site, also a Langford Tradition site, where crudeness measured 3.96 and 2.48 respectively. It has been suggested that humpbacks were one form in the continuum of producing a more finished, or less "crude", projectile point such as a Madison point because there is lack of distinctive traits between the two forms (Jeske 1992b: 476). Due to the lack of quality material and time, if steps or hinges occurred on the piece, it was not discarded but still used in its cruder form.

While it appears today that an abundance of quality raw materials are available at NobleWieting for lithics, further study may suggest this to not be the case when a village of people relying on the materials lived nearby. The pressure to create more expedient humpbacks may be due to lack of quality resources in the amount necessary for survival, or it may show pressure 
from agricultural, social, or political activities. This is only a preliminary study of this index and what it represents for this site's lithic artifacts and manufacture behavior of the people. Further research of crudeness theory with Noble-Wieting and other sites presents an opportunity for another study of lithics. Humpback knives for the 1976 excavation numbered 41, with sizes ranging between 17.2 and $38.4 \mathrm{~mm}$ in length, 13.8 and $39.2 \mathrm{~mm}$ in width, 5.3 and $13.8 \mathrm{~mm}$ in thickness, and 1.13 and 14.06 in weight in grams. Cortex was observed on $58 \%$ of the total pieces. (Figure 24.c)

\section{Polished Artifacts and Ground Stones}

\section{Abraders, Celts, and Drilled Stone Fragments}

A yellow sandstone abrader, plano on one face with linear use wear and rounded convex opposite side was recovered from Feature 13 from between the plow zone and $.9 \mathrm{ft}(.27 \mathrm{~m})$ below surface. The linear wear on the flat surface runs the length of the artifact and red ochre is apparent on the rounded side (Figure 25.a). It is ovoid in shape, $109.2 \mathrm{~mm}$ in length, $62.0 \mathrm{~mm}$ in width, $40.2 \mathrm{~mm}$ thick, and 345.86 grams. Sandstone abraders, such as this one, may have been utilized for smoothing arrow shafts or smaller tools such as awls (Iseminger 2014: 39-40). This artifact exhibits multiple grooves as opposed to one deeply defined groove.

Two celts were found, one within the plow zone of Trench 18 and the other at an unknown depth within Feature 15, a house feature. Both are manufactured from a dark, closegrained igneous rock. The first celt from the test trench location is either broken in half along the long axis, along the side edges, with one face convex, or was finished on the one side on purpose. This artifact is rectangular in shape, with one corner on the excurvate edge broken and the opposite edge straight, and has a reddish color on the smoothed side suggesting heating. It is 93.6 $\mathrm{mm}$ long, $48.8 \mathrm{~mm}$ at the broadest width, $15.5 \mathrm{~mm}$ thick, and weighs 99.28 grams. The 
second celt is finished on both faces and all edges, also rectangular or ovoid in shape, but of a larger grained igneous material and thereby having a rougher surface. It is slightly larger than the first at $103.7 \mathrm{~mm}$ long, $51.8 \mathrm{~mm}$ wide, $22.6 \mathrm{~mm}$ thick, and weighs 201.28 grams (Figure 25.b).

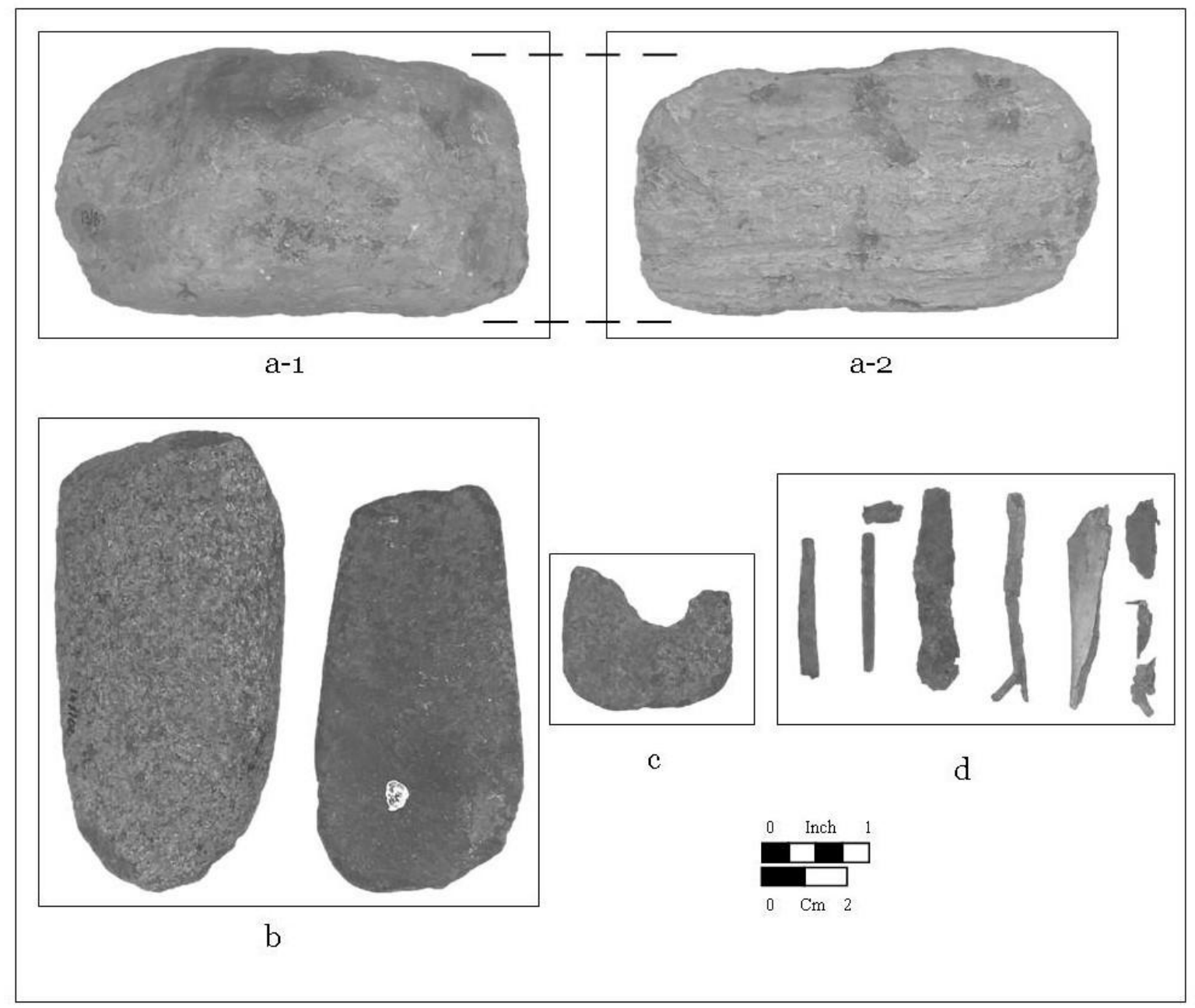

Figure 25. Abraders, Celts, Drilled Stone Fragments, and Copper. a-1. and a-2. sandstone abrader, b. celts, c. drilled stone, d. copper (and bone).

A rectangular piece of stone $33.8 \mathrm{~mm}$ long and $44.5 \mathrm{~mm}$ wide was drilled in the central region and broken within that same region, bisecting the perforation which has an approximate diameter of $15.1 \mathrm{~mm}$. The piece weighs 9.72 grams, is fairly thin at $7.4 \mathrm{~mm}$ thick, and has rounded outside corners. This piece was located in Feature 12 at a depth of 1.05 to $1.3 \mathrm{ft}(.32$ to 
$.40 \mathrm{~m}$ ) (Figure 25.c). As spindle whorls are found in various shapes and sizes, it is possible this piece was used in this manner. However, this is not conclusive.

\section{Ground Stones}

Three stones used for grinding or bipolar reduction of chipped stone artifacts were retrieved, one from each of the Features 12, 14, and 21, between 1.1 and $2.3 \mathrm{ft}(.34$ and $.70 \mathrm{~m})$ below surface, and exhibit wear marks on either one or two flattened sides or faces. The two largest pieces are rounded, mostly ovoid in shape with rounded edges. The size of these two range from 103.5 to $110.3 \mathrm{~mm}$ long, 68.8 to $86.2 \mathrm{~mm}$ wide, 45.6 to $45.9 \mathrm{~mm}$ thick, and with weights of 619.72 to 647.50 grams, respectively. The larger of the two exhibits red ochre on both faces (Figure 26.a) and the smaller of these two is reddish in color on one side, possibly an alteration in color from heat (Figure 26.b). The smallest stone piece of the three is $87.8 \mathrm{~mm}$ long, 59.6 mm wide, $33.8 \mathrm{~mm}$ thick, and weighs 362.31 grams. This piece is rectangular in shape, with one face smooth and the opposite one rougher but with use marks on both in the central regions. It has a broken appearance on the sides with one side rounded slightly and a reddish tint possibly from heat. (Figure 26.c).

\section{Stone By-product Artifacts}

\section{Cores, Flakes and Shatter}

Seventeen cores occurred between the plow zone and 2.4' below surface $(.73 \mathrm{~m})$ below surface. Aside from four surface finds, which accounted for four cores, shallow midden Features 12 and 20 contained the most number of cores with 3 in each feature. Average core weight was 25.62 grams, the largest single core weighing 136.41 grams from the largest anomaly in Feature 12 (Table 8). 


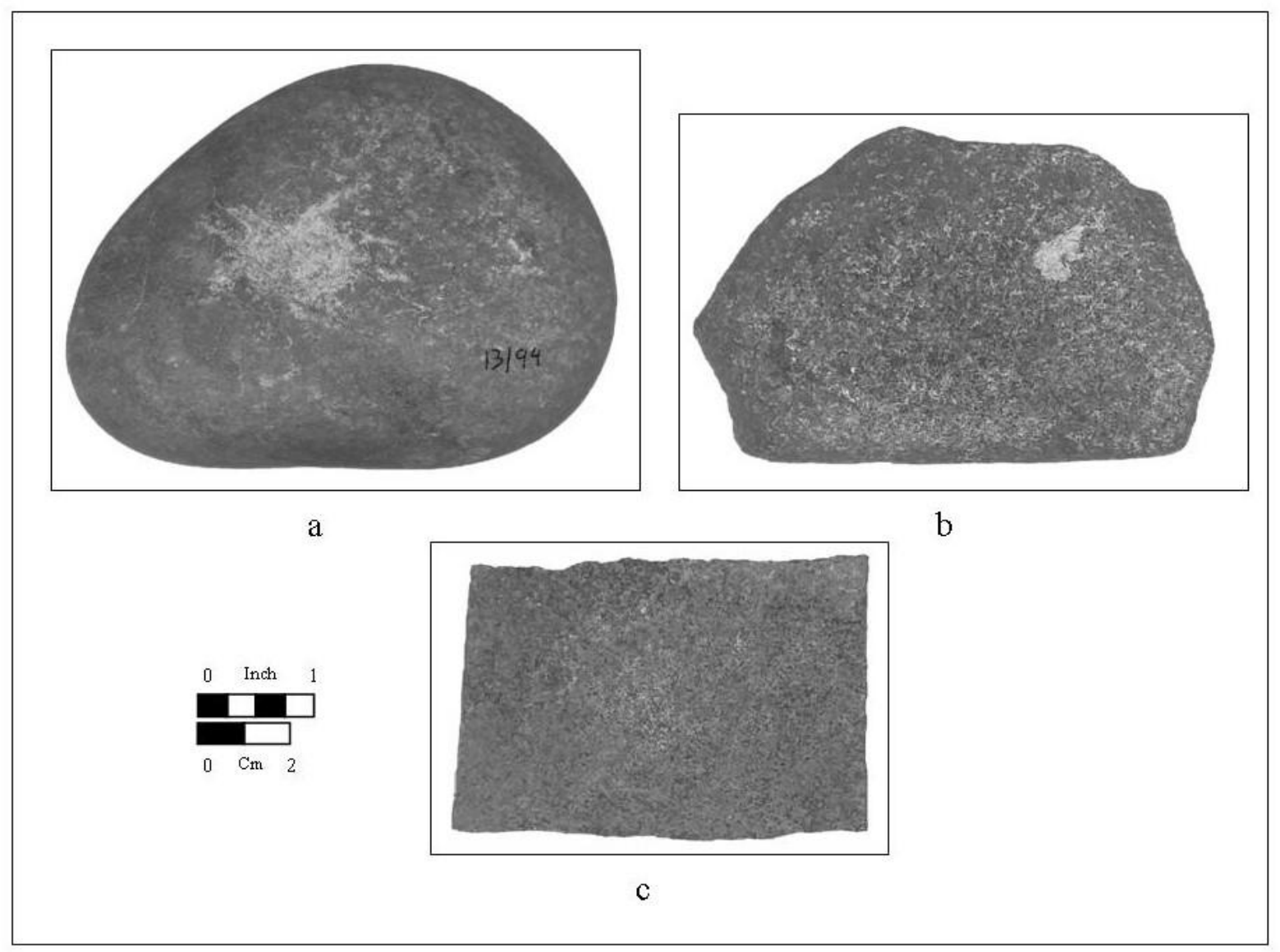

Figure 26. Ground Stones.

Chipped lithic shatter numbered 712 pieces, the majority of total shatter (26\%) recovered from all features and trenches came from Feature 12, with the most abundance of shatter in this feature $(15 \%)$ occurring between .8 and $2.0 \mathrm{ft}(.24$ and $.61 \mathrm{~m})$ below surface. Feature 13 contained the second most abundant collection of shatter (17\%), also a midden of a circular shape and of smaller size than Feature 12. The majority of shatter in this feature (46\%) was recovered at level $\mathrm{I}, .9$ to $1.4 \mathrm{ft}(.27$ to.43 $\mathrm{m})$ below surface. Level I was found to contain the most cultural material and burned remnants.

Waste flakes numbered 1788 and, as with shatter, the flakes were also most abundant in Features 12 and 13, with $31 \%$ and $18 \%$ respectively of the total flakes obtained from all features 104 
recovered. The same holds true for the depth of the flakes in both of these features, with the majority found at the same levels and $12 \%$ and $42 \%$ respectively. Feature 17 , the only deep trash pit with a depth of $4.65 \mathrm{ft}(1.62 \mathrm{~m})$, contained the largest size flakes and shatter of all the features.

Table 8

Distribution and Quantity of Chipped Stone Debitage 1976

(1966-1972 totals adapted from Schilt, 1977: 91.)

\begin{tabular}{|c|c|c|c|c|c|c|}
\hline Proven & $\begin{array}{l}\text { Feature } \\
\text { Class }\end{array}$ & Flakes & $\begin{array}{c}\text { Flake } \\
\text { Weight (g) }\end{array}$ & Shatter & Cores & $\begin{array}{c}\text { Core } \\
\text { Weight (g) }\end{array}$ \\
\hline \multicolumn{6}{|l|}{ Total surface } & 100.02 \\
\hline F12 & II & 552 & 695.5 & 188 & 3 & 160.11 \\
\hline F13 & II & 321 & 459.96 & 119 & 1 & 25.41 \\
\hline F14 & III & 183 & 268.98 & 52 & 1 & 21.27 \\
\hline F15 & IV & 5 & 31.54 & 13 & 0 & 0 \\
\hline F16 & II & 68 & 92.81 & 23 & 2 & 31.4 \\
\hline F17 & I & 121 & 198.29 & 115 & 0 & 0 \\
\hline F18 & IV & 132 & 217.41 & 93 & 2 & 41.36 \\
\hline F19 & II & 16 & 46.93 & 2 & 0 & 0 \\
\hline F20 & II & 33 & 40.04 & 11 & 3 & 65.93 \\
\hline $\mathrm{F} 21$ & IV & 32 & 34.15 & 4 & 0 & 0 \\
\hline $\mathrm{F} 22$ & VI & 38 & 50.64 & 14 & 0 & 0 \\
\hline $\mathrm{F} 23$ & III & 9 & 12.1 & 1 & 0 & 0 \\
\hline $\mathrm{T} 15$ & Trench & 64 & 87.18 & 13 & 0 & 0 \\
\hline T16 & Trench & 41 & 67.2 & 21 & 0 & 0 \\
\hline $\mathrm{T} 17$ & Trench & 69 & 94.83 & 12 & 1 & 5.33 \\
\hline T18 & Trench & 75 & 123.07 & 21 & 0 & 0 \\
\hline $\mathrm{T} 19$ & Trench & 5 & 7.41 & 5 & 0 & 0 \\
\hline \multicolumn{2}{|l|}{ Totals: } & 1788 & 2601.5 & 712 & 17 & 450.83 \\
\hline \multicolumn{2}{|c|}{ Average weights: } & & 1.45 & & & 26.52 \\
\hline \multicolumn{2}{|c|}{ Totals 1966-1972: } & 2849 & & & 15 & \\
\hline
\end{tabular}




\section{Fire-Cracked Rock}

Sixteen pieces of fire-cracked rock were accounted for and weighed. Fire-cracked rocks (FCR) typically found at this site are of an igneous material, usually dark grey or brown in color with tint of red or maroon. They have evidence of a break on at least one side, may look similar to other ground stones that had been fired, and are considered an indicator of cooking or other heating activities. Schilt mentions that collection of fire-cracked rock during the 1966-1972 excavations was not consistent due to weather and other factors and considers the FCR data to be of "limited value". Since this report defines the 1976 excavation not listed in Schilt's report but excavations were conducted in similar conditions, it could be assumed collection of FCR during 1976 was also inconsistent. As in Schilt's thesis, this report also includes what was collected and identified. However, the total weight of FCR pieces in 1976 was greater even though less in number, indicating heavier fragments were collected in 1976. Feature 13, thought to be a shallow trash pit, contained the most FCR with $38 \%$ of the total number of pieces, but the house Feature 18 contained the largest single piece and the overall largest percent of weight for all features at $20.89 \%$ (Table 9.)

\section{Copper and Ochre}

During the Wisconsinan Ice Age, copper was carried south from the Great Lakes region by the glaciers and deposited with glacial till. Some pieces were carried as far as southern Illinois (Iseminger 2014: 56; Reber et al 2017: 127), and, therefore, could have been found locally at Noble-Wieting. Exchange between groups also may have brought copper into the area and would show interaction and cultural exchange. Twelve pieces of thinned or formed copper were recovered in 1976. Four of the pieces were with a piece of bone in Feature 20. Features 12 and 
16 also contained small strips or pieces of copper. Sizes range from 11.6 to $48.2 \mathrm{~mm}$ long, 3.0 to $10.7 \mathrm{~mm}$ wide, .9 to $5.5 \mathrm{~mm}$ thick, and weighed between .07 and 1.87 grams (Figure 25.d).

Ochre is a natural clay earth pigment containing ferric oxide and ranging in colors from yellow to red to brown that has been used art in various cultures around the world (LeroiGourhan 1968: 40), with use dating back to 75,000 years ago in South Africa's Blombos Cave (Henshilwood, Errico, Watts 2009). Red and yellow ochre pieces were recorded in many of the features excavated in previous years at this site, but only two pieces were found within the materials during Schilt's analysis.

Six pieces were recovered in 1976 in Features 12, 13 and 17. The red pieces, numbering three with one broken in half to make a fourth, range in length from $15.6 \mathrm{~mm}$ to $28.6 \mathrm{~mm}$ for the one broken piece, in widths from 13.5 to $34.2 \mathrm{~mm}$, and thickness of 8.9 to $17.2 \mathrm{~mm}$. The weights

Table 9

Distribution and Quantity of Fire-Cracked Rock 1976 (1966-1976 adapted from Schilt, 1977: 90.)

\begin{tabular}{|c|c|c|c|c|c|}
\hline Provenience & Vertical & $\begin{array}{l}\text { Number } \\
\text { Fragments }\end{array}$ & $\begin{array}{c}\text { Percent } \\
\text { Total No. }\end{array}$ & $\begin{array}{l}\text { Weight } \\
\text { in grams }\end{array}$ & $\begin{array}{c}\text { Percent } \\
\text { Total Weight }\end{array}$ \\
\hline F 12 & $0-.75^{\prime}$ bs & 1 & 6.0 & 93.03 & 4.27 \\
\hline F 13 & $.9-1.4^{\prime} \mathrm{bs}$, level I & 2 & 13.0 & 223.68 & 10.26 \\
\hline F 13 & 1.4-1.9' bs, level II & 1 & 6.0 & 105.2 & 4.83 \\
\hline F 13 & 1.9-2.4' bs, level III & 3 & 19.0 & 105.62 & 4.85 \\
\hline F 14 & $.8^{\prime}$ bs trans & 2 & 13.0 & 10.43 & 0.48 \\
\hline F 14 & $.9^{\prime}$ bs trans & 1 & 6.0 & 5.05 & 0.23 \\
\hline F 15 & $1.4^{\prime} \mathrm{bs}$ & 2 & 13.0 & 380.49 & 17.46 \\
\hline F 15 & $1.5^{\prime} \mathrm{bs}$ & 1 & 6.0 & 422.97 & 19.40 \\
\hline F 18 & $1.5-2.1^{\prime} \mathrm{bs}$ & 1 & 6.0 & 455.29 & 20.89 \\
\hline F 21 & $2.0-2.3^{\prime} \mathrm{bs}$ & 1 & 6.0 & 296.54 & 13.60 \\
\hline F 22 & $\mathrm{PZ} .85^{\prime} \mathrm{bs}$ & 1 & 6.0 & 81.52 & 3.74 \\
\hline Totals 1976: & & 16 & 100.0 & 2179.82 & 100.01 \\
\hline 1966-1972: & & 26 & & 1906.00 & \\
\hline
\end{tabular}


of the red ochre pieces range from .99 to 4.88 grams. Red ochre was found on some of the lithic artifacts, including the sandstone abrader and on two sides of the largest ground stones. The two yellow ochre pieces had a combined length of $33.3 \mathrm{~mm}$, width of $13.9 \mathrm{~mm}$, thickness of $7.8 \mathrm{~mm}$, and a weight of 1.39 grams.

\section{Lithics Compilation}

The 1976 lithic material did not contain stone pendants, hammerstones, manos, pitted stones, hafted tools other than projectile points, whetstones, or other stone tools determined to be unfinished, categories which were recorded for previous excavations by Schilt (1977), other than those already mentioned in the chipped stone section. It also did not contain any type of stone artifacts unique from previous excavations. An overall comparison of lithic material recovered up to and including 1976 is provided below (Table 10).

\section{Lithics Conclusion}

The lithic assemblage at Noble-Wieting presents a selection of diagnostic Langford Tradition stone tools, especially seen in the forms of the Madison projectile points and humpback knives, and no definite diagnostic Middle Mississippian tools, such as Cahokia trinotched points. While Madison points are also found within Late Woodland and Mississippian sites, since they are recovered at most Langford sites and identified as part of the Langford tool kit they cannot be considered identifiers of influence from or interaction with Middle Mississippian groups. Two side-notched projectile points represent re-use of tools from earlier times and were identified as possibly Late Archaic or Late Woodland.

Larger agricultural, or horticultural, implements such as adzes or hoes, were also not discovered, although smaller celts were and their lesser size might indicate less reliance on large scale agriculture. Cultural exchange may have occurred between these Langford residents and 
Table 10

Lithic Artifacts Summary 1966-1976

(1966-72 adapted from Schilt, 1977: Tables 10, 11, 14.)

\begin{tabular}{|c|c|c|c|}
\hline Type & 1966-1972 & 1976 & Total each type \\
\hline $\begin{array}{l}\text { Madison Projectiles (complete \& } \\
\text { proximals) }\end{array}$ & 62 & 68 & 130 \\
\hline Side-notched Points (complete) & 1 & 2 & 3 \\
\hline Point distal tips & 20 & 13 & 33 \\
\hline Knives & 7 & 4 & 11 \\
\hline Knives - Humpbacked & 11 & 40 & 51 \\
\hline Scrapers and retouched flakes & 57 & 14 & 71 \\
\hline Perforators & 11 & 3 & 14 \\
\hline Cores & 16 & 17 & 33 \\
\hline Waste Flakes and Shatter & 2849 & 2500 & 5349 \\
\hline Abraders & 2 & 1 & 3 \\
\hline Celts & 1 & 2 & 3 \\
\hline Drilled Stone Fragments & 5 & 1 & 6 \\
\hline *Ground stones & 0 & 3 & 3 \\
\hline Fire-cracked Rock & 26 & 16 & 42 \\
\hline Limestone Pendants & 1 & 0 & 1 \\
\hline Pitted Stones & 2 & 0 & 2 \\
\hline Hammerstones & 7 & 1 & 8 \\
\hline Hafted Tools & 2 & 0 & 2 \\
\hline Unfinished Implements & 1 & 0 & 1 \\
\hline Mano fragments & 11 & 0 & 11 \\
\hline Whetstone & 1 & 0 & 1 \\
\hline Red and Yellow Ochre & 2 & 5 & 7 \\
\hline Copper & 1 & 12 & 13 \\
\hline Total for Site: & 3096 & 2702 & 5798 \\
\hline
\end{tabular}

Middle Mississippian people of the area, bringing small pieces of copper to the area, but the copper artifacts do not show formation that suggests exchange or adoption of Middle Mississippian lifeways. No figurines or effigies in stone were found in this assemblage, as well as no stone pipes, which would also identify Cahokian lifeways. 
In conclusion, the lithic assemblage from all excavated portions of Noble-Wieting to date do not show evidence of interaction or exchange with Middle Mississippian groups or emulation of ideologies. This conclusion does not support my hypothesis that this site was not an isolated village, but instead that it is strongly Langford culture and could be considered as showing a rejection of Cahokia's strong socio-political influence. The ceramic assemblage, presented in the next chapter, suggests a different conclusion regarding contact between peoples. 


\section{CHAPTER IX: CERAMICS ANALYSIS}

Creation of a vessel into a certain form may be determined by many factors, such as its intended function, as an expression of an individual's social position or wealth, as an indicator of a groups' culture, or as rejection of another group's domination. Other factors determining form may be due to available raw materials or climate (Orton and Hughes 2013: 81-82). It is unknown what social forces were at play that may have defined ceramic form during the time of Langford and Mississippian settlements in central Illinois and scholars are still debating the subject (Emerson 1999b, Emerson et al 2005, Emerson 2012, Jeske 1990, Jeske 2000). However, ceramics have been identified by their form, design, and manufacture and understood as representative of different groups of people due to typology.

This ceramic analysis' overall goal is to understand possible interactions with or cultural influence from other cultures, such as Late Woodland or Middle Mississippian. Previous ceramic analysis at the site shows a significant Langford component of $74.26 \%$ of the ceramics classified (Schilt 1977: 40) along with Late Woodland ceramics of 1.5\% (Schilt 1977: 41). Middle Mississippian ceramics represent a larger percentage at this site $(23.5 \%)$ than at other Langford sites (Schilt 1977: 191), which could be interpreted as more interaction with or emulation of Mississippian culture. Since the original study, however, other Langford sites have been investigated or reassessed, such as Zimmerman (Hart 1988), Washington Irving (Jeske 1990), Cooke (Markman 1991), Reeves, (Craig and Galloy 1996), and Russel Koster (Pearce 2006). New information from these studies regarding ceramic distribution and typology may shed new light on the Noble-Wieting assemblage. This chapter includes observations of the 1976 ceramic assemblage analysis, a synthesis of this assemblage with previous excavation analysis results, and consideration of interaction between Langford and Middle Mississippian groups at Noble- 
Wieting as may be determined through ceramic typology. Distribution of ceramics from this analysis and prior excavations from 1966 through 1972 is discussed in Chapter XI.

Langford ceramics are typically globular in shape and constructed with black grit as temper, or with crystalline grit temper (Brown et al 1967: 21). Rims are undecorated and can be rounded or flattened, but are typically flattened (Jeske 1990: 225). They may be straight or everted and occasionally are collared (Jeske 1990: 225). Observed surface treatments include cordmarked, smoothed-over cordmarked, and plain smoothed. Cordmarking is made by pressing a twisted cord or grasses to the vessel wall. Designs include cordmarks, bold curvilinear or rectangular trailings, punctate markings, and also chevrons. Trailings and chevrons are made with pressure of the finger or another rounded instrument while punctate marks are made with a reed, fingernail, or other sharpened or fine instrument. Smoothing of the vessel is accomplished by applying pressure to the vessel wall and pulling along the wall. Smoothing may leave marks similar to fine brush marks and the process may be aided with small amounts of water. Pots are considered well-fired and durable (Jeske 1990: 225) and hardness of Langford ceramics at Noble-Wieting on Moh's scale range between 2.0 and 3.0 (Schilt 1977: 42).

Local Late Woodland vessels are difficult to distinguish from the Langford specimens (Bird 1997, Brown et al 1967, Jeske 2000). Late Woodland vessels are also globular in shape, similar to Langford vessels, and with few decorations, but are typically thicker in construction than the Langford vessels and sometimes display markings on the rims, which Langford ceramics typically do not show. It has also been noted the early Langford vessels share attributes of form and surface finish with those of the American Bottom terminal or Late Woodland or Emergent Mississippian groups (Craig and Galloy 1996: 6-16). Late Woodland sites, such as those in the American Bottom, show cordmarking present on the majority of Late Woodland 
sherds (Fortier et al. 1982: 133), which is a design also noted on Langford ceramics. Trailed decorations are also present in Middle Mississippian Ramey Incised vessels of the Stirling Phase (A.D. 1050-1150) (Craig and Galloy 1996: 6-16). Miniature vessels, without decorative elements and similar to Langford mini mini-vessels, are also found in Late Woodland sites, making the overlap of these two cultures difficult to distinguish from this form of vessel.

Mississippian style ceramics were recorded at the Noble-Wieting site by Schilt in 1977 and also in the 1976 assemblage for this analysis. These ceramics are identified by their shell temper, rims more angular and everted than Langford vessels, and lips usually rounded. Vessels of Middle Mississippian style are less globular in shape and have more rounded shoulders than Langford vessels. Handles may be found on Mississippian vessels, but are typically missing from Langford forms. Decorations on Mississippian sherds include cordmarked and smoothed-over cordmarking, with decorative marks extending over the rims on occasion, a design that also separates them from Langford pieces which rarely have rim decoration. Trailings are found on vessels of both groups, but Mississippian trailings are usually thinner in width than the Langford design and may appear as incised line work. The interiors of both Mississippian and Langford vessels have found to occasionally have a red colored slip applied.

In early excavations at Noble-Wieting, four unique grit tempered-shell slipped sherds were recovered and one was examined by thin-section analysis (Schilt 1977: 76). Although appearing to be shell tempered at first glance, these sherds were determined to be grit tempered paste with a shell tempered slip cover on the external and internal sides. Similar shell slipped grit tempered sherds have been located at the Late Woodland site of Fish Lake, where a jar exhibited shell slip over a cordmarked surface and which has been suggested as a method to patch broken ceramics (Fortier et al. 1982: 106). No sherds similar to this description, however, were found 
within the 1976 ceramic assemblage and the singular sherd identified by Schilt is the only representation of this decorative element at Noble-Wieting. It is unknown if this unique technique was imported through trade or relocation, if it is an indicator of emulation of Cahokian ceramic styles, or if it suggests slight changes in cultural identity.

\section{Ceramic Analysis}

The goals of the ceramic analysis are: 1) to provide description of 1976 artifacts; 2) to compile data with that reported by Schilt (1977); 3) to identify Middle Mississippian influence or artifacts; and 4) to determine if previous conclusions should be changed regarding the interactions between Noble-Wieting inhabitants with other groups based on ceramic typology.

Prior to this analysis, ceramics were sorted by Ian Fricker. Conclusions of Fricker's research were not available at the time of this writing. However, his counts were considered and recorded, then a recount was conducted of all ceramics for this analysis in order to record all aspects of the pieces, compile the findings for artifact distribution at the site, and compare results with previous excavation information for a broader understanding of Noble-Wieting. Analysis methods for diagnostic pieces included visual observations. Diagnostic pieces include body and rim sherds with distinctive decorations, reconstructed or partial vessels, and unique pottery pieces including effigies or discs.

A total of 2591 ceramic items were recorded, including 141 rim sherds, 1888 body sherds, 77 burnt clay or daub, 17 unfired clay pieces, 483 sherdlets, and 7 ceramics pieces other than potsherds, such as discs or lugs. Grit and/or mafic tempered sherds $(n=1717)$ represented $85 \%$ of the total, shell tempered sherds $(n=292)$ accounted for $14 \%$, and untempered and eroded sherds $(n=13)$ resulted in less than $1 \%$. Shell and mafic temper combined internally in the pieces $(n=7)$, as opposed to shell slip over grit or mafic temper as mentioned above that were 
not observed in this assemblage, made up less than $1 \%$. Of the total body and rim sherds $(\mathrm{n}=$ 2029), 1818 were recovered from features. Discussion and comparison between this analysis and previous excavation results is found later in this chapter. Reconstructions and refits were considered as one piece and included 10 reconstructed rims, 3 partially reconstructed vessels, and 2 partially reconstructed mini-vessels.

\section{Body Sherds}

Body sherds were initially sorted by size and sherds smaller than $2 \mathrm{~cm}$ on the longest side were categorized as "sherdlets" $(n=483)$. Sherdlets were counted but were not divided by temper or analyzed further. Total counts for sherdlets by feature are included in Table 13 with burnt clay and daub while a discussion of distribution is included in Chapter VI.

Body sherds larger than $3 \mathrm{~cm}(\mathrm{n}=1888)$, were divided by temper into two categories of shell or grit/mafic, and further separated into categories based on surface treatment and decoration. Grit tempered body sherds $(n=1603)$ accounted for $85 \%$ and shell tempered sherds $(n=272)$ accounted for $14 \%$. Body sherds with a combination of shell and grit $(n=7)$ were less than $1 \%$ of the total and untempered body sherds from pinch pots or miniature vessels $(n=6)$ also accounted for less than $1 \%$ of the total body sherds. Red pigment or film was observed on 7 mafic tempered sherds and displayed on the inside surface of one shell rim sherd as a slip. Decorative elements, including cordmarking surface treatments, found on body sherds will be discussed later in this chapter.

\section{Rim Sherds}

Rims were separated by shell or grit/mafic temper and then further separated within those categories by any noticeable design elements. Rims were recorded separately as Langford or Mississippian types according to grit/mafic or shell temper respectively. Of 127 rim sherds, not 
including 14 identified as miniature vessels, 32 were too small to include in the attributes analysis, but were included in the overall counts recording temper. Thirty-eight rim sherds were complete enough to determine the contour of rim to body. Rims analyzed $(n=95)$ were measured with calipers for thickness of lip, body and neck, and possible orifice diameter was determined. A total of 17 rims were reconstructed by Ian Fricker and body sherds and rim sherds included in the reconstructed pieces were counted as one piece for this analysis. One vessel recovered from Feature 18 and reconstructed and recorded as Vessel \#220 by Ian Fricker, is discussed further in the section regarding design elements. It is the largest complete vessel recovered.

Including the small rim sherds, grit/mafic tempered rim sherds $(n=110)$ represented $87 \%$, shell rims $(n=16)$ totaled $12 \%$, and an untempered rim $(n=1)$ equaled less than $1 \%$ of the total. As mentioned earlier in this chapter, grit/mafic tempered rims in this assemblage are found to have a less everted rim angle than shell tempered rim sherds and are also typically square or flat lipped. Decorations on rims were recorded and are included in following table (Table 11). Lip shape was identified on larger rims and rounded lips $(n=9)$ accounted for only $10 \%$, while squared, or flattened, lip shape $(n=84)$ represented $88 \%$, and rolled lips $(n=2)$ represented by one grit/mafic sherd and one shell rim sherd represented 2\%. Miniature vessel rims resulted in the opposite conclusions with rounded lips $(n=13)$ at $93 \%$ of the total. Decorations were absent on the rim sherds of miniature vessels, except on one mini vessel, which is discussed later in the section for mini-vessels.

Although color was recorded using the Munsell soil color chart, it was apparent after consulting other individuals that color identification can vary significantly with the beholder. 
The most common color for grit tempered rims appeared reddish or orange in color, not often grey or dark, while the shell tempered sherds were often darker and less reddish in color.

Table 11

Rim Attributes 1976

\begin{tabular}{|c|c|c|c|c|c|c|c|c|c|}
\hline Feature & $\begin{array}{l}\text { Thickn } \\
\text { body }\end{array}$ & $\begin{array}{l}\text { ss: } \\
\text { neck }\end{array}$ & lip & shape & $\begin{array}{c}\text { Orifice } \\
\text { Dia. }(\mathrm{cm})\end{array}$ & $\begin{array}{c}\text { Decoration } \\
\text { Absent }\end{array}$ & $\begin{array}{l}\text { Grit/ } \\
\text { Mafic }\end{array}$ & Shell & Untemp \\
\hline surface & & & 5.0 & $\mathrm{sq}$ & & $X$ & $X$ & & \\
\hline surface & & & 5.9 & sq & & $X$ & $X$ & & \\
\hline surface & & 8.2 & 5.8 & sq & & $X$ & $X$ & & \\
\hline Trench 16 & & 7.1 & 4.9 & sq & & $X$ & $X$ & & \\
\hline Trench 17 & & 8.6 & 5.7 & sq & & $X$ & $X$ & & \\
\hline Trench 18 & & 6.6 & 6.1 & sq & & $X$ & $X$ & & \\
\hline Trench 18 & & 5.6 & 5.0 & sq & & $X$ & $X$ & & \\
\hline Trench 18 & 4.3 & 7.5 & 5.1 & sq & 17.0 & $X$ & & & \\
\hline Trench 18 & 4.5 & 5.0 & 4.0 & sq & & $X$ & & $X$ & \\
\hline Trench 19 & & 6.1 & 5.4 & sq & & $X$ & & $X$ & \\
\hline Trench 19 & & & 4.1 & sq & & $X$ & $X$ & & \\
\hline F 12 & 6.6 & 5.9 & 4.6 & sq & & $X$ & $X$ & & \\
\hline F 12 & & 7.6 & 6.3 & sq & & $X$ & $X$ & & \\
\hline F 12 & 6.1 & 6.6 & 4.6 & sq & 13.0 & $X$ & $X$ & & \\
\hline F 12 & 6.9 & 6.1 & 4.4 & sq & 11.0 & $X$ & $X$ & & \\
\hline F 12 & 6.1 & 6.0 & 5.2 & sq & & $X$ & $X$ & & \\
\hline F 12 & & 6.6 & 5.6 & sq & & $X$ & $X$ & & \\
\hline F 12 & & 4.0 & 3.6 & sq & & $X$ & & $X$ & \\
\hline F 12 & 5.7 & 8.1 & 5.5 & sq & 10.0 & $X$ & $X$ & & \\
\hline F 12 & & & 7.9 & sq & 8.0 & $X$ & & $X$ & \\
\hline F 12 & & & 5.5 & sq & & $X$ & $X$ & & \\
\hline F 12 & 6.1 & 7.8 & 5.4 & rnd & & $X$ & & $X$ & \\
\hline F 12 & 6.5 & 7.9 & 4.9 & $\mathrm{sq}$ & 12.0 & $X$ & $X$ & & \\
\hline F 12 & 4.3 & 7.4 & 5.8 & sq & 10.0 & $X$ & $X$ & & \\
\hline F 12 & & 6.0 & 5.3 & $\mathrm{sq}$ & & $X$ & $X$ & & \\
\hline F 12 & 8.4 & 8.5 & 4.1 & sq & & $X$ & $X$ & & \\
\hline F 12 & 7.1 & 8.2 & 7.2 & $\mathrm{sq}$ & & $X$ & $X$ & & \\
\hline $\mathrm{F} 12 \mathrm{~A}$ & 6.0 & 7.1 & 6.9 & sq & 12.0 & $\mathrm{X}$ & $X$ & & \\
\hline $\mathrm{F} 12 \mathrm{~A}$ & & 6.8 & 6.6 & sq & 10.0 & $X$ & $X$ & & \\
\hline $\mathrm{F} 12 \mathrm{~A}$ & & 6.4 & 6.2 & sq & & $X$ & $X$ & & \\
\hline $\mathrm{F} 12 \mathrm{~A}$ & & 8.4 & 4.4 & sq & 17.0 & $X$ & $X$ & & \\
\hline $\mathrm{F} 12 \mathrm{~A}$ & 5.1 & 6.3 & 5.6 & sq & & $X$ & $X$ & & \\
\hline $\mathrm{F} 12 \mathrm{~A}$ & & 7.8 & 5.0 & sq & & $X$ & $X$ & & \\
\hline $\mathrm{F} 12 \mathrm{~A}$ & & 7.7 & 4.4 & sq & & $X$ & $X$ & & \\
\hline $\mathrm{F} 12 \mathrm{~A}$ & & 8.2 & 4.4 & $\mathrm{sq}$ & & $X$ & $X$ & & \\
\hline $\mathrm{F} 12 \mathrm{~A}$ & 7.6 & 7.7 & 6.7 & sq & 17.0 & $X$ & $X$ & & \\
\hline $\mathrm{F} 12 \mathrm{~A}$ & & 7.0 & 6.9 & $\mathrm{sq}$ & & $X$ & $X$ & & \\
\hline $\mathrm{F} 12 \mathrm{~A}$ & 10.4 & 8.4 & 7.4 & $\mathrm{sq}$ & 17.0 & $X$ & & & \\
\hline
\end{tabular}


(Table 11, Continues)

\begin{tabular}{|c|c|c|c|c|c|c|c|c|c|}
\hline Feature & $\begin{array}{l}\text { Thickı } \\
\text { body }\end{array}$ & $\begin{array}{l}\text { ess: } \\
\text { neck }\end{array}$ & $\operatorname{lip}$ & shape & $\begin{array}{c}\text { Orifice } \\
\text { Dia. }(\mathrm{cm})\end{array}$ & $\begin{array}{c}\text { Decoration } \\
\text { Absent }\end{array}$ & $\begin{array}{l}\text { Grit/ } \\
\text { Mafic }\end{array}$ & Shell & Untemp \\
\hline F $12 \mathrm{~A}$ & & 5.3 & 4.8 & $\mathrm{sq}$ & & $X$ & $X$ & & \\
\hline F $12 \mathrm{~A}$ & & 8.7 & 5.1 & sq & & $X$ & $X$ & & \\
\hline F $12 \mathrm{~A}$ & 7.3 & 9.8 & 4.2 & $\mathrm{sq}$ & 16.0 & $X$ & $X$ & & \\
\hline $\mathrm{F} 12 \mathrm{~A}$ & 5.8 & 8.4 & 7.2 & sq & 13.0 & $X$ & $X$ & & \\
\hline F $12 \mathrm{~A}$ & & 7.5 & 4.7 & sq & & $X$ & $X$ & & \\
\hline F $12 \mathrm{~A}$ & & 6.6 & 5.7 & sq & & $X$ & $X$ & & \\
\hline $\mathrm{F} 12 \mathrm{~A}$ & & 7.5 & 7.3 & sq & & $X$ & $X$ & & \\
\hline F $12 \mathrm{~A}$ & 6.4 & 6.9 & 5.2 & $\mathrm{sq}$ & & $X$ & $X$ & & \\
\hline F $12 \mathrm{~A}$ & 6.6 & 9.5 & 4.7 & $\mathrm{sq}$ & & $X$ & $X$ & & \\
\hline F $12 B$ & & 7.4 & 3.3 & rnd & & $X$ & $X$ & & \\
\hline F $12 B$ & & 6.9 & 5.3 & $\mathrm{sq}$ & & $X$ & $X$ & & \\
\hline F 12B & 5.9 & 7.9 & 4.6 & sq & & $X$ & $X$ & & \\
\hline F 13 & & 7.4 & 6.4 & sq & & $X$ & $X$ & & \\
\hline F 13 & & 6.5 & 5.7 & $\mathrm{sq}$ & & $X$ & $X$ & & \\
\hline F 13 & 10.8 & 7.7 & 6.6 & exroll & 12.0 & $X$ & $X$ & & \\
\hline F 13 & & 7.9 & 7.7 & $\mathrm{sq}$ & & $X$ & $X$ & & \\
\hline F 13 & & 9.6 & 5.7 & $\mathrm{sq}$ & & $X$ & $X$ & & \\
\hline F 13 & & 8.8 & 6.2 & sq & & $X$ & $X$ & & \\
\hline F 13 & & 7.7 & 5.8 & $\mathrm{sq}$ & & $X$ & $X$ & & \\
\hline F 14 & & 3.6 & 4.0 & sq & & $X$ & $X$ & & \\
\hline F 14 & & 8.0 & 6.9 & sq & & $X$ & $X$ & & \\
\hline F 14 & & 6.2 & 7.1 & sq & & $X$ & $X$ & & \\
\hline F 14 & & 6.9 & 6.3 & sq & & $X$ & $X$ & & \\
\hline F 14 & & 7.9 & 4.1 & $\mathrm{sq}$ & & $X$ & $X$ & & \\
\hline F 14 & & 5.8 & 7.2 & sq & & $X$ & $X$ & & \\
\hline F 14 & & 8.4 & 5.1 & sq & 19.0 & $X$ & & $X$ & \\
\hline F 14 & 7.1 & 6.9 & 4.7 & $\mathrm{sq}$ & 10.0 & $X$ & $X$ & & \\
\hline F $14 a$ & 5.9 & 6.5 & 5.4 & sq & & $X$ & $X$ & & \\
\hline F $14 \mathrm{c}$ & & 6.6 & 5.1 & sq & & $X$ & $X$ & & \\
\hline $\mathrm{F} 14 \mathrm{c}$ & 6.2 & 7.2 & 3.8 & $\mathrm{sq}$ & & $X$ & $X$ & & \\
\hline F 14c & & 5.3 & 3.7 & sq & & $X$ & $X$ & & \\
\hline F 14c & & 6.8 & 5.3 & sq & & $X$ & $X$ & & \\
\hline $\mathrm{F} 14 \mathrm{c}$ & & 4.6 & 4.1 & $\mathrm{sq}$ & & $X$ & $X$ & & \\
\hline F 16 & 6.6 & 7.6 & 7.1 & sq & 12.0 & $X$ & $X$ & & \\
\hline F 16 & 7.0 & 11.2 & 7.0 & $\mathrm{sq}$ & 15.0 & $X$ & & $X$ & \\
\hline F 16 & & 11.3 & 8.6 & rnd & & $X$ & & $X$ & \\
\hline F 17 & & 7.4 & 4.2 & $\mathrm{sq}$ & & $X$ & $X$ & & \\
\hline F $17-220$ & & 7.7 & 6.0 & $\mathrm{sq}$ & 11.0 & $X$ & & $X$ & \\
\hline F 18 & 6.3 & 6.5 & 5.4 & rnd & & $X$ & $X$ & & \\
\hline F 18 & 6.7 & 8.5 & 6.7 & rnd & & $X$ & & $X$ & \\
\hline F 18 & 6.2 & 7.8 & 7.3 & $\mathrm{sq}$ & & $X$ & & $X$ & \\
\hline $\begin{array}{l}\text { F } 18 \\
\text { (Table Cor }\end{array}$ & nues) & 8.2 & 6.1 & $\mathrm{sq}$ & & $X$ & $X$ & & \\
\hline
\end{tabular}


(Table 11, Continues)

\begin{tabular}{lccccccccc}
\hline & \multicolumn{2}{c}{ Thickness: } & & & Orifice & Decoration & Grit/ & & \\
Feature & body & neck & lip & shape & Dia. $(\mathrm{cm})$ & $\begin{array}{c}\text { Absent } \\
\text { Mafic }\end{array}$ & Shell & Untemp \\
\hline F 18 & 7.7 & 11.9 & 6.7 & sq & 16.0 & $\mathrm{X}$ & $\mathrm{X}$ & & \\
F 18 & & 7.4 & 5.5 & sq & & $\mathrm{X}$ & $\mathrm{X}$ & & \\
F 18 & & 7.8 & 5.3 & rnd & & $\mathrm{X}$ & $\mathrm{X}$ & & \\
F 18 & 4.5 & 4.9 & 6.3 & roll & & $\mathrm{X}$ & & $\mathrm{X}$ & \\
F 19 & 6.0 & 5.8 & 6.7 & sq & & $\mathrm{X}$ & $\mathrm{X}$ & & \\
F 20 & & 7.4 & 4.7 & rnd & & $\mathrm{X}$ & $\mathrm{X}$ & & \\
F 21 & & 7.0 & 3.9 & sq & & $\mathrm{X}$ & $\mathrm{X}$ & & \\
F 21 & 7.8 & 6.6 & 7.1 & sq & 9.0 & $\mathrm{X}$ & $\mathrm{X}$ & & \\
F 22 & 8.0 & 8.8 & 6.8 & sq & 22.0 & $\mathrm{X}$ & $\mathrm{X}$ & & \\
F 22 & 7.4 & 5.0 & 4.9 & sq & & $\mathrm{X}$ & $\mathrm{X}$ & & \\
F 23 & 8.0 & 6.2 & 5.9 & sq & 11.0 & $\mathrm{X}$ & $\mathrm{X}$ & & \\
no prov & & 6.8 & 4.3 & sq & & $\mathrm{X}$ & $\mathrm{X}$ & & \\
no prov & 5.2 & 6.1 & 6.7 & sq & 18.0 & $\mathrm{X}$ & $\mathrm{X}$ & & $\mathrm{X}$ \\
no prov & & & 3.9 & rnd & & $\mathrm{X}$ & $\mathrm{X}$ & & \\
no prov & & & 5.7 & rnd & & $\mathrm{X}$ & & $\mathrm{X}$ & \\
& & & & & & & & & \\
Average & 4.64 & 8.73 & 7.57 & & 15.52 & & & & \\
\hline
\end{tabular}

\section{Surface Treatments}

Body and rim sherds were inspected for decoration and a total of 1,976 displayed surface treatment. Sherds with noticeable surface treatments were separated by grit/mafic $(n=1678)$ and shell tempering $(\mathrm{n}=263)$ were recorded as Langford or Mississippian respectively and are discussed separately below. Surface treatments were not noted on mini-vessels, except one notched rim sherd discussed later in this chapter. Thirty-five sherds appeared too eroded for proper classification but were divided by temper for total counts. A compilation and comparison of ceramic surface treatments from all excavation 1966-1976 is found in Table 12.

Langford. Forms for Langford pottery were classified as a bowls or jars and no pan or plate forms were observed for the grit tempered rims. Three partially reconstructed jars were recovered from Features $12 \mathrm{~A}, 14$ and 18. The partially reconstructed vessels from Features 12A and 14 did not exhibit surface decoration, and were recorded as Langford Plain vessels. The 
largest vessel rim reconstruction, with vertical cordmark design, was retrieved from the house feature 18 and is the most complete, although not all sherds were refit for the finished reconstructed piece (Figure 27). As the body sherds for this vessel were identified as being from this vessel, as they were bagged with the reconstructed rim and identified on the bag, the body sherds were included with this vessel as if they had been reconstructed.

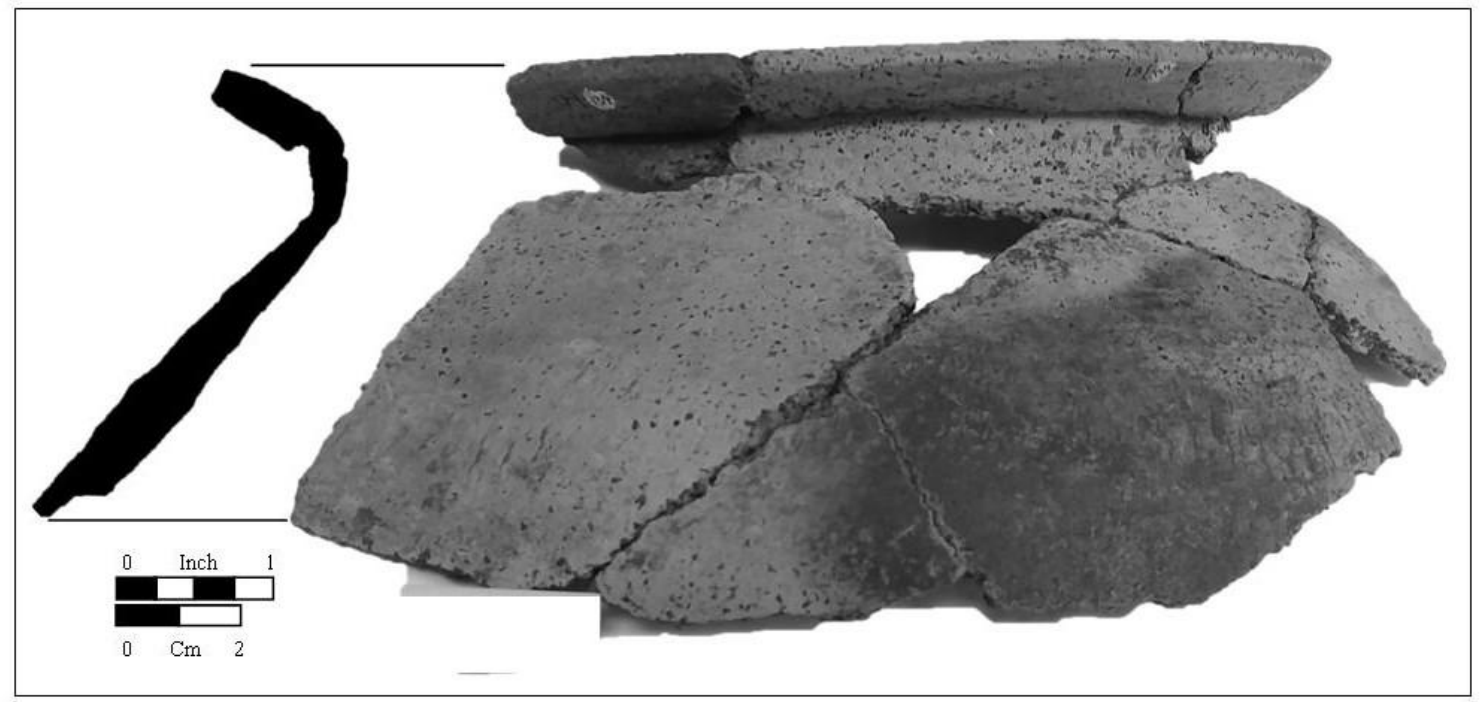

Figure 27. Langford Vertical Cordmarked Vessel from Feature 18.

Langford Plain sherds $(n=1458)$ were most abundant, representing $87 \%$ of the total of all grit tempered sherds and $75 \%$ of all ceramic pieces with design. An example of Langford Plain can be seen on the Feature 8 jar in Figure 27. Langford sherds with cordmarking total 12\% ( $n=196)$ of the Langford pieces and the second most abundant decorative element for all ceramic sherds at $10 \%$ of the total (Figure 28.c).

Thirteen Langford Trailed pieces also came to $1 \%$ of each the Langford designs, as well as the total overall for decoration, and all were body sherds (Figure 28.a). Trailing decorations ranged between $4.7-10.6 \mathrm{~mm}$ wide and $0.1-1.4 \mathrm{~mm}$ deep. The average size of trailing on 1976's Langford Trailed averaged $7.05 \mathrm{~mm}$ in width and $0.73 \mathrm{~mm}$ in depth, measured on only 12 
of the 13 sherds as one showed only a partial trail. The largest trailings were observed on a refit piece measured $10.6 \mathrm{~mm}$ wide and $0.7 \mathrm{~mm}$ in depth. These measurements average less than Langford Trailed sherds from previous excavations which had averages of $11 \mathrm{~mm}$ thick and 1.3 mm deep (Schilt 1977: 68). The 1976 assemblage's smaller sample size, as compared with 19661972, and the fact that some of the trailed sherds appeared slightly worn may have been factors in the smaller average. Eleven Langford Bold sherds represented 1\% of the total Langford designs as well as $1 \%$ of the total overall. Two rims were identified with the Langford Bold design and the rest were recorded on body sherds.

Noded decoration was not present on any Langford sherds. This may be a relatively rare type as only one sherd was identified at the Reeves site (Craig and Galloy 1996: 6-8) and one at Noble-Wieting in prior excavations (Shilt 1977: 156). With the exception of one mini-vessel sherd identified with rim notching, no grit tempered sherds had notched rims. These design elements on Langford sherds were mentioned by Craig and Galloy for the Reeves site (1996: 68) and by Brown for the Zimmerman site (1961: 31). Evidence of incising designs, fingernail impressions as chevrons, or punctuate impressions were not noted in this assemblage or in previous excavations at Noble-Wieting. Painted decorations were also rare with only five grit tempered pieces showing signs of red pigment. No examples of Langford painted sherds were identified in previous excavations, but were found on shell tempered sherds instead.

Mississippian. As mentioned previously, no pans or plates were identified within the Mississippian assemblage as have been from previous excavations at the site. Only one sherd was found with red pigment or paint on the internal face and only one shell tempered incised sherd was discovered (Figure 28.d). It should be noted that the incised sherd was recovered from the surface, not from a trench or feature, and therefore could be questioned as to how and when it 
was deposited. This sherd may be shell that has had leaching occur as only voids were visible where the temper had been. Measurements of the incised grooves were $1.7-2.5 \mathrm{~mm}$ in width and $.1 \mathrm{~mm}$ in depth. Mississippian cordmarked sherds proved to be the largest in number $(\mathrm{n}=$ 139, 53\%), while representing $7 \%$ of the overall total of decorated sherds (Figure 28.b).

Mississippian Plain sherds total 123 and account for $47 \%$ of the shell decorations and $6 \%$ of the total sherds found with surface treatment.

Late Woodland. The assemblage contained few Late Woodland sherds, although one grit tempered rim sherd from a miniature vessel was identified with notching along the rim, which could be a Late Woodland design. This small rim sherd appeared to be the only piece in the 1976 ceramic assemblage seen as possible Late Woodland in typology, although it could be included with Langford as well (Figure 29.e).

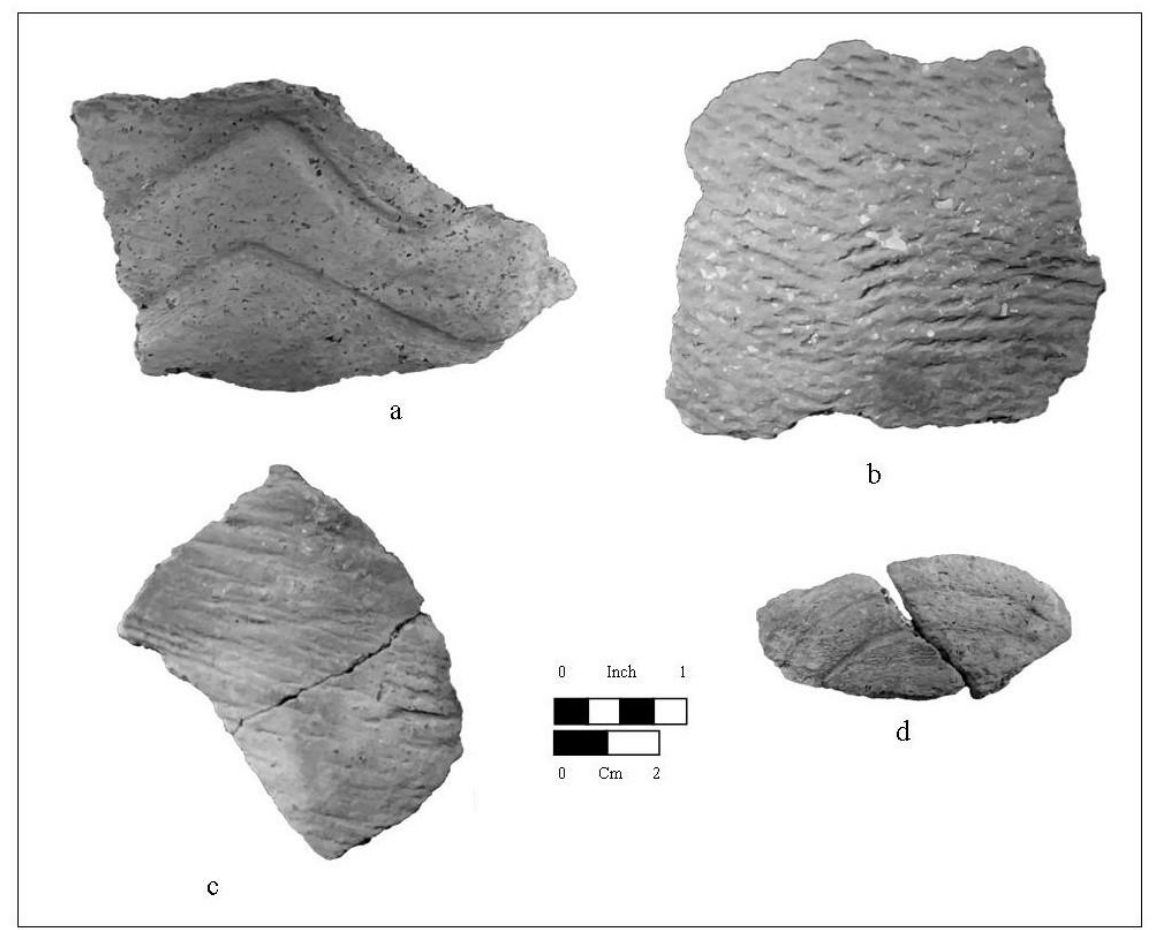

Figure 28. Design Elements on Body Sherds. a. Langford Trailed, b. Shell tempered ordmarked, c. Grit tempered cord marked, d. Shell tempered incised. 
Table 12

Decorative Elements Summary 1966-1976

(1966-1972 adapted from Schilt, 1977.)

\begin{tabular}{lcccc}
\hline & & $1966-$ & & \\
& 1976 & 1972 & Total & Percent \\
Tota & & & \\
Type & 1 & Totals & All Years & All Years \\
\hline Late Woodland notched rim & 1 & 0 & 1 & 0.0 \\
Langford Plain & 1458 & 2034 & 3492 & 64.0 \\
Langford Bold & 11 & 3 & 14 & 0.0 \\
Langford Trailed & 13 & 25 & 38 & 1.0 \\
Langford Cordmarked & 196 & 481 & 677 & 12.0 \\
Langford Noded & 0 & 1 & 1 & 0.0 \\
Pigment/Painted & 6 & 0 & 6 & 0.0 \\
Unclassified Langford eroded & 13 & 77 & 90 & 2.0 \\
& & & & \\
\cline { 2 - 5 } Total Langford/Late Woodland Series: & 1698 & 2621 & 4319 & \\
& & & & \\
Mississippian Plain & 123 & 182 & 305 & 0.0 \\
Mississippian Incised & 1 & 0 & 1 & 13.0 \\
Mississippian Cordmarked & 139 & 586 & 725 & 0.0 \\
Mississippian Lobed & 0 & 1 & 1 & 0.0 \\
Pigment/Painted & 1 & 5 & 6 & 2.0 \\
Unclassified Mississippian eroded & 22 & 70 & 92 & \\
\cline { 2 - 5 } Total Mississippian Series & 286 & 844 & 1130 & \\
Total All Decorated Sherds & & & & \\
(Note: 1976 sand and shell/grit are combined with grit sherds, lugs are not recorded. & \\
Zero percentages represent less than .01 & percent.) & & \\
\hline
\end{tabular}

Burned Clay and Daub

Burned clay was distinguished from daub by the lack of impression on the exterior surface and also by the color, which appears reddish or dark indicating firing. A total of 59 burned clay pieces were recovered from all features except 15, 16, and 22, and were also found on surface and in trenches outside of features. Fragments found in this assemblage are red, 
orange, brown, tan, yellow, or black in color. Distribution of all burned clay and daub for 1976 by weight indicates that Feature 18, a house feature, contained the largest amount of this material and Features 14 and 19, both pits contained the next highest amounts per weight respectively. It should be noted that Feature 19 contained only two large pieces of burnt clay weighing the total of 32.9 grams and this feature was not completely excavated. However, Feature 18 contained the largest amount by count and weight of burnt clay, suggesting production of ceramics or burned earth created from cooking methods occurred in this feature. It was also noted by Schilt for previous excavations that a large amount of burnt clay was located within a burnt area that may have been used for cooking (1977: 131). Burnt clay and daub continues to present opportunities for future research regarding seasonality of structure construction, use of local or distant clay sources, and possible interpretation of pottery manufacture at this site.

Daub fragments $(\mathrm{n}=18)$ were obtained from features $12,13,14$, and 21 . Surface impressions of grass or sticks, were observed on 9 pieces of daub, but no corn cob impressions were found as had been recorded in previous excavations (Schilt 1977: 79). Impressions on burned clay other than those identified as daub were not recorded for this analysis. Daub has been found to assist with identification of seasonality of structure construction (Seltzer and Peacock 2015). The Noble-Wieting 1976 excavated house Feature 18 does not present large amounts of daub, by count or by weight, within the structure or along the wall trenches, thereby suggesting this method of wall fill was not used extensively at this site. Although, it is unknown if recovery method bias at the excavation or in the lab may have resulted in material not identified or saved for analysis. 
Table 13

Burnt Clay, Daub and Sherdlets by Features and Classes Summary (1966-1972 adapted from Schilt, 1977: Table 7.)

\begin{tabular}{|c|c|c|c|c|c|c|c|}
\hline $\begin{array}{c}1976 \text { Class } \\
\& \\
\text { Totals }\end{array}$ & Feature & Pieces & $\begin{array}{c}\text { Burnt } \\
\text { Clay }\end{array}$ & Daub & $\begin{array}{c}\text { Total } \\
\text { Wt } \\
\text { (grams) }\end{array}$ & Sherdlets & $\begin{array}{c}1966-1972 \\
\text { Burnt Clay/Daub } \\
\text { Total by Class }\end{array}$ \\
\hline I - 1 & 17 & 1 & 1 & 0 & 0.5 & 20 & 220 \\
\hline \multirow[t]{5}{*}{ II - 13} & 12 & 6 & 3 & 3 & 21.6 & 192 & 10 \\
\hline & 13 & 4 & 1 & 3 & 16.8 & 33 & \\
\hline & 16 & 0 & & & 0 & 13 & \\
\hline & 19 & 2 & 2 & 0 & 33.0 & 0 & \\
\hline & 20 & 1 & 1 & 0 & 1.3 & 5 & \\
\hline \multirow[t]{2}{*}{ III - 18} & 14 & 17 & 10 & 7 & 35.3 & 67 & 86 \\
\hline & 23 & 1 & 1 & 0 & 7.3 & 0 & \\
\hline \multirow[t]{3}{*}{ IV - 38} & 15 & 0 & & & 0 & 1 & 0 \\
\hline & 18 & 36 & 36 & 0 & 110.1 & 12 & \\
\hline & 21 & 2 & 0 & 2 & 2.5 & 4 & \\
\hline VI - 0 & 22 & 0 & & & 0 & 114 & 34 \\
\hline surface - 3 & & 3 & 3 & & 11.9 & 5 & 13 \\
\hline trench -4 & & 4 & 1 & 3 & 8.9 & 17 & 2 \\
\hline Totals: & & 77 & 59 & 18 & 249.2 & 483 & 365 \\
\hline
\end{tabular}

\section{Mini-Vessels Sherds}

Miniature vessels have been viewed as paint pots, toys, or produced by apprentice potters in addition to other suggestions including their use as drinking cups or grain scoops (Fortier et al 1982: 136). Pinch pots are constructed using a technique of pinching clay into form and within this analysis were identified as appearing less refined than other ceramics. However, minivessels may be constructed using the same technique. Mini-vessel is the term used within this analysis. The miniature vessels do not present definitive conclusions as to cultural identity necessarily, as they are found within many excavations from across many times and places. 
However, mini-vessels are included in this analysis as they may assist with future research and interpretation of the daily life of the inhabitants of this site and for comparison with previous excavation results.

Noble-Wieting's 1976 assemblage contains 14 mini-vessels rims, or $10 \%$ of the rim collection, and represented $54 \%(\mathrm{n}=13)$ of the rounded lips found within the entire ceramic collection of rims. Of the 14 total mini-vessel rims, only one was constructed with a square lip. All mini-vessels rim sherds $(n=14)$ and body sherds $(n=62)$ recorded by Schilt for the 19661972 excavations were of untempered paste with the exception of a few containing small grit granules (1977: 74). This is a noted difference from the 1976 excavations, of which $43 \%(n=6)$ were untempered, 29\% ( $\mathrm{n}=4)$ were grit temper, and $29 \%(\mathrm{n}=4)$ were shell temper (Figure 29.ad).

Two of the miniature rims sherds measured $3 \mathrm{~cm}$ for orifice diameter and 8 were large enough to determine contour. Measurements of mini rims identified average lip thickness as 4.2 $\mathrm{mm}$, neck thickness as $5.9 \mathrm{~mm}$, and body thickness as $6.9 \mathrm{~mm}$. The measurements of the standard size rims, in comparison, average lip thickness as $7.6 \mathrm{~mm}$, neck thickness as $8.7 \mathrm{~mm}$, and body thickness as $4.6 \mathrm{~mm}$. As seen, the lip and neck thickness of the mini vessels is much less than standard rim sherds, but the body thickness average is greater. Clay colors were mostly reddish and orange. Only one untempered mini-vessel rim sherd contained design element in the form of notching along the rim (Figure 29.e).

\section{Ceramics Other Than Potsherds}

Pottery Discs, Handles, and Appliqué. It should be noted that all the shaped pottery pieces recovered during the 1976 excavations were constructed with shell temper, which is similar to those shaped pottery artifacts from previous excavations at the site. One complete shell 


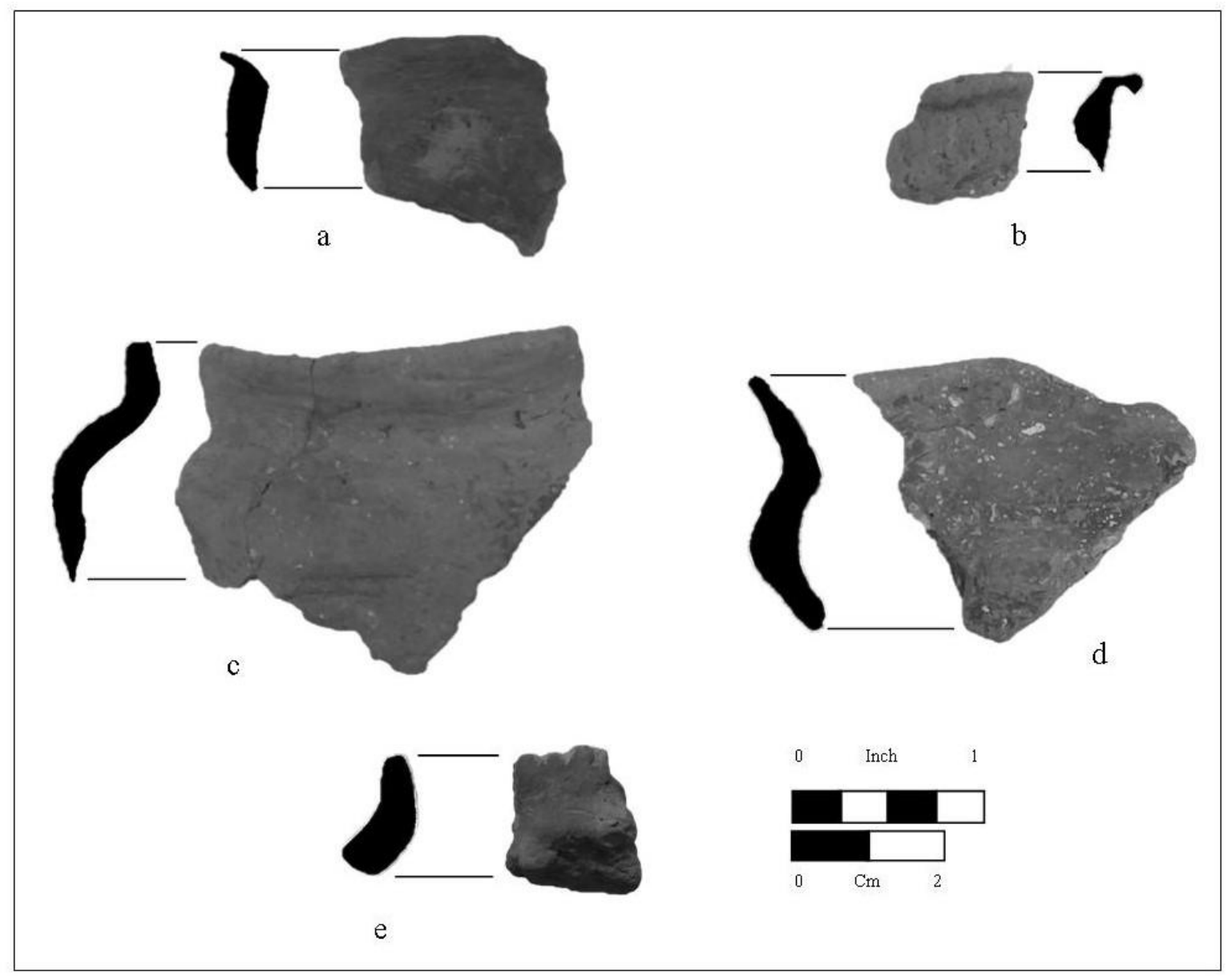

Figure 29. Mini-vessels. a. Feature 12 - untempered pinch pot; b. Feature 17 - grit tempered rounded rim; c. Feature 13 - shell tempered; d. Feature 12 - shell tempered; e. Feature 12 untempered, notched rim.

tempered pottery disc and two disc fragments were identified from Features 16, 12, and 13 respectively (Figure 30.a-c). The complete disc piece found in Feature 16 and weighing 11.15 grams, measured between 33.0 to $34.5 \mathrm{~mm}$ diameter, longer one direction than the other as ovoid, and contained a $4.4 \mathrm{~mm}$ diameter hole. One shell disc half from Feature 12, pit A, measured $50.7 \mathrm{~mm}$ long, $31.4 \mathrm{~mm}$ wide, and $6.7 \mathrm{~mm}$ thick, with a center hole diameter of approximately $5.7 \mathrm{~mm}$. One face of this disc fragment displayed cordmarking and the other face 
appeared smoothed. The second disc fragment, from Feature 13, measures $34.7 \mathrm{~mm}$ long, 18.2 $\mathrm{mm}$ to the center, and approximately $4.8 \mathrm{~mm}$ diameter hole in the center. Feature 16 contained one partial shell tempered handle (Figure 30.d), which measures $30.7 \mathrm{~mm}$ long, $16.4 \mathrm{~mm}$ wide, and $13.1 \mathrm{~mm}$ thick.

Schilt identified five loop handles, one untempered and four shell tempered, from early excavations (1977: 55) and also reported two effigy lugs retrieved from prior excavations were in the form of bird heads (78). However the lug, or handle, recovered from Feature 16 in 1976 is not identifiable as any specific form and is instead a rounded rectangular shape. A small circular appliqué piece was recovered in the plowzone of Trench $18 \mathrm{G}$, which is also above Feature 12. It measures $12.1 \mathrm{~mm}$ long and $7.9 \mathrm{~mm}$ wide, weighing .79 $(\mathrm{g})$ and is of shell tempered molded construction. (Figure 30.e). Two indiscriminate pieces of clay appearing to be shaped were recovered from Features 12 and 13.

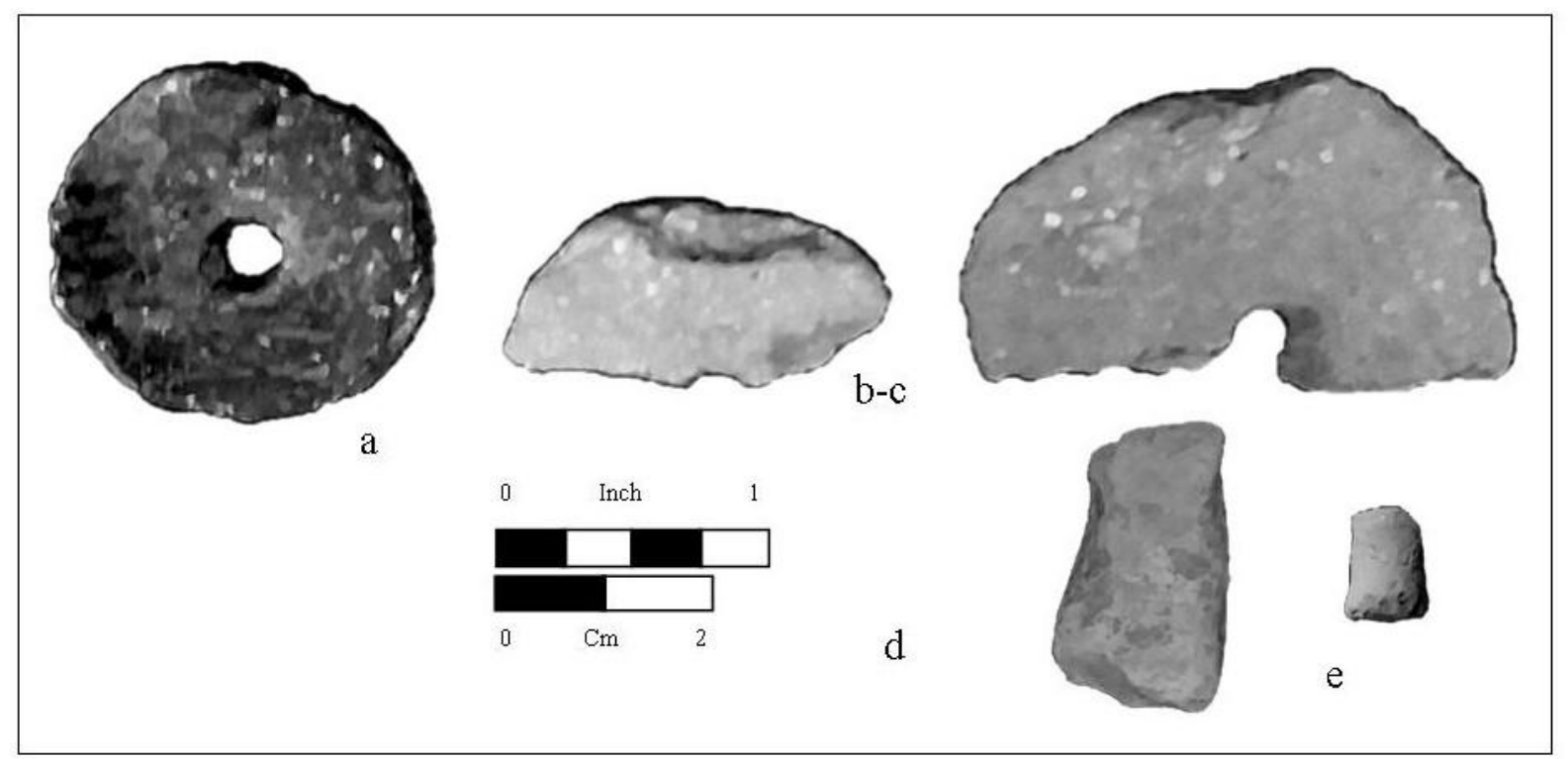

Figure 30. Ceramics Other than Potsherds. a. Complete disc; b-c. two partial discs; d. shell handle; e. appliqué. 
No ceramic earspools, as found within Middle Mississippian sites, have been identified at Noble-Wieting or at Langford sites in northern Illinois with the exception of one possible piece from the Reeves Site (Craig and Galloy 1996: 6-13). Bone and copper ear spool facings are reported for Gentleman Farm, Zimmerman, and Plum Island sites (Brown et al. 1967: 35; Craig and Galloy 1996: 6-15), but none have been discovered at Noble-Wieting.

\section{Ceramics Discussion}

It was noted that the variety of types identified, such as Mississippian Plain or Langford Cordmarked, in the 1976 assemblage $(n=10)$ was less in number than those recorded for prior excavations, which totaled 17 (Schilt 1977: 156), although lugs were not included in the analysis for external decoration and sand temper mixed with grit sherds were recorded with the grit temper counts in the 1976 analysis. The difference in number of types, recorded in this analysis as decorative elements, however, may be due to fewer number of features excavated in 1976 and not necessarily a reflection on the different areas of the site showing inhabitants' preferences or interactions with other groups. Sample size of total excavated features from $1976(\mathrm{n}=12)$, as compared to 1966-1972 ( $\mathrm{n}=32$ ), may have impacted the number of typologies identified.

However, the location of the excavations may have also been cause for differences in decorative elements or types if the southern portion of the site can later be determined through radiocarbon dating as an older area of habitation. Until further excavations are conducted in the southern portion of the site and compared to the more northern portions, it will not be understood how distribution of types of ceramics, such as Mississippian or Langford decorations and temper, has changed through the length of habitation, or if the changes are due to individual preferences and cultural connections. 
Comparisons of decoration and temper between earlier excavations and the 1976 material gives a broadened perspective of the Noble-Wieting site's internal variation, and also provides additional comparisons with other Langford sites. Noble-Wieting's Langford sherds with cordmarked treatment (12\%) and trailed impressions (1\%) are substantially less numerous than those with no decoration apparent or Langford Plain (64\%). These percentages appear to follow trends found at other Langford sites including Zimmerman (Brown 1961), Keeshin Farm (Emerson 1999a), Reeves (Craig and Galloy 1996), Gentleman Farm (Brown et al 1967), and Russel Koster (Pearce 2006). A notable difference was seen at Gentleman Farm Mortuary site with $82 \%$ decorated and 18\% plain (Brown et al 1967: 21-28) and at Fisher Mounds (Griffin 1946: 121). It can be suggested that decorative elements were not typical for utilitarian ceramics but retained for special purposes, such as burials. No vessels and only a couple of Langford sherds were reported with burials at Noble-Wieting (Schilt 1977).

Temper was a defining factor for determining if sherds were Langford series or Middle Mississippian. The new data for 1976 prompted revisiting comparisons with other Langford sites. In 1977, Schilt reported 23.5\% shell temper in the collections from 1966-1972 and suggests the high percentage at the Zimmerman site (25-28\%) may be due to the longer overall time period the site was inhabited (Schilt 1977: 192). The higher percentage at Zimmerman comes from the earlier phase of the site, while later phases only contain 2-8\% (Brown 1961: 48). The occurrence of shell tempered sherds identified at Reeves are lower yet. At $1.8 \%$, four rim sherds are considered from the Huber phase and are thought to represent trade between Huber and Langford peoples (Craig and Galloy 1996: 6-13). Fisher site contained Fisher ceramics, which are shell tempered, and these are suggested to be from an earlier habitation at the site with 
Langford habitation following and does not reflect influence from Middle Mississippian groups in the same way that Noble-Wieting sherds might (Griffin 1946: 122). Excavations from Gentleman Farm contained approximately $2 \%$ shell tempered ceramics, which were identified as Fisher and Oneota (Brown et al 1967: 38).

Other site reports did not identify any shell sherds within the collections. Washington Irving site contained almost exclusively Langford sherds, with one sherd considered a "possible exception" (Jeske 1990: 229). At Keeshin Farm, 6\% of sherds are "non-mafic grit" (Emerson 1999a: 63), but the report does not identify shell specifically and the ceramics from this site are considered to be homogenous as Langford style, thereby suggesting some form of rock, sand, or grit temper. The report of Russell Koster also does not identify shell temper within its assemblage (Pearce 2006). Robinson Reserve also contained a "majority" (Lurie 1992: 99) of grit tempered sherds, but the report did not identify other temper types or percentages. This information is obtained from a published article, however, and not the finished site report which may contain more information regarding temper and decorations on the ceramics of this site.

The 1976 Noble-Wieting analysis identified $14 \%$ of the assemblage as shell tempered ceramics, and therefore the overall percentage of shell temper sherds recovered at Noble-Wieting from $1966-1976$ is $18.75 \%$. This percentage is still well above those recorded for many other Langford sites and perhaps is due to the location in the border region between different cultures where trade and influence may be higher. This higher percentage, however, still does not define if the cause is due to immigration into the site by Middle Mississippians, intermarriage, pilgrimages to Cahokia with a return of new ideas for technology, or emulation of the Cahokian ways. 


\section{Ceramics Conclusion}

Craig and Galloy (1996: 6-17) suggest the Langford Tradition of northern Illinois experienced little change in ceramic style and function and illustrate more conformance with ceramic production techniques that follow cultural patterns already well established. This same suggestion is given here for Noble-Wieting as the ceramic assemblage continues to show strong Langford attributes even though its location is significantly closer to Cahokia and could have the potential of increased interaction and influence. However, as noted by Bird (1997: 130), the Langford series and Middle Mississippian ceramics at this site are significant in that they temporally co-occur during the occupation of the site, which differs from other more northern Langford sites. The small sample size and limited excavated site coverage at Noble-Wieting, however, can be seen as a potential limiting factor for a complete understanding of this phenomenon.

The size of the site and future excavations may hold the key to a more in-depth understanding. Since the size of the site, according to 2017 geophysical mapping, is shown as twice the size of initial reports and with many undiscovered features possibly still in place, the overall ceramic distribution and percentages of Middle Mississippian ceramics cannot be fully understood at this time. Further investigation at the site will enable a more accurate determination of how the ceramic assemblage compares to other more fully excavated sites and a better interpretation of possibly interaction, as shown in the decorative and manufacture aspects of the ceramics. 


\section{CHAPTER X: FAUNAL ANALYSIS}

According to the initial faunal analysis for Noble-Wieting, reported by Parmalee and Bogan (1980: 1), the excavations at Noble-Wieting between 1966 and 1972 resulted in less than $4 \%$ of the total site of approximately 2.75 acres producing fauna for analysis. However, this analysis does not focus on the total amount of faunal remains identified for food production or for determination of seasonality of the site, but on modifications made that signify use as tools or ornaments showing possible influence from Middle Mississippian groups. Modifications for food production, such as burning or cut marks from butchering, were not included and offer a future research opportunity. Special attention was paid to identify pieces that would exhibit effigy representations or are primarily identified as Middle Mississippian in form. A total of 58 modified bone and shell artifacts were identified for this assemblage. A complete summary of 1966-1976 Noble-Wieting bone and shell tools and ornaments is located in Table 14.

\section{Modified Antler and Bone}

\section{Antler Beams, Flakers, and Tines}

As found at other Langford sites, white-tailed deer was abundant and at this site. Deer and elk provided the most significant mammalian food source (Parmalee and Bogan 1980: 2). At this site, these animals were also found to produce the most abundance of raw material for bone tool use. White-tailed deer and elk provided beamers and antlers for scraping excess tissue from hides and also were used for production of lithic tools as pressure flakers. It was noted in the earlier report that elk was apparently abundant at this site during occupancy or inhabitants sought them out with special effort (Parmalee and Bogan 1980: 4). According to Penman (1999: Table 8.10), Noble-Wieting has the highest amounts of deer and elk remains as compared to other Langford sites in Illinois. 
Antlers from deer (Odocoileus virginianus) or elk (Cervus canadensis) were often used as pressure flakers or billets for manufacture of stone tools, as they still are today by lithic artisans. In this assemblage larger antler beams $(n=7)$ exhibit possible wear of this type with smoothed and rounded tips and indicating possible use as flakers or billets. One beam, possibly from an elk, appears polished and is broken on the tip. These artifacts were recovered from Features 12, 13, and 14 (Figure 31.a). Three antlers had tips removed and were from Features 12 and 14, and one from unknown provenience. Detached antler tines or tips $(n=7)$ were recovered from Trench 18, and Features 12, 13, and 17. They measure in length between $25.1 \mathrm{~mm}$ to 41.3 $\mathrm{mm}$ and all display rounded tips. Two of the pieces exhibit exposure to heat. One piece contains numerous chop marks all along the piece on all sides (Figure 31.b). Similar antler tips, beams, and flakers were reported at other Langford sites including as Reeves (Martin and Richmond 1996: 9-28), Gentleman Farm (Brown et al 1967: 32), and by Schilt (1977: 96-100) at NobleWieting.

\section{Modified Deer Phalanges and Gaming Pieces}

First phalanges of the white-tailed deer (Odocoileus virginianus) modified for playing a cup-and-pin game have been reported at other sites, including those of Late Woodland, Langford, and Middle Mississippian cultures. Schilt reports one modified deer phalanx at NobleWieting and this assemblage resulted in 2 complete artifacts from Features 12 and 14 and one from Feature 21 that was broken in half lengthwise (Figure 31.c-d). The complete artifacts measure $35.7 \mathrm{~mm}$ and $24.7 \mathrm{~mm}$ in length and $17.6 \mathrm{~mm}$ and $14.3 \mathrm{~mm}$ diameter on the larger end respectively. A hole has been carved into both ends and the insides removed. The broken piece may not have had a hole in both ends, as it is difficult to ascertain due from the nature of the break, however there is a small hole drilled into one side. The length is $30.5 \mathrm{~mm}$, width on the 
larger end $15.2 \mathrm{~mm}$, and the hole's diameter measures approximately $2.3 \mathrm{~mm}$. This artifact may have had a different purpose than the previous two.

Gaming or counting pieces were typically constructed from bone or antler. Four of these artifacts were recovered from Features 12,12A, 13, and 14A. The three complete pieces measure between 31.8 and $39.9 \mathrm{~mm}$ long, 6.7 and $7.6 \mathrm{~mm}$ thick, and 8.1 and $9.5 \mathrm{~mm}$ wide. One partial piece, which is broken on one end, measures $25.6 \mathrm{~mm}$ long, $9.0 \mathrm{~mm}$ wide, and $6.5 \mathrm{~mm}$ thick, and is more deteriorated than the other three. The complete gaming pieces are rounded somewhat on both ends and along the sides, smoothed, and are rectangular shape. (Figure 31.e)

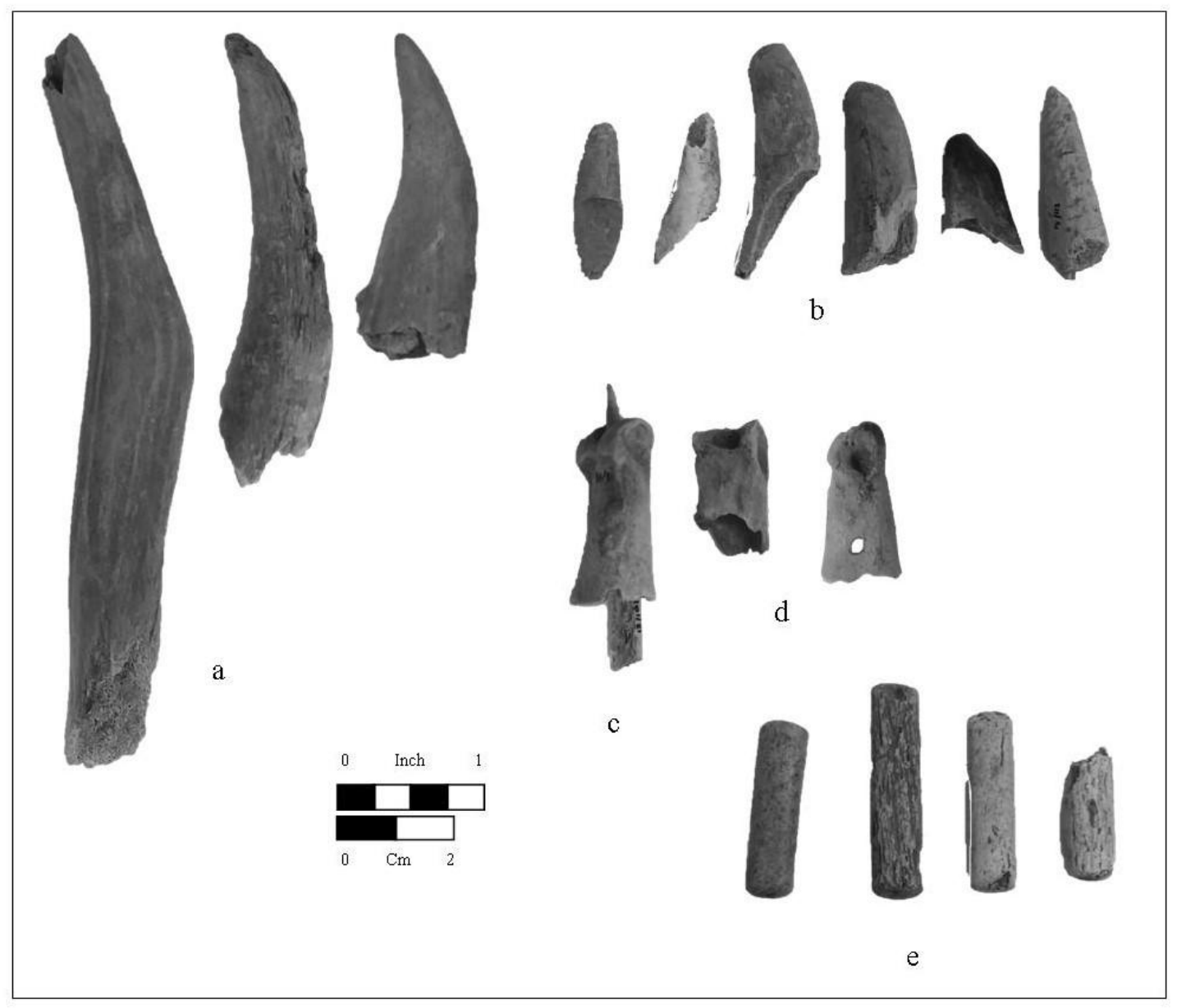

Figure 31. Modified Antler and Bone. a. antler beams and flakers, b. antler tines or tips, c. deer toe with needle through hole, d. modified deer toes, e. four bone gaming pieces. 


\section{Hooks, Awls and Needles}

Two bone pieces, recovered from Feature 13 and appearing to be from a long bone of deer (Odocoileus virginianus), were carved into "U" shape and pointed on the ends (Figure 32.a). Similarly carved pieces were identified as Archaic bone fishhooks (Iseminger 2014: 44) and it is possible others exist within Late Woodland and Langford assemblages from other sites, although further research is necessary to determine this. The lack of a comprehensive database of sites and their artifacts makes finding other examples of these hooks from Langford sites difficult, however a search for similar pieces is still underway within site records.

The larger of these two artifacts measures $74.2 \mathrm{~mm}$ long, $19.7 \mathrm{~mm}$ wide, and $11.7 \mathrm{~mm}$ thick, with a more rounded larger end. The second hook measures $43.9 \mathrm{~mm}$ long, $21.5 \mathrm{~mm}$ wide, and $4.7 \mathrm{~mm}$ thick, and is more flat in shape. A third piece was recovered from Trench 18 and appears to be partially constructed in this same manner, although the majority of the two long sides are broken off (Figure 32.b). This partial hook measures $28.6 \mathrm{~mm}$ long, $22.4 \mathrm{~mm}$ wide and $12.3 \mathrm{~mm}$ thick, and as the first mentioned is more rounded on the larger end.

Two thin hooks, both broken at both ends, were recovered from Feature 12 and 12A. These appear to be formed from avian bones. It is undetermined the final shape of these hooks, but one has a length of $54.4 \mathrm{~mm}$, width of $8.1 \mathrm{~mm}$, and a thickness of $2.6 \mathrm{~mm}$, and the other measures $49.9 \mathrm{~mm}$ long, $8.6 \mathrm{~mm}$ wide and $2.8 \mathrm{~mm}$ thick (Figure 32.c).

Broken awls or needles were removed from Features 12A and 14D (Figure 32.d). The longer of the two, from Feature 14D, is smooth and shiny and measures $56.2 \mathrm{~mm}$ long, $6.6 \mathrm{~mm}$ tapering to $1.2 \mathrm{~mm}$ point, and $3.7 \mathrm{~mm}$ thick. This piece is broken on the large end and only slightly damaged on the point. The shorter of the two is more porous bone material and 


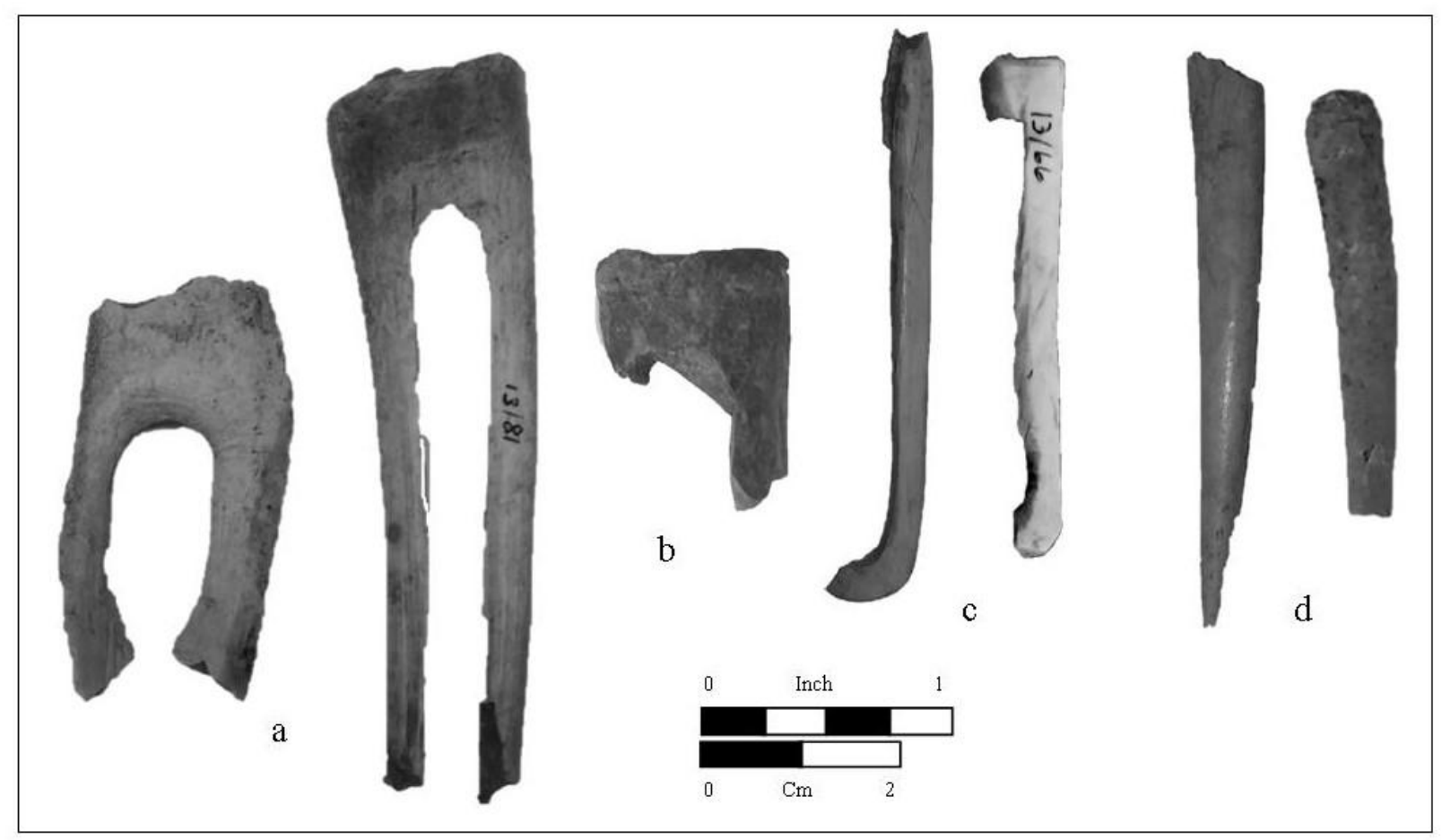

Figure 32. Bone Hooks, Needles, and Awls. a. bone fish hooks, b. partial fish hook, c. two bone hooks, d. two bone needles or awls.

measuring $41.9 \mathrm{~mm}$ long, $6.7 \mathrm{~mm}$ tapering to $4.1 \mathrm{~mm}$ in width, and $3.6 \mathrm{~mm}$ thick. This artifact is broken on the pointed end and rounded on the larger end.

\section{Teeth and Other Modified Bone}

Two carnivore canine teeth, recovered from Feature 14, appear to have been smoothed in the area of the neck, located between the crown and root, which usually displays a ridge and is rough (Figure 33.a). It is unknown if these teeth were used as an implement, such as a type of awl or chisel, but their difference from other canine teeth are noted as a possibility for further investigation. Two beaver (Castor canadensis) teeth were located in the remains of Features 12 and 21 (Figure 33.b). Schilt reports beaver tooth chisels found in previous excavations (1977: 103), however the 1976 teeth do not appear to have been modified into chisels as she describes. 
These two pieces range from $31.3 \mathrm{~mm}$ to 34.4 in length, with the end coming to a flat chisel shape, however it is uncertain if this is from normal wear by the animal or modified further.

One larger femur head, possibly from a deer (Odocoileus virginianus) was retrieved from Feature 21, measures approximately $41.9 \mathrm{~mm}$ in diameter. This piece displays a smoothed area in the area of the neck indicating use (Figure 33.c). A similar deer femur "ball" was identified from the Gentleman Farm (Brown et al 1967: 57).

A solid piece of bone, recovered from Feature 12, was rounded on one end by carving and on the opposite end scrape marks were identified (Figure 33.d). This piece measures 48.7 $\mathrm{mm}$ long, $15.0 \mathrm{~mm}$ in diameter on the larger end, and $12.5 \mathrm{~mm}$ in diameter on the smaller end, and the use is undetermined. From Feature 13, two bones contain marks similar to flaking on stone tools. It is unknown why these were cut in this fashion. Two other bones were recovered from Features 13 and 21 that exhibit deep scoring before breaking, as if the longer portion was removed for use.

Polished bone and other fragments $(\mathrm{n}=12)$ that displayed carved or worked areas not in the form of butchering patterns were recovered from many features. These exhibited modifications ranging from minimal markings or scratches to larger rounded or polished areas. The use of these pieces is undetermined. Most are from deer or elk and a couple possibly from larger avian animals, such as turkey (Figure 33.e).

A raccoon baculum was retrieved from Feature 22. Schilt reports a similar piece from previous excavations that was formed into a weaving tool or needle (1977: 101) and others have been identified at Gentleman Farm (Brown et al 1967: 33), Reeves (Martin and Richmond 1996: 9-31) and Fisher (Griffin 1946: 33, 60). However, the specimen from this assemblage does not show modifications or other markings other than possibly from disarticulation of the animal. 


\section{Other Bone}

Field notes from 1976 suggested human remains, perhaps from a child, may have been located in Feature 16, however none were located within that feature's materials. Two human elements were identified from Features 13 and 14. A human molar was identified with the Feature 13 faunal remains and was shaped with a fairly flat top, which was determined to be normal wear (A. Chipp-Stone, personal communication 2019). From Feature 14 a calcaneous bone of a foot was identified and removed from the faunal remains (A. Chipps-Stone and D. Cobb, personal communications 2019). No other human remains were identified, however it is the author's suggestion that further examination be conducted as this investigation was only cursory and not all remains were identification by species.

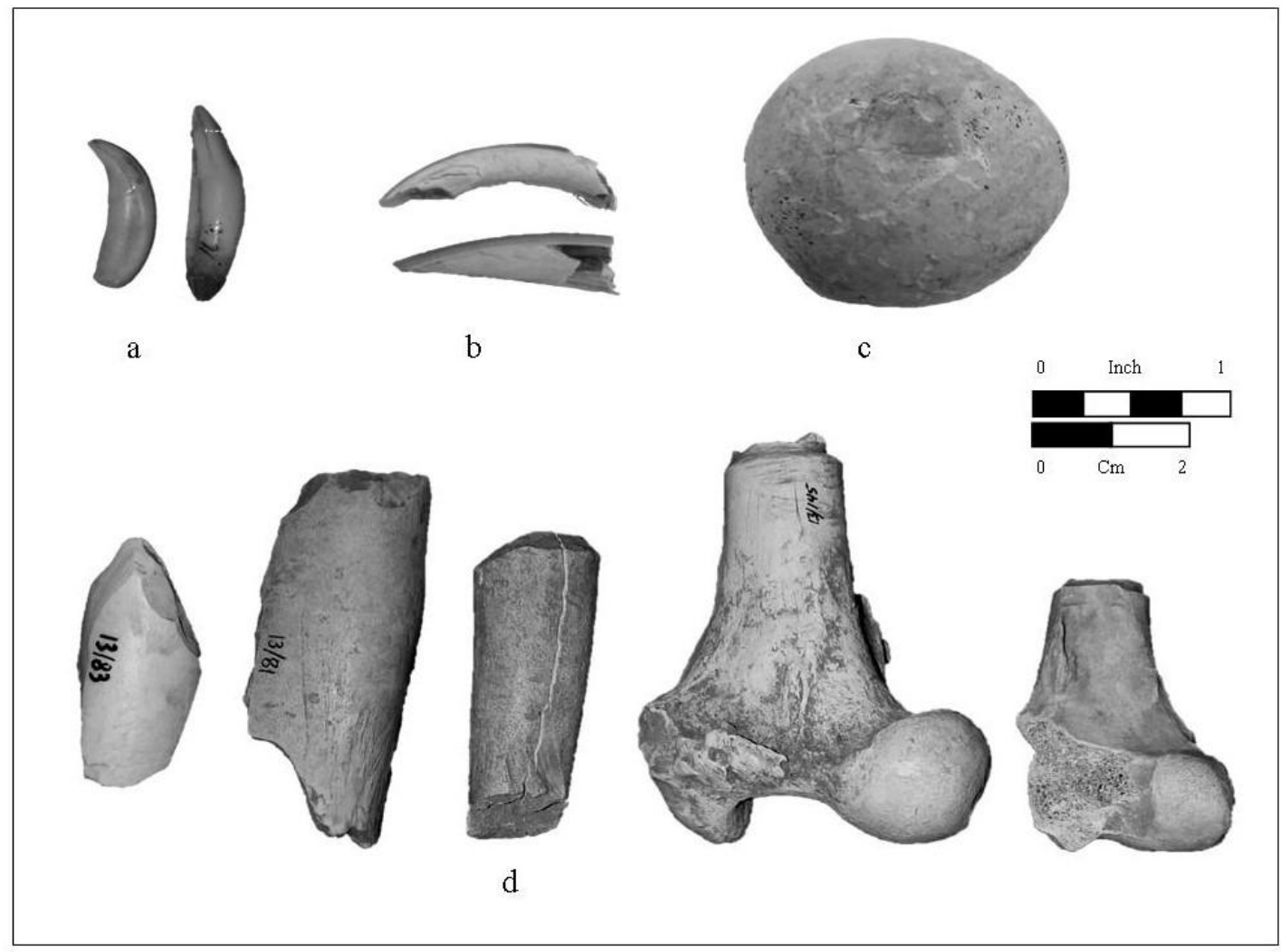

Figure 33. Teeth and Other Modified Bone. a. smoothed canine teeth, b. beaver teeth, c. femur ball, d. other modified bones. 


\section{Modified Shell}

Mussel shells were used for various functions, some as utilitarian spoons or scrapers and some as decorations as pendants. For this analysis no attempt was made to identify the species of shell, but instead focus was primarily on classification of possible use, comparison with previous shell artifacts recovered, and identification of possible Mississippian influence as represented in design elements.

Shell hoes were also recovered at the Langford sites of Keeshin (Penman 1999: 123) and Zimmerman (Brown 1961: 59).These implements were used for light digging or weeding as they were too fragile for deeper digging or extensive field work. A hole broken through the central area allowed for a stick or handle to be inserted. Schilt previously recorded one shell hoe at Noble-Wieting and this assemblage also produced one shell hoe from Feature 12A (Figure 34.a). This hoe measures $103.7 \mathrm{~mm}$ long, $68.3 \mathrm{~mm}$ wide, and $17.7 \mathrm{~mm}$ thick with a hole diameter of $17.0 \mathrm{~mm}$. Two shell halves and one piece, all from Feature 12A, display slightly rounded edges and may have been utilized as spoons or light scrapers. Similar shells spoons were identified by Schilt (1977) and also at the Keeshin site (Penman 1999: 123), Zimmerman (Brown 1961: 57), Gentleman Farm (Brown et al 1967: 34) and Reeves (Martin and Richmond 1996: 9-31).

Two round beads were carved from thick pieces of shell and found within Feature 12A (Figure 31.b). The larger bead measures approximately $11.1 \mathrm{~mm}$ diameter, $6.3 \mathrm{~mm}$ thick, and with a hole diameter of $2.6 \mathrm{~mm}$. The smaller bead is not as uniformly round with a diameter of 10.3 to $11.0 \mathrm{~mm}$, a thickness of $7.0 \mathrm{~mm}$, and a hole diameter of $2.5 \mathrm{~mm}$. Both are whitish in color. Three thin shell beads, one complete and two halves, were recovered from Feature 13 (Figure 34.c). The diameter of the completed bead measures $8.2 \mathrm{~mm}$ with a central hole diameter of $2.1 \mathrm{~mm}$ and a thickness of $3.6 \mathrm{~mm}$ tapering to $2.4 \mathrm{~mm}$. The other two, which are less than 
halves, are estimated at $7.5 \mathrm{~mm}$ diameter for the first and the second measures $6.8 \mathrm{~mm}$ long. Hole diameter for these are estimated at $2.5 \mathrm{~mm}$ and $2.0 \mathrm{~mm}$ respectively with thicknesses of .9 $\mathrm{mm}$ and $.6 \mathrm{~mm}$. Three shells that exhibited rounded edges and possible use were also recovered from Feature 12A.

A shell pendant was recovered from Feature 13 (Figure 34.d). This ornament is triangular in shape with a $2.9 \mathrm{~mm}$ hole drilled into the larger end and the piece measures $33.7 \mathrm{~mm}$ long and $13.1 \mathrm{~mm}$ wide. It is pearl in color on both sides. This is the first shell pendant identified from Noble-Wieting, but one was recovered at Gentleman Farm that was circular in shape with a drilled hole and found with one of the burials (Brown 1967: 58).

Three serrated shell pieces were obtained from Features 12A and 13 (Figure 34.e-f). These display different shapes, but all contain notches on one or more sides creating a serrated appearance. A rectangular piece from Feature 12A with notches on three sides measures 36.7 $\mathrm{mm}$ long, $15.7 \mathrm{~mm}$ wide, and $2.8 \mathrm{~mm}$ thick. Also from Feature 12A is a more rounded notched piece, notches on the rounded side, and measuring $25.9 \mathrm{~mm}$ long, $15.2 \mathrm{~mm}$ wide, and $4.0 \mathrm{~mm}$ thick. The third piece from Feature 13 is triangular in shape with notches on one side and measures $20.2 \mathrm{~mm}$ on the longest side, $15.3 \mathrm{~mm}$ wide, and $2.6 \mathrm{~mm}$ thick. One square cut piece of shell was also obtained from Feature 13 and measures $13.2 \mathrm{~mm}$ long, $13.8 \mathrm{~mm}$ wide, and $4.8 \mathrm{~mm}$ thick. In the 1976 assemblage, no shells appeared to be modified for use as spoons and none displayed carving, such as might show Mississippian exchange or cultural influence. Schilt recorded a "decorated shell spoon" (1977: 108) that displayed notches along one side and similar shells were recovered at Gentleman Farm (Brown et al 1967: 34), Reeves site (Martin and Richmond 1996: 9-31), and Zimmerman site (Brown 1961: 52). A summary of all modified shell for Noble-Wieting site 1966-1976 is found below (Table 14). 


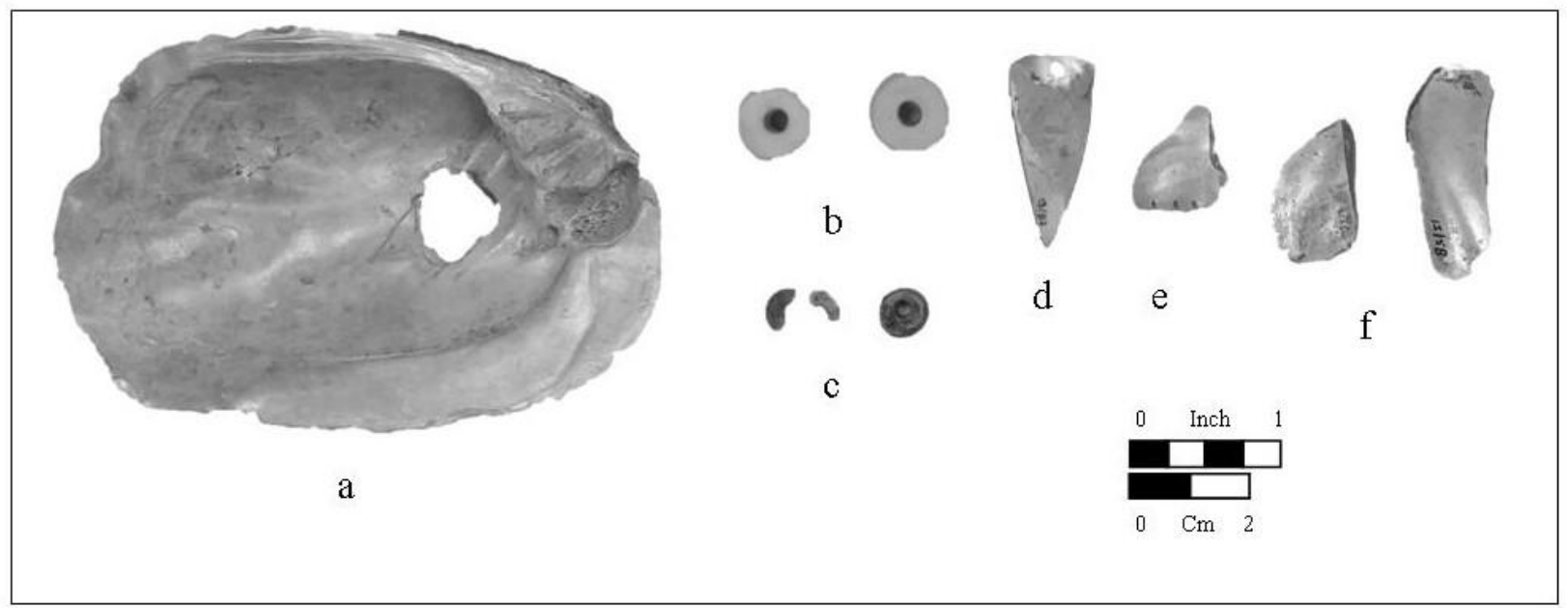

Figure 34. Shell Artifacts. a. shell hoe, b. thick shell beads, c. 2 bead fragments and 1 complete bead, d. pendant, e - f. serrated or notched shell.

\section{Fauna Compilation}

Features containing the most worked bone artifacts for this assemblage fall into the Classes designated as shallow trash pits, fire pits, or irregular features (ie. II, III, and VI). Feature $12(n=16)$ contained the most worked bone while Features $13(n=15)$ and $14(n=11)$ also contained many such artifacts. It was also noted that Feature 12 contained the most burned, butcher marked, and turtle remains. Earlier excavations analyzed by Schilt (1977) revealed deep trash pits and fire pits contained the majority of modified bone, but this analysis determined the shallower pits near the house structures to contain the most. Differences between the categories for the pieces may be from different researchers' viewpoints. However, an attempt was made to keep the designations in line with the previous report as well as with other site reports in order to assist with future research of Langford in general. Unusual pieces in this collection, such as smoothed canid teeth, were not located in previous reports of Langford sites and more research needs to be done in this area. A large database of all sites in Illinois and their complete assemblages would be ideal to assist researchers, however this is not available at this time. 
In comparison with previous excavations, faunal remains did not contain raccoon baculum awls, modified wolf or turtle remains, bone rings, cut scapula tools, and shell spoons identified previously. Modified bird bones in the form of awls or hooks were identified in 1976. Other modified tools were not identified by species, such as avians, but were included within the total for "modified fragments". New to the site's assemblage are bone beads, which had been calcified in heat, bone hooks that resemble those from Archaic and Woodland site formed in a "U" shape, and bones that were scored as if to remove the longer portion for use.

\section{Faunal Remains Conclusion}

Noteworthy is the absence of bison, elk, or deer scapula hoes at Noble-Wieting. Bison scapula hoes have been identified at Zimmerman (Brown 1961: 57) which has both Healy Complex and Langford components and at Oneota sites. Jeske (1990: 226) suggests the absence of bone hoes may indicate a difference in horticulture patterns between Oneota and Langford. Shell hoes, instead of bone hoes, appear to be the common gardening implement at Langford sites, although this tool appears to be somewhat fragile for intensive and large scale horticulture or agriculture. Cultivated crop remains have been identified (ie. corn, squash, and beans) and isotopic studies have shown Langford sites to be reliant on maize as a food source (Emerson et al, 2005: 100). Shell hoes may have been used for smaller garden areas or weeding around houses. It is apparent that there are opportunities for future experimental research that may assist in identifying prehistoric horticultural tools at this site, including tools that may not have weathered the test of time, such as wooden implements.

Abundance of large mammal remains at this site may determine more reliance on a meat based diet and thus the influence from Middle Mississippian culture for intensive maize production is not apparent. However, a detailed analysis of the botanical remains for Noble- 
Wieting has not been completed and botanical remains from the 1976 are not abundant. Researchers have also found through isotope analysis the maize production is higher than previously determined for Langford sites and future work at Noble-Wieting may also prove this (Emerson et al 2005).

Matting needles noted at Zimmerman (Brown 1961: 57) and tools found at Gentleman Farm, such as jaw sickles, decorated bone disks, and golf-tee shaped antler point (Brown et al 1967: 32) were not noted at Noble-Wieting in any of the excavations. Modified shell differed from previous excavations at this site with the recovery of a shell pendant and small shell fragments with notches along edges in this assemblage in the southern portion of the site excavated in 1976. Shell spoons were not identified within the 1976 assemblage, but a shell hoe is similar in appearance to those of other sites and within the 1966-1972 collection.

The artifacts from this and previous excavations are recovered from features of all classifications, with the most abundance located in trash pits or fire pits. It is noted that the 1976 artifacts were removed from shallow trash pits more often than the previous excavations' faunal artifacts, which were retrieved from deep trash pits and fire pits. This may be due to the excavation of only one deep trash pit and only two fire pits during the 1976 field work, while shallow trash pits were more common. In all excavations, artifacts or modified bone were not recovered as often from house features. A comprehensive map of artifact distribution in Chapter XI allows for a visual representation that may better clarify the locations of faunal artifacts.

As seen from this analysis, comparisons with modified faunal remains at other Langford sites are similar in nature. No specialized tools that can be identified as Middle Mississippian or those identified as ornamentation with religious symbols are found in this analysis. In conclusion, the faunal remains from the southern portion of the site are in alignment with 
Table 14

Modified Fauna Summary 1966-1976

(1966-1972 adapted from Schilt, 1977.)

\begin{tabular}{|c|c|c|c|c|c|c|}
\hline $\begin{array}{l}\text { Artifact Type } \\
\text { Antler and Bone: }\end{array}$ & $\begin{array}{c}1966- \\
1972 \\
\text { Total }\end{array}$ & $\begin{array}{l}\text { Feature } \\
\text { Classes }\end{array}$ & $\begin{array}{l}1976 \\
\text { Total }\end{array}$ & $\begin{array}{l}\text { Feature } \\
\text { Classes }\end{array}$ & Features & Totals \\
\hline Antler tines - detached & 10 & $\begin{array}{l}\text { I, III, } \\
\text { IV }\end{array}$ & 7 & I,II & $\begin{array}{l}\text { T18, F12, 13, } \\
17\end{array}$ & 17 \\
\hline Modified antler beams & 2 & III, IV & 7 & II, III & $\mathrm{F} 12,13,14$ & 9 \\
\hline Awls or needles & 6 & I, III & 2 & II, III & $\mathrm{F} 12,14$ & 8 \\
\hline Awl, turkey & 1 & I & & & & 1 \\
\hline Awl, raccoon penis bone & 1 & III & & & & 1 \\
\hline Beamers & 6 & $\begin{array}{l}\text { I, III, } \\
\text { VI }\end{array}$ & & & & 6 \\
\hline $\begin{array}{l}\text { Projectile points - bone and } \\
\text { antler }\end{array}$ & 3 & III, VI & & & & 3 \\
\hline Beaver tooth chisels/scrapers & 3 & $\mathrm{I}, \mathrm{PZ}$ & & & & 3 \\
\hline Cut wolf humerus & 1 & $\mathrm{I}$ & & & & 1 \\
\hline Polished turtle bone & 1 & I & & & & 1 \\
\hline Bone rings & 2 & $\mathrm{I}$ & & & & 2 \\
\hline Modified deer phalanges & 1 & VI & 3 & $\begin{array}{l}\text { II, III, } \\
\text { IV }\end{array}$ & $\mathrm{F} 13,14,21$ & 4 \\
\hline Elk femur ball & 1 & III & 1 & IV & $\mathrm{F} 21$ & 2 \\
\hline Cut scapula tool & 3 & I & & & & 3 \\
\hline Modified bird bones & 2 & I, III & & & & 2 \\
\hline Counters/gaming pieces & 5 & I, III & 4 & II, III & $\mathrm{F} 12,13,14$ & 9 \\
\hline Bone - modified fragments & 7 & I, III & 12 & $\begin{array}{l}\text { I, II, } \\
\text { III, }\end{array}$ & $\begin{array}{l}\text { F12, 13, 14, } \\
17,19\end{array}$ & 19 \\
\hline Bone hooks & & & 5 & II & $\mathrm{T} 18$ \& F12, 13 & 5 \\
\hline Bone - scored or shaped & & & 5 & II & $\mathrm{F} 12,13,20$ & 5 \\
\hline Smoothed canid teeth & & & 2 & III & F14 & 2 \\
\hline \multicolumn{7}{|l|}{ Shell: } \\
\hline Shell hoe & 1 & III & 1 & II & F12 & 2 \\
\hline Decorated spoon & 1 & III & & & & 1 \\
\hline Shell scrapers & 11 & I, III & 3 & II & F12 & 14 \\
\hline Shell - modified fragments & 5 & I, III & 4 & II & F12 \& F13 & 9 \\
\hline Shell pendant & & & 1 & II & F13 & 1 \\
\hline Shell beads & & & 5 & II & F12 \& F13 & 5 \\
\hline Totals & 73 & & 62 & & & 135 \\
\hline
\end{tabular}


previous results and present no more display of interaction or influence from Middle Mississippian culture than found earlier at the site. The modified remains in the 1976 assemblage are similar to those reported for other Langford sites and with no more variation, thus suggesting cultural identity as Langford was not changing or faunal remains were created and used in similar manners by different groups of peoples, including Late Woodland and Middle Mississippian. 


\section{CHAPTER XI: ARTIFACT DISTRIBUTION}

This chapter examines spatial patterning in the distribution of material culture for all features excavated from 1966-1976. The site map created for all features excavated, as seen in Figure 22, not only gives an overview of the features' relations to each other, but allows for a better understanding of artifact distribution across all of the site excavations up to and including 1976. Data presented in Chapter VI for the 1976 features with information from previous excavations is combined in this chapter in an attempt to provide an interpretation of the relationships between features. The goal of this distributional analysis is primarily to gain insight into the patterning of cultural material at the site and to observe how artifacts with possible Mississippian influence are distributed. The results of this combination of data will serve as a baseline for future excavations.

Even though vertical distribution of artifacts was recorded in 1976, as in Schilt's 1977 report vertical distribution is not considered in this report as the site has not been determined to have various occupations of different phases or cultures. Spatial distribution is recorded in tables presented in this chapter for each type of artifact and then also provided in a visual format on excavation maps for selected artifact types. While features are the primary consideration and even though surface and trenches may have had material repositioned or deposited through environmental or external factors such as deep plow agricultural techniques, the latter are included in the tables so all artifact finds are represented. The trenches are not, however, included in the distribution maps. As in previous excavations, not all the features in 1976 were completely excavated due to time constraints. In fact, out of the 12 features identified, only 5 were completely excavated and include Features $12,14,17,22$, and 23 . A sixth, the house Feature 18 only was brought down to the sterile soil level of 2.1 to 2.3 feet in the north-west 
quadrant. Therefore, it should be noted that interpretation of all features are considered superficial for the majority of the features excavated as it is unknown the final outcome of the material distribution if the entirety of all the features had been excavated.

\section{Distribution of Materials}

This discussion regarding cultural material distributions is divided into the three sections of lithics, ceramics, and fauna with further discussion of artifact types within each class. Maps show only the presence or absence of material where the presence is noted by shading and referenced with a legend. As in previous maps, burials are not included. Further discussion regarding feature use and relationships and artifact distribution is offered later in this chapter.

\section{Lithics Distribution}

Chipped stone and/or ground stone artifacts were recovered from all 1976 features except Features 19, 20 and 23. All features contained waste flakes or shatter from lithic production. It should be noted that sample size may be determinate on the size and extent of excavation of each feature. For instance, Feature 12 had a high frequency of material, but was also one of the few features completely excavated. The greatest abundance collectively of Madison projectile points and humpback knives $(n=48 ; 44 \%)$ were recovered from Feature 12 , as compared to the other features, and the second most abundance $(n=25 ; 23 \%)$ from surface and trench areas. House Feature 18 had the third most abundance with $13 \%(n=14)$. The least amounts came from features that were partially excavated or from pits that contained more gravel, such as Feature 22. This pattern of distribution was also seen for waste flakes and ochre. Fire-cracked rock was most abundant in two pits, Features 13 and 14, which contained 56\% (n=9) of the total amount recovered and not within house Feature 18's hearth region, which could signify outdoor cooking 
as opposed to indoor. The small sample size of fire cracked rock may greatly sway the percentages, however.

From all excavations, 1966-1976, the Class II shallow pits or middens contained the most lithic materials $(\mathrm{n}=1,673 ; 29 \%)$. Surface surveys and trenches that may or may not have been located over features also presented a large amount of lithic material $(\mathrm{n}=1,230 ; 21 \%)$, which could be interpreted as showing movement of artifacts from environmental or agricultural mechanics. Specialized artifacts, such as knives or perforators, were located within pits as opposed to in house features and waste flakes were more commonly found in pits than houses, perhaps indicating work was done outside near pits.

Table 15

Lithics Distribution 1976

\begin{tabular}{|c|c|c|c|c|c|c|c|c|c|c|c|c|c|c|}
\hline \multirow[b]{3}{*}{ Types } & \multicolumn{14}{|c|}{ Class and Feature: } \\
\hline & II & II & III & IV & II & I & IV & II & II & IV & VI & III & Surface/ & \\
\hline & 12 & 13 & 14 & 15 & 16 & 17 & 18 & 19 & 20 & 21 & 22 & 23 & Trenches & Totals \\
\hline \multicolumn{15}{|l|}{ Chipped Stone } \\
\hline $\begin{array}{l}\text { Madison Projectiles - } \\
\text { Completes }\end{array}$ & 18 & 0 & 5 & 0 & 0 & 0 & 10 & 0 & 0 & 0 & 1 & 0 & 10 & 44 \\
\hline $\begin{array}{l}\text { Madison Projectiles - } \\
\text { Proximals }\end{array}$ & 9 & 6 & 1 & 0 & 0 & 1 & 2 & 0 & 0 & 0 & 0 & 0 & 5 & 24 \\
\hline Side-notched Points & & & 2 & & & & & & & & & & & 2 \\
\hline Point distal tips & 3 & & & & 1 & 1 & 1 & & & 1 & & & 6 & 13 \\
\hline Knives & 1 & & 1 & & & & & & & & & & 2 & 4 \\
\hline Knives - humpbacked & 21 & 5 & 2 & & & & 2 & & & & & & 10 & 40 \\
\hline Scrapers - Uniface & & & & & & & & & & & & & 2 & 2 \\
\hline Scrapers - Biface & 2 & & 1 & & & 1 & 1 & & & & & & 3 & 8 \\
\hline Retouched flakes & & & 1 & & & & 1 & & & & & & 2 & 4 \\
\hline Perforators & 1 & & 1 & & & & 1 & & & & & & & 3 \\
\hline $\begin{array}{l}\text { Cores } \\
\text { Waste Flakes and }\end{array}$ & 3 & 1 & 1 & & 2 & & 2 & & 3 & & & & 5 & 17 \\
\hline Shatter & 740 & 440 & 235 & 50 & 91 & 236 & 225 & 18 & 44 & 36 & 52 & 10 & 323 & 2500 \\
\hline Subtotals: & 798 & 452 & 250 & 50 & 94 & 239 & 245 & 18 & 47 & 37 & 53 & 10 & 368 & 2661 \\
\hline
\end{tabular}

(Table Continues) 
(Table 15, Continues)

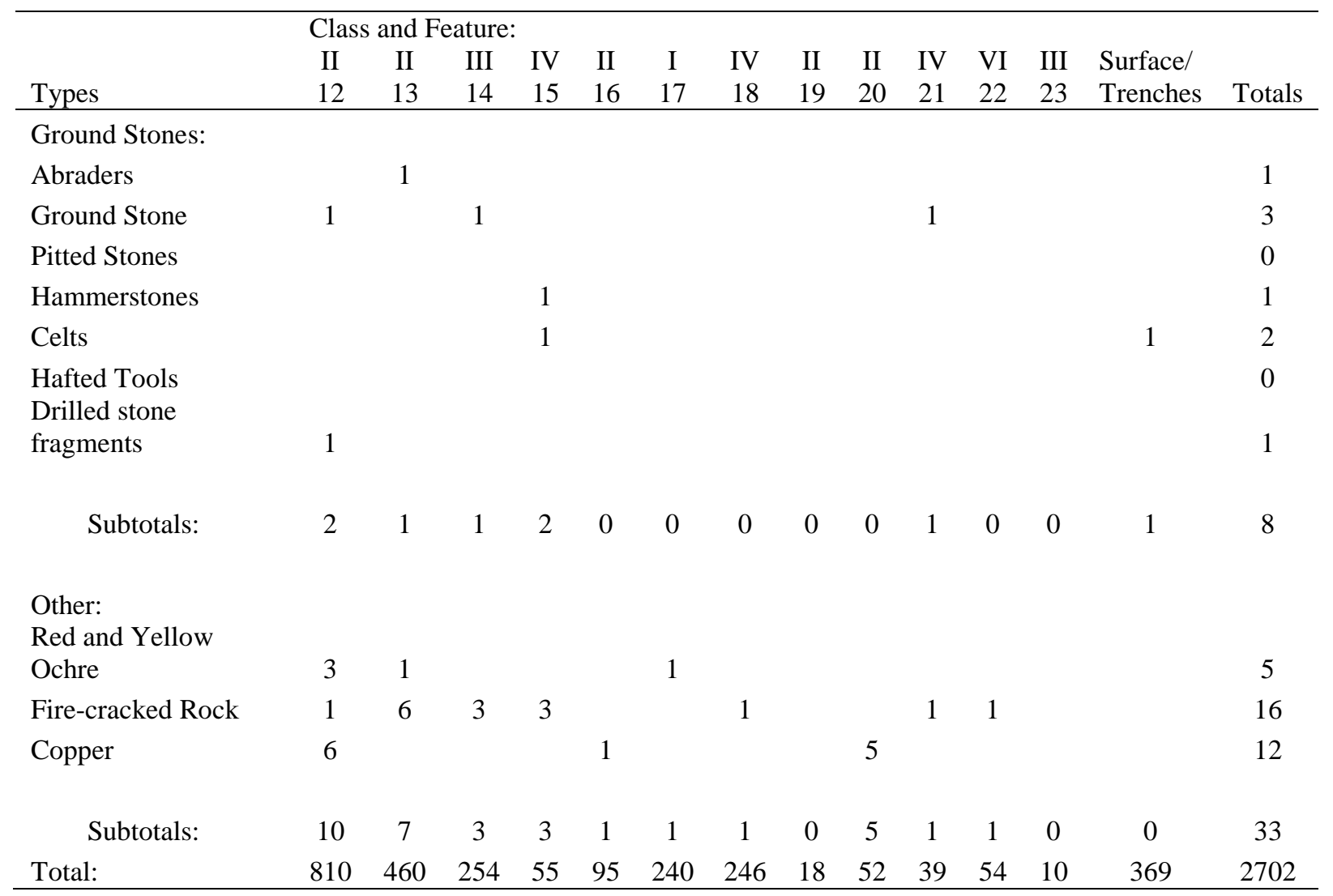

Table 16

Lithics Distribution Summary 1966-1976

(1966-1972 adapted from Schilt, 1977: Tables 10, 11 \& 14.)

\begin{tabular}{|c|c|c|c|c|c|c|c|c|}
\hline Types & $\begin{array}{c}\text { Classes: } \\
\text { I }\end{array}$ & II & III & IV & V & $\begin{array}{c}\text { Misc/ } \\
\text { VI }\end{array}$ & $\begin{array}{l}\text { Surface/ } \\
\text { Trenches }\end{array}$ & Totals \\
\hline Madison Projectiles - & & & & & & & & \\
\hline Complete & 9 & 19 & 9 & 17 & & 5 & 14 & 73 \\
\hline Madison Projectiles - & & & & & & & & \\
\hline Proximal & 15 & 16 & 9 & 4 & & 5 & 8 & 57 \\
\hline Side-notched Points & & & 3 & & & & & 3 \\
\hline Point distal tips & 9 & 4 & 6 & 4 & & 4 & 6 & 33 \\
\hline Knives & 2 & 2 & 2 & 1 & & 1 & 3 & 11 \\
\hline Knives - humpbacked & 5 & 26 & 4 & 4 & & 1 & 11 & 51 \\
\hline Scrapers - Uniface & 2 & 1 & 1 & 1 & & 3 & 4 & 12 \\
\hline Scrapers - Biface & 2 & 3 & 3 & 1 & & 1 & 7 & 17 \\
\hline
\end{tabular}


(Table 16, Continues)

\begin{tabular}{|c|c|c|c|c|c|c|c|c|}
\hline Types & $\begin{array}{c}\text { Classes: } \\
\text { I }\end{array}$ & II & III & IV & V & $\begin{array}{c}\text { Misc/ } \\
\text { VI }\end{array}$ & $\begin{array}{l}\text { Surface/ } \\
\text { Trenches }\end{array}$ & Totals \\
\hline Retouched flakes & 15 & 2 & 3 & 7 & & 4 & 11 & 42 \\
\hline Perforators & 6 & 1 & 3 & 3 & & 1 & & 14 \\
\hline Cores & 4 & 11 & 2 & 6 & & 2 & 8 & 33 \\
\hline Waste Flakes and Shatter & 1101 & 1550 & 592 & 653 & 4 & 297 & 1152 & 5349 \\
\hline Abraders & 1 & 1 & 1 & & & & & 3 \\
\hline Celts & & & 1 & 1 & & & 1 & 3 \\
\hline Drilled Stone Fragments & & 2 & & 3 & & & 1 & 6 \\
\hline Groundstones & & 1 & 1 & 1 & & & & 3 \\
\hline Fire-cracked Rock & 6 & 16 & 10 & 7 & & 3 & & 42 \\
\hline Limestone Pendants & & & 1 & & & & & 1 \\
\hline Pitted Stones & 1 & & 1 & & & & & 2 \\
\hline Hammerstones & 1 & 1 & 2 & 3 & & & 1 & 8 \\
\hline Hafted Tools & 1 & & & & & & 1 & 2 \\
\hline Unfinished Implements & & & 1 & & & & & 1 \\
\hline Mano fragments & 2 & 1 & 3 & 1 & & 2 & 2 & 11 \\
\hline Whetstone & & & 1 & & & & & 1 \\
\hline Red and Yellow Ochre & 1 & 4 & & 1 & & 1 & & 7 \\
\hline Copper & 1 & 12 & & & & & & 13 \\
\hline Totals: & 1184 & 1673 & 659 & 718 & 4 & 330 & 1230 & 5798 \\
\hline
\end{tabular}




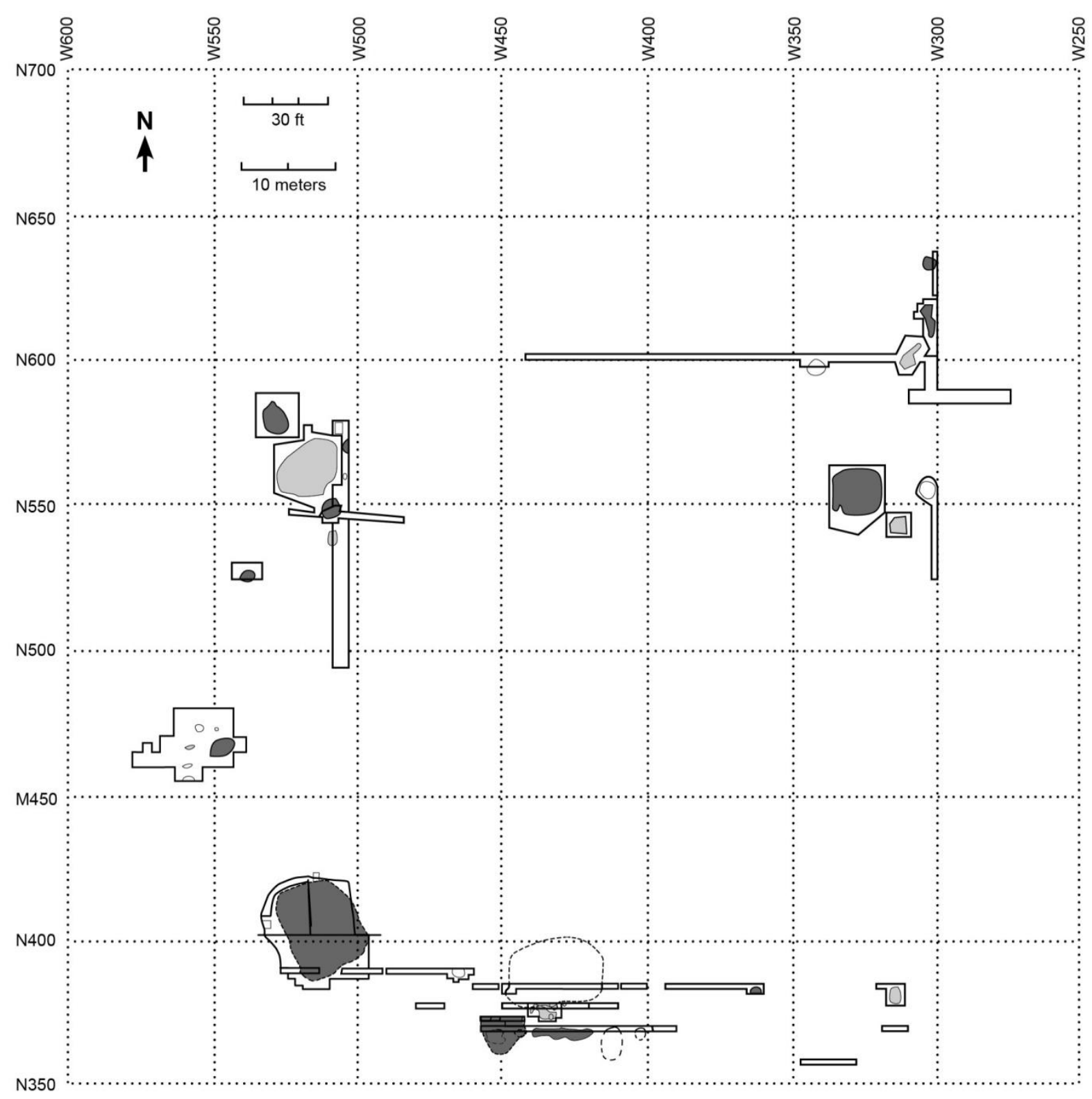

\section{LEGEND}

*Note: There were no excavation areas that contained only Humpback Knives.
Madison Points

Only
Both Madison Points and Humpback Knives

Figure 35. Distribution of Madison Points and Humpback Knives. (1966-1972 distribution adapted from Schilt, 1977.) 


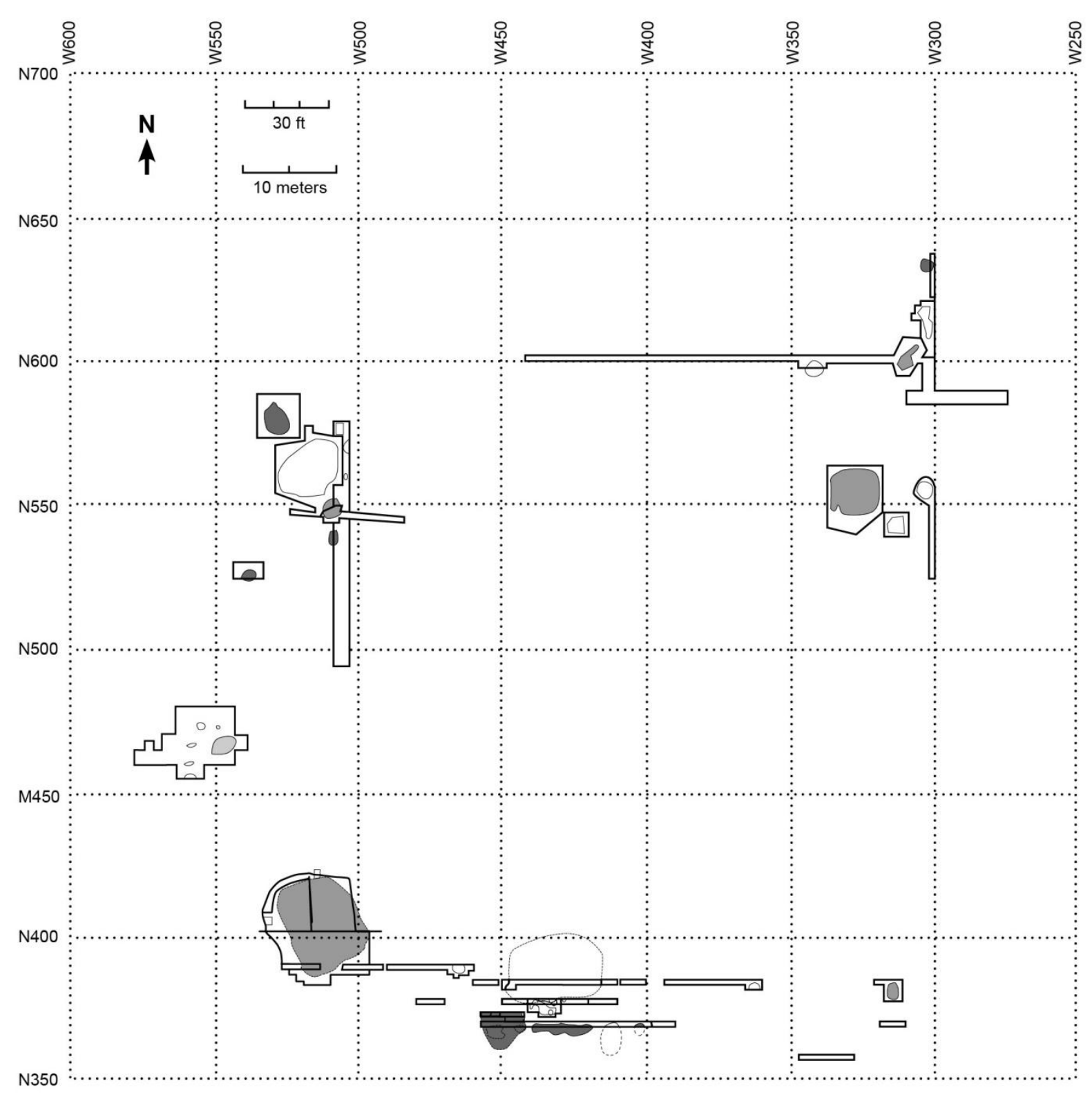

\section{LEGEND}

Knives (non-Humpback)

Scrapers

Both Knives (non-Humpback) and Scrapers

Figure 36. Distribution of Knives (non-Humpbacks) and Scrapers. (1966-1972 distribution adapted from Schilt, 1977.) 


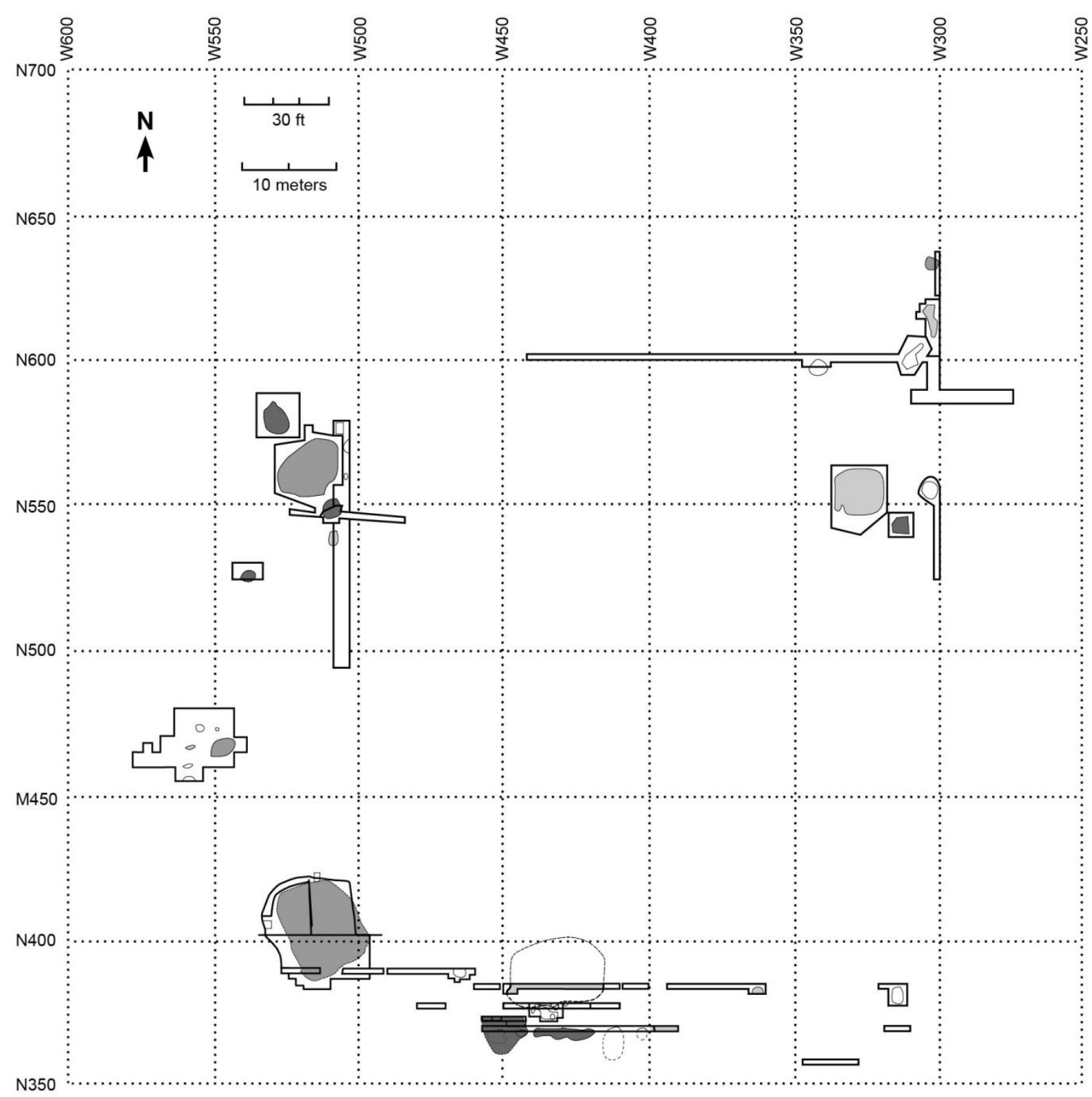

\section{LEGEND}

$\square$ Stones $\square$ Perforators $\square \begin{aligned} & \text { Both Ground Stones } \\ & \text { and Perforators }\end{aligned}$

Figure 37. Distribution of Ground Stones and Perforators. (1966-1972 distribution adapted from Schilt, 1977.) 


\section{Ceramics Distribution}

Ceramics were recovered from all features in 1976. The most abundant ceramics are Langford Plain sherds, accounting for $74 \%(\mathrm{n}=1,458)$ of the ceramic sherds, were recovered from all features. Langford sherds in general accounted for $85 \%(\mathrm{n}=1,691)$ of the ceramics. Middle Mississippian style shell tempered sherds represented 14\% $(\mathrm{n}=285)$ and were also found in almost all of the features with the exception of Features 19 and 22. This co-occurrence of Langford and Middle Mississippian pottery is noted by Schilt in earlier excavations as well $(\mathrm{n}=$ 1977: 161). From the 1976 excavations, the majority of sherds were found in Class II and III, shallow pits and fire pits, as well as on the surface or in trenches. Langford sherds Bold and Trailed sherds were only recovered from four of the features, while cordmarking on Langford sherds was noted in all but the three Features 15, 21, and 23. These three features were small and partial excavations, so it cannot be assumed that cordmarking would not have been found within them if these had been fully excavated. The largest vessel fragment, recovered from Feature 18 exhibits vertical cordmarking. It is undetermined if other Langford Cordmarked sherds in this assemblage were vertical or horizontal markings.

As with the 1976 lithic assemblage, the small sample size of ceramics and the fact that not all features were completely excavated should be taken into consideration when interpreting the types of features and the amount of materials recovered from each class. In 1976, the Class I deep pit features were only represented by Feature 17 and was the class that contained the least amount of ceramics overall. Specialized pieces of ceramics, such as discs or shaped pieces, were only located in Class II shallow pit features. Daub was retrieved from the 1976 excavated house Feature 18, but does not present large amounts by count or by weight along the wall trenches, 
thereby suggesting this method of wall construction was not used extensively at this site. It was noted that the majority $(n=36 ; 61 \%)$ of burnt clay was found in house Feature 18.

For all excavations 1966-1976, Langford series pottery represented 79\% $(\mathrm{n}=4,318)$

recovered and Middle Mississippian series sherds represented the remaining 21\% $(\mathrm{n}=1130)$. Langford Plain $(\mathrm{n}=3,492 ; 64 \%)$ and Mississippian Cordmarked $(\mathrm{n}=725 ; 13 \%)$ were the most abundant types within each series respectively.

Table 17

Ceramic Distribution 1976

\begin{tabular}{|c|c|c|c|c|c|c|c|c|c|c|c|c|c|c|}
\hline \multirow[b]{3}{*}{ Ceramic Type } & \multicolumn{14}{|c|}{ Class and Feature: } \\
\hline & II & II & III & IV & II & I & IV & II & II & IV & VI & III & Surface/ & \\
\hline & 12 & 13 & 14 & 15 & 16 & 17 & 18 & 19 & 20 & 21 & 22 & 23 & Trench & Total \\
\hline \multicolumn{15}{|l|}{ Body Sherds: } \\
\hline Shell & 72 & 56 & 43 & 1 & 23 & 9 & 26 & & 4 & 11 & & 2 & 25 & 272 \\
\hline shell and mafic & 1 & & & & & & 1 & & & & & & 5 & 7 \\
\hline grit/mafic & 762 & 155 & 249 & 4 & 45 & 33 & 77 & 12 & 48 & 18 & 30 & 4 & 163 & 1600 \\
\hline grit/mafic/sand & & & & & & 1 & 1 & & 1 & & & & & 3 \\
\hline Untempered & 2 & & 1 & & & 1 & 1 & & 1 & & & & & 6 \\
\hline Mini-Vessels & 7 & 4 & 1 & & 1 & 1 & & & & & & & & 14 \\
\hline \multicolumn{15}{|l|}{ Rims: (standard) } \\
\hline Shell & 5 & 1 & 1 & & 2 & 1 & 3 & & & & & & 3 & 16 \\
\hline grit/mafic & 48 & 13 & 16 & & 1 & 2 & 7 & 1 & 2 & 3 & 2 & 1 & 14 & 110 \\
\hline Untempered & & & & & & & & & & & & & 1 & 1 \\
\hline Sherd lets & 192 & 33 & 67 & 1 & 13 & 20 & 12 & & 5 & 4 & 114 & & 22 & 483 \\
\hline Unburned/tempered & 6 & & 5 & & 1 & & & & & 3 & & & 2 & 17 \\
\hline Burnt clay & 3 & 1 & 10 & & & 1 & 36 & 2 & 1 & & & 1 & 4 & 59 \\
\hline Daub & 3 & 3 & 7 & & & & & & & 2 & & & 3 & 18 \\
\hline Perforated Discs & & 1 & & & 1 & & & & & & & & & 2 \\
\hline Handle/Lug & & & & & 1 & & & & & & & & & 1 \\
\hline Effigy & & & & & & & & & & & & & 1 & 1 \\
\hline Shaped Clay & 1 & 1 & & & & & & & 1 & & & & & 3 \\
\hline Totals: & 1102 & 268 & 400 & 6 & 88 & 69 & 164 & 15 & 63 & 41 & 146 & 8 & 243 & 2613 \\
\hline
\end{tabular}


Table 18

Decorative Elements Distribution by Feature Class 1976

\begin{tabular}{lcccccccc}
\hline & \multicolumn{2}{l}{ Classes: } & \multicolumn{3}{c}{ Surface/ } \\
Design Elements: & I & II & III & IV & V & VI & Trench & Total \\
\hline Late Woodland notched rim & & 1 & & & & & & 1 \\
& & & & & & & & \\
Langford Plain & 32 & 910 & 235 & 98 & & 28 & 155 & 1458 \\
Langford Bold & & 4 & 4 & 0 & 0 & 3 & 11 \\
Langford Trailed & & 8 & 2 & 1 & 0 & 2 & 13 \\
Langford Cordmarked & 3 & 146 & 21 & 9 & 4 & 13 & 196 \\
Unclassified Langford eroded & & 2 & 5 & 0 & 0 & 6 & 13 \\
Mississippian Plain & 7 & 67 & 18 & 11 & 0 & 20 & 123 \\
Mississippian Incised & & 0 & 0 & 0 & 0 & 1 & 1 \\
Mississippian Cordmarked & 3 & 86 & 27 & 18 & 0 & 5 & 139 \\
Unclassified Mississippian eroded & & 6 & 2 & 12 & 0 & 2 & 22 \\
Totals: & 45 & 1230 & 314 & 149 & 0 & 32 & 207 & 1977 \\
\hline
\end{tabular}

Table 19

Decorative Elements by Feature 1976

\begin{tabular}{|c|c|c|c|c|c|c|c|c|c|c|c|c|c|c|}
\hline \multirow[b]{3}{*}{ Design elements: } & \multicolumn{14}{|c|}{ Class and Feature: } \\
\hline & II & II & III & IV & II & I & IV & II & II & IV & VI & III & Surface/ & \\
\hline & 12 & 13 & 14 & 15 & 16 & 17 & 18 & 19 & 20 & 21 & 22 & 23 & Trench & Total \\
\hline $\begin{array}{l}\text { Late Woodland } \\
\text { notched rim }\end{array}$ & 1 & & & & & & & & & & & & & 1 \\
\hline Langford Plain & 682 & 134 & 231 & 4 & 41 & 32 & 74 & 12 & 41 & 20 & 28 & 4 & 155 & 1458 \\
\hline Langford Bold & 4 & & 3 & & & & & & & & & 1 & 3 & 11 \\
\hline Langford Trailed & 6 & & 2 & & & & 1 & & 2 & & & & 2 & 13 \\
\hline Langford Cordmarked & 105 & 28 & 21 & & 5 & 3 & 9 & 1 & 7 & & 4 & & 13 & 196 \\
\hline $\begin{array}{l}\text { Unclassified Langford } \\
\text { eroded }\end{array}$ & 2 & & 5 & & & & & & & & & & 6 & 13 \\
\hline Mississippian Plain & 39 & 21 & 16 & 1 & 4 & 7 & 9 & & 3 & 1 & & 2 & 20 & 123 \\
\hline $\begin{array}{l}\text { Mississippian Incised } \\
\text { Mississippian }\end{array}$ & & & & & & & & & & & & & 1 & 1 \\
\hline Cordmarked & 35 & 31 & 27 & & 19 & 3 & 11 & & 1 & 7 & & & 5 & 139 \\
\hline $\begin{array}{l}\text { Unclassified } \\
\quad \text { Mississippian eroded }\end{array}$ & 1 & 5 & 2 & & & & 9 & & & 3 & & & 2 & 22 \\
\hline Totals: & 875 & 219 & 307 & 5 & 69 & 45 & 113 & 13 & 54 & 31 & 32 & 7 & 207 & 1977 \\
\hline
\end{tabular}


Table 20

Ceramic Decorative Elements Summary 1966-1976

(1966-1972 adapted from Schilt, 1977: Table 15.)

\begin{tabular}{lccc}
\hline & 1976 & $1966-1972$ & Total \\
Series and Type & Total & Totals & All Years \\
\hline Langford Plain & 1458 & 2034 & 3492 \\
Langford Bold & 11 & 3 & 14 \\
Langford Trailed & 13 & 25 & 38 \\
Langford Cordmarked & 196 & 481 & 677 \\
Langford Noded & 0 & 1 & 1 \\
Pigment/Painted & 6 & 0 & 6 \\
Unclassified Langford eroded & 13 & 77 & 90 \\
Subtotal Langford Series: & 1697 & 2621 & 4318 \\
Mississippian Plain & 123 & 182 & 305 \\
Mississippian Incised & 1 & 0 & 1 \\
Mississippian Cordmarked & 139 & 586 & 725 \\
Mississippian Lobed & 0 & 1 & 1 \\
Pigment/Painted & 1 & 5 & 6 \\
Unclassified Mississippian eroded & 22 & 70 & 92 \\
Subtotal Mississippian Series: & 286 & 844 & 1130 \\
Total Decorated Sherds & 1983 & 3465 & 5448 \\
(Note: 1976 sand and shell/grit are combined with grit sherds, lugs are not recorded.) \\
\hline
\end{tabular}




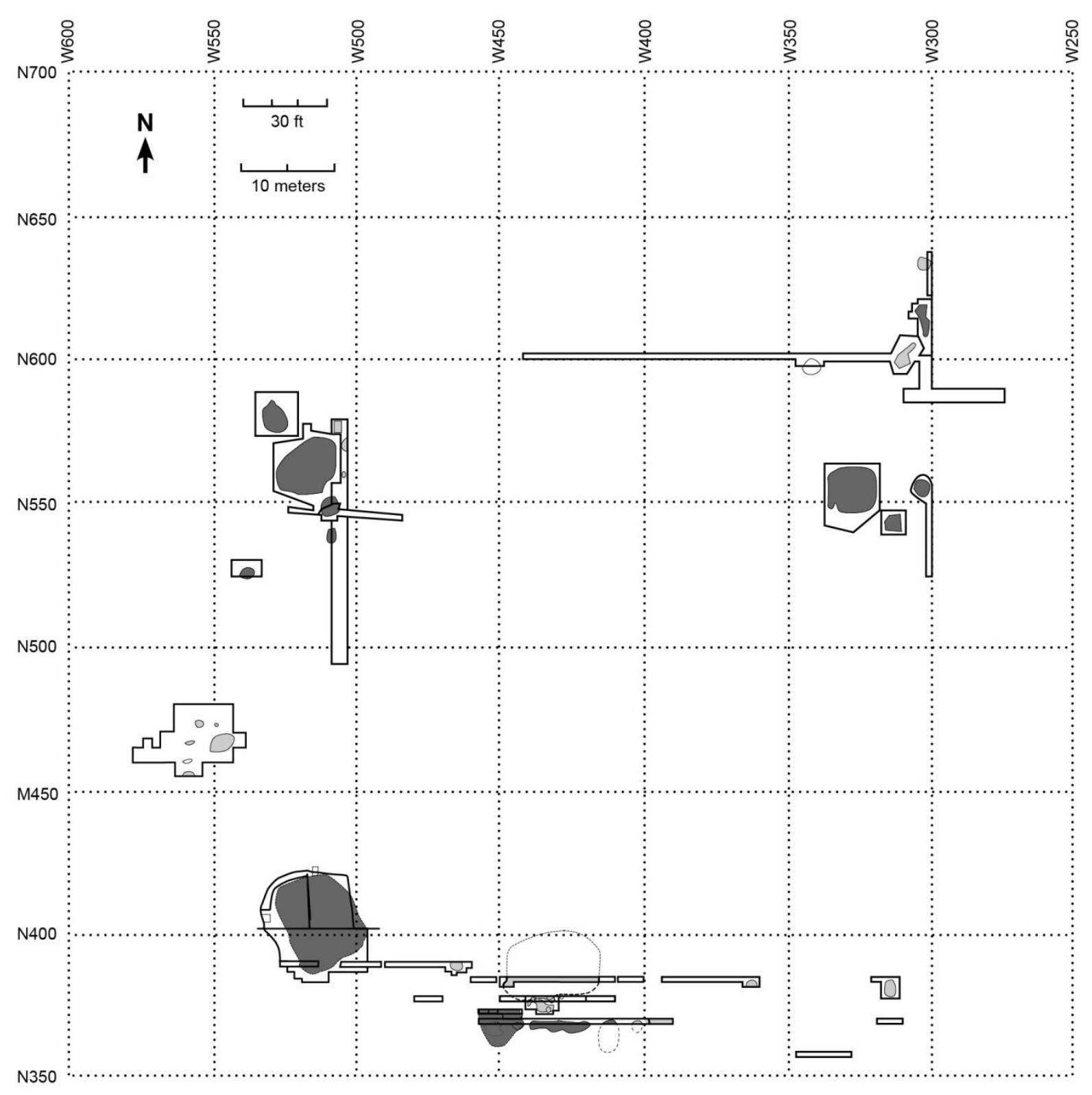

\section{LEGEND}

Either Langford Plain or Cordmarked Only
Either Langford Bold

or Trailed Only
Langford Plain, Cordmarked,

Bold, and Trailed Combined

Figure 38. Distribution of Langford Series Ceramics. (1966-1972 distribution adapted from Schilt, 1977.) 


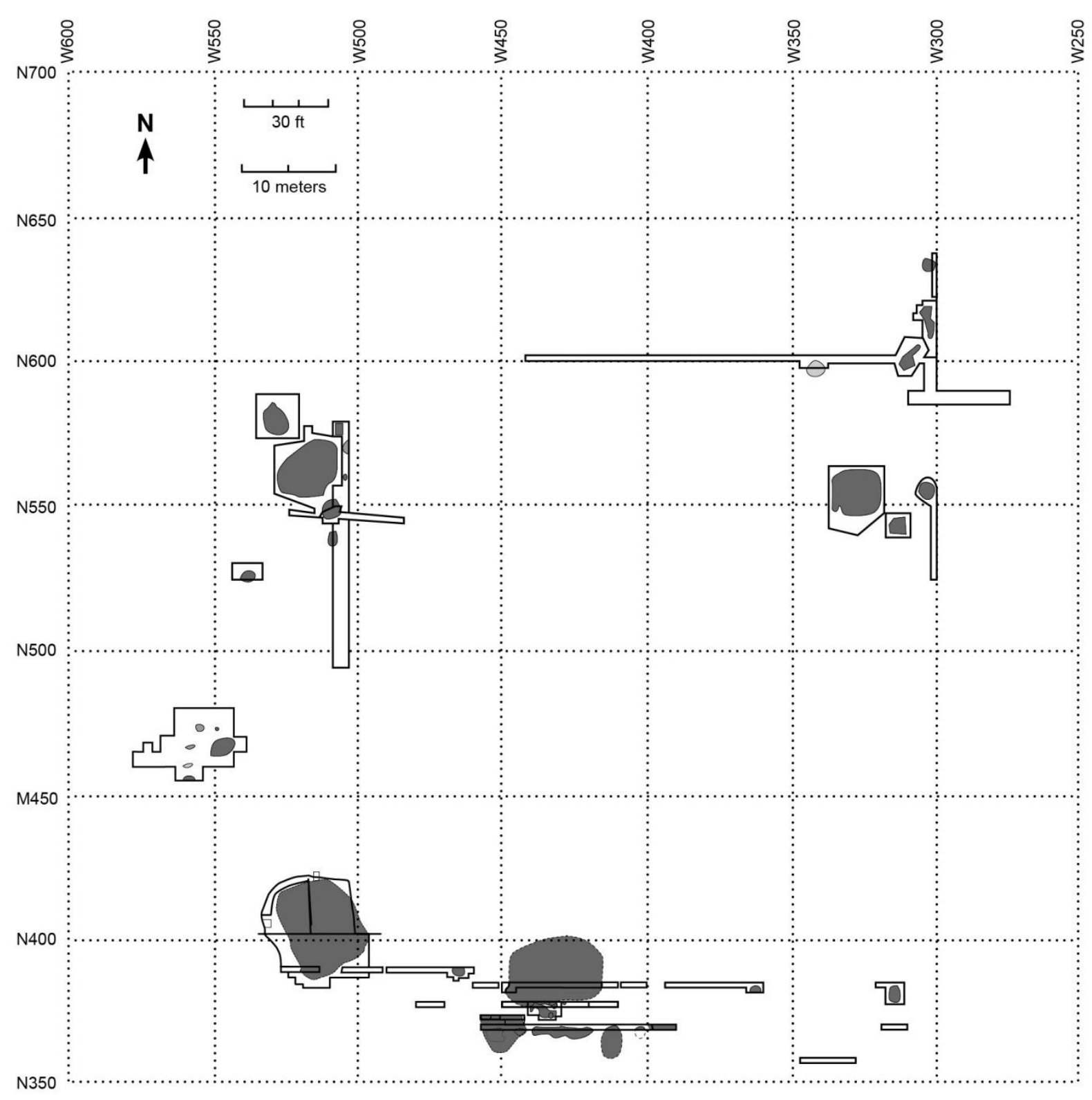

\section{LEGEND}

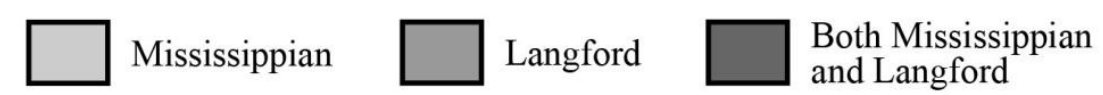

Figure 39. Distribution of Mississippian Series and Langford Series Ceramics. (1966-1972 distribution adapted from Schilt, 1977.) 


\section{Faunal Distribution}

The majority of worked bone, antler, or shell artifacts from 1976 excavations were retrieved from Features 12, 13, and $14(\mathrm{n}=53 ; 85 \%)$, with Class II shallow pit features containing the majority of these types of artifacts $(n=44 ; 71 \%)$. Feature 12 contained the most modified fauna of all the features $(n=22 ; 35 \%)$. None of the modified faunal remains were found within house Features 15 or 18 and low amounts were found on the surface and trenches $(\mathrm{n}=3 ; 5 \%)$. This latter fact deviates from the distribution of lithics and ceramics of which higher amounts were found on the surface and in trenches, as noted earlier, and is most likely due to the differential in preservation of bone exposed to the open environment. Modified shells were recovered from only two features of 12 and 13, both of which were Class II shallow pits. This also held true for the summary of all excavations, 1966-1972, which shows that Classes I deep pits, Class II shallow pits, and Class III pits with fired areas contained modified shell, but none was found within house features, burials, or in the miscellaneous feature Class VI. None of the faunal pieces can be determined to possess influence from external Middle Mississippian culture. Due to time constraints, the unmodified faunal remains from 1976 were not counted or weighed for the features and it is unknown which features contained the most overall.

Human remains were minimal in the 1976 distribution with only two fragments found within the faunal remains of pit features. The mound and surrounding area was not excavated further and while one possible burial of a child was suggested within the notes for Feature 16, no bones were identified from this feature as human. 
Table 21

1976 Modified Faunal Distribution

\begin{tabular}{|c|c|c|c|c|c|c|c|c|c|c|c|c|c|c|}
\hline \multirow[b]{3}{*}{ Fauna Type } & \multicolumn{14}{|c|}{$\begin{array}{l}\text { Class and } \\
\text { Feature: }\end{array}$} \\
\hline & II & II & III & IV & II & $\mathrm{I}$ & IV & II & II & IV & VI & III & Surface/ & \\
\hline & 12 & 13 & 14 & 15 & 16 & 17 & 18 & 19 & 20 & 21 & 22 & 23 & Trenches & Totals \\
\hline \multicolumn{15}{|l|}{ Bone and Antler: } \\
\hline $\begin{array}{l}\text { Detached antler } \\
\text { tines }\end{array}$ & 4 & 1 & & & & 1 & & & & & & & 1 & 7 \\
\hline Modified antler & & & & & & & & & & & & & & \\
\hline beams & 2 & 3 & 1 & & & & & & & & & & 1 & 7 \\
\hline Gaming piece & 2 & 1 & 1 & & & & & & & & & & & 4 \\
\hline Modified phalanges & 1 & & 1 & & & & & & & 1 & & & & 3 \\
\hline Awls or Needles & 1 & & 1 & & & & & & & & & & & 2 \\
\hline Bone hooks & 2 & & & & & & & & & & & & & 2 \\
\hline \multicolumn{15}{|l|}{ Bone "U" shape } \\
\hline hook & & 2 & & & & & & & & & & & 1 & 3 \\
\hline Modified teeth & & & 2 & & & & & & & & & & & 2 \\
\hline Modified fragments & 2 & 7 & 5 & & & 1 & & 1 & 1 & & & & & 17 \\
\hline Femur ball & & & & & & & & & & 1 & & & & 1 \\
\hline Subtotals: & 14 & 14 & 11 & 0 & 0 & 2 & 0 & 1 & 1 & 2 & 0 & 0 & 3 & 48 \\
\hline \multicolumn{15}{|l|}{ Shell: } \\
\hline Serrated shell pieces & 2 & 1 & & & & & & & & & & & & 3 \\
\hline Shell pendant & & 1 & & & & & & & & & & & & 1 \\
\hline Shell beads & 2 & 3 & & & & & & & & & & & & 5 \\
\hline Shell hoe & 1 & & & & & & & & & & & & & 1 \\
\hline $\begin{array}{l}\text { Shell square cut } \\
\text { piece }\end{array}$ & & 1 & & & & & & & & & & & & 1 \\
\hline Used shells & 3 & & & & & & & & & & & & & 3 \\
\hline Subtotals: & 8 & 6 & 0 & 0 & 0 & 0 & 0 & 0 & 0 & 0 & 0 & 0 & 0 & 14 \\
\hline Total all Fauna: & 22 & 20 & 11 & 0 & 0 & 2 & 0 & 1 & 1 & 2 & 0 & 0 & 3 & 62 \\
\hline
\end{tabular}


Table 22

Distribution of Modified Fauna by Class Summary 1966-1976

(1966-1972 adapted from Schilt, 1977.)

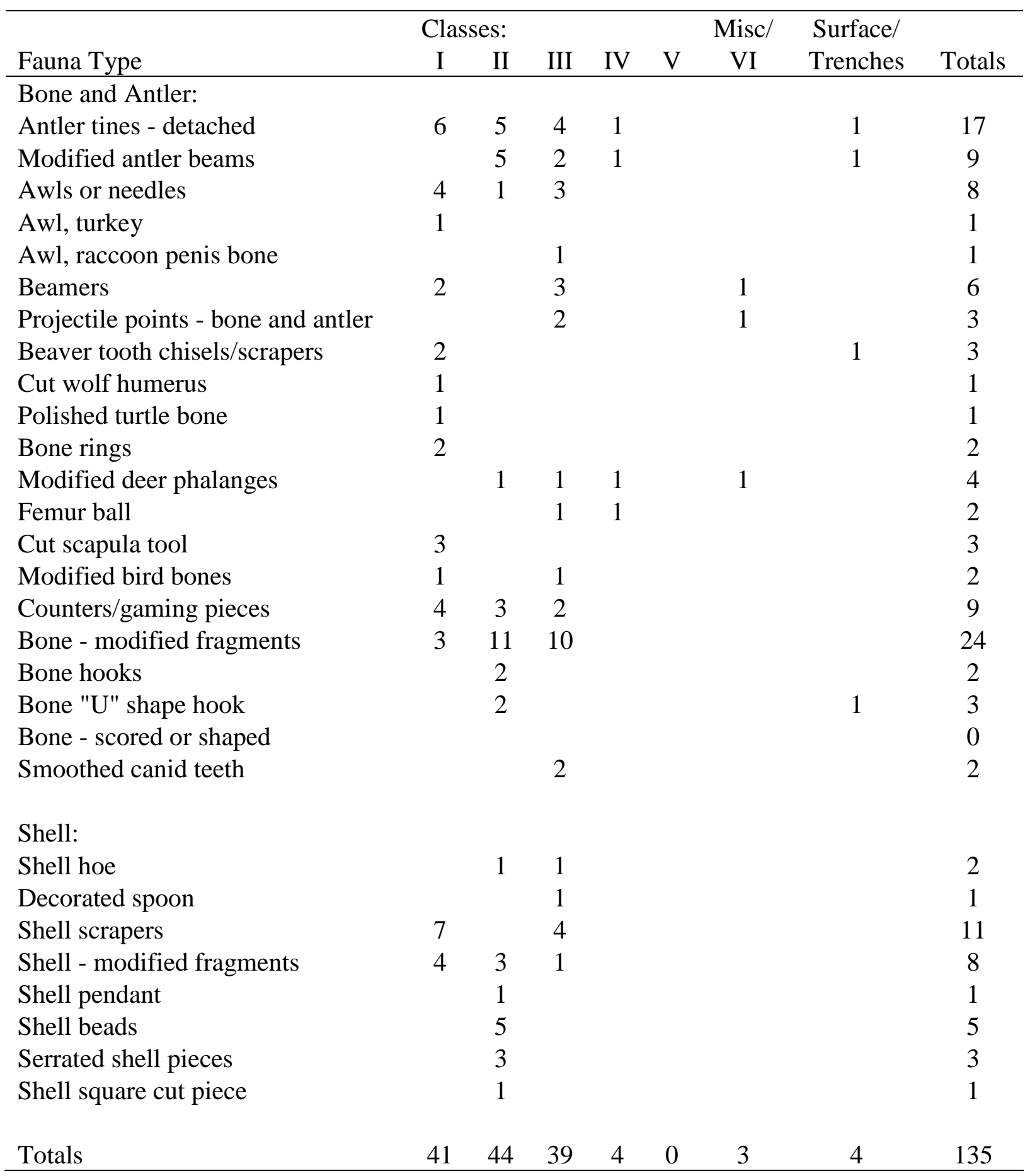




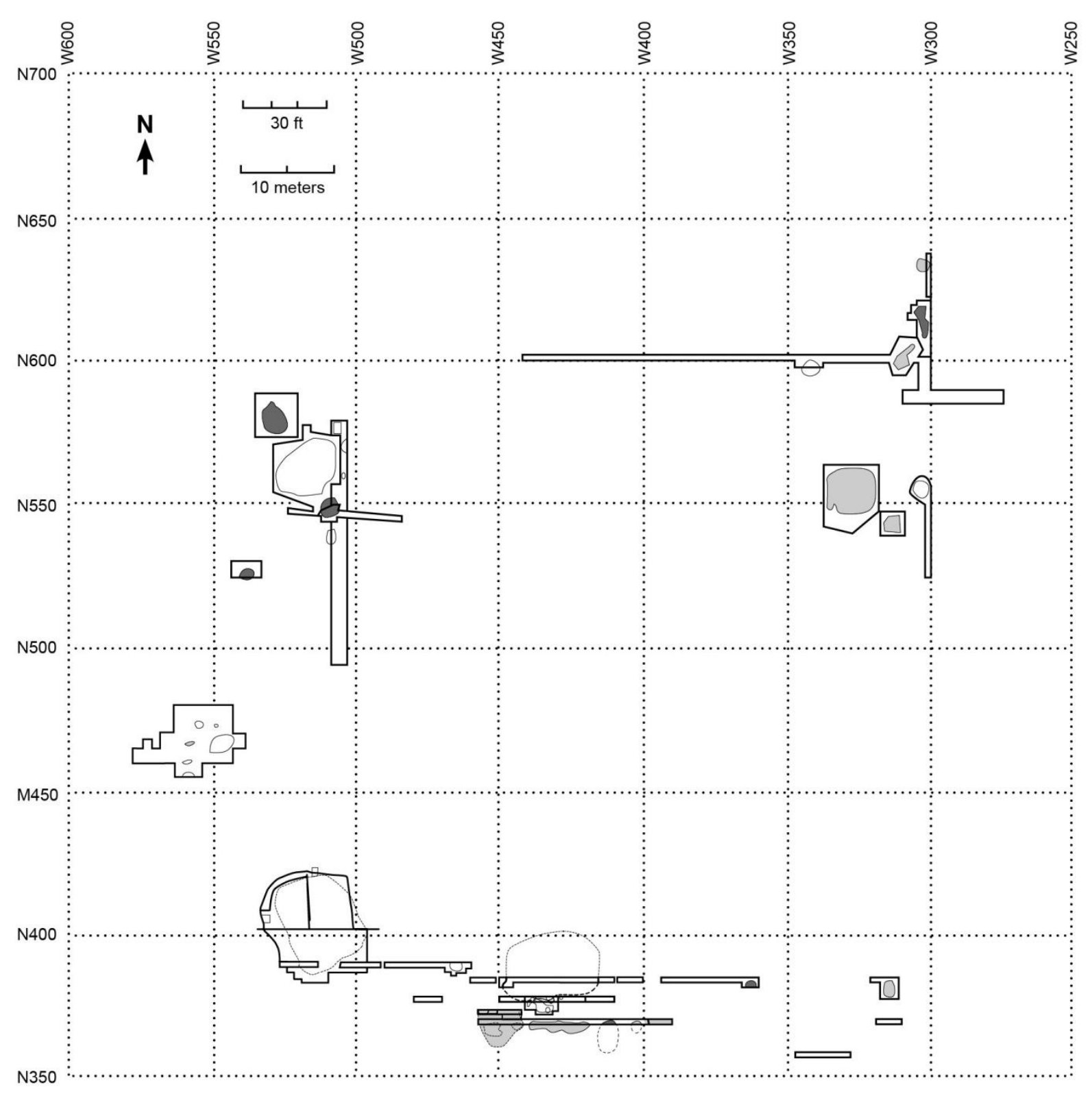

\section{LEGEND}

*Note: There were no excavation areas that contained only Shell.

Modified Fauna, Bone and Antler Only
Both Modified Fauna and Shell

Figure 40. Distribution of Modified Faunal Bone, Antler and Shell. (1966-1972 distribution adapted from Schilt, 1977.) 


\section{Discussion of Features}

As noted previously, this distributional analysis is limited by the fact that features were not fully excavated and therefore artifacts found within the majority of them are only a representation of what may have been within the whole feature. Clustering of artifact categories was not identified, which follows with previous site conclusions.

Within this analysis Class I, II, and III pits were defined by depth and content. Class I was considered a deeper pit for storage and then midden use, Class II as a shallow midden, and Class III as a possible fire pit, hearth, or trash pit with burn areas. These classifications follow the format used by Schilt (1977) for previous excavations and it is noted that more Class II features were excavated or possibly occur in the 1976 southern portion of the site. Without further excavation in this region of the site, the conclusion of more numerous Class II pits is preliminary. House features were similar in both areas of the site, in the middle region from 1966-1972 excavations and in the southern 1976 region, with wall trenches, some charcoal remains or burnt logs, and similar artifact types. In the 1976 excavations, house features contained less cultural material than pit areas. This distribution appears to be true for previous excavations as well. Burned remains within the features could be understood to be from burning the remnants of a house in order to build another one in its place, remains from hearths raked across the floor to create a hardened floor surface, or burning of the building upon abandonment of the site. This analysis shows pit features as located somewhat nearby house features, offering a convenient place to throw refuse.

\section{Lifestyle Inferences}

Inferences can be made from the results of the distributional analysis that the inhabitants of this site disposed of artifacts along with other materials before the apparent abandonment of 
the village. Evidence of a palisade, suggesting the need for protection from other peoples, or violence has not been found at the site, nor has evidence of the burning of the village. Burning and evidence of traumatic violence or warfare would be cause for quick abandonment, perhaps causing artifacts to be left in place within the house structures, as opposed to disposal or abandonment of artifacts in trash middens or fire pits, such as appears to be the case here. Thus, at this point, the most likely assumption is that the people left the village on easy accord and cultural materials found in pits were discarded there on purpose or by accident when other detriment was discarded.

Perhaps the inhabitants created their tools, played games, or did chores outside in the fresh air instead of within the houses, thus discarding or losing items within the trash areas. Possibly the areas around the house were swept and kept clear of vegetation and in order to prevent animals in the area, sweepings were pushed into pits, and thus lost artifacts were deposited into the pits as well. Or, like is found today, the inhabitants just got tired of certain pieces and discarded them in order to use a newer one, even though the old tools were still functional. These are only musings on the subject of how so much apparently usable cultural material ended up within pits and were not found within the houses.

\section{Artifact Distribution Conclusion}

What can be seen from this analysis is the influence of Middle Mississippian culture or ideologies within the site as identified by the artifact assemblage. Influence or interaction is only obvious within the ceramic component as seen from shell tempered pottery sherds. House Feature 8 contained almost twice the amount of shell tempered sherds as Langford sherds (Schilt 1977: Table 15) and may represent an individual or family with more cultural contact to Middle Mississippian groups. Aside from this house, a tentative suggestion can be made that inhabitants 
were still very strongly entrenched in their Langford Tradition ways. But, without further excavation of the site, this conclusion is very limited.

Cultural artifacts of the southern 1976 assemblage show less Middle Mississippian influence than the excavations researched by Schilt in 1977, which may signify the southern portion is an earlier construction period for the site. Initial radiocarbon dates for the site were determined to be ca. A.D. 1250. Internal temporal change at the site can now be questioned due to recent radiocarbon dates of A.D. $1295+/-15$ and $1355+/-15$, which were obtained in the northernmost feature excavated during 2017-2018. It cannot be determined if 1977 dates are questionable or if the site moved toward the north through time. Radiocarbon dating for the southern portion was not possible for this thesis. It is, therefore, the author's suggestion that further excavations be conducted in the southern portion, as geophysical mapping has identified possible larger structures and more pit areas in that area. Radiocarbon dates for the southern area will enable a broader understanding the overall construction timeline and internal habitation movement of the site. 


\section{CHAPTER XII: SUMMARY AND CONCLUSION}

This thesis broadens our understanding of interaction or contact between Langford Tradition and Middle Mississippian peoples in the east-central Illinois area, as seen at the village of Noble-Wieting, by including the 1976 excavations into the recorded information for a more comprehensive view of the Langford Tradition in the border region. Building on previous research conducted by Schilt (1977), the results of my analysis and synthesis of excavation data is summarized here.

\section{Summary}

A limited portion of the site has been excavated from 1966 through 1976 and thus the analysis and interpretation of the site as a whole is also limited. A more comprehensive view of the internal nature of the site and interaction between the Langford inhabitants with other groups can only be understood fully through further excavations. Twelve features were discovered in the southern portion of the site during 1976 , but only five of those features were fully excavated. The most completely excavated house Feature 18, with only one quarter excavated to the clay level, was revealed as similar in construction to the 1966-1972 analyzed house features. Feature 18 contained wall trenches with post molds and a Langford Plain pot was found on the southern side. This house's construction is also similar to houses identified at other Langford sites and the construction characteristic of houses at Middle Mississippian sites as well. No features in the southern area of this site were associated with the burial mound, even though this area was closer physically to the mound than previous excavations. Shallow trash pits and fire pits were also similar to the previous conclusions for this site in their shape and size and the 1976 midden, Feature 12, contained the most abundance of cultural material. A total of 44 features had been excavated up to and including 1976. 
The lithic materials analyzed were of similar types to those identified by Schilt in 1977 with Madison projectile points and humpback knives the identifiers of the Langford Tradition, although Madison points have also been recovered from Late Woodland and Mississippian sites. There were no lithics suggesting interaction or influence from Middle Mississippian groups, such as tri-notched Cahokia projectile points or chunky stones. There were also no lithics with etchings or carvings suggestive of Cahokian ideologies. No figurines, effigy stones, or stone pipes were identified, which would also suggest connections with Mississippian people.

Two side-notched projectile points of possible Late Archaic or Late Woodland times were identified in this assemblage. Larger agricultural tools, such as adzes or hoes, were not discovered, although smaller celts were. Twelve copper pieces that were thin and long were recovered in 1976, which is more than those identified from earlier excavations to the north in the site $(n=1)$. The copper may suggest interaction and exchange with groups to the far north in the Great Lakes region. The lithic component does not support my hypothesis that this site was not isolated, but instead it is strongly entrenched in the Langford culture.

The faunal component also does not support my hypotheses of less isolation than previously thought. Of the fifty-eight pieces identified as modified, no pieces could be identified as having strong influence from Mississippian groups. Early excavations revealed deep trash pits and fire pits contained the most modified bone, however the shallow trash pits of this assemblage contained the most. Raccoon baculum awls, modified wolf or turtle remains, bone rings, cut scapula tools, and shell spoons were identified in the 1966-1972 features and none of these types of artifacts were recovered in 1976. Bone beads, however, were identified for 1976 as well as a triangular shaped shell pendant, all of which had not been previously found at the site. As with the lithics, some faunal piece designs could be attributed as holdovers from earlier Archaic or 
Woodland times, such as "U" shaped fishing hooks. Noteworthy is the absence of bison, elk, or deer scapula hoes, which have been recovered at other Langford sites, as well as at Oneota sites, to the north. Shell hoes appeared to be the gardening implement of choice at Noble-Wieting. Matting needles, jaw sickles, decorated bone disks, and golf-tee shaped antler points that have been recovered at other sites were also not identified at Noble-Wieting. Bone and copper ear spools, such as those found at Gentleman Farm, Zimmerman, and Plum Island sites (Brown et al. 1967:35; Craig and Galloy 1996: 6-15) were not found within any of the excavations at this southern location. No modified bone or shell contained ornamentation with religious symbols, such as shell gorgets found at Mississippian sites, and which could suggest Middle Mississippian or Cahokian influence.

The ceramic component also proved to be strongly Langford Tradition in characteristics with $86 \%$ identified as grit-tempered Langford series. Schilt's previous conclusion of $23.5 \%$ shell-tempered Mississippian series ceramics for the site was brought down by the $14 \%$ identified in the 1976 assemblage to $18.75 \%$ for the site up to and including 1976 . This percentage is still high compared to most other Langford sites, however, and suggests that interaction and contact between groups was occurring. This supports my conclusion that the site is not an isolated outpost. It is unknown if the inhabitants of Noble-Wieting were trading with other groups or if they were using different construction technology for ceramics due to the availability of shell near their homes. Shell-temper enables a thinner walled vessel and also allows for higher temperatures to be used, so it could be that these people were acting on these ideas of technological improvement and not necessarily that their use of shell was due to influence of others. 
No ceramic pieces displayed characteristics of effigies or religious Mississippian symbols and no effigies were identified as part of a vessel. Vessel shapes also did not present Mississippian influence, such as a plate or jar, and the most complete vessels were grit temper and of a globular shape. As identified in earlier excavations by Schilt, the decorative elements and surface treatments for Langford series ceramics were most abundant in the Langford Plain category $(\mathrm{n}=1458)$ with cordmarking second in abundance $(\mathrm{n}=196)$. For shell-tempered Mississippian series sherds, cordmarked pieces ranked first $(\mathrm{n}=139)$ and plain pieces second $(\mathrm{n}$ = 123). It was noted again, as Schilt had in 1977, that the grit-tempered Langford ceramics and the shell-tempered Mississippian ceramics were located in features together. This co-occurance suggests to this researcher that not one family or person was strongly Mississippian in cultural background, such as a person who might marry into a family would be, but rather that the influence to use shell-tempered wares was widespread throughout the village. Further excavations at the site may change this interpretation, however.

In all, the first of my two hypotheses suggested a continued higher percentage of Middle Mississippian materials as compared to other Langford sites. This proves correct after the inclusion of the 1976 material culture from the southern excavations into the data for the site. However, the southern area contained less shell-tempered ceramics than earlier excavations revealed and no other artifacts with strong Middle Mississippian influence. With a percentage of $18.75 \%$, which is still higher than at other northern Langford sites, it could be concluded that more interaction or influence was occurring between groups in this borderland region.

Noble-Wieting can still be considered culturally identified with the Langford Tradition more strongly than with Middle Mississippian culture, yet influence is still apparent. It is not understood at this time if the Middle Mississippian artifacts suggest contact, interaction, 
immigration, or internal change of identity. As there are no religious or symbolic representations on artifacts, such as carvings or shaping of artifacts such as found at Mississippian sites, the influence of external ideology on these Langford inhabitants does not appear strong.

My second hypothesis guiding this thesis suggested the analysis of cultural material combined with research into the surrounding area will identify less isolation of this site than presumed. This is inconclusive and preliminary research identifies the following conclusions.

1. Possible habitation areas in the region were identified through GIS mapping, but time constraints limited further investigation. Use of GIS mapping may assist future research.

2. Two reports of studies conducted in the area, those of the Mackinaw River watershed and the FAP 412 by Warren et al. (1992) did not suggest Langford sites in the area of NobleWieting. The Hinshaw A sites received the designation of "Mississippian" instead of "Upper Mississippian" or "Langford" in the site files. However, Bird's research (1997) resulted in identification of the Hinshaw A sites as Langford due to intense ceramic analysis. It is my conclusion that further examination of more CRM reports, discussion with local collectors regarding possible Langford artifacts within their personal collections, and use of GIS mapping may present information leading to potential sites not previously considered Langford Tradition. Without further investigation into the surrounding area, it cannot be concluded this is an isolated Langford site.

\section{Suggestions for Further Research}

The extent of occupation and social interaction at Noble-Wieting is still not completely known as large portions of the site remain unexplored. I suggest that in order to fully understand the interaction taking place between the Langford inhabitants of this site and their Middle Mississippian neighbors that excavations at this site should continue with the following questions 
in mind. What is the extent of Middle Mississippian artifacts throughout the entire site? Can radiocarbon dating of all areas of the site show internal movement of the site and in turn identify interaction increasing through time?

I also suggest extensive research into the east-central Illinois region, using various methods to identify other potential Langford sites. Bird's (1997) and Coleman's (1985) investigations into the area are preliminary in nature and further investigation may reveal other sites previously unidentified. While sites in this region are not in now known to be in abundance, the borderland area represents its own set of unique considerations when discussing the overlap of cultural regions, interactions or contact, and influence or emulation. Noble-Wieting should not be left out of discussions of the Langford Tradition. Its continued opportunities for research potential enable scholars of Mississippian cultures, Langford Tradition, and Mississippianization make it one of the most important sites to consider in upcoming years.

It is my suggestion that this east-central Illinois region be given its own designation, just as those of the American Bottom, Central Illinois River Valley, Upper Illinois River Valley, and Apple River areas. Furthermore, to enhance Langford Tradition research as a whole, I suggest a database of all Langford sites would greatly assist researchers to compare and contrast Langford sites and habitation areas as a whole.

\section{Conclusion}

Bringing Noble-Wieting's archaeological record up to date was an important step to broadening our understanding of the interactions between Langford and Middle Mississippian groups in the border region between the two. This site's cultural materials, features, and site structure reflect the strong cultural identity of these Langford Tradition people who may have lived far from their cultural roots, while also representing connections with other groups in the 
area. Advancing the interpretations of this site's spatial and social relation within its own borders, as well as its connections to contemporary Langford and Middle Mississippian cultures in the surrounding area, contributes to the field of archaeology's foundational knowledge for the Langford Tradition and for understanding changes in cultural identity along border regions between cultures. 


\section{REFERENCES}

Berres, Thomas Edward

$2001 \quad$ Power and Gender in Oneota Culture: A Study of Late Prehistoric People. Northern Illinois University Press, DeKalb, Illinois.

Binford, Lewis R.

1965 Archaeological Systematics and the Study of Cultural Processes. American Antiquity. 31:203-310.

Bird, M. Catherine.

1997 Broken Pieces: Langford Tradition Settlement System and the Role of Material Culture in the Maintenance of Social Boundaries. PhD Dissertation.

Department of Anthropology. University of Wisconsin-Milwaukee, Wisconsin. University Microfilms, Milwaukee.

Boszhardt, Robert F.

2012 The Effigy Mound to Oneota Revolution in the Upper Mississippi River Valley. In The Oxford Handbook of North American Archaeology, edited by Timothy R. Pauketat. pp.398-409. University of Oxford Press, New York.

Brown, James A.

1961 The Zimmerman Site: A Report on the Excavations of the Grand Village of Kaskaskia, La Salle County, Illinois, Report of Investigations No.9. edited by James A. Brown. Illinois State Museum, Springfield, Illinois. 
Brown, James A., Roger W. Willis, Mary A. Barth, Georg K. Neumann

1967 The Gentleman Farm Site, La Salle County, Illinois, Reports of

Investigations No. 12. Illinois State Museum, Springfield, Illinois.

Brown, Margaret Kimball

1975 The Zimmerman Site: Further Excavations at the Grand Village in

Kaskaskia. Illinois State Museum Reports of Investigations, No. 32.

Springfield, Illinois.

Bryson, Reid A.

1978 Cultural, Economic, and Climatic Records. In Climatic Change and

Variabiltiy. edited by A. B. Pittock, L. A. Frakes, D. Jenssen, J. A.

Peterson, and J. W. Zillman, pp. 316-327. Cambridge University Press.

Burnham, J. H.

1900 "The Randolph Mound and McLean County Indian Relics.” The Sunday

Bulletin. Bloomington, Illinois, XX (253). December 9, 1900.

Caldwell, Joseph R.

1971 “The Mississippian Period.” In Illinois Archaeology, edited by Elaine A.

Bluhm. Illinois Archaeological Survey, Bulletin 1:33-39.

Coffee, George N., C. W. Ely, and Charles J. Mann

1903 Soil Survey of McLean County, Illinois. United States Department of

Agriculture, Natural Resources Conservation Service, pp 777-797.

https://www.nrcs.usda.gov/Internet/FSE_MANUSCRIPTS/illinois/

mcleanIL1903/mcleanIL1903.pdf 
Coleman, Roger Eugene

1984 The Spatial Analysis of a Prehistoric Hunting Adaptation: Model Development and Testing for the Noble-Wieting site (ML 28), McLean County, Illinois.

Master's Thesis. Department of Anthropology, Texas A \& M, Station, Texas.

Craig, Joseph and Joseph M. Galloy

1996 The Reeves Site (11 WI 555)Archaeological Investigations at a Langford Tradition Settlement on the Dupage River, Northeastern Illinois. Hanson Engineers Incorporated, Springfield, Illinois.

D’Arrigo, Rosanne, et al.

2014 Dendroclimatic Studies:Tree Growth and Climate Changes in Northern Forests. American Geophysical Union, Washington D.C.

Ellis, Linda

2006 Ceramics. In Archaeology in Practice: A Student Guide to Archaeological Analyses. edited by Jane Balme and Alaistar Paterson. Oxford University Press.

Emerson, Thomas E.

1999a The Keeshin Farm Site and the Rock River Langford Tradition in Northern Illinois. edited by Thomas E. Emerson. Illinois Transportation Archaeology Research Program, Urbana, Illinois.

1999b The Langford tradition and the process of tribalization on the Middle Mississippian borders. Midcontinental Journal of Archaeology. 24(1):3-56.

2012 Cahokia Interaction and Ethnogenesis in the Northern Midcontinent. In The Oxford Handbook of North American Archaeology, edited by Timothy R. Pauketat. pp.398-409. University of Oxford Press, New York. 
Emerson, Thomas E., Hedman, K. M., \& Simon, M. L

2005 Marginal Horticulturalists or Maize Agriculturalists? Archaeobotanical,

Paleopathological, and Isotopic Evidence Relating to Langford Tradition

Maize Consumption. Midcontinental Journal of Archaeology, 30(1):67-118.

Emerson, Thomas E. and James A. Brown

1992 The Late Prehistory and Protohistory of Illinois. In Calumet and

Fleur-de-Lys: Archaeology of Indian and French Contact in the

Midcontinent. edited by J. A. Walthall and T. E. Emerson, pp. 77-128.

Smithsonian Institution Press, Washington, D.C.

Foresman, Tim

1997 The History of GIS (Geographic Information Systems). Geographic Information Science. Nov 10:416

Fortier, Andrew C., Richard B. Lacampagne, and Fred A. Finney

1984 The Fish Lake Site (11-Mo-608). University of Illinois Press, Urbana, IL

Fortier, Andrew C., Fred A. Finney, and Richard B. Lacampagne

1982 The Mund Site (11-S-435): a Stratified, Multicomponent Occupation in

the American Bottom. Dept of Anthro, U of I, Urbana-Champaign,

FAI-270 Archaeo Mitigation Project Report 41. 
Fowler, Melvin L.

1952 The Robinson Reserve Site. Journal of the Illinois State Archaeological Society 2:50-62.

1975 A Precolumbian Urban Center on the Mississippi. Scientific American. 233:92-101.

Gardner, William M.

1973 Ecological or Historical Determinants in Cultural Patterning Among the Prehistoric Occupants of the Upper Kaskaskia River Valley, Illinois. In Variations in Anthropology: Essays in Honor of John C. McGregor, edited by Donald W. Lathrap and Jody Douglas. pp 189-197. Illinois Archaeological Survey, Urbana, Illinois.

Griffin, James B.

1943 The Fort Ancient Aspect: Its Cultural and Chronological Position in Mississippi Valley Archaeology. Anthropological Papers 28. Museum of Anthropology, University of Michigan, Ann Arbor. (reprinted 1966).

Griffin, John W.

1946 The Upper Mississippi Occupations of the Fisher Site, Will County, Illinois. Master's thesis, Department of Anthropology, University of Chicago, Chicago.

Hart, John P., David L. Asch, C. Margaret Scarry and Gary W. Crawford.

2002 The Age of the Common Bean (Phaseolus vulgaris L.) in the Northern Eastern Woodlands of North America. Antiquity, 76:377-385 
Henshilwood, Christopher S., Francesco d'Errico, and Ian Watts

2009 Engraved Ochres from the Middle Stone Age levels at Blombos Cave, South Africa. Journal of Human Evolution 57(1):27-47.

Hodder, Ian

1986 Reading the Past: Current Approaches to Interpretation in Archaeology. Cambridge University Press.

Hoffmeister, Donald F.

1989 Mammals of Illinois. University of Illinois Press, Urbana, IL

Iseminger, William R.

2014 Identifying and Understanding Artifacts of Illinois and Neighboring

States. Illinois Association for Advancement of Archaeology (IAAA), Rediscovery, vol 6. Springfield, Illinois.

Illinois State Geological Survey (ISGS).

2018 "End Moraines of the Wisconsin Glacial Episode." University of Illinois

Board of Trustees, Urbana, Illinois. Retrieved from

http://isgs.illinois.edu/outreach/geology-resources/quaternaryglaciations-illinois

Jackson, Douglas K.

2018 “The Collins Site: Vermillion County, Illinois.” presentation Midwest Archaeological Conference, 2018

Jackson, Douglas K., A. C. Fortier, and J. A. Williams

1992 The Sponemann Site 2:The Mississippian and Oneota Occupations (11MS 517).

Vol 24, Illinois Transportation. 
Jeske, Robert J.

1990 Langford Tradition Subsistence, Settlement, and Technology.

Midcontinental Journal of Archaeology. 15(2):221-249.

1992a Environment, Ethnicity, and Subsistence Change: The Late Woodland to Mississippian Transition in the Upper Midwest. Michigan Archaeologist 38:55-70.

1992b Energetic Efficiency and Lithic Technology: An Upper Mississippian Example. American Antiquity 57(3):467-481.

2000 The Washington Irving Site: Langford Tradition Adaptation in Northern Illinois. In Mounds, Modoc, and Mesoamerica: Papers in Honor of Melvin L. Fowler. edited by S. R. Abler. pp 265-293. Scientific Papers Vol. 18. Illinois State Museum. Springfield, Illinois.

Jeske, Robert J. and Katherine M. Sterner-Miller

2015 Microwear Analysis of Bipolar Tools from the Crescent Bay Hunt Club Site (47JE904). Lithic Technology. 40(4):366-376.

Jeske, Robert J. and John P. Hart

1988 Report on Test Excavations at Four Sites in the Illinois and Michigan Canal National Heritage Corridor, La Salle and Grundy Counties, Illinois. Contribution. No. 6. Northwestern Archaeological Center, Northwestern University, Evanston, Illinois. 
Jesuit Relations and Allied Documents

1904 Reuben Gold Thwaites, editor and translator. The Burrows Brothers Publishers, Cleveland, quoted in Vermaat, Jacqueline C., "History of the Grand Village of the Kickapoo Park" (2011). A with Honors Projects. 27.

http://spark.parkland.edu/ah/27

Justice, Noel D.

1987 Stone Age Spear and Arrow Points of the Midcontinental and Eastern United States: A Modern Survey and Reference. Indiana University Press, Bloomington, Indiana.

Kelly, John E., Andrew C. Fortier, Steven J. Ozuk, and Joyce A. Williams

1987 The Range Site:Archaic through Late Woodland Occupations (11-S-47). University of Illinois Press, Urbana, Illinois.

Killey, M. M.

2000 End moraines of the Wisconsin glacial episode. In Quaternary glaciations in Illinois, GeoNote 3, p. 10. Illinois State Geological Survey, Champaign, Illinois.

Kindscher, Kelly

1987 Edible Wild Plants of the Prairie: An Ethnobotanical Guide. University of Lawrence Press, Lawrence, Kansas.

Koldehoff, Brad and Ronald Kerns

1993 Using Stone Tools to Detect Mississippian Homesteads. Illinois Antiquity. (28):3 . 
Leroi-Gourhan, A.

1968 The Art of Prehistoric Man in Western Europe. Thames and Hudson, London.

Lurie, Rochelle

1992 Robinson Reserve: A Langford Tradition Habitation and Mound Site along the Des Plaines River in Chicago. Michigan Archaeologist. 8(1/2):90-104.

Mackinaw River Area Assessment

1997 Mackinaw River Area Assessment, Volume 2. Illinois Department of Natural

Resources, Springfield, Illinois. 2:3.1-3.7.

Markman, Charles W.

1991 Above the American Botttom: The Late Woodland-Mississippian

Transition in Northeast Illinois. In New Perspectives on Cahokia, Views

from the Periphery. edited by James B. Stoltman, pp. 177-208.

Monographs in World Archaeology 2, Prehistory Press, Madison,

Wisconsin.

Martin, Terrance J. and J. C. Richmond

1996 Faunal Analysis. In The Reeves Site (11 WI 555)Archaeological Investigations at a Langford Tradition Settlement on the Dupage River, Northeastern Illinois. edited by Joseph Craig and Joseph M. Galloy. Pp 9.1-9.35. Hanson Engineers Incorporated, Springfield, Illinois. 
Miller, G. Logan, B. Jacob Skousen, and Robert G. McCullough

2017 Preliminary Results of a Joint ISU and ISAS Field School at the Noble-Wieting

Site (11ML 24). Poster presented at the $61^{\text {st }}$ Annual Meeting of the Midwest Archaeological Conference, Indianapolis, Indiana.

Munson, Patrick J. and Cheryl A. Munson.

1972 Unfinished Triangular Projectile Points or 'Hump-Backed' Knives?

Pennsylvania Archaeologist. 42(3):31-36.

Orton, Clive and Michael Hughes

2013 Pottery in Archaeology. Cambridge: Cambridge University Press.

Parmalee, Paul W. and Arthur E. Bogan

1980 A Summary of the Animal Remains from the Noble-Wieting site (ML 28), McLean County, Illinois. Transactions of the Illinois Academy of Science, pp. 1-6.

Pauketat, Timothy R.

2004 Ancient Cahokia and the Mississippians. Cambridge University Press.

Pauketat, Timothy R., Susan M. Alt, and Janet M. Pauketat

2006 Some Problems Detecting Mississippian Farmsteads in Southwestern Illinois. Illinois Archaeology. 17:154-167.

Pearce, Jennifer.

2006 The Russell Koster Site: Langford Phase Settlement in the Elkhorn Creek Locality of Whiteside County, Illinois. Illinois Archaeology. 18:100-121. 
Penman, John T.

1999 Faunal Remains from the Keeshin Farm Site. In The Keeshin Farm Site and the Rock River Langford Tradition in Northern Illinois. edited by Thomas E.

Emerson. pp. 115-150. Transportation Archaeological Research Reports No. 7. Illinois Transportation Archaeological Program. University of Illinois, Urbana, Illinois.

Prince, Ezra M. and John H. Burnham

1908 The History of McLean County. In The Encyclopedia of Illinois. edited by Newton Bateman and Paul Selby. pp. 617-1360.

Reber, R. J., S. L. Boles, T. E. Emerson, M. G. Evans, T. J. Loebel, D. L. McElrath, and D. J. Nolan

2017 Projectile Points and the Illinois Landscape: People, Time, and Place.University of Illinois Board of Trustees, Urbana, Illinois.

Ritchie, William A.

1969 A Typology and Nomenclature for New York Projectile Points. New York State Museum and Science Service Bulletin No. 384. New York State Museum, Albany, NY:

Riley, Thomas J. and Gary A. Apfelstadt

1978 Prehistoric Missionaries in East Central Illinois. Field Museum of Natural History Bulletin. 49(4): 16-21. 
Schilt, Arlene Rose

1977 Noble-Wieting: An Early Upper Mississippian Village. Master's thesis.

Department of Anthropology, Illinois State University, Normal, Illinois.

Seltzer, Jennifer L. and Evan Peacock

2015 Determining the Season of Mississippian House Construction from Plant

Impressions in Daub. Southeastern Archaeology, 31(1): 123-133.

The Daily Pantagraph

1900 “Opened an Indian Mound.” October 18:7. Bloomington, Illinois.

Transeau, Edgar N.

1935 The Prairie Peninsula. Ecology. 16(3):423-437.

United States Department of Agriculture: Natural Resources Conservation Service (USDA-

NRCS)

1998 Soil Survey, McLean County, Illinois. Washington D.C.: USDA-NRCS.

pg 171.

United States Department of Agriculture: United States Geological Survey (USGS)

195115 Minute Quadrangle Map, LeRoy Quadrangle.

Warren, Robert E.

1992 Prairie Archaeology: Environment and Human Settlement Along

Interstate-39 in North-Central Illinois. Illinois State Museum, Springfield, Illinois.

Wendland, Wayne M.

1978 Holocene Man in North America: The Ecological Setting and Climatic

Background. Plains Anthropologist. 23:273-287. 
Wiant, Michael D. and Charles R. McGimsey.

1986 Woodland Period Occupations of the Napoleon Hollow Site in the Lower Illinois Valley. Center for American Archaeology, Kampsville, Illinois. 